\title{
Detonation Equation of State at LLNL, 1993
}

P. C. Souers and L. C. Haselman, Jr.

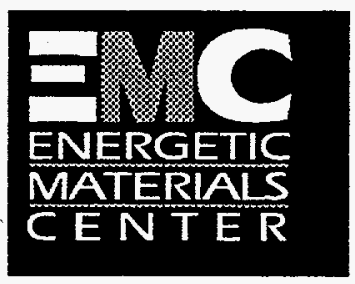

Energetic Materials Center

Lawrence Livermore National Laboratory

March 1, 1994 


\section{DISCLAIMER}

This report was prepared as an account of work sponsored by an agency of the United States Government. Neither the United States Government nor any agency thereof, nor any of their employees, make any warranty, express or implied, or assumes any legal liability or responsibility for the accuracy, completeness, or usefulness of any information, apparatus, product, or process disclosed, or represents that its use would not infringe privately owned rights. Reference herein to any specific commercial product, process, or service by trade name, trademark, manufacturer, or otherwise does not necessarily constitute or imply its endorsement, recommendation, or favoring by the United States Government or any agency thereof. The views and opinions of authors expressed herein do not necessarily state or reflect those of the United States Government or any agency thereof. 


\section{DISCLAIMER}

Portions of this document may be illegible in electronic image products. Images are produced from the best available original document. 


\section{Table of Contents}

Page

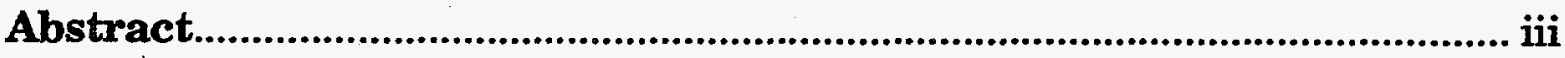

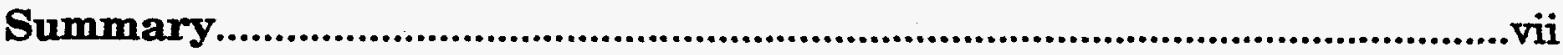

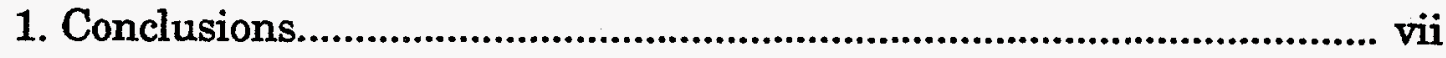

2. Suggestions for Experiment............................................................... $\mathrm{x}$

3. Suggestions for Code Work......................................................................... xi

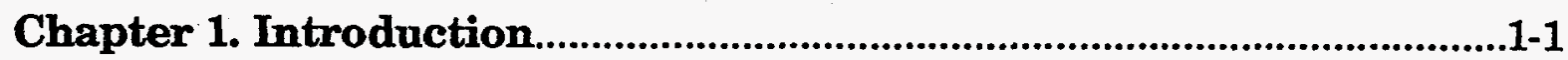

1. The Problem of Equation of State......................................................... 1-1

2. Notes Regarding This Work..............................................................1-3

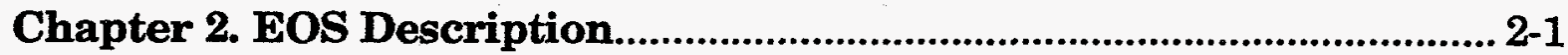

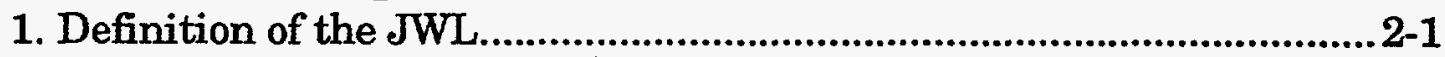

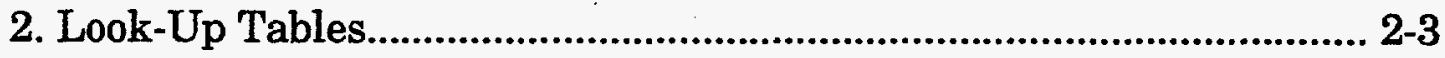

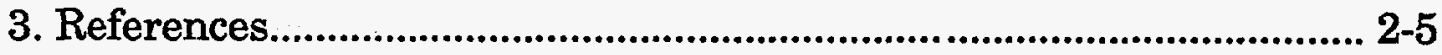

Chapter 3. Deriving Cylinder JWLs ........................................................ 3-1

1. Description of the Cylinder Test.................................................................3-1

2. How the LLNL Cylinder JWL Is Obtained........................................... 3-3

3. Choosing the PETN Standard............................................................. 3-5

4. Accuracy of the JWL Energy of Detonation ..........................................3-6

5. Uniqueness of the JWL Parameters for PETN......................................3-7

6. Total Detonation Energy from the Cylinder and the Calorimeter .......3-8

7. Approaching Perfect Gas Behavior....................................................3-10

8. Generating Systematic JWL Constants............................................3-11

9. Variations of the JWL Function........................................................... 3-12

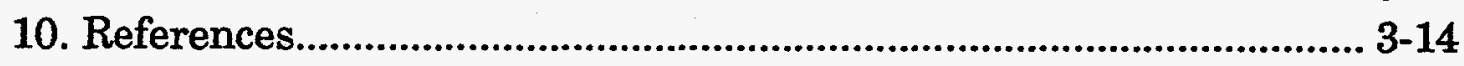

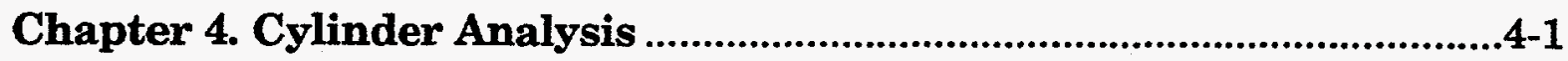

1. Cylinder Relative Volumes with Wall Thinning....................................4-1

2. Comparing Streak and Fabry Data......................................................4-2

3. Cylinder Codes with PETN .............................................................4-4

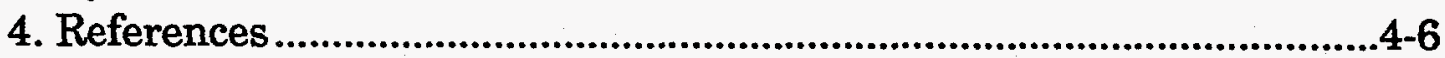

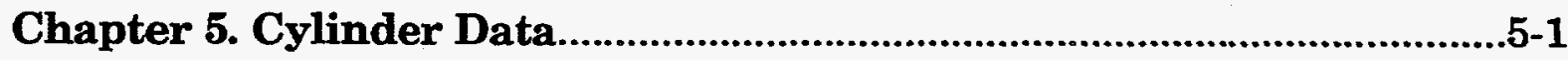

1. Jump-Off Velocity and Detonation Pressure..........................................5-1

2. List of Cylinder JWLs.............................................................................5-2

3. Comparison of JWLs............................................................................... 
4. Describing Cylinder Relative Volumes...............................................5-5

5. One-Dimensional Cylinder Analysis....................................................5-6

Chapter 6. One-Dimensional Plate Data...................................................6-1

1. The Jump-Off Velocity of Metal Plates...............................................6-1

2. Experimental Plate Jump-Off Results ...............................................6-3

3. Establishing a Plate Test...................................................................6-5

4. The Lucite PETN Experiment ........................................................6-7

5. Supracompression as a Search for C-J...............................................6-8

6. The Supracompressed PETN Experiment..........................................6-10

7. Supracompression of HMX and TATB................................................6-12

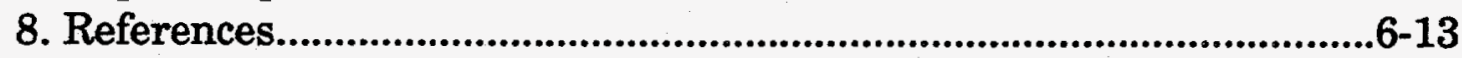

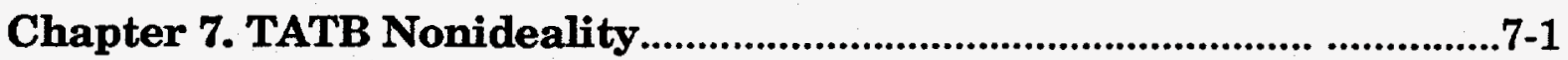

1. Detonation Front Curvature..................................................................7-1

2. Summary of Measured Pressures and Theory ..........................................7-3

3. The Ignition and Growth Model...........................................................7-6

4. Inner Workings of I\&G...............................................................

5. Results from the I\&G Model..............................................................7-12

6. Estimating the Reactant and Product JWLs.......................................7-13

7. Changes for a Future Production Model.............................................7-14

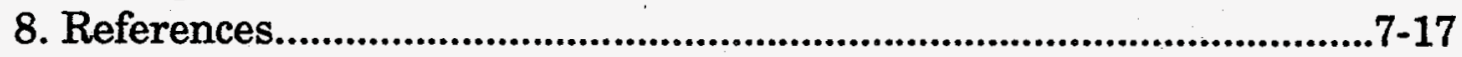

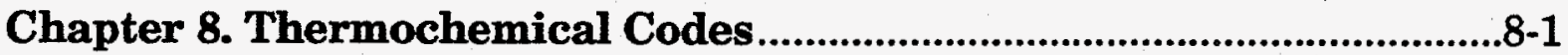

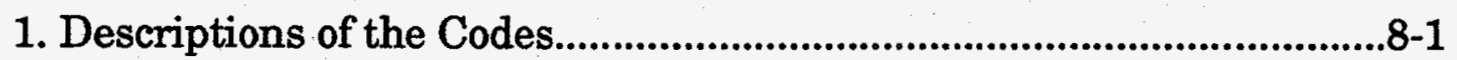

2. Comparison of Code Results ...................................................................

3. Detonation Temperature for Nitromethane.........................................8-5

4. Freezing the Compositions.................................................................8-6

5. Phase Transitions and Look-Up Tables From CHEQ ...........................8-8

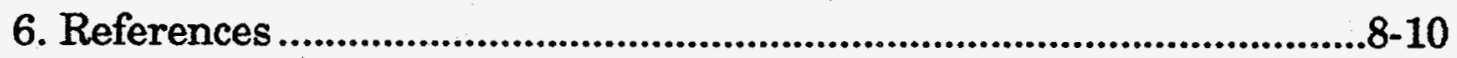

Chapter 9. Composite Explosives $\quad$.............................................................

1. The Problem of Nonreactivity .................................................................9-1

2. Cylinder Data and Infinite Size.........................................................9-1

3. Percent Detonated in a Cylinder …........................................................9-3

4. Possible Standards ............................................................................4

5. The Need for Predictive Capability ........................................................9-5

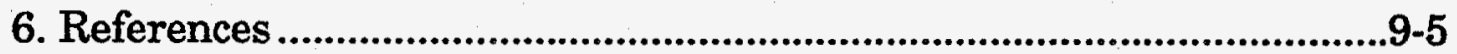

Appendix: Composition and Grain Sizes of Explosives......................... A-1 


\section{Summary}

\section{Conclusions}

Our conclusions, based on the available data, are as follows.

1. Careful terminology regarding detonation points is needed. We distinguish between the spike pressure $\left(P_{k}\right)$, the measured jump-off or supracompression pressure $\left(P_{p}\right)$, the Cylinder Test JWL pressure $\left(P_{j}\right)$, the adiabat pressure $\left(\mathrm{P}_{\mathrm{a}}\right)$, the Chapman-Jouget $(\mathrm{C}-\mathrm{J})$ pressure $\left(\mathrm{P}_{\mathrm{cj}}\right)$, and the sonic point pressure $\left(\mathrm{P}_{\mathrm{n}}\right)$. The C-J pressure requires true thermodynamic equilibrium and may exist only in a thermochemical code. The adiabat pressure is the actual nonequilibrium start of the Principal Adiabat in an explosive of infinite size and at steady state. The sonic pressure is the start of an adiabat for an explosive neither at infinite size nor at steady state. At present, the term "C-J" covers all of these pressures in an indiscriminate way.

2. The low-effort method of deriving cylinder JWLs using PETN as the standard plus three to five smoothed data points from the unknown explosive works within the accuracy of data obtained from the streak camera. However, Fabry-Perot interferometry is at all times during the shot more accurate for velocities than is the streak camera-Fabry data, therefore, should be taken to long times. Nonetheless, the streak camera will always be valuable as an record of the distance. The ratio of the two methods is a good measurement of the overall validity of the shot.

3. The homogeneous explosives run with the LLNL cylinder method produces total detonation energies in agreement of $1 \pm 4 \%$ with calorimetric experiment.

4. The LLNL Cylinder JWL equation of state (EOS) contains two important assumptions: (1) the energy of detonation at a given volume is nearly constant for a wide variety of JWL parameters and (2) the kinetic and detonation energies have the same proportionality for all explosives. A simple cylinder model suggests that the first assumption is good to $\pm 2 \%$ for $1<\mathrm{v}<0$ for velocities known to $\pm 0.015 \mathrm{~mm} / \mu \mathrm{s}$. The second assumption is probably correct within a few percent as shown by near-constant, cylinder wall-pushing efficiencies.

5. The JWL formalism provides different answers according to how the coefficients are derived; no correlation is evident among the resulting constants. The Urtiew / Hayes proposal to set A, B, and C proportional to $\mathrm{p}_{0} \mathrm{D}^{2}$, 
and at the same time, confine the other constants appears unsuccessful. The use of a look-up table for describing the adiabats is a possible solution, but these tables have not been calibrated across different experiments.

The same plate velocity data have a scatter of $\pm 0.02 \mathrm{~mm} / \mu \mathrm{s}$ according to where the data were found and how they were processed. This means that returning to a few good experiments with better statistical methods will be necessary to calibrate the JWLs more accurately.

6. Detonation pressure measurements (in GPa) for five, often-run explosives have been collected from various sources and are compared as follows:

\begin{tabular}{ccccccc} 
& \multicolumn{2}{c}{ 1-D plate. $P_{p}$} & \multicolumn{2}{c}{ Cylinder } & & \\
\cline { 2 - 5 } & $\begin{array}{c}\text { Jump-off } \\
\text { velocity }\end{array}$ & $\begin{array}{c}\text { Supra- } \\
\text { compress }\end{array}$ & $\begin{array}{c}\text { Jump-off } \\
\text { velocity, } \\
P_{p}\end{array}$ & $\begin{array}{c}\text { Three-point, } \\
\text { JWL fit, } \\
P_{j}\end{array}$ & $\begin{array}{c}\text { Haselman } \\
\text { compression, } \\
P_{p}\end{array}$ & $\begin{array}{c}\text { TIGER } \\
\text { BKWR } \\
P_{c j}\end{array}$ \\
\hline LX-14 & $35 \pm 2$ & & $37 \pm 3$ & $38 \pm 2$ & 36 & 35 \\
PBX-9404 & $39 \pm 2$ & $38 \pm 2$ & $34 \pm 5$ & $38 \pm 2$ & 37 to 39 & 36 \\
PETN & $32 \pm 4$ & $31 \pm 2$ & $31^{*} \pm 3$ & $32 \pm 2$ & & 31 \\
RX-26-AF & & $34 \pm 2$ & $36 \pm 2$ & $34 \pm 2$ & 32.5 & 32 \\
LX-17 & 34 & $32 \pm 2$ & $32 \pm 4$ & $26 \pm 1$ & 30 & 27
\end{tabular}

a. PETN, with an adiabat pressure determined by supracompression as $31 \pm 2 \mathrm{GPa}$, is a good standard explosive. The C-J-derived relation $\partial U_{\mathrm{s}} / \partial \mathrm{u}_{\mathrm{p}} \rightarrow 0$ was seen in this case.

b. Detonation pressures for LX-14 and PBX-9404 are consistent by all sources. TIGER is always low in its calculation.

c. LX-17 has a low, 26- to 27-GPa adiabat pressure as given by the Cylinder Test and the Ignition \& Growth model. The larger detonation pressure seen in plates may be caused by a failure of the impedancematch equation.

d. For three explosives, $\partial U_{s} \partial u_{p}$ did not approach zero in supracompression. Nonequlibrium behavior with an absence of the C-J condition is a possible reason.

7. The most accurately measurable quantity, after the detonation velocity, is the total detonation energy. Continued detonation calorimetry is important. 
8. The percent of cylinder detonation energy that appears as the kinetic energy of wall motion is proportional to the cylinder pressure/ energy ratio $\left(\mathrm{P}_{\mathrm{j}} / \mathrm{E}_{0}\right)$. The JWL detonation volume $\left(\mathrm{v}_{\mathrm{j}}\right)$, is inversely proportional to $\mathrm{P}_{\mathrm{j}} / \mathrm{E}_{0}$ so that more efficient explosives push back with heated gaseous products. The spring constant for the pushing back is $\rho_{0} \mathrm{D}^{2}$.

9. The TIGER thermochemical code predicts absolute detonation energies only to $\pm 10 \%$ for homogeneous explosives at a given relative volume. The total detonation energies may be predicted within $\pm 6 \%$. TIGER should not be used to set JWLs directly, although there is sometimes no choice but to do so.

Specifically, BKWR produces its detonation energies only by a $10 \%$ correction that involves PETN. Its C-J temperatures are also $1000 \mathrm{~K}$ too low, but it predicts the C-J pressures closely. BKWS fixes both problems by resetting the constant temperature, $Q$, but the spread of detonation energies is broader. JCZ3 delivers better energy values, but the $\mathrm{v}=2$ values are consistently too high and thus the $\mathrm{v}=4$ and $\mathrm{v}=7$ results are usually used for comparison. CHEQ's energy values are no better, and the program takes too much time for production calculations. Both JCZ3 and CHEQ calculate temperatures correctly but are 5 to $10 \%$ low in C-J pressure and have no library for aluminum and other metals. All versions of TIGER are strongly library-dependent, and the code is not robust.

10. CHEQ postulates adiabat shapes, albeit assuming perfect equilibrium. A study of TATB suggests that the diamond-graphite transition will change the detonation energy enough for experimental verification but that the $\mathrm{N}_{2}-\mathrm{H}_{2} \mathrm{O}$ phase transition will not. CHEQ has done its job of introducing new ideas. Modeling of nonequilibrium behavior may be the next step.

11.The Ignition \& Growth model is the only theory model that incorporates kinetics. Because of inadequate documentation and lack of upgrades to the programming, it has not received the appreciation and attention it deserves. LX-17 could be converted into a standard explosive for this model.

12. Few cylinder runs on composite explosives produce infinite diameter results that can be compared with those of TIGER. Possible standards include HMX with $10 \%$ or less fine aluminum powder and $65 \% \mathrm{HMX} / 30 \%$ potassium perchlorate. Four very large ANFO shots provide infinite diameter data, but the distance to steady state is about a meter. More work is needed to find composite standards.

13. The less than $1 \%$ explosive-accuracy touted by code-runners is really precision. Absolute knowledge of the adiabat is about 3 to $5 \%$ at high pressures 
and $30 \%$ or less at low pressures with the adiabat starting point unknown by 2 to $3 \mathrm{GPa}$.

14. The lack of predictive capability in composite explosives is extensive. Only two composites might serve as standards in a 100-mm cylinder test. Four types of ANFO are described for which the infinite-diameter detonation velocity has been obtained. It is not possible to unravel size effects from the inherent inability to burn.

\section{Suggestions for Experiment} findings.

Experimental explosives work should benefit from some of these

1. Fabry-Perot interferometry should be used on all cylinder shots and run out to long times. Work-to-date suggests that 40- $\mu$ s fabry times will provide sufficient light and allow considerable time slippage for starting the film. The streak camera should be maintained for total displacement.

2. All cylinder tests with nonideal explosives should include the end-on measurement of detonation front curvature as standard. This inexpensive method would have provided vast data on nonideality had it been rigorously applied. It appears to work even with gels possessing surfaces difficult to make flat.

3. A flat-plate "test" should be formalized and run as a fast and inexpensive way of getting JWLs at a fraction of the cost of a cylinder test. A good combination with a $25-\mathrm{mm}$ diameter is $10-\mathrm{mm}$ thickness of explosive and $10 \mathrm{mil}(250 \mathrm{~nm})$ of either copper or tantalum run out to $1.5 \mu \mathrm{s}$ or more. A 20$\mathrm{mm} / 20$-mil combination run to $3 \mu \mathrm{s}$ would produce similar results, but a 50$\mathrm{mm}$ diameter would be needed.

4. The lack of reproducibility in many plate and cylinder shots that are supposedly the same means that an important level of detail is unknown to us. Improved quality control is needed.

Experiments that would provide needed information are described.

1. The classic test for the spike and adiabat pressure is to measure and analyze the jump-off velocities as a function of plate thickness for thicknesses less than and exceeding the reaction zone. A limited amount of data was assembled for LX-17 in this work, and more is needed. 
2. The available lithium fluoride data were not analyzed for this work. The use of a crystal "plate" impedance matched to the explosive offers the possibility of direct read-out of the adiabat pressure. This work needs to be developed.

3. Direct measurement of pressure and volume would supplant the relative derivation of EOSs by cross comparison of code results and "standards" - this appears never to have been done. Present gauges are said to be accurate to $\pm 1.5 \%$. Unfortunately, this is probably not good enough to distinguish between CHEQ and cylinder JWL results between the adiabat point and $v \sim 1.2$. From $v=1.5$ on, direct measurement might now work. The task of relating constant-pressure gas-gun or diamond-anvil work to an adiabat remains to be done.

4. The detonation point is poorly known, only to $\pm 3 \mathrm{GPa}$ in most cases. Supracompression experiments offer the best means of finding this point. Future experiments should include pressure-gauge measurements and detailed work near the adiabat point and below, where nonequilibrium effects may be seen.

5. Direct temperature and chemical species measurement are needed. Ignition \& Growth people expected this work to be completed long ago, but it has not happened. There is a limit to what can be surmised by pushing metal. Eventually, the true innards of detonation must be studied.

\section{Suggestions for Code Work}

1. At the very least, TIGER needs to be reworked. It needs a more robust solver and C-J point seeker. More work needs to be done on renormalization, including detonation energy as an input along with detonation velocity and assumed C-J pressure and temperature.

2. If we must use the old TIGER code, a complete parameter study and renormalization is needed. The reset would be to C-J pressure, detonation velocity, and detonation energy for several often-used explosives, both ideal and nonideal. At this time, either BKW or JCZ3 appears to be a possible choice for this refit. Should JCZ3 be chosen, it needs to be extended to aluminum and other metals.

3. A production model containing Ignition \& Growth-type kinetics is needed. M. Murphy has suggested the use of a faster, two-term model for detonation and $a U_{s}-u_{p}$ unreacted Hugoniot. The model could be further simplified by changing the temperature-dependent, reacted JWL to a regular 
JWL. A programmed burn with changing detonation vs distance would be useful for initiation.

4. It is time to create a new thermochemical model based on chemical kinetics of the product gases. This will force the consideration of real reactions and processes and start the search for their rates. Such a model would add the missing ingredient of nonequilibrium effects. It is especially needed for composite explosives, where size effects and run-to-detonation cannot be guessed. 


\section{Chapter 1. Introduction}

\section{The Problem of Equation of State}

The science of explosives often appears to be merely a collection of opinions. Experiments are difficult and expensive, and there is little university research in this area. Also, the motion of a piece of metal, which is the primary source of data, can be described by different paths in phase space, and thus, rival models compete for validity. Finally, the totally programmatic orientation of the field has led to poor documentation and a virtual absence of critical review.

The purpose of this report is to draw together recent LLNL data on detonation equations of state (EOS), to summarize our current understanding of the field, and to suggest new and predictive avenues of work.

A detonation EOS describes the pressure, $P$, of an explosion as a function of volume, $v$, energy, $E$, and perhaps, temperature. Also present may be a set of rate equations that link one EOS to another. These rates, while not strictly part of the EOS, are so entwined with it that the sum of the pressure/volume information and the rates form a de facto EOS. The resulting combination is entered in a hydrodynamics code (hydrocode) to calculate the motion of something as a function of time. Generally, EOSs have been cobbled together for whatever calculation currently suits programmatic needs, with the justification that the dearth of fundamental knowledge makes ad hoc modeling the only practical approach. Ultimately, an EOS should have scientific underpinning and fit a wide and well-understood selection of cases. Unfortunately, this has too often been neglected.

The process by which an EOS is obtained is as important as the result itself. An EOS is easier to accept if the following conditions are met:

1. Measured data are included in the EOS before the hydrocode run. This is important because a variety of data tests an EOS more stringently than does a single experiment. New EOSs are rarely checked against old data and can, in fact, be used to correct errors that occur elsewhere in the calculation and are not associated with the explosive.

2. The EOS is as complex as the quality and quantity of the measured data that support it-which is why the humble JWL is so popular.

3. The EOS is created by a numerical procedure rather than by the operator. This approach removes much of the opinion input and forces a reproducible process. 
4. A standard is used. A standard is a special explosive with properties better understood than most. The standard provides the scientist with a comparison on which a large amount of work has been done.

5. Adequate documentation and ease of operation. The more complicated the EOS becomes, the more important is this requirement. Given that documentation is generally poor in the explosives' field, the JWL again wins in this category.

The ideal EOS might be obtained from a CHEQ-like program and include reaction kinetics, which independently have been fit to a large collection of Hugoniots, all of which have been documented. The program would generate all points in the two-dimensional (2-D) pressure-volume (P-v) space. It could then be simplified into a 2-D table input or more likely, into a one-dimensional (1-D) (with only the Principle Adiabat) input for the hydrocode. This example shows that we often erroneously consider the final input to the hydrocode to be the EOS, apart from the database that generated it.

Three examples will be considered; all are main topics of this report. The first is the LLNL Cylinder JWL, placed in its present form by John Kury. The JWL is a simple $\mathrm{P}, \mathrm{v}, \mathrm{E}$ equation for the Principal Adiabat. The approach uses a 1.763-g/cc PETN standard for which the JWL is believed, although the pedigree could be upgraded. The cylinder wall velocities of other explosives are converted into detonation energies by velocity-squared comparisons with PETN. The results are JWLs, which are used and supported in all codes because of their simplicity. The EOS for a new explosive is the process of obtaining the final JWL from cylinder data before the hydrocode is run. Although the description sounds simple, it actually took two decades for this EOS to be derived, and it has not been compactly described until this report. The simplicity of the JWL explains its longevity.

The second example is the Look-Up Table described below. This is the Principal Adiabat in $\mathrm{P}, \mathrm{v}, \mathrm{E}$ form but arranged in a table with interpolation between points. Its advantage is that it gives a Principal Adiabat unconstrained by an analytic form (e.g., a JWL) that does not conform to physical reality. The thermochemical code CHEQ supplies the input. The major weakness is that the CHEQ output is not, for several reasons, necessarily accurate. Thus, operator intervention is necessary to correct the table, and the validity of the table is again dependent on operator judgement and the quality of the database. Considerable work needs to be done to validate the tables.

The third example is Ignition \& Growth (I\&G or Reactive Flow). Usually, two temperature-dependent JWLs are used, one for the unreacted explosive and one for the reaction products. Sometimes, a third JWL is added 
to represent reaction products further along in time. A set of time-dependent rate equations link the EOSs. For nonideal explosives, kinetics must be accounted for if detonation is to be accurate. For initiation, the time dependence cannot be ignored. At present, I\&G is the only model with these features.

I\&G has not fared well in production at LX-17-oriented LLNL. It is a complicated EOS, used generally by experts, and it is not well-supported in the codes. It runs up to ten times slower in a hydrocode than does the JWL version. Its input contains no experimental data, and the constants are generated by the operator as he/she runs successive hydrocodes. The output does not implicitly show detonation velocity. Despite the enormous output on LX-17, this explosive has never been converted into a standard. No review articles describe I\&G, and no user-friendly computer features have been invented. Finally, LX-17 is only slightly nonideal, and the JWL or the table can be adjusted to make up the difference. A explosive like ANFO is so highly nonideal that I\&G is absolutely necessary.

Significant practical problems are associated with I\&G. Because I\&G attempts to explicitly describe the detonation front, the zoning for a problem must reflect this. Thus, the running time for a problem is prohibitive for anything but the simplest problems. Also, the large number of empirically derived constants does not inspire confidence in the fundamental validity of the model. For these reasons, I\&G has been confined to a small set of special case problems and has not been tested in larger and more complex configurations.

\section{Notes Regarding This Work}

A. Detonation Points. In writing this report, we found the term "C-J point" to be used indiscriminately. Al Nichols argues that the C-J point is the true thermodynamic equibrium point at which temperature becomes defined in the reaction products behind the shock wave. It holds for an explosive of infinite diameter and at steady state. In this light, a C-J point is probably obtained only in a thermochemical code. All other points are different and must be defined. Here, a list of various detonation points are defined in terms of their pressures.

$\mathbf{P}_{\mathbf{k}}$. This is the first, high-pike pressure seen in the thin-plate test or used in the I\&G code. It results from the initial compression of the unburned or partly burned explosive. As the reaction continues, this pressure drops down the Rayleigh Line toward a detonation point where it diverges onto the Principal Adiabat. 
$\mathbf{P}_{\mathbf{a}}$. The adiabat pressure is the point at which a steady-state, largesize explosive leaves the Rayleigh Line and commences its journey down the Principal Adiabat. True thermodynamic equilibrium has not been proved, but no obvious size effect is known. This point is a practical but special characteristic of a bulk explosive and is what many people call the "C-J" point. This is also the point at which the burn fraction equals 1 in the I\&G code. Because this is a special point, special efforts must be made with any experiment to show that the data describe an adiabat point and not just a detonation point containing other effects.

$\mathbf{P}_{\mathbf{p}}$. The plate pressure is obtained from plate experiments using the algebraic impedance-match equation as defined in Chapter 5. Jump-off velocity (for a plate or cylinder) or supracompression with a plate may be used. When the plate is thin, the pressure seen is $P_{k}$ for a near-ideal explosive. When the thickness of the plate is equal to the reaction zone, the pressure is thought to be $\mathrm{P}_{\mathrm{a}}$ for a near-ideal explosive. The latter may become the initial pressure in a plate-derived JWL.

$\mathbf{P}_{\mathbf{j}}$. The Cylinder Test JWL pressure is obtained using a three-point fit to the wall velocity data. It is not considered to be a true C-J point.

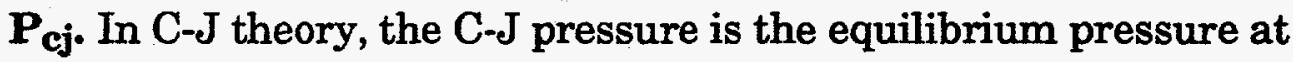
the rear of the reaction zone. It is the initial pressure obtained in a thermochemical code, perhaps the only place that true equilibrium exists. It is likely about $2 \mathrm{GPa}$ below the adiabat pressure, where nonequilibrium effects occur.

$\mathbf{P}_{\mathbf{n}}$. The sonic pressure is the point at which the products move onto the Principal Adiabat for an explosive known not to be in thermodynamic equilibrium because (1) the explosive is at steady state but not at large-diameter or (2) the detonation has not reached steady state. Virtually all composites fall into this group.

B. Rankine-Hugoniot Equations. These equations for the conservation of mass, momentum, and energy assume a piston-driven shock wave, a situation only found explicity for an ideal explosive in a gas-gun experiment with a heavy sabot. The equations nevertheless are used everywhere. They are:

$$
\begin{aligned}
& \text { Mass: } \rho_{o} D=\rho_{p}\left(D-u_{p}\right) \\
& \text { Momentum: } P_{p}-P_{o}=-D d m / d t+d m / d t\left(D-u_{p}\right)
\end{aligned}
$$


where $\rho_{0}$ and $\rho_{p}$ are the densities of the initial unburned explosive and the burned products, $P_{p}$ is the detonation pressure, $P_{0}$ is the initial pressure (essentially zero), $D$ is the detonation velocity, $u_{p}$ is the explosive particle velocity, $m$ is mass, and $t$ is time. The two equations may be combined to form the shock impedance relation

$$
P_{p}=\rho_{0} D u_{p}
$$

Energy conservation leads to the Hugoniot equation:

$$
\text { Energy: } E_{2}-E_{1}=\left(P_{2}+P_{1}\right)\left(v_{1}-v_{2}\right) / 2 \text {, }
$$

where $E$ is energy, $v$ is relative volume, and the subscripts refer to any two points on the curve. Unlike Eqs. (1) and (3), Eq. (4) is too general to be used by itself. In thermochemical codes, the energy of detonation is dumped into the product gases at $1 \mathrm{~atm}$. Then, the Hugoniot is traced out, using Eq. (4) and various thermodynamic descriptions of the products.

C. Units. Mbar units and certain other units are found thoughout this report. Conversions may be made as follows:

Pressure: $\mathrm{Mba} \rightarrow \mathrm{GPa}$ multiply by 100

Energy: Mbar.cc/cc $\rightarrow$ kJ/cc multiply by 100 .

A calorie becomes a joule when it is multiplied by 4.184. TIGER gives atmospheres for pressure. A mega-atmosphere (Matm) becomes a GPa when it is multiplied by 101.325 .

Pressure in the Rankine-Hugoniot momentum relation is maintained, luckily, with the following "mongrel" equality:

$$
\mathrm{GPa}=(\mathrm{g} / \mathrm{cc})(\mathrm{mm} / \mu \mathrm{s})^{2} .
$$

Pressure and energy may be compared using

$$
\mathrm{GPa}=\mathrm{kJ} / \mathrm{cc} \text {. }
$$

D. Detonation energy is presented as a positive number in this text. It is usually negative in chemical thermodynamic literature because the reaction is exothermic. 
E. The data listed in this report come from a mixture of internal sources, including detailed files from the Cray, the Cylinder Handbook, and loose pages in the shot folders. The resources were not available to process the data in a systematic, statistical way. It may be possible to obtain more detail by mining the old data with more care. Many explosives are referred to many times in Chapters 2 to 8. See the Appendix for compositions and details of these explosives. Finally, all persons mentioned here without a footnote are LLNL employees. 


\section{Chapter 2. EOS Description}

\section{Definition of the JWL}

The (standard) JWL (for Jones, Wilkins, and E. L. Lee) is the most used EOS at LLNL. The JWL is a coupled set of equations. From the initial $v=1$ condition, the detonation compresses the explosive to the detonation volume, $\mathrm{vj}$. The straight line that connects these two points in P-v space is called the Rayleigh line. It is given by

$$
P=\rho_{0} D^{2}(1-v),
$$

where $P$ is pressure, $D$ is the detonation velocity, and $v$ is the relative volume. At the detonation point, we have

$$
v_{j}=1-P_{j} / \rho_{o} D^{2} .
$$

The detonation velocity, $\mathrm{D}$, is measured, and the detonation pressure, $P_{j}$, is estimated. From this, $v_{j}$ is determined. At the detonation point, the slope of the pressure is

$$
d P_{j} / d v_{j}=-\rho_{0} D^{2}
$$

This may be recast into the variable $\gamma_{j}$ given by

$$
\gamma_{j}=-d \ln P_{j} / d \ln v_{j}=\rho_{0} D^{2} v_{j} / P_{j},
$$

which is generally expected to lie between 2.6 and 3.0. Also,

$$
\begin{aligned}
& v_{j}=\gamma_{j} /\left(\gamma_{j}+1\right), \\
& \gamma_{j}=v_{j} /\left(1-v_{j}\right),
\end{aligned}
$$

and

$$
\mathrm{P}_{\mathrm{j}}=\rho_{\mathrm{o}} \mathrm{D}^{2} /\left(\gamma_{\mathrm{j}}+1\right)
$$

For one initial cubic centimeter of explosive, the total energy of compression to the detonation point , $\mathrm{E}_{\mathrm{c}}$, is 


$$
\mathrm{E}_{\mathrm{c}}=\rho_{\mathrm{o}} \mathrm{D}^{2}\left(1-\mathrm{v}_{\mathrm{j}}\right)^{2 / 2}=\mathrm{P}_{\mathrm{j}} 2 / 2 \rho_{\mathrm{o}} \mathrm{D}^{2} .
$$

At the detonation point, the compressed explosive suddenly transforms into hot gaseous reaction products, which then expand along the adiabat with a pressure, $P_{S}$, such that

$$
P_{s}(v)=A \exp \left(-R_{1} v\right)+B \exp \left(-R_{2} v\right)+C v(1+\omega) .
$$

This equation may be integrated, assuming constant entropy, by $-\mathrm{P}_{\mathrm{S}} \mathrm{dV}$ to obtain

$$
E_{s}(v)=\left(A / R_{1}\right) \exp \left(-R_{1} v\right)+\left(B / R_{2}\right) \exp \left(-R_{2} v\right)+C / \omega v \omega
$$

$E_{s}$ is a positive number, which decreases from the detonation point, $E_{s}\left(v_{j}\right)$, to zero for infinite volume of the detonation products. Note that $E_{\mathrm{s}}$ is a total energy and is different from the thermal energy found elsewhere in the temperature-dependent JWL. In order to obtain the energy of detonation at volume $v, E_{d}(v)$, we need to subtract the energy of compression from the energy of the adiabatic expansion:

$$
E_{d}(v)=\left[E_{s}\left(v_{j}\right)-E_{s}(v)\right]-E_{c} .
$$

If all energies on the right side of the equation are positive, $E_{d}$ will be negative at small volumes and positive for larger volumes of practical significance. (We have noted that this physics convention is opposite from the chemical convention, which sets exothermic reactions as negative.) $\mathbf{E}_{d}$ is zero at the point where the adiabat energy output equals the energy put in by compression. This usually occurs not at $v=1$, but at about $v=0.92$. The energy of detonation at infinite volume is a positive number, $E_{0}$ :

$$
E_{0}=E_{s}\left(v_{j}\right)-E_{c},
$$

so that

$$
E_{\mathrm{d}}(\mathrm{v})=\mathrm{E}_{\mathrm{o}}-\mathrm{E}_{\mathrm{s}}(\mathrm{v}) \text {. }
$$

For $v \rightarrow \infty, E_{s}(v) \longrightarrow 0$, and $E_{d}(\infty) \longrightarrow E_{0}$, the infinite volume energy of detonation.

The derivative is 


$$
\begin{aligned}
d P_{s} / d v=-\rho_{0} D^{2}= & -R_{1} A \exp \left(-R_{1} v\right)-R_{2} B \exp \left(-R_{2} v\right) \\
& -(\omega+1) C v-(\omega+2),
\end{aligned}
$$

which may be converted to $\gamma$ by multiplying it by $-\left(v / P_{s}\right)$.

One can eliminate $C$ between Eqs. (9) and (10) to obtain this form of the pressure adiabat, which is identical to Eq. (9):

$$
P_{S}=A\left(1-\omega / R_{1} v\right) \exp \left(-R_{1} v\right)+B\left(1-\omega / R_{2} v\right) \exp \left(-R_{2} v\right)+\omega E_{S} / v
$$

Eq. (15) is the form of the JWL used in codes. At the detonation point, $P_{s}, E_{s}$, and $v$ are all known. One then slightly increases the volume by $\Delta v$. By using Eq. (15) with the new $v$ and the old $E_{S}, P_{S}$ can be calculated. Then, $E_{s}$ is adjusted by

$$
E_{s}(\text { new }) \sim E_{s}-P_{s} \Delta v
$$

By moving in steps of $\Delta v=0.001$ or less, the form of the analytical equation Eq. (15) is reproduced. A code then inputs $A, B, R_{1}, R_{2}, \omega, D$, and $E_{0}$. The detonation point value of $E_{s}$ is calculated from $E_{0}$ so that $C$ is not needed.

The JWL is popular because it can be integrated easily and the integral converges even to $v \rightarrow \infty$, which removes the need of selecting a real endpoint for the expansion process. However, a cutoff at 1 atmosphere is actually the physical endpoint.

\section{Look-Up Tables}

Certain features of the JWL may be questioned. First, it seems reasonable that $\gamma=-\partial \ln P / \partial \ln v$ should be constant or decreasing at the detonation point. Instead, it rises in the JWL from the detonation point to a maximum at about $\mathrm{v}=1$. The rising $\gamma$ is caused by the " $\mathrm{A}$ " term of the JWL, which dominates near the detonation point. An exponential divided by its derivative is a constant, so the volume term in $\gamma$ dominates. A second JWL problem is the double peak in $\gamma$ caused by the presence of the two exponentials. The presence of phase transitions between graphite/diamond and nitrogen/water may further complicate the adiabat.

An alternative to the JWL is the Look-Up Table, where $\gamma$ may be designed to suit. Such a table could list $P_{S}$ and $v$ point by point, but the table is built instead on the function $\mathrm{f}(\mathrm{v})$ and the adiabat energy in the form

$$
P_{s}(v)=f(v) E_{s}(v) / v
$$


This equation has been placed in both 1-D and 2-D codes. In these codes, $P_{s}, E_{s}, f$, and $v$ are all known at the detonation point. Then, $v$ is increased by $\Delta v$ and a new $f$ is calculated using either a function or the LookUp Table. Using the new $v$ and $f$ and the old $E_{s}$, a new $P_{s}$ is calculated using Eq. (17). $\mathrm{E}_{\mathrm{s}}$ is then adjusted downward by

$$
E_{S}(\text { new }) \sim E_{s}-P_{S} \Delta v \text {. }
$$

With small volume increments of 0.001 or less, the adiabat is reproduced.

We consider some of the properties of the function $f$. The derivative of Eq. (17) is

$$
\frac{\partial P_{s}}{\partial v}=\frac{E_{s}}{v} \frac{\partial f}{\partial v}+\frac{f}{v} \frac{\partial E_{s}}{\partial v}-\frac{f E_{s}}{v^{2}} .
$$

We multiply both sides by $-v / P_{S}$ and substitute $\partial \mathrm{E}_{S} / \partial v=-P_{S}$ in Eq. (17) to obtain

$$
\gamma=-\partial \ln P_{s} / \partial \ln v=f+1-\partial \operatorname{lnf} / \partial \ln v .
$$

One may use the definition of $\gamma$ and its integral to obtain pressure by integration with

$$
\ln P_{s}=\int \frac{\gamma d v}{v} .
$$

The integration will be numerical with

$$
\Delta \ln \mathrm{P}_{\mathrm{s}}=(\gamma / \mathrm{v}) \Delta \mathrm{v}+\text { sum of previous terms, }
$$

where we start at the detonation point-where $P_{S}$ and $E_{S}$ can be set. We then integrate both to lower and higher volumes. Finally, we use Eq. (17) to obtain $\mathrm{E}_{\mathrm{s}}$. An advantage is that $\gamma$ changes slowly with $\mathrm{v}$ so that we can use a large volume differential ( 0.001 to 0.01 , depending on $v$ ), and we will still get a good answer. Hence, the integration may even be done on a large spreadsheet.

The meaning of $f$ may be further explored. At large volumes, the JWL pressure is

$$
\mathrm{P}_{\mathrm{S}}=\mathrm{C} / \mathrm{v}^{1+\omega},
$$

and the adiabat energy is 


$$
E_{s}=C / \omega^{\omega} .
$$

Then, by Eq. (17),

$$
f=\omega
$$

at large volumes.

The function $f$ can be put into an analytical format as well. PETN of $1.763 \mathrm{~g} / \mathrm{cc}$ can be described from its JWL using

$$
f \sim 10 \exp \left(-2.5 \mathrm{v}^{0.25}\right)+0.57 \text {. }
$$

From CHEQ, the fit is

$$
f \sim 11 \exp \left(-2.45 \mathrm{v}^{0.50}\right)+0.285 \text {. }
$$

A similar EOS has been recently put forth by W. C. Davis. ${ }^{1}$ His equation is

$$
P_{s}=\left(E_{s} / v\right)\{g-1+F(v)\} .
$$

The same ratio of $P_{S} / E_{S}$ appears, with $F(v)$ used to make the function change as it should. He also has extended his function of the off-adiabat case. Here, and above, the intent is to use the ratio $P_{\mathrm{S}} / \mathrm{E}_{\mathrm{s}}$ and create a slowly changing function over the many decades of pressure and energy.

\section{References}

1. W. C. Davis, "Equation of State for Detonation Products," presented at the Tenth International Detonation Symposium, Boston, MA, July 12-16, 1993. 


\section{Chapter 3. Deriving Cylinder JWLs}

\section{Description of the Cylinder Test}

The Livermore Cylinder Test has long been the means of obtaining the JWL. 1-5 The precisely machined cylinder is made of OHFC copper. Two wall thicknesses are used: one is $1 / 20$ th the inner diameter (half-wall) and the other is $1 / 10$ th the inner diameter (full-wall). The full wall, which is easier to machine, came first. The explosive inside is initiated at the bottom and detonates upward, blowing out the copper walls into an inverted funnel. The elastic/plastic properties of the copper allow the wall to deform elastically up to nearly three times the original diameter. A horizontal slit is focused at a given point on the cylinder to measure the wall motion perpendicular to the cylinder axis with a streak camera. The cylinder wall displacement is measured as a function of time, with two cameras taking pictures of both sides for a total of four records. The wall velocity is then calculated at three standard distances of $6,12.5$, and $19 \mathrm{~mm}$ of cylinder wall displacement for a $12.7-\mathrm{mm}$ inner radius. In addition to the streak cameras, two Fabry-Perot interferometers, set $180^{\circ}$ apart, measure opposite-wall velocities directly at an angle, $\Theta_{p}$, of $7^{\circ} \pm 0.2^{\circ}$ to the cylinder axis, and also at the height of the observation slit. The Fabry beam does not hit the point seen by the streak camera, but is rotated around the cylinder at the same height (about 3-5 mm).

Most cylinders used in this report are 1 or 2 in. in diameter. They are $300 \mathrm{~mm}$ long with inner radii of 12.7 and $25.4 \mathrm{~mm}$. The 1 -in. cylinder is a standard in that all data are scaled to this size. For a $12.7-\mathrm{mm}$ radius, a halfwall thickness is $1.27 \mathrm{~mm}$, so the outer radius is $13.97 \mathrm{~mm}$. The full-wall thickness is $2.54 \mathrm{~mm}$, so the outer radius is $15.24 \mathrm{~mm}$. The observation slit for the streak camera or Fabry is $210 \mathrm{~mm}$ from the base of the cylinder. The pins to measure detonation velocity are set 90 and $290 \mathrm{~mm}$ from the base. It is assumed that the detonation velocity has reached steady state by $90 \mathrm{~mm}$ and that the detonation front is steady at $210 \mathrm{~mm}$.

A 4-in. cylinder is sometimes used for nonideal explosives. This cylinder has an inner diameter of $50.8 \mathrm{~mm}$ and can be half- or full-wall. The cylinder is $1000 \mathrm{~mm}$ long with the observation slit at $710 \mathrm{~mm}$. The detonation velocity pins are set 380 and $990 \mathrm{~mm}$ from the bottom of the cylinder. The largest, the 8-in. cylinder, has an inner diameter of $203 \mathrm{~mm}$ and a length of $1220 \mathrm{~mm}$.

The initiation train at the bottom of a 25-mm cylinder starts with an SE-1 (PETN) detonator with a bridge wire. This ignites a $12.7-\times 12.7-\mathrm{mm}$ tetryl cylindrical pellet and drives a plane-wave lens of PBX9501/TNT that enters a 12-mm-thick booster pad of Comp B (detonation pressure $29 \mathrm{GPa}$ ) or Detasheet $(18-20 \mathrm{GPa})$. Comp B is $63 \mathrm{wt} \% \mathrm{RDX}, 36 \% \mathrm{TNT}$, and $1 \%$ wax. Detasheet 
EL-506C is 63 wt\% PETN, 8\% nitrocellulose, and the plasticizer 29\% ATBC (acetyl-tributyl citrate).

A thin, $0.25-\mathrm{mm}$ stainless steel sheet is the final barrier to the bottom of the cylinder. The lens, booster pad, and steel sheet overlap the outer edge of the cylinder for all sizes except the largest. The lenses in use are the P-16 (40.6-mm or 1.6-in. diameter), the P-22 (560-mm or 2.2-in. diameter), the P-40 (102-mm or 4.0-in. diameter), and the P-78 (198-mm or 7.8-in. diameter). The current PBX9501/TNT lenses are from Los Alamos National Laboratory (LANL) and replace an older Comp B/Baratol version used until about 1992. The variation in flatness is thought by $L$. Shaw to be about $\pm 30 \mathrm{~ns}$ for a 1-in.-diameter lens. F. Helm believes the variation to be about $\pm 60 \mathrm{~ns}$ for a 4-in. lens.

The data are always listed as scaled to a 25-mm- (1-in.-) diameter cylinder. To scale down from a 51-mm- (2-in.-) diameter cylinder, time and the increase in radius, $R-R_{0}$, are divided by 2 . To scale from 102-mm (4-in.) cylinder, time and distance are divided by 4 . Velocities are never divided. However, it is easy to combine a correct velocity with the wrong scaled time or distance.

Certain times must be considered in the Cylinder Test. In the smaller cylinders, the detonation wave that we measured at $210 \mathrm{~mm}$ will blow out the top of the cylinder $90 \mathrm{~mm}$ above. For $1.763 \mathrm{~g} / \mathrm{cc}$ PETN, the detonation velocity is $8.274 \mathrm{~mm} / \mu \mathrm{s}$. We take the shock wave speed in copper as about $4.5 \mathrm{~mm} / \mu \mathrm{s}$. The rarefaction wave from the top of the cylinder will move back down the $90 \mathrm{~mm}$ to the slit position. The time we have for measurement is $31 \mu \mathrm{s}$, a long time for a $25-\mathrm{mm}$-diameter cylinder, but only $15.5 \mu \mathrm{s}$ for a scaled-down, $51-\mathrm{mm}$ cylinder.

Also, the detonator on the bottom is larger than the base of the cylinder; thus it drives the copper upward and also ignites the explosive. The detonation wave passes the slit $25.4 \mu \mathrm{s}$ after detonation at the bottom. The shock wave coming up the copper starts at $4.5 \mathrm{~mm} / \mu \mathrm{s}$ but degrades to the sound speed of $3.94 \mathrm{~mm} / \mu$ s with the wave spreading out spatially. For the $25-\mathrm{mm}$ cylinder, the crest of the wave passes the slit at about 52 or $27 \mu \mathrm{s}$ after the detonation wave. The crest of the wave passes the slit at only $13.5 \mu$ s for a $51-\mathrm{mm}$ cylinder.

Suppose we had a weak explosive with a detonation velocity of only $5.5 \mathrm{~mm} / \mu \mathrm{s}$. The difference between the explosive and the copper is only about $1.5 \mathrm{~mm} / \mu \mathrm{s}$. In a 25-mm cylinder, the time for the top reflection to return to the slit is about $37 \mu \mathrm{s}$, but the bottom shock wave in the wall reaches the slit only $14 \mu \mathrm{s}$ later. The effect of the rising wave in the copper wall does not appear to have been much considered.

The cylinder is an EOS "test" because it possesses a geometry that allows the approximate calculation of the relative volume of the gaseous detonation products, $v$. If we calculate a geometric volume, $v_{g}$, from the expansion of the cylinder, and if 


$$
\mathbf{v} \sim \mathbf{v}_{\mathbf{g}},
$$

then we can use this volume in the JWL EOS.

What is measured is the outer radius, $R$, although we usually think of the explosive inside with an inner radius, $S$. Possible confusion of the two must always be kept in mind. The cylinder data have generally been measured at radial displacements, $R-R_{0}$, of $6,12.5$, and $19 \mathrm{~mm}$, where $R$ is the outer radius at time $t$ and $R_{0}$ is the initial outer radius, taken as scaled to an initial inner radius of $12.7 \mathrm{~mm}$. The radial displacements above have traditionally been associated with the rough relative volume values of 2,4 , and 7 . From a geometric view of the cylinder, we might expect, if the gas pressure is all outward, that

$$
\mathrm{v} \sim\left(\mathrm{R} / \mathrm{R}_{0}\right)^{2},
$$

which produces values of $2.17,3.94$, and 6.23 , respectively, for the radial displacements listed above. The use of Eq. (2) assumes that the wall thickness is constant with relative volume. We then examined our hydrocode output to correct for the expansion of the cylinder and the decrease in gas pressure as gas moves backward in the cylinder. ${ }^{6}$ This adjusts the volumes to $2.2,4.1$, and 6.5 at $6,12.5$, and $19 \mathrm{~mm}$, respectively.

\section{How the LLNL Cylinder JWL Is Obtained}

It would be possible to run hydrocodes for every cylinder ever fired and match the JWLs with the measured velocities. This would be extremely expensive, however, and it was long ago abandoned for the standard explosive. The standard used to be PBX-9404 but is now PETN at $1.763 \mathrm{~g} / \mathrm{cc}$. The JWL, listed in the next section, for PETN is taken as delivering believable energies. We list three special PETN points:

\begin{tabular}{ccccc} 
& Rel. & \multicolumn{2}{c}{ Velocity $(\mathrm{mm} / \mu \mathrm{s})$} & $\mathrm{E}_{\mathrm{d}}$ \\
\cline { 3 - 4 } $\begin{array}{c}\mathrm{R}-\mathrm{R}_{\mathrm{0}} \\
(\mathrm{mm})\end{array}$ & \begin{tabular}{c} 
Vol. \\
\cline { 3 - 4 }
\end{tabular} & $\begin{array}{c}\text { PETN } \\
\text { half-wall }\end{array}$ & $\begin{array}{c}\text { PETN } \\
\text { full-wall }\end{array}$ & $\begin{array}{c}\text { PETN } \\
(\mathrm{kJ} / \mathrm{cc})\end{array}$ \\
\hline 6 & 2.2 & 2.09 & 1.58 & 6.51 \\
12.5 & 4.1 & 2.28 & 1.72 & 7.87 \\
19 & 6.5 & 2.38 & 1.78 & 8.55
\end{tabular}

One next obtains the measured outer wall velocities of a new explosive at the same values of $R-R_{0}$. At each volume, $v$, the expected energy of detonation of the new explosive, $E_{d}$, will be 


$$
E_{d}=\left(\frac{u}{u(P E T N)}\right)^{2} E_{d}(\text { PETN })
$$

where $u$ is the cylinder wall velocity. Eq. (4) equates the square of the velocity, by way of kinetic energy, to the detonation velocity. This allows us to calculate three detonation energies at volumes of $2.2,4.1$, and 6.5 for explosive $x$.

The "three-point" method for obtaining a JWL uses the points at $v=2.2$, 4.1, and 6.5. One sets up a small program that first calculates the detonation volume, $v_{j}$, from the Rayleigh Line, as described in Chapter 2 . Then, the following three $J W L$ equations are solved at the detonation point. $E_{s}(j)$ is the adiabat energy at the detonation point.

$$
\begin{aligned}
& d P_{j} / d v_{j}=-p_{0} D^{2}=-R_{1} A \exp \left(-R_{1} v_{j}\right)-R_{2} B \exp \left(-R_{2} v_{j}\right) \\
& -(\omega+1) \mathrm{Cv}_{\mathrm{j}}-(\omega+2) \\
& P_{j}=A \exp \left(-R_{1} v_{j}\right)+B \exp \left(-R_{2} v_{j}\right)+C v_{j}-(1+\omega) \\
& E_{s}(j)=\left(A / R_{1}\right) \exp \left(-R_{1} v_{j}\right)+\left(B / R_{2}\right) \exp \left(-R_{2} v_{j}\right)+C / \omega v_{j} \omega
\end{aligned}
$$

where

$$
E_{s}(j)=P_{j}^{2} / 2 \rho_{0} D^{2}-E_{0}
$$

If one estimates $E_{0}, P j, R_{1}, R_{2}$, and $\omega$, then Eqs. (5), (6), and (7) may be solved as a set of linear simultaneous equations using the method of determinants. One then adjusts the constants until the closest fit, usually 0.5 to $1 \%$, is obtained with the PETN-modified energies. The operator has a major role in this process. From the value of $D$, the operator estimates $P_{j}$ and $E_{0}$, so they start fairly close. The percent spread in the three measured points is observed. Then, minor changes are made until this spread is a minimum. Operator inertia keeps this from expanding to a larger parameter space. The resulting minimum may be a local one and a fitting routine may go far offcourse to find a better answer, but the three-point process works very well in finding answers that appear right.

There are two major assumptions to the LLNL Cylinder EOS: (1) the uncertainties in the fixing of the JWL parameters do not greatly affect the energy of detonation and (2) the ratio of the energy of detonation/ velocitysquared is the same for all explosives. The first is considered below, and the second in Chapter 5. 


\section{Choosing the PETN Standard}

PETN of density 1.760 to $1.765 \mathrm{~g} / \mathrm{cc}$ is considered a suitable standard explosive because it has a very short reaction zone, does not form solid carbon,7 and has nearly constant products in various conditions of confinement as found by calorimetry. ${ }^{8}$ It is oxygen-rich and close to being an ideal explosive. The reaction zone has been estimated by $L$. Green to be less than $0.07 \mathrm{~mm}$. The absence of carbon was surmised by $B$. Hayes from the low $100 \mathrm{mhos} / \mathrm{m}$ conductivity found at 400 to $2000 \mathrm{MHz}$ in runs of up to $20 \mathrm{~ns}{ }^{7}$ In contrast, the conductivity of liquid TNT rose to $10,000 \mathrm{mhos} / \mathrm{m}$ at $20 \mathrm{~ns}$. Hayes estimated the carbon content in PETN to be only about $0.1 \mathrm{~g} / \mathrm{cc}$. The absence of solid carbon allows the PETN detonation energy to be measured with great accuracy. Ornellas' measured heat of detonation for confined $1.735 \mathrm{~g} / \mathrm{cc}$ PETN was only $1.1 \%$ below that calculated from the products. ${ }^{8}$ Unlike many explosives, this energy is the same with various wall materials and even for the unconfined detonation.

The JWL for PETN has received considerable attention. It was studied by Hornig et al. from the shocks sent into Plexiglas. ${ }^{9}$ The standard JWL was generated using the 1-D hydrocode KOVEC from this work. Detonation pressures from 31.5 to $32.5 \mathrm{GPa}$ were run, and it is impossible to make a final determination between them. Next, the Fabry data from PETN cylinder no. 511 were modeled in HEMP by J. Walton. The Fabry data were taken only for $6 \mu \mathrm{s}$, corresponding to a final $R-R_{0}$ of 11.5 , and as discussed further in Chapter 5, it did not bear the correct ratio to the streak data. Two HEMP runs were plotted: the $31.5 \mathrm{GPa}, \mathrm{E}_{\mathrm{o}}=-10.8 \mathrm{~kJ} / \mathrm{cc}$ standard and a $32.0 \mathrm{GPa},-10.1$ $\mathrm{kJ} / \mathrm{cc}$ model. The standard JWL appeared to fit the data, whereas the $32 \mathrm{GPa}$ curve lay a few percent too high. Thus, the 31.5-GPa standard JWL was born. Supracompressed studies on PETN were added by Green, Holmes, and Kury, and the Hugoniot data fit the JWL of the adiabat by $6 \%$ at $80 \mathrm{GPa}, 2.4 \%$ at 63 $\mathrm{GPa}$, and $1.3 \%$ or less below $40 \mathrm{GPa} .{ }^{10}$

J. Kury and L. Green, who worked on the PETN standard, felt that its properties were known with considerable accuracy. They estimated the detonation pressure to be known to $2 \%$, i.e., $31.5 \pm 0.6 \mathrm{GPa}$, with $\pm 1.0 \mathrm{GPa}$ at the 95\% confidence level. They gave the detonation velocity for PETN at 1.763 $\mathrm{g} / \mathrm{cc}$ as $8.274 \pm 0.01 \mathrm{~mm} / \mu \mathrm{s}$. Thus, the cylinder-standard PETN constants were set to be 10

$\begin{array}{ll}\mathrm{A} & 1032.158 \mathrm{GPa} \\ \mathrm{B} & 90.57014 \mathrm{GPa} \\ \mathrm{C} & 3.72735 \mathrm{GPa} \\ \mathrm{R}_{1} & 6.00 \\ \mathrm{R}_{2} & 2.60\end{array}$




$\begin{array}{ll}\omega & 0.57 \\ \mathrm{P}_{\mathrm{j}} & \quad 31.5 \mathrm{GPa} \\ \mathrm{D} & \quad 8.274 \mathrm{~mm} / \mu \mathrm{s}\end{array}$

Also, $v_{j}=0.739008, \gamma_{j}=2.83153$, and $E_{0}=10.80 \mathrm{~kJ} / \mathrm{cc}$. The large number of digits does not mean that they are significant; they are needed, however, to make the coupled equations come out right, regardless of whether $\mathrm{C}$ or $\mathrm{E}_{0}$ is used as a constant for calculation. Even a small round-off in a JWL constant can produce a large change in the calculated detonation energy.

Not all PETN sample densities are exactly $1.763 \mathrm{~g} / \mathrm{cc}$. On the basis of three densities from 1.26 to $1.76 \mathrm{~g} / \mathrm{cc}$, we find

$$
\mathrm{D} \sim \rho_{0},
$$

and for two densities at 1.5 and $1.76 \mathrm{~g} / \mathrm{cc}$

$$
\mathrm{E}_{\mathrm{o}} \sim \rho_{\mathrm{o}}
$$

It appears that the purity of old PETN may not have been as good as originally believed. A recent analysis has shown the presence of $3.8 \mathrm{wt} \%$ petrin, an analog in which one nitro group is replaced by a hydrogen, thereby creating a hydroxyl group. ${ }^{11}$ This would be a less energetic molecule.

\section{Accuracy of the JWL Energy of Detonation}

Table 3-1 lists several JWLs for LX-14 and LX-17. The first two are from cylinders; the last are from other, high-compression experiments. The two cylinder JWLs are separated by at least a decade and have not been derived from the same wall and detonation velocity data. The detonation energies as calculated at $\mathrm{v}=2.2,4.1$, and 6.5 are listed. The 1985 , old-handbook cylinder ${ }^{12}$ JWL and the No. 381 JWL for LX-14 were considered to be "in agreement" because they had the same value near $\mathrm{v}=2$.

Table 3-1 also shows that the LX-17 1985, old-handbook cylinder JWL12 and the No. LH JWL are 2 to $3 \%$ low at all volumes. At the time, the difference was thought to be about $4 \%$, and the cylinder was considered to be at fault. In fact, the differences are within the jitter seen with LX-14. If one redoes the cylinder JWL, the differences become worse, reaching -3 to $-8 \%$. The reason is that the three-point cylinder process produces a detonation pressure of about 26 to $27 \mathrm{GPa}$ for LX-17, whereas the pressure measured in other experiments is higher. 
It is interesting to reconstruct the thinking of the mid1980s when the LX-17 JWLs were constructed..$^{13}$ Ed Lee first constructed a cylinder JWL with a 27.5-GPa detonation pressure. This is the original analog of the $26.5 \mathrm{GPa}$ version in Table 3-1. However, L. Haselman determined a value of $30 \mathrm{GPa}$ based on experiments with compression to small volumes. Others, using the Sack EOS, came up with 33 to $34 \mathrm{GPa}$. Electric-gun plate shots were just starting in the High Explosives Applications Facility (HEAF) and were producing 32-GPa values. E. Lee took the $30 \mathrm{GPa}$ Haselman value and modeled the early-time cylinder behavior, as shown in Fig. 3-1, with DYNA2D. A 30-GPa detonation pressure obviously fits the jump-off better than $26 \mathrm{GPa}$, but the 26-GPa JWL fits better at $4 \mu \mathrm{s}$. This behavior is caused by the nonideality of LX-17.

\section{Uniqueness of the JWL Parameters for PETN}

The well-known JWLs have been run over time and over various experiments. The code-runner remembers the results and adjusts the coefficients until the result is fairly accurate. Unfortunately, this process cannot be demonstrated later on nor can it be easily reproduced. The result is a lack of documented pedigree for the JWLs.

We may next ask how sensitive the JWL parameters are to a Cylinder Test. It is not easy to run large sets of hydrocodes because of the time requirement. An easier way is to use Ernie Baker's analytical cylinder code model. 14,15 This model, which runs instantly on a PC, is a set of massmomentum-energy algorithms that approximate the physics. In Chapter 4, we derive the cylinder angles, where $\Theta_{\mathrm{S}}$ is the angle of the fanning out of the wall. The radial velocity is $u_{s}=D \tan \Theta_{s}$, where $D$ is the detonation velocity. Baker's model works by letting $\Theta_{\mathrm{S}}$ increase, taking the radial velocity with it.

For $1.763 \mathrm{~g} / \mathrm{cc}$ PETN, we ran various JWLs using Baker's Spherical Products (number 4) cylinder model. One obtains wall velocity as a function of the cylinder's change of radius, $\left(R / R_{0}\right)^{2}$. Thus, the velocity is zero when $\left(R / R_{0}\right)^{2}=1$. This, and the absence of a jump-off velocity, puts about $3 \%$ less energy into the analytical model. The Baker-model JWLs used to fit actual data are boosted by this amount as compared to cylinder JWLs. However, we are interested in the relative difference. We require the model to reproduce the experimental half-wall radial velocities of $2.09 \mathrm{~mm} / \mu \mathrm{s}$ at $\mathrm{v}=2.2$ and $2.38 \mathrm{~mm} / \mu \mathrm{s}$ at $\mathrm{v}=6.5$ within $\pm 0.02 \mathrm{~mm} / \mu \mathrm{s}$. This is the precision of a real experiment, at least when streak cameras are used.

The results for $1.763 \mathrm{~g} / \mathrm{cc}$ PETN are shown in Table 3-2. We see that the velocities may be accurately represented with detonation pressures that vary by $2.5 \mathrm{GPa}(8 \%)$ or with total detonation energies, $\mathrm{E}_{0}$, that vary by $1.2 \mathrm{~kJ} / \mathrm{cc}$ (11\%). In-between combinations of $4 \%$ change in $P_{j}$ with $5 \%$ change in $E_{0}$ also 
work. We see that the $v=2.2$ and $v=6.5$ detonation energies (proportional to the velocity-squared) cannot be distinguished from one another.

The wide assortment of parameters that fit should not disguise the gentle but real minimum that exists. A carefully done JWL fit finds this minimum fairly well so that the resulting detonation pressures and total energies are, in many cases, close to the measured ones. The energy, $E_{0}$, and the detonation velocity are the only accurately known quantities that can be found for a detonation. It is important for the physical reality of the JWL that its $E_{0}$ agree with the calorimetric value, even if we must adjust the other parameters somewhat. We see that this is easily achieved.

The Cylinder Test really works in the region $2<\mathrm{v}<7$ with the detonation point being set by extrapolation, assuming the validity of the JWL function. As we see in Table 3-2, the detonation energies that look so similar at $2<\mathrm{v}<7$ diverge at $\mathrm{v}=1$.5. In the past, a study of the cylinder jump-off led to the final adjustment of the JWL, but it can be more easily done now by adding a plate shot, which sees the low volume region. The JWLs of Table 3-2 include results from the LLNL 1-D code for a PETN thickness of $20 \mathrm{~mm}$ and a tantalum plate of 20 mils. The calculated velocities at jump-off and at the fifth dip at $1.3 \mu \mathrm{s}$ are listed. We see that enough variability exists that the plate experiment could easily see the difference.

At this time, we cannot establish a solid pedigree for the PETN standard in terms of cylinder and plate shots. This must await further work in comparing hydrocode output.

\section{Total Detonation Energy from the Cylinder and the Calorimeter}

In setting the JWL, the total energy of detonation, $\mathrm{E}_{0}$, is changed as if it were one of the variables. It is important to see how close these values come to experimental values. The measured heats of detonation, $\mathrm{H}_{0}($ exptl), were taken from Ornellas, as listed in Table 3-3.8 These values are compared with cylinder shots using almost but not quite the same explosive density. A linear adjustment is made to the heats using the density.

Ornellas' heats also contain the heat of condensation of the water, and we wish to use an energy in which the water is still a gas, even at room temperature. The energy of vaporization is

$$
\mathrm{E}_{\mathrm{water}}=44.016 \mathrm{v}_{\mathrm{water}} \rho_{0} / \mathrm{M} \text {, }
$$

where the molar energy of vaporization is $44.016 \mathrm{~kJ} / \mathrm{mole}, v_{\text {water }}$ is the number of mols of water found by Ornellas per mol of explosive, and $\mathrm{M}$ is the molecular weight of the explosive. This adjustment is negative and decreases the detonation energy because energy thought to be derived from detonation in the 
calorimeter is really derived from water becoming liquid. In the case of dense PETN and HMX, this energy is $0.9 \mathrm{~kJ} / \mathrm{cc}$, or a large $8 \%$ effect.

Another, smaller adjustment is made for the positive PV energy, which is

$$
\mathrm{E}_{\mathrm{PV}}=\mathrm{RT} \mathrm{T}_{\mathrm{o}} v_{\text {total }} \rho_{\mathrm{o}} / \mathrm{M}
$$

where $R$ is the gas constant $(8.3144 \mathrm{~J} / \mathrm{mol} \cdot \mathrm{K}), T_{0}$ is $298 \mathrm{~K}$, and $v_{\text {total }}$ is the total number of mols of products per mol of explosives as found by Ornellas. The final energy of detonation with water as a liquid is

$$
E_{0}(\operatorname{exptl})=H_{0}(\operatorname{exptl})-E_{\text {water }}+E_{P V}
$$

The comparison of measured cylinder and JWL energies shown in Table 3-3 are quite good, so that $\mathrm{E}_{\mathrm{o}}$ in the JWL is close to the actual measured energy. The agreement between calorimetric experiment and JWL cylinder derivation for these homogeneous explosives is

$$
\%=0.7 \pm 3.7 \% \text {. }
$$

It is worth reiterating that, after the detonation velocity, $E_{0}$ is the most accurate experimental explosive number. Calorimetry remains a basic measurement for explosives.

Also, in Table 3-3, we calculate the total heat of detonation with the gaseous water (energy of detonation plus PV), $\mathrm{H}_{0}$ (exptl, gas). We next calculate this heat from

$$
\left.\mathrm{H}_{\mathrm{o}}(\text { exptl, gas })=\mathrm{H}_{\mathrm{f}} \text { (products, gas }\right)-\mathrm{H}_{\mathrm{f}}(\text { reactant }) \text {. }
$$

The heat of formation of the explosive (reactant) is listed in the Appendix. The heats of formation for the products are for the gases, including water, and for $\mathrm{CO}_{2}, \mathrm{H}_{2} \mathrm{O}, \mathrm{HF}, \mathrm{CH}_{4}$, and $\mathrm{NH}_{3}$ are $392,238,269,74.9$, and $46.0 \mathrm{~kJ} / \mathrm{mol}$, respectively. The steps for calculation are (1) react all fluorine to $\mathrm{HF}$, (2) react all oxygen to water, (3) react all carbon with remaining oxygen to $\mathrm{CO}_{2}$ leaving unreacted carbon as the element, (4) react remaining hydrogen with carbon to methane, and (5) react remaining hydrogen with nitrogen to ammonia. The result for the 16 explosives in Table $3-3$ is $12 \pm 13 \%$ for the complete burning of carbon. By setting to an $80 \%$ burn to $\mathrm{CO}_{2}$ with $20 \% \mathrm{CO}$, we have an agreement of

$$
0 \pm 11 \%
$$


with the measured data. The broad band of uncertainty comes because we cannot guess ahead of time how efficient the burning of the carbon will be. HNS is the least efficient of all; BTF, NM, low density HMX, and TNT are also low. The most efficiency explosives are HNB, RX-23-AA, and high density HMX.

\section{Approaching Perfect Gas Behavior}

One means of establishing credibility for an EOS is to make it approach perfect gas behavior at large volumes. CHEQ meets this requirement, as can be found by calculating the compressibility, $z$, using

$$
\mathrm{z}=\mathrm{PvV}_{\mathrm{d}} \mathrm{nRT} \text {, }
$$

where $\mathrm{P}$ in $\mathrm{GPa}, \mathrm{v}$ is dimensionless, $\mathrm{V}_{\mathrm{o}}$ is in $\mathrm{cc} / \mathrm{mol}, \mathrm{n}$ is dimensionless ( $\mathrm{mols} / \mathrm{mol}$ ), and $\mathrm{R}$ (the Gas Constant) is $8.314 \times 10^{-3} \mathrm{~kJ} / \mathrm{mol} \cdot \mathrm{K}$. The parameter $\mathrm{n}$ is the number of moles of gas created per mole of explosive. In CHEQ, $z \rightarrow 1$, as expected.

For adiabatic expansion, the change in entropy is

$$
\mathrm{dS}=0=\mathrm{C}_{\mathrm{v}} \mathrm{dT} / \mathrm{T}+\mathrm{RdV} / \mathrm{N},
$$

where $\mathrm{C}_{\mathrm{v}}$ is the heat capacity at constant volume. If $\mathrm{C}_{\mathrm{v}}$ is temperatureindependent, then

$$
T \sim \mathrm{V}^{-R / C_{v}}
$$

so that

$$
\omega \sim \mathrm{R} / \mathrm{C}_{\mathrm{v}} \text {. }
$$

This is the source of making $\omega$ a constant at large volumes. If $\omega$ were the same for all explosives, we would fully understand one end of the EOS. The CHEQ code (see Chapter 8), with an adjusted adiabat energy, produces $\omega=0.28$ for PETN at $1.763 \mathrm{~g} / \mathrm{cc}$ and $\omega=0.22$ for HNB at $1.965 \mathrm{~g} / \mathrm{cc}$. PETN from $500<\mathrm{v}<1760$ (1 atm) cools from 520 to $360 \mathrm{~K}$. HNB from $500<\mathrm{v}<2960$ (1 atm) cools from 1050 to $710 \mathrm{~K}$. Therefore, HNB is hotter, $\mathrm{C}_{\mathrm{v}}$ is larger, and $\omega$ is smaller.

$\omega$ is, therefore, really a constant only at a defined 1 atmosphere temperature because $\mathrm{C}_{\mathrm{v}}$ actually increases with temperature. For

$\mathrm{C}_{\mathrm{v}}+\mathrm{A}+\mathrm{BT}$ 
Eq. (23) becomes

$$
\mathrm{Aln} \mathrm{T}+\mathrm{BT}=-\mathrm{R} \ln \mathrm{V},
$$

and no simple relation can be found. Including this would destroy the simplicity of the JWL. The result in practice is that the JWL $\omega$, as derived from the cylinder for $2<\mathrm{v}<7$, is larger than that calculated from CHEQ. Thus, $\omega$ for PETN is 0.57 in the JWL and 0.28 in CHEQ. $\omega$ for HNB has values of 0.28 in the JWL and 0.22 in CHEQ.

\section{Generating Systematic JWL Constants}

One of the disturbing results of the JWL is that the constants of different explosives show no apparent trends. This suggests that maybe too many constants are used and simplification is possible. However, the pressure and energy drop steeply from the detonation point, but change very slowly at large volumes. The transition from the $A$ to the $\mathrm{C}$ term in the JWL is discontinuous, and for this reason, the B term was added to smooth it. A function that handles very different rates of change over 6 to 9 orders of magnitude is difficult to find.

Urtiew and Hayes made a clever attempt to unify the JWL situation. ${ }^{16,17}$ They created dimensionless units based on the initial density times the square of the detonation velocity. Their relationships are

$$
\begin{aligned}
& \mathrm{A} / \rho_{0} \mathrm{D}^{2}=5.35545 \\
& \mathrm{~B} / \rho_{0} \mathrm{D}^{2}=0.094983 \\
& \mathrm{C} / \rho_{0} \mathrm{D}^{2}=0.0112292 \\
& \mathrm{R}_{1}=4.41604 \\
& \mathrm{R}_{2}=0.27 \mathrm{R}_{1} \\
& \omega=1 / 3 \\
& \mathrm{Pj} / \rho_{0} \mathrm{D}^{2}=0.2653 \\
& \mathrm{E}_{0} / \rho_{0} \mathrm{D}^{2}=0.204-0.0734 \rho_{0}
\end{aligned}
$$

The results are shown below. We have taken the cylinder JWLs for 32 explosives and calculated the dimensionless constants. 


\begin{tabular}{rlll} 
& $\mathrm{A} / \rho_{0} \mathrm{D}^{2}$ & $\mathrm{~B} / \rho_{0} \mathrm{D}^{2}$ & $\mathrm{C} / \rho_{0} \mathrm{D}^{2}$ \\
\hline Urtiew & 5.355 & 0.095 & 0.011 \\
average & 5.518 & 0.095 & 0.017 \\
st. dev & 1.81 & 0.128 & 0.011 \\
& & & \\
PETN & 8.552 & 0.750 & 0.031 \\
LX-17 & 8.925 & 0.157 & 0.013 \\
LX-14 & 4.667 & 0.038 & 0.013 \\
RX-26-AF & 4.511 & 0.036 & 0.005
\end{tabular}

The average is close to the Urtiew/Hayes values, but the standard deviation is very large. PETN of $1.763 \mathrm{~g} / \mathrm{cc}$ is far off, and we obtain $\mathrm{E}_{\mathrm{o}}=9.0$ $\mathrm{kJ} / \mathrm{cc}$ instead of the actual value of $10.3 \mathrm{~kJ} / \mathrm{cc}$ or the JWL value of 10.8 . The resulting PETN energies at the cylinder volumes of interest are about $10 \%$ low. In Chapter 5, we show that $\rho_{0} \mathrm{D}^{2}$ is the spring constant for the compression of the explosive. It is not surprising that this value does not relate to the later time behavior of energy release, which depends on the kinetics of each reaction.

\section{Variations of the JWL Function}

Many attempts have been made to alter the form of the JWL. Most variations make it more complicated. The first of these is the temperaturedependent JWL used in the Ignition and Growth (I\&G) model (see Chapter 7). It has the Gruneison form

$$
P_{S}(v, T)=R_{1} \exp \left(-R_{5} v\right)+R_{2} \exp \left(-R_{6} v\right)+R_{3} T / v .
$$

Although they are similar, this is a different equation from the regular JWL, which does not include temperature. Eq. (27) is a true Gruneison EOS, which is defined by 18,19

$$
P=P_{0}+\rho_{0} \omega(v) E_{t}(v, T) / v,
$$

where $P_{0}$ is the pressure at $0 \mathrm{~K}$ and $E_{t}$ is the thermal energy. Thus, we split the energies into the cold energy of compression and the energy solely involved in heating it.

The second, more complicated, form is that of E. L. Baker, which is called the JWLB EOS. In this form, the adiabat is given by 20,21 


$$
P_{s}=\sum_{i} A_{i}\left(1-\frac{\lambda}{R_{i} v}\right) \exp \left(-R_{i} v\right)+\frac{\lambda E_{s}}{v}+C\left(1-\frac{\lambda}{\omega}\right) v^{-(\omega+1)}
$$

where

$$
\lambda=\sum_{\mathbf{i}}\left(\mathrm{A}_{\lambda_{\mathrm{i}} \mathrm{v}}+\mathrm{B}_{\lambda_{\mathrm{i}}}\right) \exp \left(-\mathrm{R}_{\lambda_{\mathrm{i}} \mathrm{v}}\right)+\omega
$$

In addition to the detonation velocity and the usual detonation parameters, there are 16 constants in the JWLB EOS for octol. (The JWLB has been placed in DYNA2D and is available at LLNL.)

A more complex version of the JWL by $E$. Lee et al. seeks to make $\omega$ a function of volume. ${ }^{22}$ The pressure adiabat is given by

$$
P_{s}=A \exp \left(-R_{1} v\right)+B \exp \left(-R_{2} v\right)+C / v^{\omega+1}+a v^{2} /\left(1+b v^{2}\right)^{2},
$$

which adds two more constants.

A final version was designed by Miller and Guirguis for composite explosives in which energy comes out at long times. ${ }^{23}$ The late energy caused by burning the aluminum is $\lambda Q$. The JWL adiabat becomes

$$
\begin{aligned}
P_{S}= & A\left(1-\omega / R_{1} v\right) \exp \left(-R_{1} v\right)+B\left(1-\omega / R_{2} v\right) \exp \left(-R_{2} v\right)+ \\
& \omega\left(E_{s}+\lambda Q\right) / v
\end{aligned}
$$

where

$$
\mathrm{d} \lambda / \mathrm{dt}=\mathrm{a}(1-\lambda)^{1 / 2} \mathrm{P}_{\mathrm{s}}{ }^{1 / 6},
$$

where $a$ is a constant. Then,

$$
\lambda=1-\frac{\mathrm{a}^{2}}{4}\left[\int_{0}^{\mathrm{t}} \mathrm{p}^{1 / 6}(\mathrm{t}) \mathrm{dt}\right]
$$

Near the detonation point, the integral is large, and $\lambda \sim 0$. At long times, with $P_{s}$ small, the integral is small, and $\lambda$ is large. More energy is then added to the last term. 


\section{References}

1. J. W. Kury, H. C. Hornig, E. L. Lee, J. L. McDonnel, D. L. Ornellas, M. Finger, F. M. Strange, and M. L. Wilkins, "Metal Acceleration by Chemical Explosives," Proceedings of the Fourth Symposium (International) on Detonation, White Oak, MD, October 12-15, 1965, pp. 3-12.

2. E. L. Lee, H. C. Hornig, and J. W. Kury, Adiabatic Expansion of High Explosive Detonation Products, Lawrence Livermore National Laboratory, Livermore, CA, UCRL-50422 (1968).

3. E. Lee, D. Breithaupt, C. McMillan, N. Parker, J. Kury, C. Tarver, W. Quirk, and J. Walton, "The Motion of Thin Metal Walls and the Equation of State of Detonation Products," Proceedings of the Eighth Symposium (International) on Detonation, Albuquerque, NM, July 15-19, 1985, pp. 613-624. (1989).

4. R. M. Doherty, J. M. Short and M. J. Kamlet, Combus. Flame 76, 297

5. H. Hormberg and F. Volk, Propellants, Explosives, Pyrotechnics 14, 199 (1989).

6. P. C. Souers and J. W. Kury, Propellants, Explosives, Pyrotechnics 18, 175 (1993).

7. B. Hayes. "On Electrical Conductivity in Detonation Products," Proceedings Fourth Symposium (International) on Detonation, White Oak, MD, October 12-15, 1965, pp. 595-601.

8. D. L. Ornellas, Calorimetric Determinations of the Heat and Products of Detonation for Explosives: October 1961 to April 1982, Lawrence Livermore National Laboratory, Livermore, CA, UCRL-52821 (1982), pp. 57-61.

9. H. C. Hornig, E. L. Lee, M. Finger, and J. E. Kurrle, "Equation of State of Detonation Products," Proceedings Fifth Symposium (International) on Detonation, August 18-21, 1970, Pasadena, CA, p. 503.

10. L. Green, N. Holmes, and J. Kury, "Shock Measurements on Explosives in the Supra-Compressive Region," presented at the Int' Symposium on Pyrotechnics and Explosives, Beijing, China, October 12-15, 1987; Lawrence Livermore National Laboratory, Livermore, CA, UCRL-95461 (1987).

11. R. Clarkson, memo to R. Simpson, February 26, 1993. 
12. B. M. Dobratz and P. C. Crawford, LLNL Explosives Handbook, Lawrence Livermore National Laboratory, Livermore, CA, UCRL-52997 (1985), pp. 8-21-8-23.

13. Memo from E. Lee to S. Cochran, November 28, 1985; the memories of J. Kury and C. Tarver.

14. E. L. Baker, Modeling and Optimization of Shaped Charge Liner Collapse and Jet Formation, U.S. Army Research, Development, and Engineering Center, Picatinny Arsenal, NJ, Report ARAED-TR-92019 (1993).

15. E. L. Baker, Picatinny Arsenal, NJ, private communication, 1993.

16. P. A. Urtiew and B. Hayes, Empirical Estimate of Detonation Parameters in Condensed Explosives, Lawrence Livermore National Laboratory, Livermore, CA, UCRL-JC-103219 (1990).

17. P. A. Urtiew and B. Hayes, "Parametric Study of the Dynamic JWLEOS for Detonation Products," presented at the Third Int'1 Lavrentiev's Readings Conference, Novosibirsk, USSR, September 10-14, 1990; Lawrence Livermore National Laboratory, Livermore, CA, UCRL-JC-103218 (1990).

18. D. O'Keeffe and J. D. Pastine, Metallurgical Effects at High Strain Rates, R. W. Rohde, B. M. Butcher, J. R. Holland and C. H. Karnes, eds. (Plenum, New York, 1973), pp. 157-169.

19. D. O'Keeffe, J. Geophys. Research 75, 1947 (1970).

20. E. L. Baker, An Explosives Products Thermodynamic Equation of State Appropriate for Material Acceleration and Overdriven Definition: Theoretical Background and Formulation, ARDEC Report ARAED-TR-91013, Picatinny Arsenal, NJ (1991).

21. E. L. Baker and J. Orosz, Advanced Warheads Concepts: An Advanced Equation of State for Overdriven Detonation, ARDEC Report ARAED-TR-91007, Picatinny Arsenal, NJ (1991).

22. E. L. Lee, M. Van Thiel, L. G. Green and A. Mitchell, "Detonation Product EOS: The Region Above Chapman Jouget Pressure," in Shock Waves in Condensed Matter-1983, J. R. Asay, R. A. Graham and G. K. Straub, eds. (Elsevier Science Publishers, 1984), pp. 617-620.

23. P. J. Miller and R. H. Guirhuis, "Experimental Study and Model Calculations of Metal Combustion in Al/AP Underwater Explosives," Materials Research Society, Symposium Proceedings, 296 199-304 (1993). 


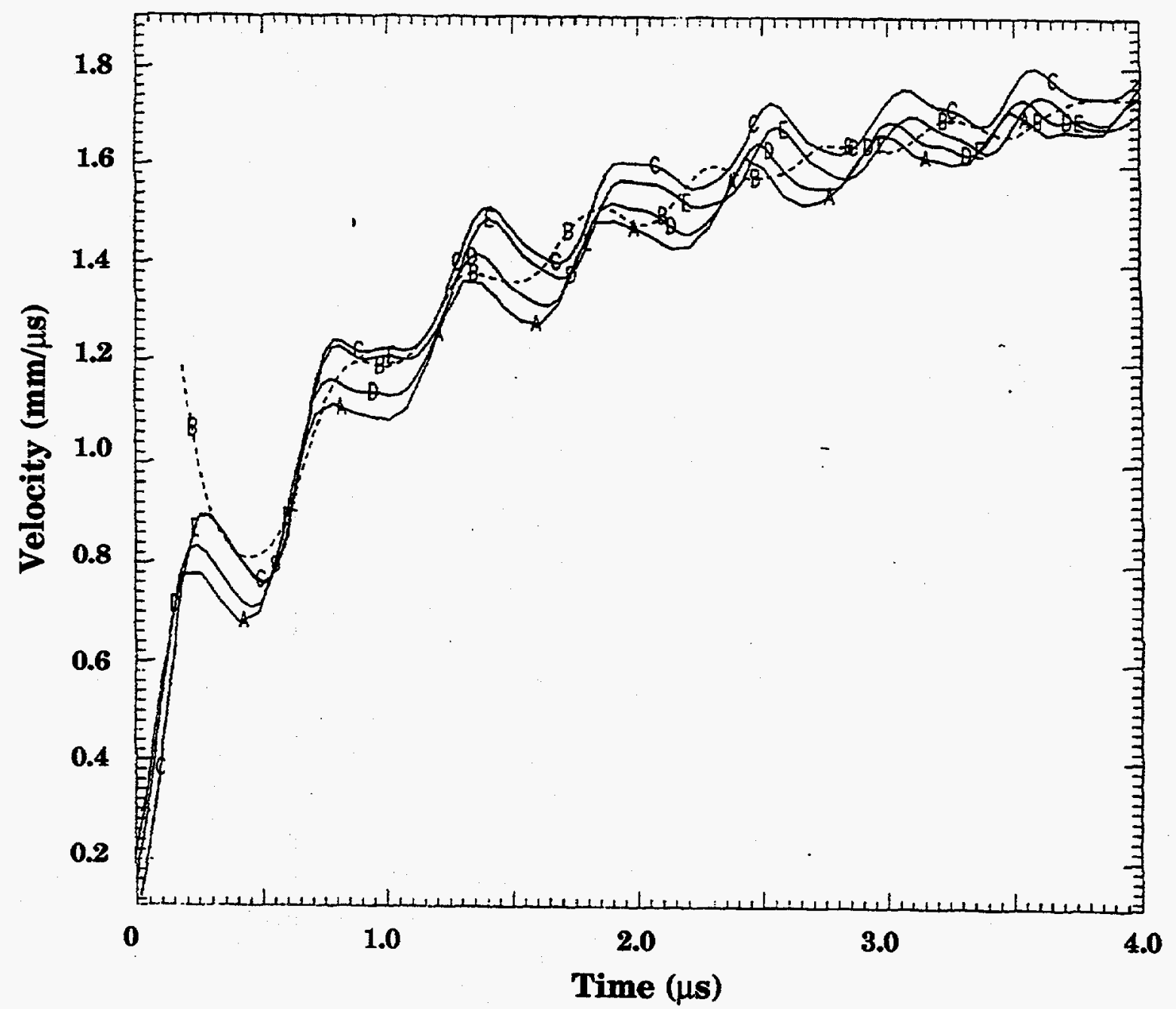

Fig. 3-1. DYNA2D runs for LX-17 in the cylinder test. Unconfined wall velocity is plotted against the scaled $25 \mathrm{~mm}$-diameter time. A JWL with a 30-GPa detonation pressure fits the jump-off velocity but not the behavior at $4 \mu \mathrm{s}$. A 26-GPa JWL shows the reverse. The data are curve $B$, a smoothed average of the streak camera data in cylinder numbers $470,471,522$, and 523. The DYNA curves with the JWL detonation pressures and the A coefficients are: curve A 26 GPa, A = 9.326; C Haselman's $30 \mathrm{GPa}, \mathrm{A}=4.603$; D $28 \mathrm{GPa}, \mathrm{A}=6.205$; $\mathrm{E} 30 \mathrm{GPa}, \mathrm{A}$ $=4.572$. 
Table 3-1. Comparison of historical JWLs used for LX-14 and LX-17. Although Mbar units are used for the JWLs, the energies are in $\mathrm{kJ} / \mathrm{cc}$.

\begin{tabular}{|c|c|c|c|c|c|c|}
\hline & \multicolumn{3}{|c|}{$\begin{array}{l}\mathrm{LX}-14,1.830 \text { to } 1.835 \mathrm{~g} / \mathrm{cc} \text {, } \\
8.80 \text { to } 8.83 \mathrm{~mm} / \mu \mathrm{s}\end{array}$} & \multicolumn{3}{|c|}{$\begin{array}{l}\mathrm{LX}-17,1.900 \text { to } 1.905 \mathrm{~g} / \mathrm{cc} \text {, } \\
7.596 \text { to } 7.63 \mathrm{~mm} / \mu \mathrm{s}\end{array}$} \\
\hline & $\begin{array}{l}\text { New } \\
\text { from } \\
\text { cylinder }\end{array}$ & $\begin{array}{c}\text { Old } \\
\text { cylinder f. } \\
\text { Handbook }\end{array}$ & $\begin{array}{l}\text { JWL no. } \\
381\end{array}$ & $\begin{array}{l}\text { New } \\
\text { from } \\
\text { cylinder }\end{array}$ & $\begin{array}{c}\text { Old } \\
\text { cylinder f. } \\
\text { Handbook }\end{array}$ & $\begin{array}{l}\text { JWL no. } \\
\text { LH }\end{array}$ \\
\hline A (Mbars) & 6.614142 & 8.261 & 7.5598 & 9.897607 & 4.46 & 4.603 \\
\hline B (Mbars) & 0.054007 & 0.1724 & 0.2267 & 0.174413 & 0.01339 & 0.09544 \\
\hline C (Mbars) & 0.018257 & 0.01296 & 0.009825 & 0.014271 & 0.01306 & 0.01265 \\
\hline $\mathbf{R}_{1}$ & 4.118 & 4.55 & 4.44 & 5.15 & 3.85 & 4.00 \\
\hline $\mathbf{R}_{2}$ & 0.95 & 1.32 & 1.5 & 1.713 & 1.03 & 1.70 \\
\hline$\omega$ & 0.40 & 0.38 & 0.3 & 0.45 & 0.46 & 0.48 \\
\hline $\mathbf{v} \mathbf{j}$ & 0.732 & 0.740 & 0.734 & 0.766 & 0.727 & 0.726 \\
\hline $\mathbf{P}_{\mathbf{j}}(\mathrm{GPa})$ & 38.0 & 37.0 & 38.1 & 26.0 & 30.0 & 30.0 \\
\hline $\mathrm{E}_{\mathrm{o}}(\mathrm{J} / \mathrm{cc})$ & 10.8 & 10.2 & 10.1 & 7.0 & 6.9 & 6.9 \\
\hline$E_{d}(v=2)$ & 6.75 & 6.95 & 6.95 & 4.54 & 4.78 & 4.94 \\
\hline$E_{d}(v=4)$ & 8.09 & 8.15 & 7.92 & 5.31 & 5.43 & 5.56 \\
\hline $\mathbf{E}_{d}(v=7)$ & 8.63 & 8.52 & 8.23 & 5.63 & 5.71 & 5.83 \\
\hline
\end{tabular}

Table 3-2. Set of JWLs for $1.763 \mathrm{~g} / \mathrm{cc}$ PETN that give the right answer to a Cylinder Test. These were run in the Baker cylinder model for a 25 -mm-diameter, half-wall cylinder until the experimental velocities of 2.09 and $2.38 \mathrm{~mm} / \mu \mathrm{s}$, each $\pm 0.02 \mathrm{~mm} / \mu \mathrm{s}$, were obtained. All detonation velocities are $8.274 \mathrm{~mm} / \mu \mathrm{s}$. The detonation pressure is in $\mathrm{GPa}$, the detonation energies $E_{0}$ and $E_{d}$ are in $\mathrm{kJ} / \mathrm{cc}$, the velocities at jump-off and the 5 th dip for the plate are in $\mathrm{mm} / \mu \mathrm{s}$, and all other units are in Mbar. The text describes how these JWLs are narrowed to standard values. Both JWL no. 5 and 6 meet the standard conditions.

\begin{tabular}{|c|c|c|c|c|c|c|c|c|}
\hline No. & 1 & 2 & 3 & 4 & 5 & 6 & 7 & 8 \\
\hline$\overline{P_{j}}$ & 34.5 & 34.5 & 32.0 & 32.0 & 31.0 & 32.0 & 28.5 & 28.5 \\
\hline$E_{0}$ & 12.0 & 10.8 & 10.8 & 10.8 & 10.3 & 10.8 & 10.8 & 9.6 \\
\hline A & 5.5338 & 5.0536 & 23.8298 & 14.9186 & 10.2432 & 7.6647 & 31.6650 & 16.3837 \\
\hline B & 0.8229 & 0.6312 & 1.6003 & 1.3337 & 0.3272 & 0.2834 & 0.5394 & 0.1758 \\
\hline C & 0.0226 & 0.0282 & 0.0306 & 0.0310 & 0.0304 & 0.0296 & 0.0316 & 0.0307 \\
\hline $\mathrm{R}_{1}$ & 5.0 & 4.7 & 8.0 & 7.0 & 5.5 & 5.0 & 7.3 & 6.0 \\
\hline $\mathrm{R}_{2}$ & 2.35 & 2.30 & 2.8 & 2.7 & 1.75 & 1.75 & 2.00 & 1.25 \\
\hline$\omega$ & 0.35 & 0.50 & 0.52 & 0.52 & 0.60 & 0.52 & 0.55 & 0.80 \\
\hline$E_{d}(1.5)$ & 5.29 & 5.23 & 5.18 & 5.10 & 4.92 & 4.93 & 4.85 & 4.63 \\
\hline$E_{d}(2.2)$ & 6.89 & 6.82 & 6.77 & 6.71 & 6.74 & 6.68 & 6.74 & 6.66 \\
\hline$E_{\alpha}(6.5)$ & 8.64 & 8.59 & 8.58 & 8.54 & 8.65 & 8.65 & 8.75 & 8.74 \\
\hline jump-off & 1.65 & 1.65 & 1.55 & 1.54 & 1.49 & 1.53 & 1.39 & 1.38 \\
\hline 5 th dip & 3.12 & 3.09 & 3.05 & 3.01 & 2.91 & 2.94 & 2.83 & 2.75 \\
\hline
\end{tabular}


Table 3-3. Comparison of measured calorimetric total energies of detonation with those derived from the cylinder JWLs. The final, adjusted total energies of detonation, as derived from the calorimeter, $\mathbf{E}_{0}$, are in bold. The agreement between the calorimeter and the cylinder for these homogeneous explosives is better than expected. All heats and energies are in $\mathrm{kJ} / \mathrm{cc}$.

\begin{tabular}{|c|c|c|c|c|c|c|}
\hline Explosive & $\begin{array}{c}\text { Measured } \\
\text { density } \\
(\mathrm{g} / \mathrm{cc})\end{array}$ & $\begin{array}{l}\text { Measured } \\
\text { confined } \\
\text { heat of } \\
\text { detonation } \\
(\mathrm{kJ} / \mathrm{cc}) \\
\end{array}$ & $\begin{array}{c}\text { Our } \\
\text { densities } \\
\text { (g/cc) }\end{array}$ & $\begin{array}{c}\text { Adjusted } \\
\text { measured } \\
\text { heat of } \\
\text { detonation } \\
(\mathrm{kJ} / \mathrm{cc})\end{array}$ & $\begin{array}{c}\begin{array}{c}\text { Energy of } \\
(\mathrm{kJ} / \mathrm{cc})\end{array} \\
\text { from heat of } \\
\text { detonation }\end{array}$ & 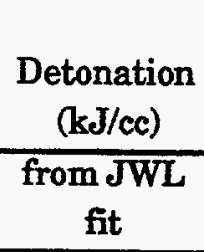 \\
\hline BTF & 1.86 & 10.98 & 1.852 & 10.93 & 11.2 & 11.3 \\
\hline 1,2-DP & 1.265 & 7.09 & 1.26 & 7.06 & 72 & 6.9 \\
\hline FEFO & 1.607 & 8.56 & 1.607 & 8.60 & 8.3 & 8.2 \\
\hline HMX & 1.89 & 11.70 & 1.893 & 11.71 & 11.0 & 11.0 \\
\hline HMX & 1.20 & 6.63 & 1.188 & 6.56 & 6.2 & 6.4 \\
\hline HNB & 1.918 & 13.27 & 1.965 & 13.59 & 13.7 & 13.2 \\
\hline HNS & 1.649 & 7.58 & 1.655 & 7.61 & 7.5 & 7.5 \\
\hline HNS & 1.017 & 3.74 & 1.001 & 3.68 & 3.7 & 3.6 \\
\hline NM & 1.13 & 5.80 & 1.13 & 5.80 & 5.2 & 5.0 \\
\hline PETN & 1.732 & 10.81 & 1.763 & 11.01 & 10.3 & 10.8 \\
\hline PETN & 1.496 & 9.41 & 1.503 & 9.46 & 8.9 & 8.5 \\
\hline RX-23-AA & 1.424 & 7.98 & 1.424 & 7.98 & 6.5 & 6.5 \\
\hline $\mathrm{RX}-23-\mathrm{AB}$ & 1.356 & 6.24 & 1.356 & 6.24 & 4.3 & 4.1 \\
\hline RX-23-AC & 1.136 & 4.66 & 1.136 & 4.66 & 4.1 & 4.5 \\
\hline TATB & 1.87 & 7.96 & 1.83 & 7.92 & 7.3 & 7.3 \\
\hline TNT & 1.533 & 7.01 & 1.632 & 7.46 & 7.1 & 7.1 \\
\hline
\end{tabular}




\section{Chapter 4. Cylinder Analysis}

\section{Cylinder Relative Volumes with Wall Thinning}

What makes the Cylinder Test a "test" is that the relative volume may be determined directly from the cylinder expansion by calculating volume segments of the cylinder. In Chapter 2, we considered a wall of constant thickness and arrived at volumes of 2.2, 4.1, and 6.5 for perpendicular streak camera expansions of $6,12.5$, and $19 \mathrm{~mm}$ with a 25 -mm-diameter cylinder.

However, one should include the thinning of the wall as the cylinder expands. Then, on the horizontal line just defined, we initially define the geometric relative volume, $\mathrm{vg}_{\mathrm{g}}$, as

$$
\mathrm{v}_{\mathrm{g}} \sim\left\{\left[\mathrm{S}_{\mathrm{o}}+\left(\mathrm{R}-\mathrm{R}_{\mathrm{o}}\right)\right] / \mathrm{S}_{\mathrm{o}}\right\}^{2}
$$

where $S_{0}^{\prime}$ and $R_{0}$ are the initial inner and outer radii and $R$ is the outer radius at a later time. If we let $W_{0}$ be the initial wall thickness and $W$ be the thickness at a later time, the decreased wall thickness at time $t$ is given by

$$
\mathrm{W} \sim\left\{\mathrm{R}_{0} / \mathrm{R}\right\} \mathrm{W}_{0} .
$$

The decreased wall thickness $\mathrm{W}_{0}-\mathrm{W}$ is now added as gas space, and we obtain the new geometric volume

$$
\mathbf{v}_{\mathrm{g}} \sim\left\{\left[\mathrm{S}_{\mathrm{o}}+\left(\mathrm{R}-\mathrm{R}_{\mathrm{o}}\right)+\left(\mathrm{W}_{\mathrm{o}}-\mathrm{W}\right)\right] / \mathrm{S}_{\mathrm{o}}\right\}^{2}
$$

The results are now dependent on the initial wall thickness, and we have a different set of values for the half- and full-wall cylinders, as listed below.

\begin{tabular}{cclc} 
& \multicolumn{3}{c}{ Relative Volumes, $\mathrm{vg}_{\mathrm{g}}$} \\
\cline { 2 - 4 } Distance & Constant & \multicolumn{2}{c}{ Thinning wall } \\
\cline { 3 - 4 } $\mathrm{R}-\mathrm{R}_{\mathrm{o}}$ & wall, & Half- & Full- \\
$(\mathrm{mm})$ & approx. & wall & wall \\
\hline 6 & 2.2 & 2.26 & 2.36 \\
12.5 & 4.1 & 4.14 & 4.34 \\
19 & 6.5 & 6.53 & 6.84
\end{tabular}

One would then have to compare the corrections for wall motion from the hydrocodes. A correction for wall thinning has not yet seemed important enough to add, considering the accuracy of the JWL. 


\section{Comparing Streak and Fabry Data}

The streak camera and the Fabry interferometer measure different things on the cylinder.1,2 To see this, we consider the schematic in Fig. 4-1. The cylinder is vertical, with the central axis lying along $\mathrm{A}^{\prime} \mathrm{B}^{\prime}$, the original wall along $\mathrm{AB}$, and the detonation wave of velocity, $\mathrm{D}$, moving upward. The cylinder wall is blown outward to the line $\mathrm{BC}$, and all later surfaces will be parallel to BC (and farther out). At the time of Fig. 4-1, the wall has swung out from the vertical, as though on a hinge, from point $B$. The streak camera looks in at point $C$ and so constantly sees new points from below on the cylinder. The Fabry looks in at point $E$ along the line $A E$ and so sees a point at $A$ on the cylinder at $t=$ zero.

In the simple "hinged wall" model, the wall has swung along the arc $\mathrm{AE}$, which is very close to the straight line $\mathrm{AE}$. Thus, the Fabry path $\mathrm{AE}$ is close to the path of the same point on the wall and is the one-dimensional path of interest. The streak camera, looking at point $C$, however, sees a new wall moving constantly upward into its field of view.

In this simple model, velocities and distances are assumed to be proportional to the geometry shown (strictly, the velocities change with time and hold only for a differentially small set of triangles). Because of the hinge, the distances $A B=B E$. The angle of the hinged wall to the original wall is $A B F$ $=\Theta_{\mathrm{s}}$; the 7 or $8^{\circ}$ angle of the Fabry line-of-sight to the horizontal is $\mathrm{EAC}=\Theta_{\mathrm{p}}$. Because angle $\mathrm{BAF}=90^{\circ}-\Theta_{\mathrm{s}}$, angle $\mathrm{FAC}=\Theta_{\mathrm{s}}$. Because two sides of the triangle $\mathrm{ABE}$ are the same, angles $\mathrm{BAE}=\mathrm{BEA}=90^{\circ}-\Theta_{\mathrm{S}} / 2$. The right angle $\mathrm{BAC}$ is composed of the sum of angles $\mathrm{BAE}$ and $\mathrm{EAC}$ so that angle $\mathrm{BAC}=90^{\circ}=$ $90^{\circ}-\Theta_{\mathrm{s}} / 2+\Theta_{\mathrm{p}}$. Then

$$
\Theta_{\mathrm{s}}=2 \Theta_{\mathrm{p}}
$$

From triangle AEF with angle FAE $=\Theta_{\mathrm{s}}-\Theta_{\mathrm{p}}$, we obtain, using Eq. (5),

$$
u_{d}=u_{f} \cos \left(\Theta_{s}-\Theta_{p}\right)=u_{f} \cos \Theta_{p} .
$$

From triangle ACF, using Eq. (5),

$$
u_{d}=u_{s} \cos \Theta_{s}=u_{s} \cos 2 \Theta_{p} .
$$

Then the approximate Fabry path, from Eqs. (5) and (6), is

$$
\begin{aligned}
u_{\mathrm{f}} / u_{\mathrm{s}}=\cos 2 \Theta_{\mathrm{p}} / \cos \Theta_{\mathrm{p}} & =0.978 \text { for } \Theta_{\mathrm{p}}=7^{\circ} \\
& =0.971 \text { for } \Theta_{\mathrm{p}}=8^{\circ}
\end{aligned}
$$


We may obtain the actual value of $u_{s}$ from triangle $A B C$ and angle $A B C$ :

$$
\mathrm{u}_{\mathrm{s}}=\mathrm{D} \tan \Theta_{\mathrm{s}}=\mathrm{D} \tan 2 \Theta_{\mathrm{p}}
$$

Also, the arc distance $\mathrm{AE}$ is found from

$$
\mathrm{AE} / \Theta_{\mathrm{S}}=\mathrm{AE} / 2 \Theta_{\mathrm{p}}=2 \pi \mathrm{D} / 360^{\circ},
$$

so that

$$
\begin{aligned}
u_{f} / u_{s}-A E / u_{s}=4 \pi \Theta_{p} / 360^{\circ} \tan 2 \Theta_{p} & =0.980 \text { for } \Theta_{p}=7^{\circ} \\
& =0.974 \text { for } \Theta_{p}=8^{\circ}
\end{aligned}
$$

The Fabry path length is always shorter than that of the streak camera.

In practice, the outer radial displacements $R-R_{0}$ of $6,12.5$, and $19 \mathrm{~mm}$ will be used for both streak and Fabry analysis. For the streak camera, it is directly measured; for the Fabry, it is obtained by integration of the velocity. The time scales are different (it will take longer for the Fabry to reach the same displacement), and of course, the paths are different.

At LLNL, our experience leads us to set the Fabry angle, $\Theta_{p}$, to $7^{\circ}$ as the best value over the course of a cylinder shot. L. Green notes that the angle may be larger in the early stages of the shot and that it may be a degree larger for a more powerful explosive. The accuracy of this model can be demonstrated with RX-48-AA (92.4\% ABNBF/7.6\% Kel-F) in Fig. 4-2. At the same time, the Fabry velocity lies just below the streak velocity. The scatter in the streak data, created by the differentiation from the displacement, is obvious. The ratio of streak/Fabry is just below 1 and is constant after just a few microseconds. Such comparisons of Fabry and streak camera data allows us to ascertain the overall accuracy of the entire experiment.

A larger list of cylinder data is given in Table 4-1, where we list the Fabry/streak velocity ratios at given times. The streak camera $R-R_{0}$ data have been summed for the four cameras, then differentiated and smoothed five times. One set of unsmoothed data is shown for comparison. The two Fabry velocities are averaged. The ratios are presented from $3 \mu \mathrm{s}$ (of scaled 25-mmdiameter time) to the end of the Fabry trace and also for the last $2 \mu$ s of the trace. We conclude that the Fabry/streak ratio is constant beyond $3 \mu \mathrm{s}$. For the HMX-level explosives, the average ratio is 0.968 , and for the TATB-level explosives, it is about 0.975 . This offers evidence that a Fabry angle of $8^{\circ}$ may be better for the more powerful explosives.

The Fabry angle is expected to change with time. A simple velocity description might be 


$$
\mathrm{u}=\mathrm{G}[1-\exp (-\mathrm{gt})]+\mathrm{H} \mathrm{t}^{1 / 2},
$$

where $u$ is either a streak or Fabry velocity and $G, g$, and $H$ are constants. Eq. (12) is acceptable because the acceleration will approach zero at long times. More terms could be used to fit real data. The angle is

$$
\Theta_{\mathrm{p}}=\Theta_{\mathrm{S}} / 2=(1 / 2) \tan ^{-1}\left[\left(\mathrm{R}-\mathrm{R}_{\mathrm{o}}\right) / \mathrm{Dt}\right],
$$

where

$$
R-R_{0}=G[t+\exp (-g t) / g]+2 H t^{3 / 2 / 3} .
$$

At short times, the exponential decay dominates and the angle decreases. At long times, the exponential is gone and the argument in brackets in Eq. (13) becomes $\left[\mathrm{G}+2 \mathrm{Ht}^{1 / 3} / 3\right] / \mathrm{D}$. Because $\mathrm{H}$ is a small number, we expect the increase of the angle at long times to be gentle. The minimum angle is expected when the exponential dies and Eq. (12) returns to its slower mode of behavior.

\section{Cylinder Codes with PETN}

Two codes were run with $1.763 \mathrm{~g} / \mathrm{cc}$ PETN in a half-wall copper cylinder as part of the process of establishing the pedigree of the standard JWL (Chapter 3, Eq. (9)). Both codes are explicit Lagrangian.

We first ran in DYNA2D, ${ }^{3}$ with cylinder dimensions of $150-\mathrm{mm}$ length, 12.7-mm inner radius, and $14.0-\mathrm{mm}$ outer radius. The zoning was 300 elements long by 12 wide for a total of 7525 nodes and 7200 elements. This was $0.50 \mathrm{~mm} /$ zone axially, $1.06 \mathrm{~mm} /$ zone radially in the $P E T N$, and $0.11 \mathrm{~mm} /$ zone in the copper. The wall and explosive were merged, and a stonewall was run across the bottom, where 300 elements were lit at time zero by program burn. The detonation then proceeded upward. The artificial viscosity parameters were increased slightly to 2.0 and 0.10 for a slight filtering effect.

The code was rezoned twice for speed. The detonation reached the top of the cylinder at about $18 \mu \mathrm{s}$. At $19 \mu \mathrm{s}$, a rezoning removed the bottom $2 \mathrm{~cm}$ and the top $1 \mathrm{~cm}$. If rezoning was not done, zone-tangling resulted that slowed down the run considerably. At $23 \mu$ s, the run was rezoned, with the top and bottom $1 \mathrm{~cm}$ removed. The run stopped at $27 \mu \mathrm{s}$; total CPU time was about $61 / 2$ minutes on a Cray YMP. The effect of not rezoning was to add extra steps

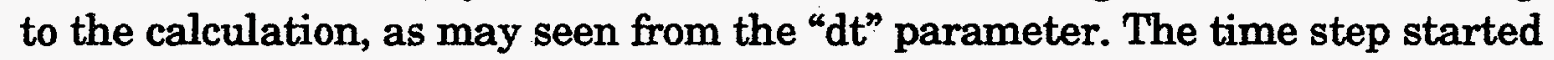
at about $0.008 \mu \mathrm{s}$ and decayed to $0.0008 \mu \mathrm{s}$ at $19 \mu \mathrm{s}$. Rezoning boosted it to $0.004 \mu \mathrm{s}$, and it decayed to $0.0008 \mu \mathrm{s}$ again at $23 \mu \mathrm{s}$. Rezoning put it back to $0.003 \mu \mathrm{s}$ for the last run.

The observed slit height was at $9.5 \mathrm{~cm}$ out of the $15 \mathrm{~cm}$ total. For PETN, this should be reached at just over $11 \mu$ s. In DYNA2D, the run was usually 
sent with one dump to $10 \mu \mathrm{s}$. A restart deck was run from 10 to $27 \mu$ s with a dump time of about $0.06 \mu \mathrm{s}$. In order not to overload the output, the rule used was

Time between dumps $(\mu \mathrm{s}) \sim 5 \times 10^{-7}$ (no. of zones)(run time in $\mu \mathrm{s}$ ).

A second means of running, which generates almost no output files, is to set the dump to ORION for every $3 \mu$ s (so there is something to monitor), but to collect the main data using DYNACYL. This DYNA2D modification was created by M. Murphy. It determines a set of velocities and pressures at selected points on or in the cylinder wall. Both the streak and the Fabry velocities are obtained.

Using 300-zone lighting, steady state for PETN is achieved in $6 \mathrm{~cm}$, whereas $10 \mathrm{~cm}$ is required if only a single line of elements are lit. With 100 zones, it requires an 8-cm length. The addition of a type- 1 slide line along the explosive-metal interface may seem more physical, but it greatly increases the zone tangling, and the results are not worth the effort. The simple material model for copper with the cut-off (spall) pressure of $-0.012 \mathrm{Mbar}$ is quite good.

Several types of velocity output must be considered in DYNA2D. The ORION output is either the pure radial velocity or the maximum velocity in an element. The DYNACYL program differentiates between streak and Fabry velocities.

The second code is HEMP. 4 The cylinder length was $210 \mathrm{~mm}$ with the same widths as in the first model, but unlike DYNA, the cylinder is horizontal. A type-1 slideline was placed between the explosive and the metal, and stonewalls were placed at the ends. A program burn along the left edge (bottom of the cylinder) was used. The detonation proceeded horizontally from left to right. The Steinberg-Guinan copper model (spall 1) was used with the cut-off (spall) pressure of $-0.012 \mathrm{Mbar} .^{5}$ The artificial viscosity was set at 0.5 for mild smoothing. Steady state was achieved in about $75 \mathrm{~mm}$ of axial distance. 5 The code ran with no rezoning in just under 90 minutes on the Cray YMP.

The DYNA2D mesh has so few zones in the metal that there was no hope of adequately reproducing the oscillations of the shock wave in the metal. However, HEMP added zones to the metal just as the detonation reached the slit point at $16 \mathrm{~cm}$. In the explosive, the zoning was $0.05 \mathrm{~mm} /$ zone axially on the cylinder and about $1 \mathrm{~mm} /$ zone radially. In the copper, the zoning was about $0.025 \mathrm{~mm} /$ zone axially and radially. (If extended to the entire $210-\mathrm{mm}$-long cylinder in the DYNA2D manner, it would require 50,000 zones in the explosive and 400,000 zones in the copper.). This was sufficient to reproduce the shock wave oscillations. The HEMP cylinder must be close to being zoned to convergence, as long as a JWL, which simulates an ideal explosive, is being used. 
The results of the code runs on PETN are summarized in Fig. 4-3. All four streak camera results from shot no. 511 are plotted, and the HEMP result, first run by John Walton, runs through them. The less highly-zoned DYNA2D models fall in different places. The best agreement in DYNA was obtained by using the maximum velocity (element variables component number 27). 6 We note that the agreement with HEMP is not perfect at long times, so that more work is probably needed if PETN is to be used as a standard. In summary-to get an accurate EOS result from the cylinder, the problem must be zoned to convergence.

Fig. 4-4 shows the calculated Fabry/streak camera ratio, as a function of time, as calculated in the two codes run with a $7^{\circ} \mathrm{Fabry}$ angle. The three horizontal dashed lines represent, from top to bottom, the "hinge model" prediction for 7,8 , and $9^{\circ}$ angles. We see that the ratios decrease in both models toward a steady state value, indicating that the angles start at $7^{\circ}$ and increase slightly with time.

Finally, because this section uses the codes in an effort to confirm the standard PETN JWL, we include several 1-D plate runs, which are shown in Fig. 4-5. The data are from electric gun shot ppe88003 with 10-mm PETN and $0.25-\mathrm{mm}$ tantalum. Further details of this shot are listed in the tables of Chapter 5. We note the excellent agreement of the jump-off and the first three wiggles with the codes, both the LLNL 1-D code and DYNA2D. Although zoned to convergence, the wiggles get out of phase at long times. The tantalum cutoff pressure of $-0.044 \mathrm{Mbar}$ was used, but the results are otherwise independent of the material model used.

\section{References}

1. E. Lee, D. Breithaupt, C. McMillan, N. Parker, J. Kury, C. Tarver, W. Quirk, and J. Walton, "The Motion of Thin Metal Walls and the Equation of State of Detonation Products," Proceedings Eighth Symposium (International) on Detonation, Albuquerque, NM, July 15-19, 1985, p. 613.

2. David Goosman, private communication, 1993.

3. J. O. Halquist, User's Manual for DYNA2D, Lawrence Livermore National Laboratory, Livermore, CA, UCID-18756, Rev. 3 (1988). The runs shown here were done under NLTSS.

4. E. L. Lee, H. C. Hornig and J. W. Kury, Adiabatic Expansion of High Explosive Detonation Products, Lawrence Livermore National Laboratory, Livermore, CA, UCRL-50422 (1968). 
5. D. J. Steinberg, Equation of State and Strength Properties of Selected Materials, Lawrence Livermore National Laboratory, Livermore, CA, UCRL-MA-106439 (1991).

6. J. O. Hallquist and J. L. Levatin, Orion : An Interactive Color PostProcessor for Two Dimensional Finite Element Codes, Lawrence Livermore National Laboratory, Livermore, CA, UCID-19310, Rev. 2 (1985), p. 18. 


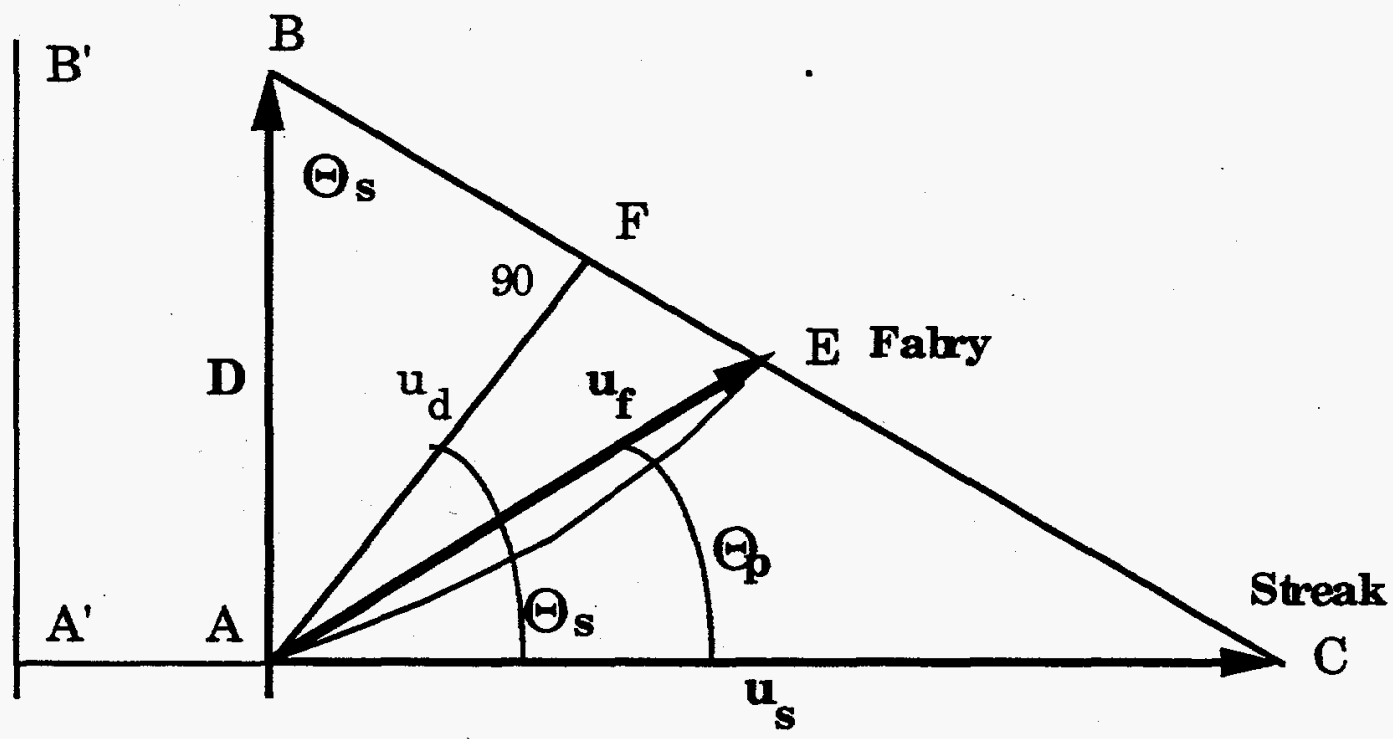

Fig. 4-1. Geometry of the Fabry/streak camera conversion using the simple "hinged wall" model. The cylinder axis lies along $A^{\prime} B$ ' and the initial cylinder wall lay along $A B$. The detonation velocity, $D$, moves upward along $A B$. The Fabry beam looks along $A E$, and the particle velocity of the outer cylinder wall, $u_{f}$, lies approximately on this line. The velocity $u_{f}$ moves actually along the curved dashed line $\mathrm{AE}$. The radial streak camera velocity, $u_{S}$, of the outer wall moves along $\mathrm{AC}$. Line $\mathrm{AE}$ is the closest to a one-dimensional path of motion. 


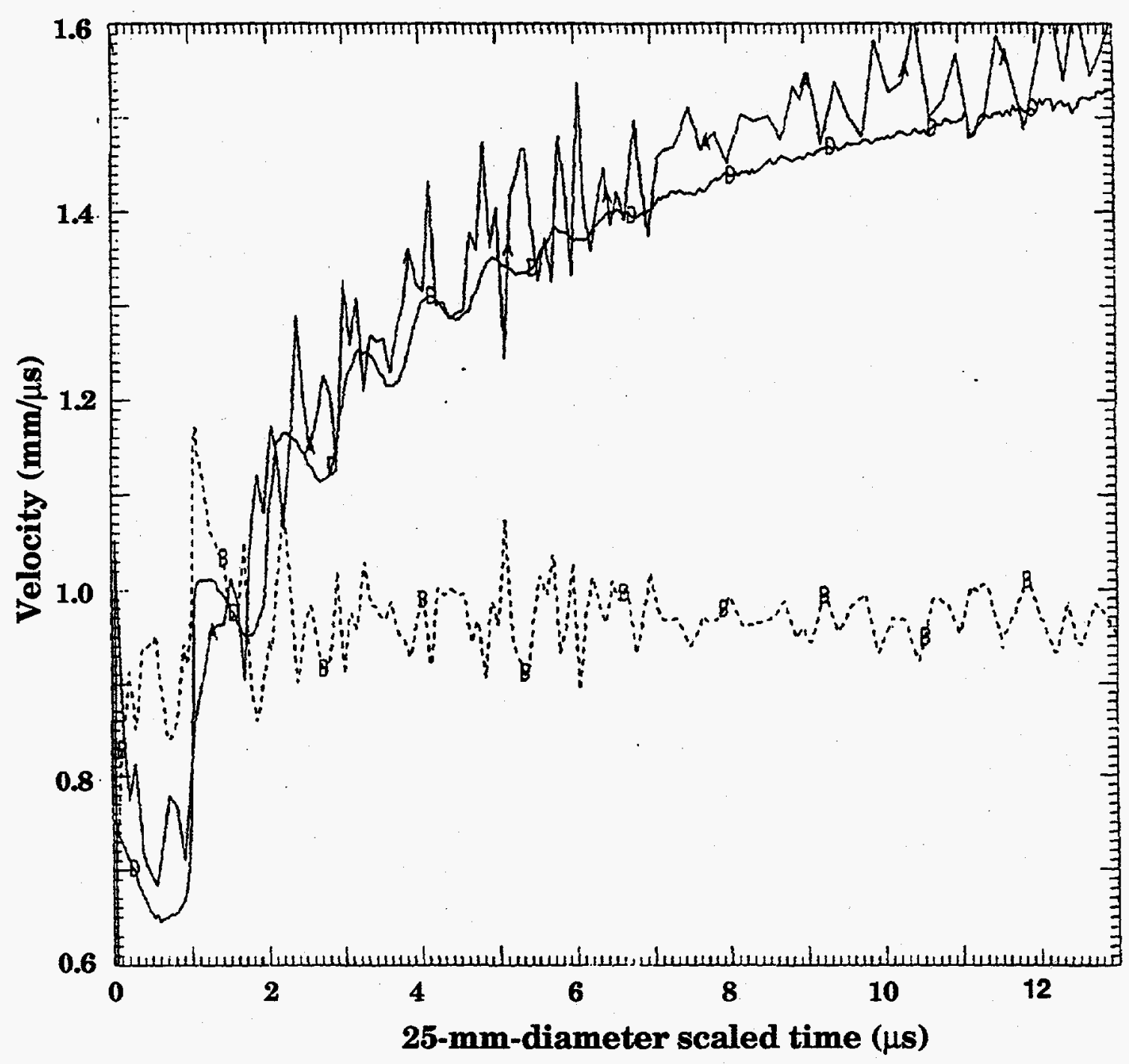

Fig. 4-2. Measured streak camera and Fabry cylinder velocities for shot no. 579 for RX-48-AA (92.4\% ADNBF). The cylinder was $25 \mathrm{~mm}$ in diameter and full wall. The four streak cameras (A) are averaged as are the two Fabrys (D). The dashed curve (B) is the Fabry/streak ratio, and it is about 0.97 from 5 to $13 \mu \mathrm{s}$. The considerable scatter is derived from the differentiated streak camera data. 


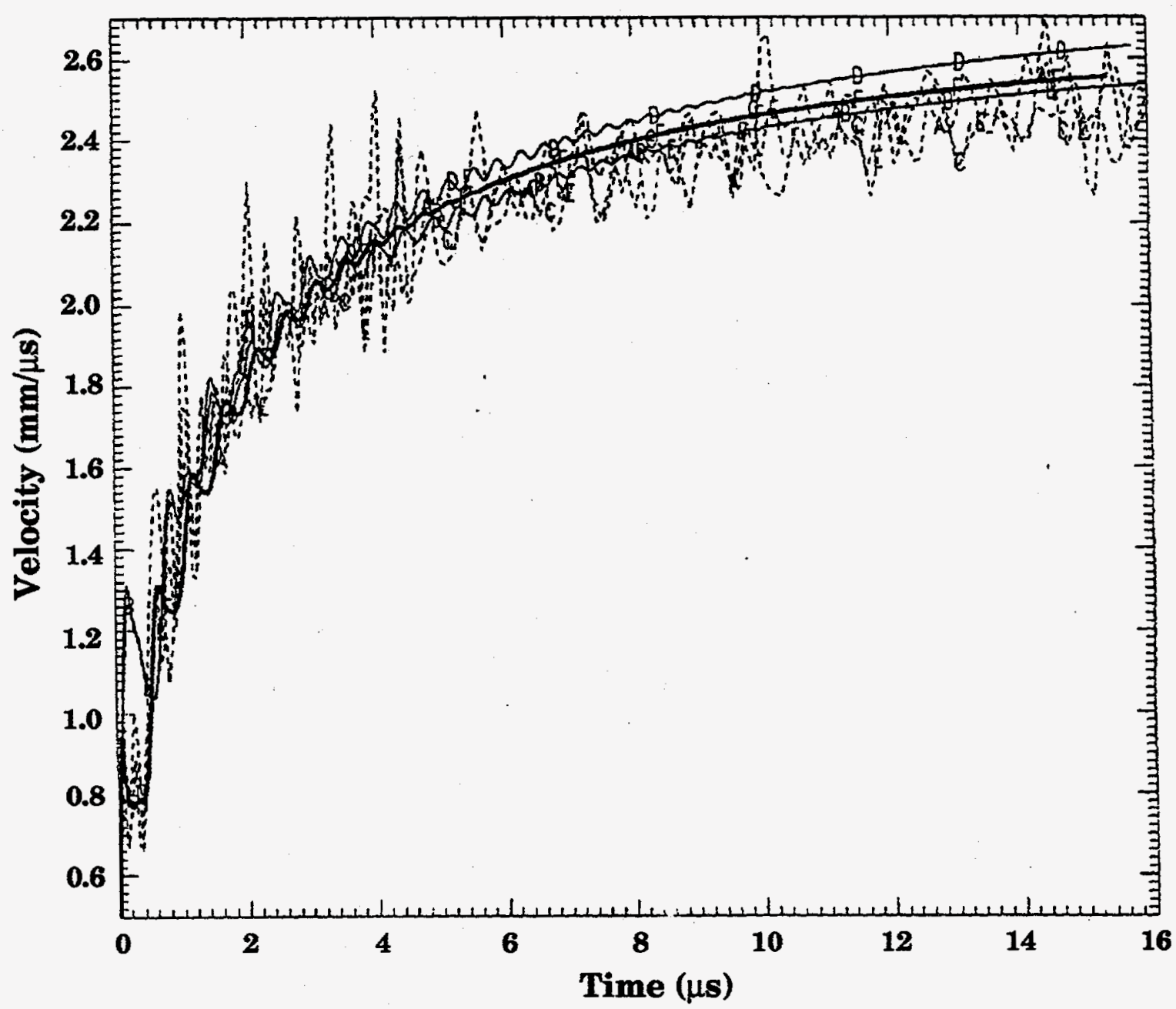

Fig. 4-3. Comparison of outer-wall cylinder streak camera velocities for PETN at $1.763 \mathrm{~g} / \mathrm{cc}$ (dashed lines) as compared with several code runs that use the standard JWL. The best agreement is obtained from the radial velocity calculated in HEMP (heavy line). The light line below the HEMP result is the DYNA2D maximum velocity. The light line above the HEMP line is the DYNACYL result. The smaller zoned DYNA2D model best approximates the HEMP result and the data when the maximum velocity is used as output. The cylinder radius was $25 \mathrm{~mm}$. 


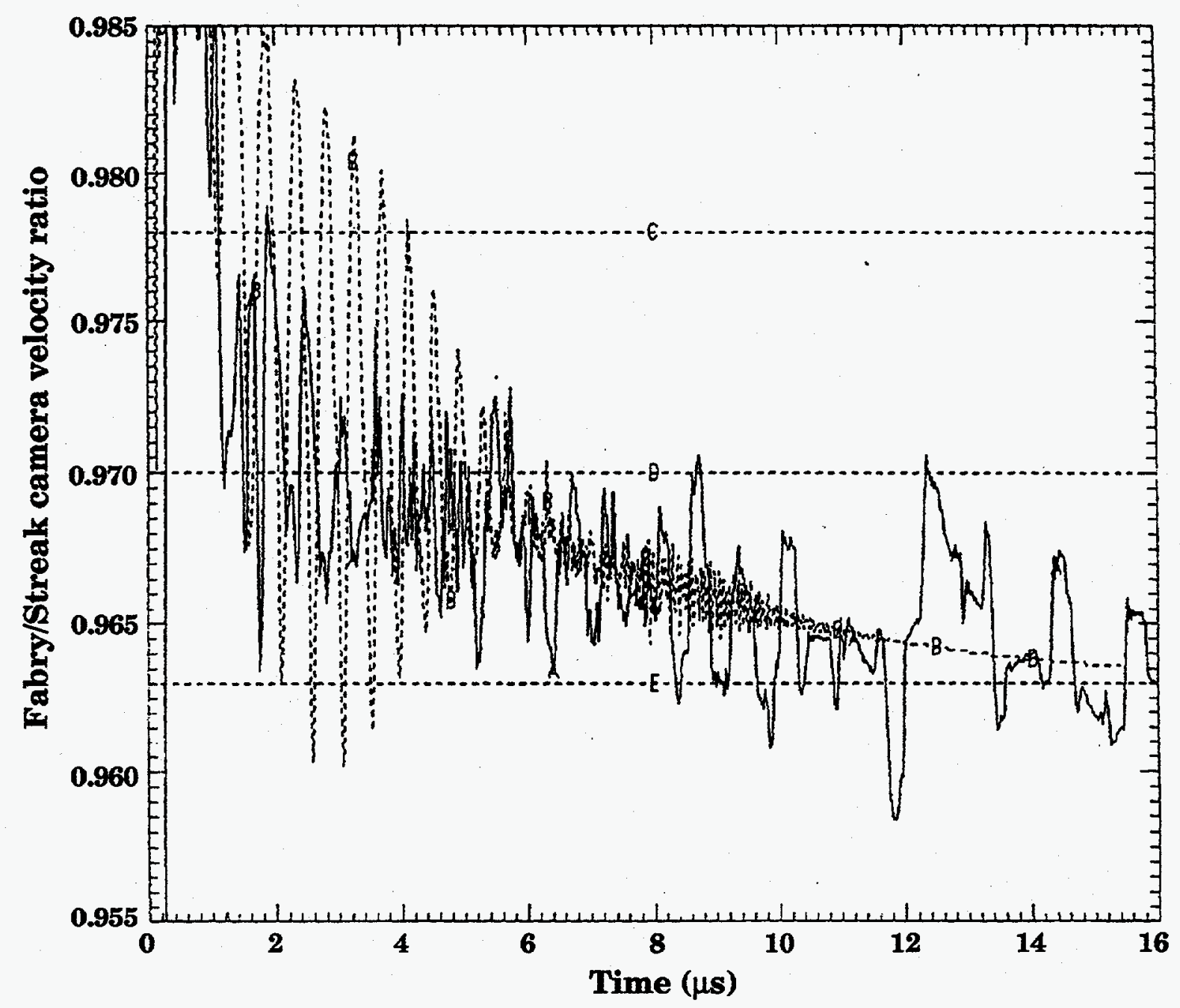

Fig. 4-4. The Fabry/streak camera velocity ratio as determined for $1.763 \mathrm{~g} / \mathrm{cc}$ PETN in HEMP (dashed line) and in DYNACYL (solid line). The dashed horizontal lines indicate the predictions of the simple "hinged wall" model for 7,8 and $9^{\circ}$, respectively. Although a $7^{\circ}$ Fabry angle was used, an $8^{\circ}$ angle appears to be slightly better. 


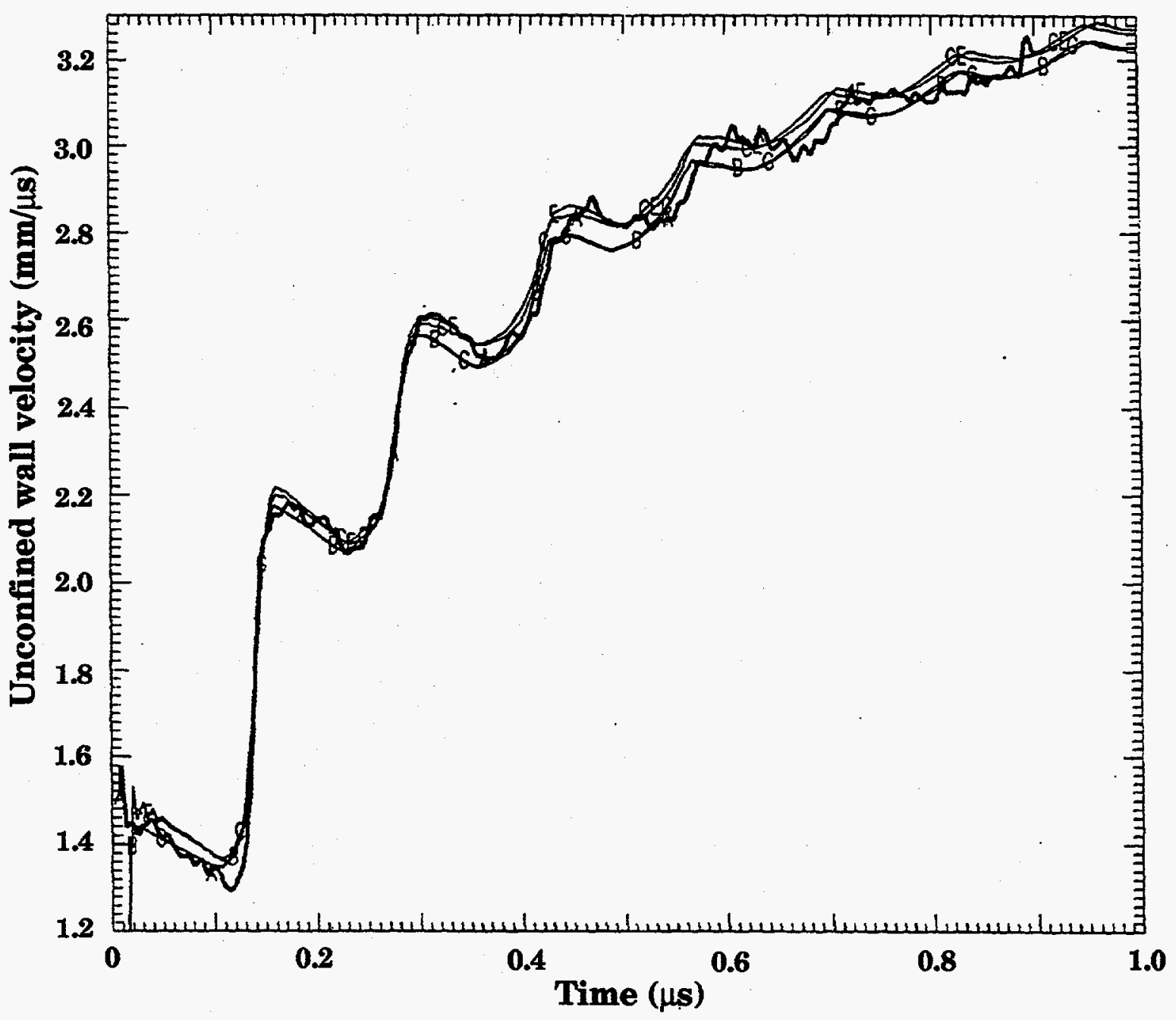

Fig. 4-5. Electric gun shot on $1.71 \mathrm{~g} / \mathrm{cc}$ PETN (heavy line, shot ppe88003) showing the validity of the standard PETN JWL. The explosive length was $10 \mathrm{~mm}$ and the plate was $0.25-\mathrm{mm}$ (10mil) tantalum. The models are the 1-D code (B and G, low at long times) and DYNA2D (C and $\mathrm{E}$, high at long times). We note that DYNA is slightly different from the 1-D and neither agrees with the wiggles, despite the zoning to convergence. Various material models are used, but they show no differences. 
Table 4-1. Comparison of averaged streak camera and Fabry-Perot interferometer data at constant scaled times. "High" performance is HMX-level; "low" is TATB. No difference is seen for cylinder no. 579 as a function of smoothing.

\begin{tabular}{|c|c|c|c|c|c|c|c|}
\hline \multirow{2}{*}{$\begin{array}{l}\text { Cyl. } \\
\text { shot } \\
\text { no. }\end{array}$} & \multirow[b]{2}{*}{$\begin{array}{l}\text { Perfor- } \\
\text { mance }\end{array}$} & \multirow{2}{*}{$\begin{array}{l}\text { No. } \\
\text { of } \\
\text { points }\end{array}$} & \multirow[b]{2}{*}{ Smooth } & \multirow{2}{*}{$\begin{array}{c}\text { Scaled } \\
\text { time } \\
\text { range } \\
(\mu \mathrm{s})\end{array}$} & \multicolumn{2}{|c|}{$\begin{array}{l}\text { Fabry/streak velocity } \\
\text { ratio at constant time }\end{array}$} & \multirow{2}{*}{$\begin{array}{c}\text { Last } \\
2 \mu \mathrm{s} \\
\text { Fabry/ } \\
\text { streak } \\
\text { ratio }\end{array}$} \\
\hline & & & & & Average & $\begin{array}{l}\text { Standard } \\
\text { deviation }\end{array}$ & \\
\hline 547 & high & 335 & 5 & 3 to 9 & 0.962 & 0.008 & 0.961 \\
\hline 549 & high & 344 & 5 & 3 to 10 & 0.962 & 0.009 & 0.958 \\
\hline 555 & high & 277 & 5 & 3 to 9 & 0.982 & 0.008 & 0.984 \\
\hline 560 & high & 270 & 5 & 3 to 12 & 0.965 & 0.012 & 0.959 \\
\hline 580 & high & 710 & 5 & 4 to 12.5 & 0.969 & 0.011 & 0.970 \\
\hline 554 & low & 308 & 5 & 3 to 10 & 0.978 & 0.012 & 0.984 \\
\hline 573 & low & 287 & 5 & 3 to 11 & 0.981 & 0.007 & 0.978 \\
\hline 574 & low & 484 & 5 & 3 to 10 & 0.981 & 0.007 & 0.980 \\
\hline 575 & low & 251 & 5 & 3 to 11 & 0.980 & 0.006 & 0.982 \\
\hline 579 & low & 1072 & none & 3 to 13 & 0.971 & 0.024 & 0.973 \\
\hline 579 & low & 1072 & 5 & 3 to 13 & 0.970 & 0.010 & 0.970 \\
\hline 579 & low & 1072 & 10 & 3 to 13 & 0.970 & 0.009 & 0.970 \\
\hline 585 & low & 332 & 5 & 3 to 15 & 0.968 & 0.009 & 0.961 \\
\hline
\end{tabular}




\section{Chapter 5. Cylinder Data}

\section{Jump-Off Velocity and Detonation Pressure}

Historically, the cylinder was the first LLNL test to refine the JWL . We have culled the LLNL records for the most often-fired explosives and listed their wall velocity results in Table 5-1. These include many of the more modern half-wall shots. All wall thickness are greater or equal to the reaction zone lengths. Most cylinder data were taken by streak camera, with only a few Fabry runs. The streak camera data were obtained by direct differentiation of the four channels of unsmoothed raw data, so that the error was $\pm 0.15-0.3 \mathrm{~mm} / \mu \mathrm{s}$, with $\pm 0.2 \mathrm{~mm} / \mu \mathrm{s}$ the average. The Fabry data showed same-sample precisions of $\pm 0.1 \mathrm{~mm} / \mu$ s for the PETN, $\pm 0.03-0.05$ for the $\mathrm{LX}-14$, and $\pm 0.02 \mathrm{~mm} / \mu \mathrm{s}$ for the $\mathrm{LX}-17$.

Table 5-2 lists wall velocity data taken over many years on homogeneous explosives, both liquid and solid. These should be directly comparable to TIGER results so that any analysis of JWLs to chemical composition would take place here. The data, however, are almost all old full-wall shots and are less reliable than those of Table 5-1.

The data presented here cover a long time. The cylinder shot numbers $100,200,300,400$, and 500 come from $1963,1965,1974,1976$, and 1984. Virtually all of it is taken by streak camera; Fabry interferometer data appear in the early 500 s.

The data include measured unconfined wall velocities for the jumpoff, at $v=2.2\left(R-R_{0}=6 \mathrm{~mm}\right), v=4.1(12.5 \mathrm{~mm}), \mathrm{v}=6.5(19 \mathrm{~mm})$, and the last measured value. The streak-measured jump-off velocities, $u_{p}$, have never been considered accurate or important, and there is no equation to relate them to detonation pressures as we do in one dimension with plates. However, we may average the PETN data and relate it to the 31-GPa adiabat pressure, as determined by supracompression in Chapter 6 . We have

$$
P_{p}-34.7 u_{s}{ }^{\circ} .
$$

We use Eq. (1) to calculate detonation pressures from the cylinder jump-off. The best results are from Table 5-1, which we summarize here. 


\begin{tabular}{ccccc} 
& $\begin{array}{c}\text { Average } \\
\text { jump-off } \\
\text { velocity } \\
(\mathrm{mm} / \mu \mathrm{s})\end{array}$ & $\begin{array}{c}\text { Calc } \\
\text { det'n } \\
\text { pressure } \\
(\mathrm{GPa})\end{array}$ & $\begin{array}{c}\text { Standard } \\
\text { deviation } \\
\text { pressure } \\
(\mathrm{GPa})\end{array}$ & $\begin{array}{c}\text { Cylinder } \\
\text { JWL det'n } \\
\text { pressure } \\
(\mathrm{GPa})\end{array}$ \\
\cline { 2 - 5 } LX-14 & $\mathbf{1 . 0 6}$ & 37 & $\mathbf{3}$ & 38 \\
PBX-9404 & 0.99 & 34 & 5 & 38 \\
PETN & 0.89 & 31 & 3 & 32 \\
RX-26-AF & 1.04 & 36 & 2 & 34 \\
LX-17 & 0.92 & 32 & 4 & 26
\end{tabular}

The error in measuring the streak camera jump-off is $\pm 0.1 \mathrm{~mm} / \mu \mathrm{s}$ at best and creates the standard deviation in precision seen above. The first three are in agreement, given the wide spread of values. The discrepancy between values for $\mathrm{LX}-17$ is most obvious. The $32-\mathrm{GPa}$ value seen here is consistent with the spike pressure, as estimated from Ignition \& Growth. It quickly decays, and the total JWL seen by the cylinder is consistent with a 26-GPa adiabat pressure.

\section{List of Cylinder JWLS}

We move to the data used to compile the preceeding comments. The velocities at volumes of 2.2,4.1, and 6.5 in Tables 5-1 and 5-2 are the ones used in deriving the JWLs. Table 5-3 lists the cylinder-derived JWLs, using PETN as the standard material. The detonation pressures are those obtained from the cylinder fit; hence, $\mathrm{LX}-17$ has the low $26-\mathrm{GPa}$ value. The $\mathrm{E}_{0}$ values are those from the cylinder fit with the calorimetric values as a bias where appropriate. Many significant digits are included, not because these EOSs are accurate but to avoid round-off errors. It is easy to have significant differences between a pressure calculated using $A, B$, and $C$ as opposed to $A$, $B$, and $E_{0}$ unless many digits are included. Any recalculation of the data produces slightly different velocities, and the JWLs are hypersensitive to small changes.

We note a definite difference in full and half-wall PBX-9404 data. In comparing half-wall streak camera data, we find these results:

\begin{tabular}{ccc} 
& \multicolumn{2}{c}{$\begin{array}{c}\text { Percent velocity-squared } \\
\text { compared with PETN }\end{array}$} \\
\cline { 2 - 3 } Relative & Half-wall & Full-wall \\
volume & Three runs & Four runs \\
\hline 2.2 & 8.6 & 3.2 \\
4.1 & 6.9 & 2.7 \\
6.5 & 4.5 & 3.4
\end{tabular}


The full-wall runs are cylinder nos. 175 to 273 from years ago. The half-wall runs are nos. 512 and 528 of recent times. Both have an average density of $1.84 \mathrm{~g} / \mathrm{cc}$. There is no known composition difference, so that we may be seeing the changes in the cylinder measurements over twenty years.

\section{Comparison of JWLs}

We shall consider two measures of energy delivery. One is the "\% of energy out"at $\mathrm{v}=2.2, \mathrm{k}_{2}$. This is the percent of the total detonation energy to have come out into the cylinder wall at this volume. At steady state, a cylinder volume of explosive, $\pi R^{2} h$, with $R$ the inner radius and $h$ the length, pushes the wall of mass, $m=\rho_{m} \pi\left[(R+W)^{2}-R^{2}\right] h$, where $\rho_{m}$ is the metal density and $W$ is the wall thickness. Then, we have

$$
\mathrm{k}_{2}=100 \mathrm{mu}_{2}{ }^{2} / 2 \mathrm{E}_{\mathrm{o}}
$$

where $u_{2}$ is the velocity at $v=2.2$. Enough ringing of the shock wave has taken place in the metal wall that $u_{2}$ is taken to be the rigid-body velocity. Then, the quantity $\mathrm{k}_{2}$ is a measure of the steepness of the adiabat. For "fast" explosives, it should be as large as possible. Another measure of this quantity is the pressure-to-energy ratio,

$$
\mathrm{P}_{\mathrm{j}} / \mathrm{E}_{0} \text {. }
$$

Fig. 5-1 shows a plot of $\mathrm{k}_{2}$ as a function of $\mathrm{P}_{\mathrm{j}} / \mathrm{E}_{0}$, and the proportionality is clearly there. LX-14 is a good example of a fast explosive. Two points are given for $\mathrm{LX}-17$, one for $\mathrm{P}_{\mathrm{j}}=26 \mathrm{GPa}$, and the other for $32 \mathrm{GPa}$. The 26-GPa point lies on the central line, showing that the Cylinder Test delivers the lower detonation pressure.

We next consider the fraction of kinetic energy in the initial shock in the cylinder wall. Previously, we took data so late that the entire wall was in motion like a rigid body. The measured unconfined wall velocity, $u_{p}$, may then be considered representative of the entire wall. This is not so for the jump-off. In a plate DYNA2-D run, we find that the confined wall velocity is nearly constant over the first $2 / 3$ of the plate thickness. The unconfined wall velocity (twice as great) appears in the last $1 / 3$ of the plate. At the $2 / 3 \mathrm{rds}$ boundary inside the plate, the velocity jumps to the confined value, briefly lingers, and then hops up to the unconfined value. As an average across the wall, we take:

$$
u \text { (average) } \sim 2 u_{p} / 3 .
$$

The \% kinetic energy in the shock wave is then

$$
\mathrm{k}(\text { jump-off })=100 \mathrm{mu}(\text { average })^{2} / 2 \mathrm{E}_{0} \text {. }
$$


The results for Tables 5-1 and 5-2 are

$$
\mathrm{k} \text { (jump-off })=6.3 \pm 2.7 \%
$$

and

$$
\mathrm{k}(\text { jump-off })=5.4 \pm 3.0 \% \text {. }
$$

The idea that speedy explosives expend more of their energy by $\mathrm{v}=\mathbf{2 . 2}$ suggests that $k$ (jump-off) should also vary according to the speed of the explosive. However, the data, mostly taken with the streak camera, show no such trend. The importance of the approximate $6 \%$ number is that it represents the initial shock wave with no further pushing-to be found in an explosion with no confinement.

We next want to consider the relative efficiency in converting detonation energy to wall kinetic energy. If $u_{2}$ is the wall velocity at $v=2.2$, then the efficiency, $\mathrm{e}_{2}$, is

$$
\mathrm{e}_{2}=100 \mathrm{mu}_{2} 2 / 2 \mathrm{E}_{\mathrm{d}}(\mathrm{v}=2.2) .
$$

The velocity that should be used is the Fabry velocity. Most of our data are from the streak camera. Using Eq. (11) from Chapter 4, we correct the streak velocities by 0.98 (assuming a $7^{\circ}$ Fabry angle). For the diverse full-wall cylinder explosives of Table 5-2, we find

$$
e_{2}=72.1 \pm 1.1 \% \text {. }
$$

The efficiency is the same regardless of the explosive speed and shows the high pushing efficiency of the Cylinder Test. The full-wall cylinders give a comparable efficiency of about $60.5 \%$. The value is lower because the containment is less.

Eq. (11) is directly applicable to the second major assumption of the LLNL Cylinder EOS:

$$
E_{d} / u^{2}=\text { constant, for all explosives. }
$$

It is not obvious that the total detonation energy would partition itself into the same fractions of kinetic and thermal energy for every explosive. Yet the efficiencies of Table 5-2 say that this is true within a few \% within the cylinder, where the confinement causes the product to interact with the walls over a long time.

The variability of the derived JWL detonation volumes, $v_{\mathbf{j}}$, is another puzzle. These values all cluster about 0.74 , but a constant volume will not fit all JWLs. Consider a force, F, compressing a spring: 


$$
F=P A=k \Delta x
$$

where $P$ is the pressure, $A$ the area, $k$ the spring constant, and $\Delta x$ the displacement. In one dimension, $\Delta x=1-v$ (for a unit area and initial volume), so that

$$
P_{j}=k\left(1-v_{j}\right) .
$$

From Chapter 2, we recall that

$$
P_{j}=\rho_{o} D^{2}\left(1-v_{j}\right),
$$

and

$$
k=\rho_{0} D^{2} .
$$

In physical terms, $\rho_{0} \mathrm{D}^{2}$ is the spring constant for compression of the explosive.

In Fig. 5-2, we plot the detonation volume, $v_{j}$, as a function of the pressure/energy, $\mathrm{P}_{\mathrm{j}} / \mathrm{E}_{\mathbf{0}}$. We find that the low energy-pushing explosives compress to a smaller volume, because there is a less energetic product gas pushing back on the compression. Fast explosives, with large $\mathrm{P}_{j} / \mathrm{E}_{0}$ ratios, have larger detonation volumes.

\section{Describing Cylinder Relative Volumes}

It may be possible to elicit more information from the Cylinder Test. This test is useful because the relative volume of the product gases, $v$, is close the geometric volume, $\mathrm{v}_{\mathrm{g}}$, obtained from the radius of the expanding cylinder. Because the wall moves outward, a difference exists, and a correction must be made.

We are interested in checking how close the hydrocodes predict the geometric volumes. For this reason, the cylinder model was run with DYNA2D using various conditions. A contour plot for relative volume was obtained at some given time, as shown in Fig. 5-3 for PETN. There are three ways to obtain geometric volumes. One can then integrate along a path to obtain the average relative volume, given by

$$
\mathrm{v}_{\mathrm{a}}=\frac{1}{\mathrm{~A}} \sum_{\mathrm{i}} \mathrm{A}_{\mathrm{i}} \mathrm{v}_{\mathrm{i}}
$$

where the ith volume and ith area are included. The volume corresponding to the 1-D problem is the Fabry path A'AE. We note in Fig. 5-3 that the path AE 
moves into a region of gas with a smaller relative volume. This is why we require the hydrocode to make the volume adjustment.

The results are shown in Fig. 5-4 for the average volumes. The ratio of the average volume to the geometric volume for the Fabry path is:

$$
\varepsilon=\mathrm{v}_{\mathrm{a}} / \mathrm{v}_{\mathrm{g}}=1.01\left[1-\exp \left(-1.8 \mathrm{v}_{\mathrm{g}}\right)\right]+0.003 \mathrm{v}_{\mathrm{g}} .
$$

The same equation may describe the ratio for the streak camera path $\mathrm{A}^{\prime} \mathrm{AC}$, but this path is not a 1-D problem path. Both the Fabry and streak volume ratios are shown in Fig. 5-4, and they are both fit by Eq. (18).

The relative volume next to the wall at point $E, v_{w}$, shows more scatter as a result of the different types of code settings, and the value is larger. We may describe the results by

$$
\mathrm{v}_{\mathrm{w}} / \mathrm{v}_{\mathrm{g}} \sim 1.11\left[1-\exp \left(-1.6 \mathrm{v}_{\mathrm{g}}\right)\right] .
$$

\section{One-Dimensional Cylinder Analysis}

We can use DYNA2D to consider the behavior of the parts of the copper wall during the 1.763-g/cc PETN cylinder shot, and the results are shown in Fig. 5-5. The spall pressure has been set to a large number to accentuate the oscillations. The unconfined outer face is out of phase with the inner face by the time necessary for the shock wave to cross the copper wall. Reverberating shock waves in the wall cause the oscillations of the inner and outer faces, whereas the center of the wall motion is relatively smooth. We note that the oscillations appear every half-cycle for the center of the wall and every full cycle for the outer face. The center-of-the-wall motion is smoother than that of the outer face.

We also note that the center-of-the-wall velocity is always larger than the average outer velocity. This difference is accounted for by the thinning of the wall with the inner wall advancing into the space previously occupied by the metal.

We now move to the 1-D cylinder wall problem, in which the wall is accelerated from its center of mass, which is taken to be the center of the wall shown in Fig. 5-5. Within the 1-D approach to this problem, we may write the force on the wall as

$$
\mathrm{P}_{\mathbf{f}} \mathrm{A}=\mathrm{ma} \text {, }
$$

where $P_{f}$ is the pressure on the wall along the Fabry path, $A$ is the area of push, $m$ is the mass of the wall, and $a$ is the acceleration. The area is $2 \pi(R-W / 2) d h$, where $R$ is the outer radius, $W$ the wall thickness, and dh an arbitrary 
distance along the cylinder. The mass being pushed is $\pi \rho_{m}\left[R^{2}-(R-W)^{2}\right] d h$, where $r_{m}$ is the density of the copper cylinder. These are combined to give

$$
P_{f}=\rho_{m} \frac{\left[R^{2}-(R-W)^{2}\right]}{2(R-W / 2)} a,
$$

where, from Eq. (2), Chapter 4, the thinning wall is given by

$$
\mathrm{W}=\left\{\mathrm{R}_{0} / \mathrm{R}\right\} \mathrm{W}_{0} \text {. }
$$

The initial outer radius is $R_{0}$, and the wall thickness is $W_{0}$. Finally, we need to obtain a relative volume. We modify the geometric volume, $\mathrm{v}_{\mathrm{g}}$, from Eq. (3) from Chapter 4 , to produce an average volume, $v_{a}$ :

$$
v_{\mathrm{a}}=\varepsilon \mathrm{v}_{\mathrm{g}}=\varepsilon\left\{\left[\mathrm{S}_{\mathrm{o}}+\left(\mathrm{R}-\mathrm{R}_{0}\right)+\left(\mathrm{W}_{\mathrm{o}}-\mathrm{W}\right)\right] / \mathrm{S}_{\mathrm{o}}\right]^{2},
$$

Now, $S_{0}$ is the initial inner radius $\left(R_{0}-W_{0}\right)$, so that

$$
\mathrm{v}_{\mathrm{a}}=\varepsilon\left[(\mathrm{R}-\mathrm{W}) /\left(\mathrm{R}_{0}-\mathrm{W}_{0}\right)\right]^{2} .
$$

All this can be followed in a simple model. The difficult part is getting a good fit for the acceleration. From Fig. 5-5, we note that the velocity peaks of the unconfined face are equivalent to the velocity of the center of mass. Also, the zero-time of the center of mass occurs slightly before this. By taking data beyond 3 to 4 scaled $\mu$ s, i.e., beyond the ringing, we obtain accelerations that should be close to those of the center of mass-adding the extra time at the start will not matter in the differentiation from velocity to acceleration as we process the Fabry data.

The first data tried were raw streak-camera data for the outer copper face, with several hundred pairs of $R-R_{0}$ vs time points. The four sets of data points (two cameras on two sides) were averaged to give the overall curve. This curve was smoothed, then fit with a polynomial to the sixth power. The acceleration was obtained by double differentiation of the fitted function. The results for $1.763 \mathrm{~g} / \mathrm{cc}$ PETN are shown in Fig. 5-6. The data for shot no. 511, a half-wall cylinder, maintain their fit out to $\mathrm{v} \sim 10$. The older, full-wall no. 209 shows the common problem of trying to fit noisy streak camera data. The fit deviates at low volumes, and the pressure becomes unphysical. This noisiness does not affect the creation of a JWL because this is not really a fit of all the data. Also shown for comparison are the adiabats derived from the JWL and from CHEQ. Agreement is good, although both the data and CHEQ suggest that the adiabat could lie slightly below the JWL values. 
Consideration of the more accurate Fabry data remains for the future. One approach is to average the two velocity vs time curves, and then fit the region from $4 \mu$ s onto a polynomial:

$$
u_{f}-u_{0}=F+G\left(t-t_{0}\right)+H\left(t-t_{0}\right)^{2}+I\left(t-t_{0}\right)^{3}+J\left(t-t_{0}\right)^{4},
$$

where $t_{0}$ is about $4 \mu \mathrm{s}, u_{0}$ is the velocity at this time, and F, G, H, I, and J are constants. The acceleration is obtained by differentiating Eq. (25). Perhaps a more accurate function can be found. 


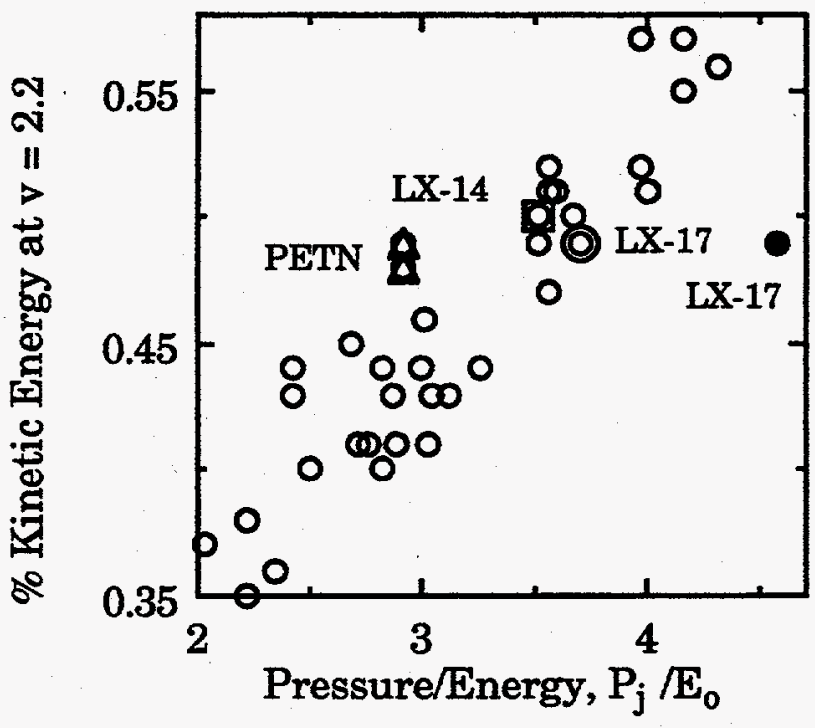

Fig. 5-1. Fraction of total detonation energy appearing as kinetic energy at $v=2.2$ as a function of the ratio of $P_{j} / E_{0}$ for full-wall cylinder shots. Special explosives are $1.763 \mathrm{~g} / \mathrm{cc}$ PETN (triangles); LX-14 (squares); LX-17 with a 26 GPa detonation pressure (open circles); and LX-17 at $32 \mathrm{GPa}$ (closed circles). The higher value for LX-17 does not fit the pattern, which may be taken as evidence that $26 \mathrm{GPa}$ is the actual $\mathrm{LX}-17$ adiabat pressure. 


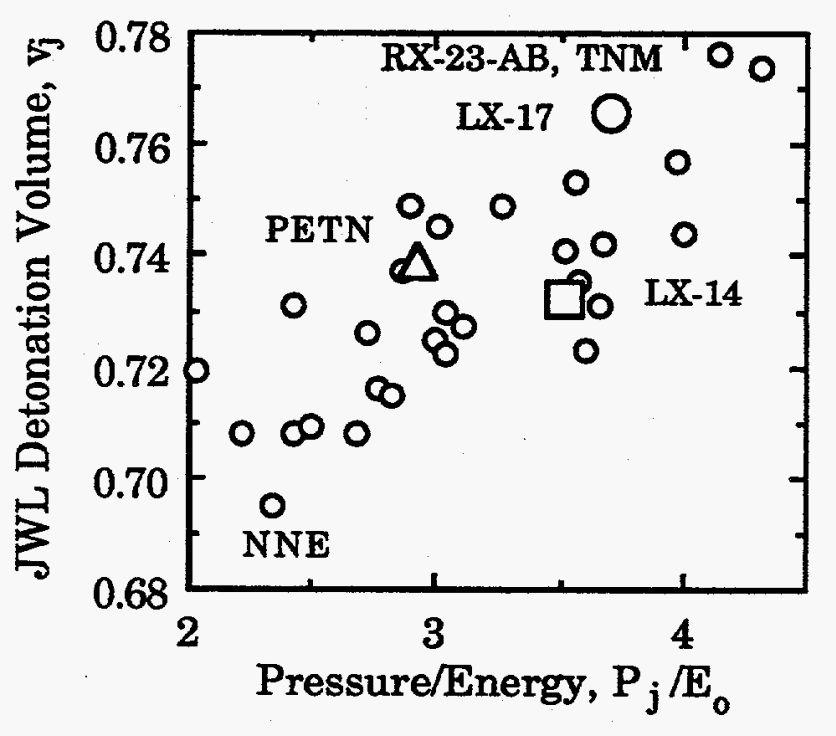

Fig. 5-2. JWL detonation volume, $v_{j}$, as a function of $\mathrm{P}_{\mathrm{j}} / \mathrm{E}_{\mathrm{o}}$ for full-wall cylinder shots. "Slower" explosives compress to smaller volumes. Special points are 1.763 g/cc PETN (triangles); LX-14 (squares); and LX-17 with a $26 \mathrm{GPa}$ detonation pressure (circles). The explosive acronyms are explained in the Appendix. 


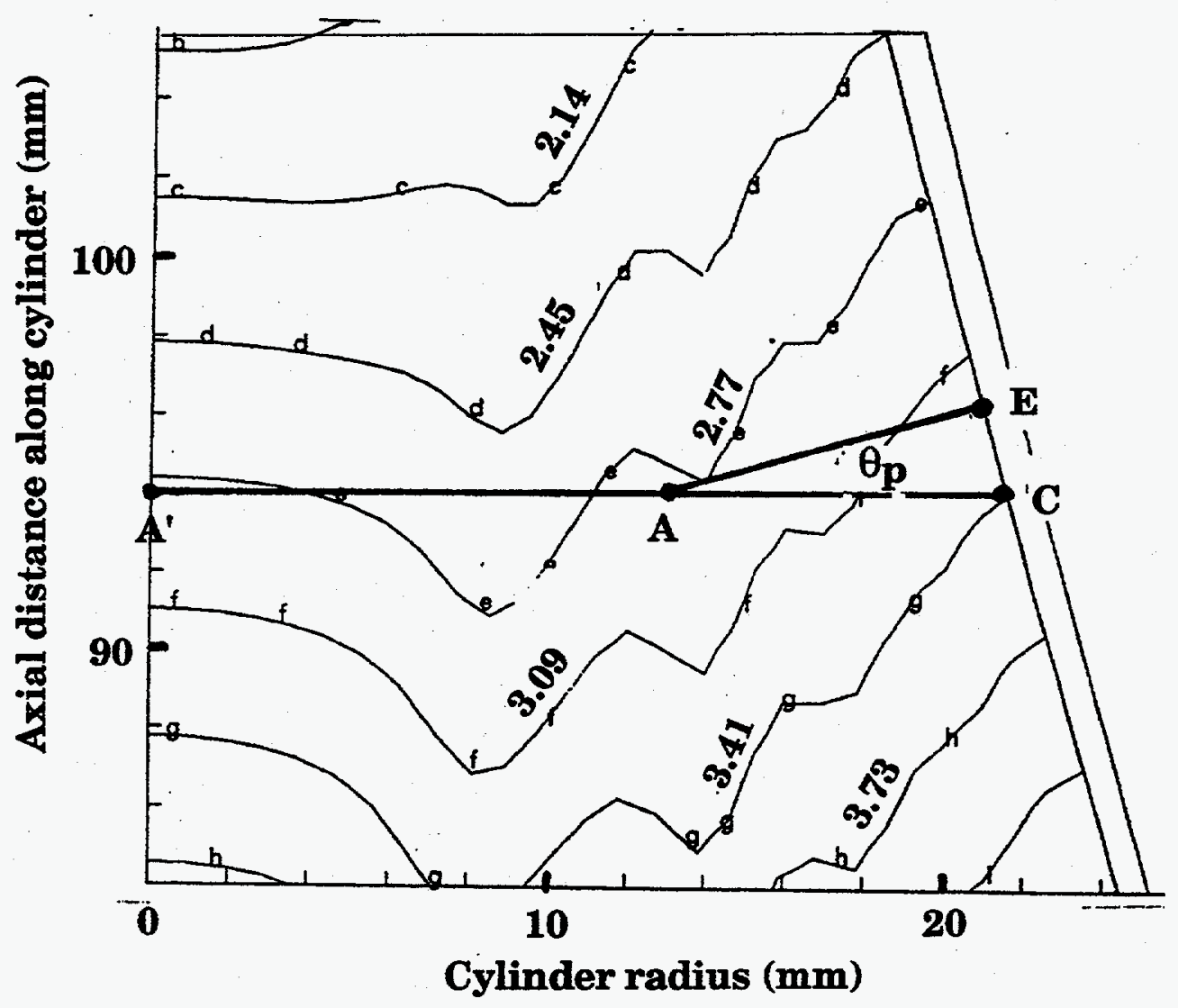

Fig. 5-3. Relative volume contours in a $1.763 \mathrm{~g} / \mathrm{cc}$ PETN cylinder as calculated by DYNA2D. The letters are the same points used in the Fabry/streak camera model shown in Figure 3-1. The path for calculating the average streak volume is A'AC; for the Fabry, it is A'AE. As we move to the cylinder wall, the relative volume of the gas increases because of cylinder expansion. 


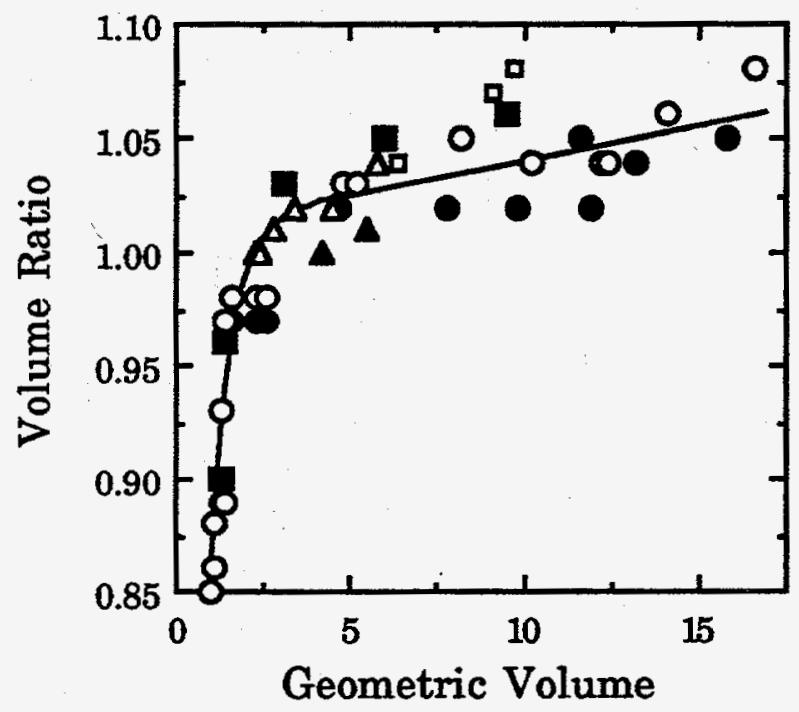

Fig. 5-4. Ratio of average relative volume to the geometric relative volume, $\varepsilon$, as a function of geometric volume, $\mathrm{vg}_{\mathrm{g}}$ (as calculated from the hydrocode). The streak and Fabry cases fit the same curve although the volumes are defined differently and the points are offset. The open symbols are for the streak camera data; the closed symbols are for the Fabry data. A mixture of programmed and beta burn, with and without a slide-line, was run. The cases run are PETN, full-wall (circles) and half-wall (triangles), and nitromethane full-wall (squares). 


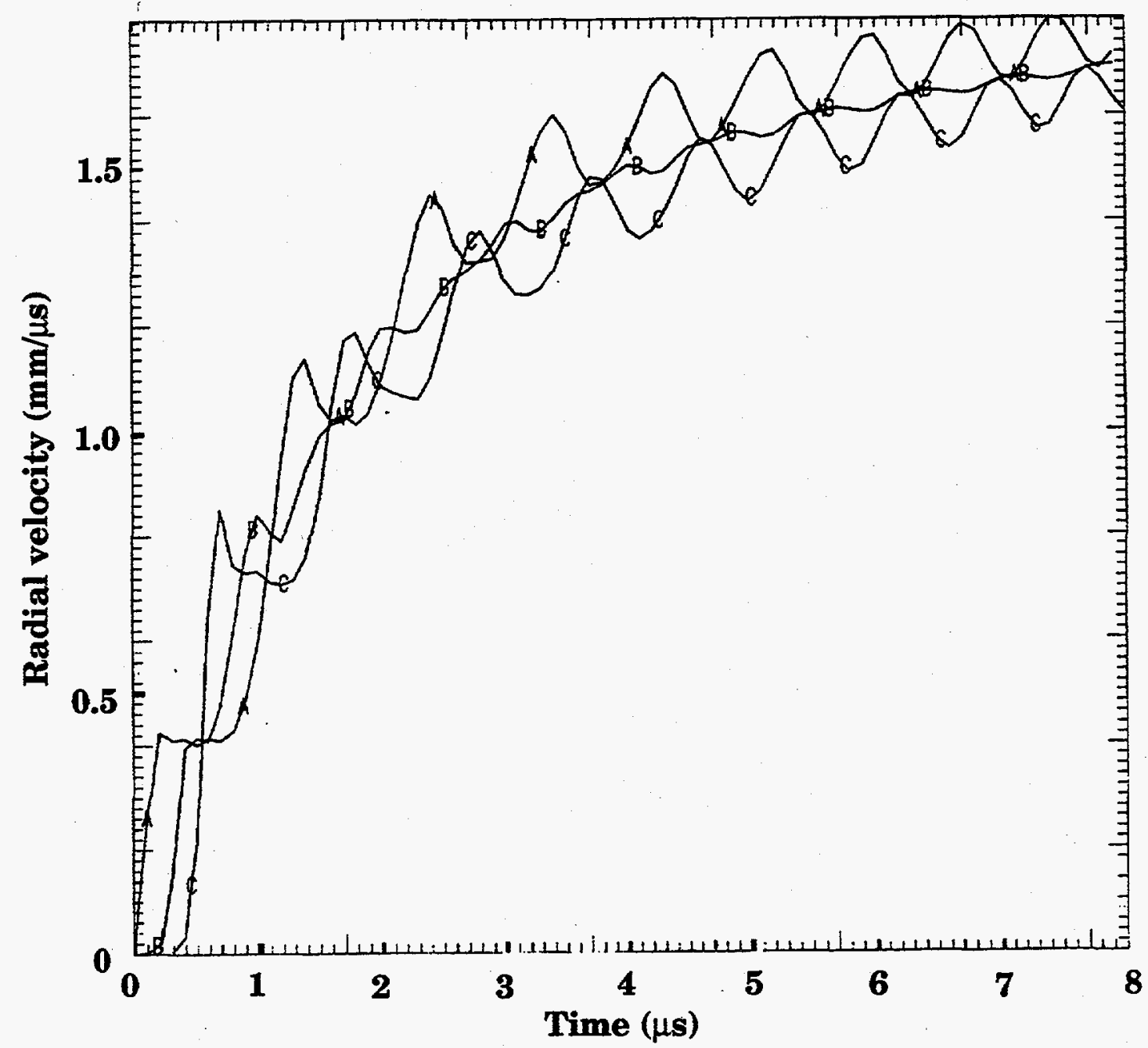

Fig. 5-5. Calculation of the velocity at three places in a copper wall of as cylinder driven by PETN of $1.763 \mathrm{~g} / \mathrm{cc}$. The curves are from top to bottom the inner (confined) wall (A), the center of motion of the wall (B), and the outer (unconfined)wall (C). All code burns and mergings give the same result. Reverberating shock waves in the wall cause the inner and outer faces to be out of phase throughout, whereas the center of mass motion is relatively smooth. Experimentally, only the velocity of the outer face is measured. 


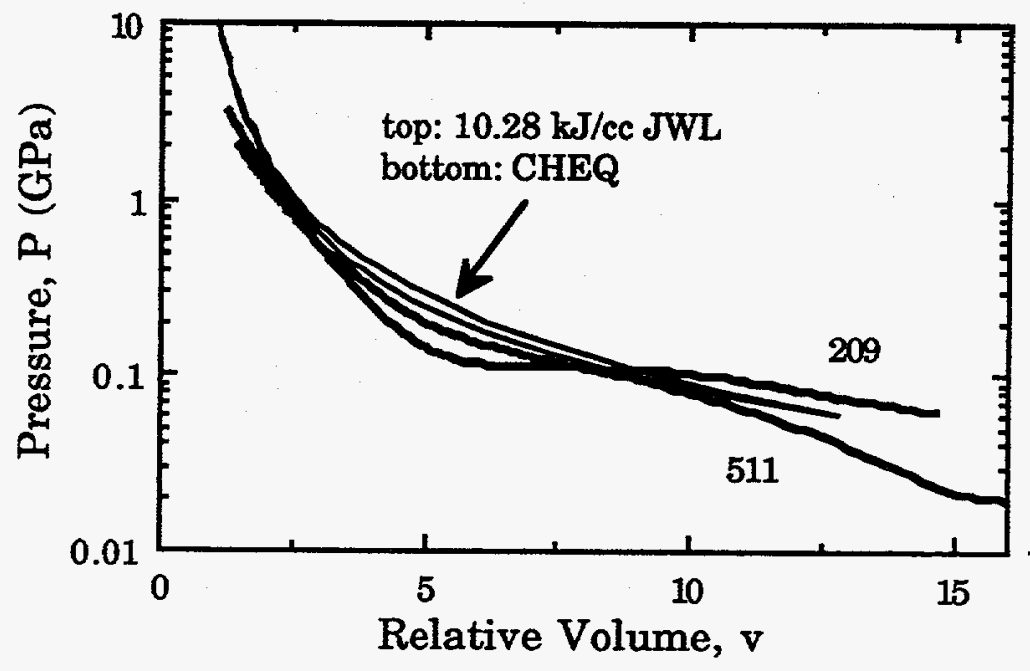

Fig. 5-6. Direct calculation of the adiabat pressure from streak camera data for PETN. The fit for shot no. 511 looks good to $\mathrm{v} \sim 10$ but the older shot no. 209 is too noisy and the fit deviates at low volumes. 
Table 5.1. Basic copper cylinder data, including velocities, for five often-measured explosives, as determined by streak camera (S) and Fabry (F). In a different column, $\mathrm{F}$ is full-wall, and $\mathrm{H}$ is half-wall.

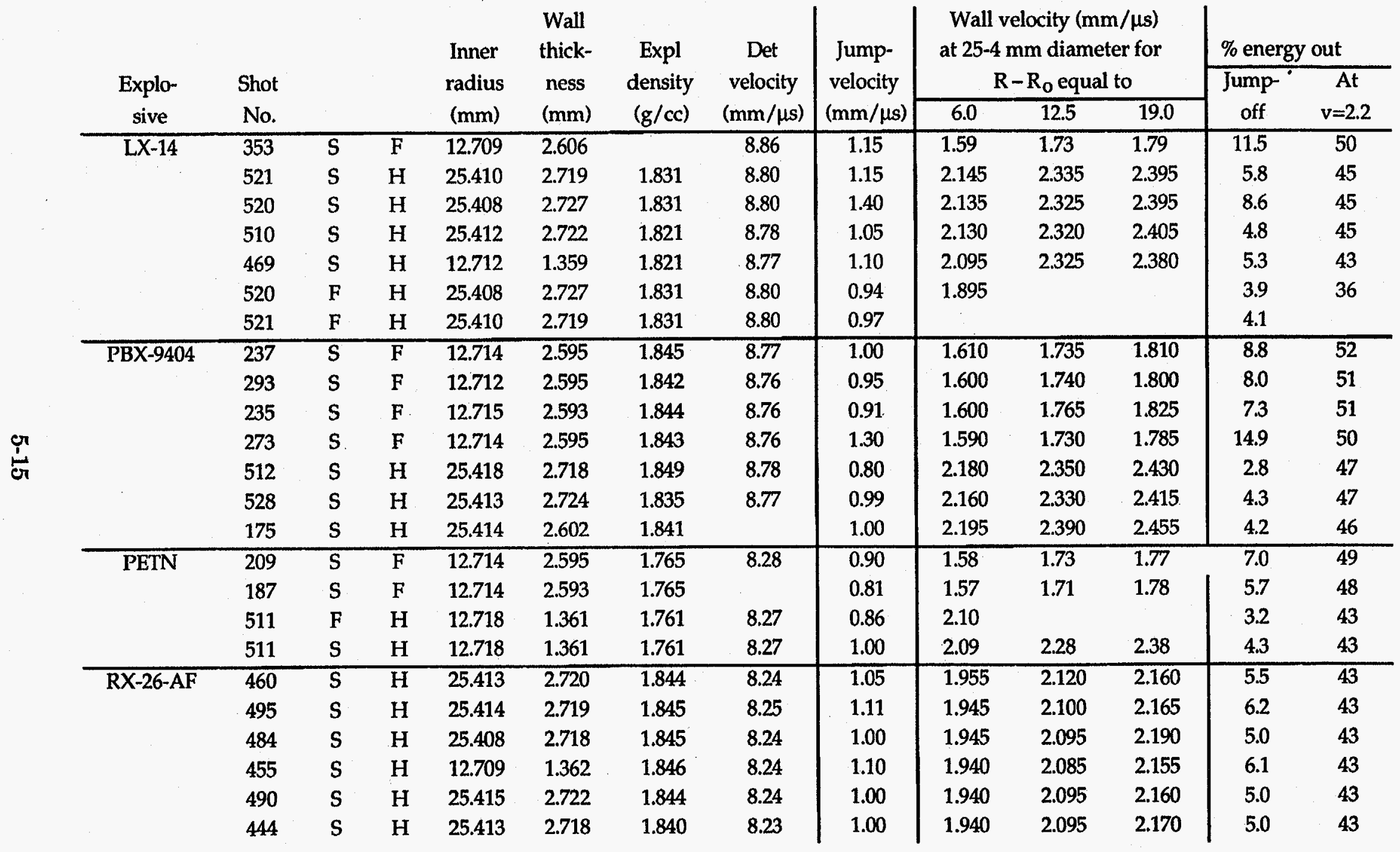


Table 5-1, part 2

\begin{tabular}{|c|c|c|c|c|c|c|c|c|c|c|c|c|c|}
\hline \multirow{3}{*}{$\begin{array}{l}\text { Explo- } \\
\text { sive }\end{array}$} & \multirow{3}{*}{$\begin{array}{l}\text { Shot } \\
\text { No. }\end{array}$} & & & \multirow{3}{*}{$\begin{array}{l}\text { Inner } \\
\text { tadius } \\
(\mathrm{mm})\end{array}$} & \multirow{3}{*}{$\begin{array}{l}\text { Wall } \\
\text { thick- } \\
\text { ness } \\
(\mathrm{mm})\end{array}$} & \multirow{3}{*}{$\begin{array}{c}\text { Expl } \\
\text { density } \\
(\mathrm{g} / \mathrm{cc})\end{array}$} & \multirow{3}{*}{$\begin{array}{c}\text { Det } \\
\text { velocity } \\
(\mathrm{mm} / \mu \mathrm{s})\end{array}$} & \multirow{3}{*}{$\begin{array}{l}\text { Jump- } \\
\text { off } \\
\text { velocity } \\
\text { (mm/ } / \mu \mathrm{s})\end{array}$} & \multirow{2}{*}{\multicolumn{3}{|c|}{$\begin{array}{l}\text { Wall velocity }(\mathrm{mm} / \mu \mathrm{s}) \\
\text { at } 25.4-\mathrm{mm} \text { diameter for } \\
\mathrm{R}-\mathrm{R}_{\mathrm{O}} \text { equal to }\end{array}$}} & \multicolumn{2}{|c|}{$\%$ energy out } \\
\hline & & & & & & & & & & & & \multirow{2}{*}{$\begin{array}{c}\text { Jump- } \\
\text { off }\end{array}$} & \multirow{2}{*}{$\begin{array}{c}\text { At } \\
v=2.2\end{array}$} \\
\hline & & & & & & & & & 6.0 & 12.5 & 19.0 & & \\
\hline \multirow[t]{8}{*}{$\overline{L X}-17$} & 349 & $\mathrm{~S}$ & $\bar{F}$ & 25.414 & 5.210 & 1.900 & 7.63 & 1.02 & 1.293 & 1.409 & 1.453 & 13.5 & 49 \\
\hline & 434 & $\mathrm{~S}$ & $\mathbf{F}$ & 25.420 & 5.184 & 1.875 & 7.55 & 0.74 & 1.29 & 1.41 & 1.46 & 7.0 & 49 \\
\hline & 523 & $S$ & $\mathrm{H}$ & 25.417 & 2.722 & 1.917 & 7.66 & 1.05 & 1.754 & 1.884 & 1.953 & 7.2 & 45 \\
\hline & 470 & $S$ & $\mathrm{H}$ & 25.417 & 2.718 & 1.904 & 7.63 & 0.80 & 1.750 & 1.856 & 1.933 & 4.1 & 45 \\
\hline & 439 & $\mathrm{~S}$ & $\mathrm{H}$ & 25.412 & 2.714 & 1.912 & 7.65 & 0.90 & 1.74 & 1.89 & 1.95 & 5.2 & 44 \\
\hline & 522 & $\mathrm{~s}$ & $\mathrm{H}$ & 25.414 & 2.723 & 1.908 & 7.64 & 1.05 & 1.741 & 1.880 & & 7.2 & 44 \\
\hline & 471 & $\mathbf{S}$ & $\mathrm{H}$ & 25.407 & 2.724 & 1.906 & 7.63 & 0.85 & 1.724 & 1.861 & 1.930 & 4.7 & 43 \\
\hline & 523 & $\mathrm{~F}$ & $\mathrm{H}$ & 25.417 & 2.722 & 1.917 & 7.66 & 1.02 & 1.70 & & & 6.8 & 42 \\
\hline , & 522 & $\mathrm{~F}$ & $\mathrm{H}$ & 25.414 & 2.723 & 1.908 & 7.64 & 0.81 & 1.69 & & & 4.3 & 42 \\
\hline
\end{tabular}


Table 5-2. Summary of experimental streak-camera, copper-cylinder wall velocity data for homogeneous explosives in full-wall copper cylinders.

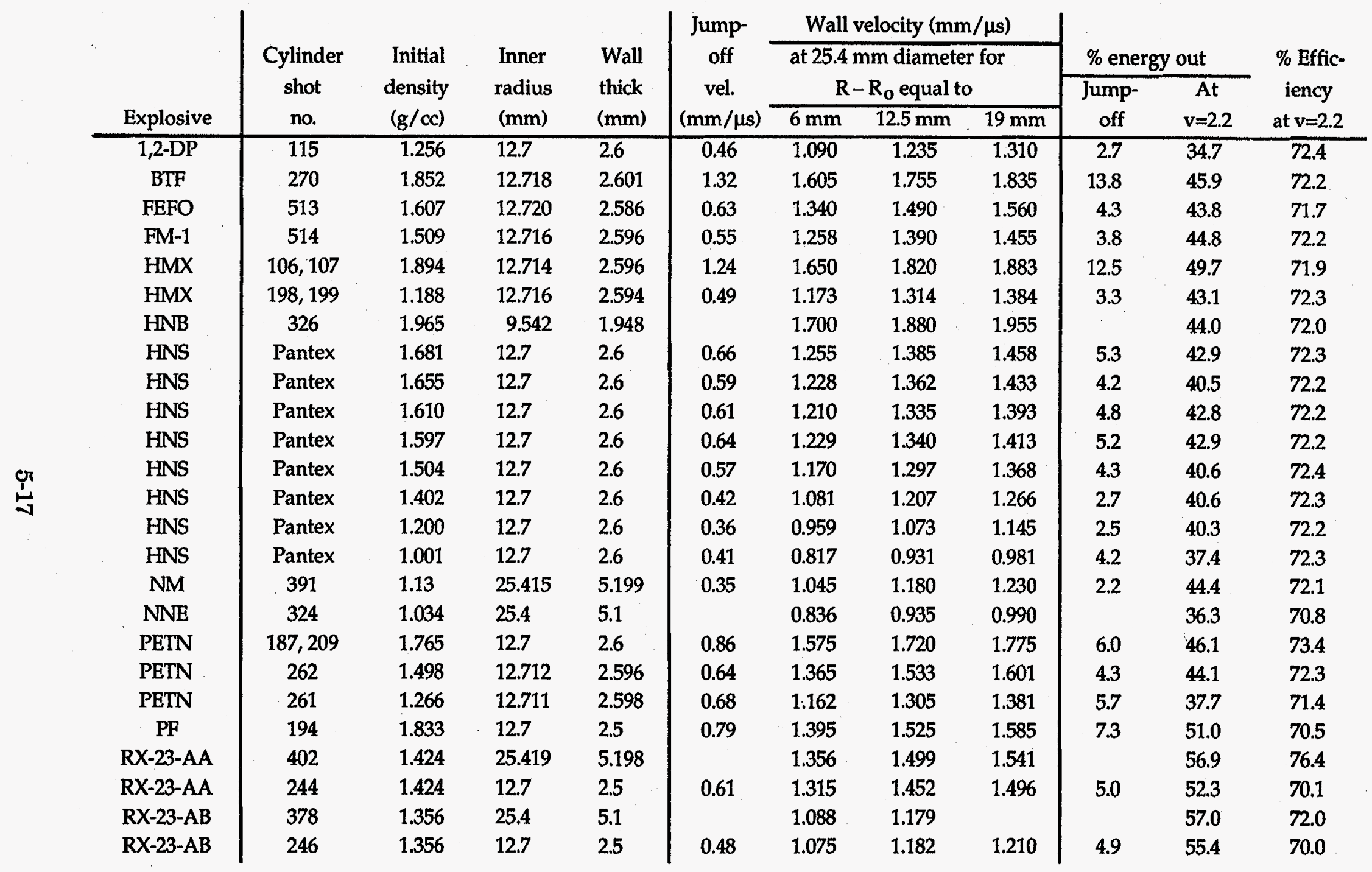




\begin{tabular}{|c|c|c|c|c|c|c|c|c|c|c|c|}
\hline \multirow[b]{4}{*}{ Explosive } & \multirow{4}{*}{$\begin{array}{l}\text { Cylinder } \\
\text { shot } \\
\text { no. }\end{array}$} & \multirow{4}{*}{$\begin{array}{l}\text { Initial } \\
\text { density } \\
(\mathrm{g} / \mathrm{cc})\end{array}$} & \multirow{4}{*}{$\begin{array}{l}\text { Inner } \\
\text { radius } \\
(\mathrm{mm})\end{array}$} & \multirow{4}{*}{$\begin{array}{l}\text { Wall } \\
\text { thick } \\
(\mathrm{mm})\end{array}$} & \multirow{4}{*}{$\begin{array}{l}\text { Jump- } \\
\text { off } \\
\text { vel. } \\
(\mathrm{mm} / \mu \mathrm{s})\end{array}$} & \multirow{3}{*}{\multicolumn{3}{|c|}{$\begin{array}{c}\text { Wall velocity }(\mathrm{mm} / \mu \mathrm{s}) \\
\text { at } 25.4 \mathrm{~mm} \text { diameter for } \\
R-R_{o} \text { equal to }\end{array}$}} & \multirow{2}{*}{\multicolumn{2}{|c|}{$\%$ energy out }} & \multirow{4}{*}{$\begin{array}{l}\% \text { effic- } \\
\text { iency } \\
\text { at } v=2.2\end{array}$} \\
\hline & & & & & & & & & & & \\
\hline & & & & & & & & & \multirow{2}{*}{$\begin{array}{c}\text { Jump- } \\
\text { off }\end{array}$} & \multirow{2}{*}{$\begin{array}{c}\text { At } \\
v=2.2\end{array}$} & \\
\hline & & & & & & $6 \mathrm{~mm}$ & $12.5 \mathrm{~mm}$ & $19 \mathrm{~mm}$ & & & \\
\hline $\mathrm{RX}-23-\mathrm{AC}$ & 245 & 1.136 & 25.4 & 5.1 & 0.49 & 1.077 & 1.175 & 1.219 & 4.7 & 50.9 & 71.3 \\
\hline TATB & 322,379 & 1.83 & 25.408 & 5.207 & 0.97 & 1.300 & 1.403 & 1.453 & 11.6 & 46.7 & 72.5 \\
\hline TNGU & 413 & 1.885 & 12.711 & 2.598 & & 1.600 & 1.750 & 1.825 & & 49.0 & 72.3 \\
\hline TNM & 474 & 1.650 & 12.715 & 2.592 & 0.48 & 1.000 & 1.095 & 1.130 & 5.7 & 55.7 & 72.1 \\
\hline TNT & $140-1,271$ & 1.632 & 25.427 & 5.186 & 0.57 & 1.210 & 1.355 & 1.410 & 4.1 & 41.4 & 71.7 \\
\hline
\end{tabular}


Table 5-3. JWL coefficients as determined from the Cylinder Test. GPa may be converted to Mbar and $\mathrm{kJ} / \mathrm{cc}$ to $\mathrm{Mbar} \cdot \mathrm{cc} / \mathrm{cc}$ by multiplying by 0.01 . A, B, and C are listed to six significant digits so that round-off errors will not occur in their use. Explosives are listed in order of the PETN standard, often-run explosives, and homogeneous explosives.

\begin{tabular}{|c|c|c|c|c|c|c|c|c|c|c|c|}
\hline Explosive & $\begin{array}{c}\text { Initial } \\
\text { density } \\
\rho_{0} \\
(\mathrm{~g} / \mathrm{cc})\end{array}$ & $\begin{array}{c}\text { Detona- } \\
\text { tion } \\
\text { velocity } \\
\mathrm{D} \\
(\mathrm{mm} / \mu \mathrm{s})\end{array}$ & $\begin{array}{c}\text { Energy } \\
\text { of det- } \\
\text { onation } \\
\mathrm{E}_{\mathrm{O}} \\
(\mathrm{kJ} / \mathrm{cc})\end{array}$ & $\begin{array}{c}\text { Det } \\
\text { pres- } \\
\text { sure } \\
P_{\mathbf{j}} \\
(\mathrm{GPa})\end{array}$ & $\begin{array}{c}\mathrm{A} \\
(\mathrm{GPa})\end{array}$ & $\begin{array}{c}\text { B } \\
\text { (GPa) }\end{array}$ & $\begin{array}{c}\mathrm{C} \\
(\mathrm{GPa})\end{array}$ & $\mathrm{R}_{1}$ & $\mathrm{R}_{2}$ & $\omega$ & $\gamma_{i}$ \\
\hline PETN & 1.763 & 8.274 & 10.8 & 31.5 & 1032.158 & 90.57014 & 3.72735 & 6.000 & 2.60 & 0.57 & 2.832 \\
\hline PBX-9404 & 1.843 & 8.76 & 10.5 & 37.5 & 740.349 & 11.7009 & 0.725292 & 4.317 & 1.05 & 0.25 & 2.771 \\
\hline LX-14 & 1.830 & 8.80 & 10.8 & 38.0 & 661.414 & 5.40066 & 1.825670 & 4.118 & 0.95 & 0.40 & 2.729 \\
\hline $\mathrm{RX}-26-\mathrm{AF}$ & 1.844 & 8.24 & 9.2 & 33.7 & 564.811 & 4.47297 & 0.656169 & 3.998 & 0.887 & 0.20 & 2.715 \\
\hline LX-17 & 1.905 & 7.63 & 7.0 & 26.0 & 989.761 & 17.4413 & 1.42712 & 5.15 & 1.713 & 0.45 & 3.274 \\
\hline$\overline{\text { BTF }}$ & 1.852 & 8.49 & 11.3 & 34.0 & 954.6163 & 22.66797 & 2.956620 & 5.027 & 1.60 & 0.50 & 2.926 \\
\hline 1,2-DP & 1.26 & 5.97 & 6.9 & 13.5 & 167.6882 & 3.630269 & 1.419315 & 4.118 & 1.00 & 0.33 & 2.326 \\
\hline FEFO & 1.607 & 7.45 & 8.2 & 24.5 & 405.2865 & 4.158285 & 1.424809 & 4.148 & 0.84 & 0.40 & 2.641 \\
\hline FM-1 & 1.509 & 6.57 & 7.1 & 19.0 & 267.2952 & 7.795149 & 1.712195 & 4.281 & 1.23 & 0.48 & 2.428 \\
\hline $\mathrm{HMX}$ & 1.894 & 9.10 & 11.0 & 40.5 & 858.0805 & 7.546531 & 0.781274 & 4.306 & 0.80 & 0.30 & 2.873 \\
\hline HMX & 1.188 & 6.68 & 6.4 & 15.5 & 218.2000 & 4.959453 & 1.977170 & 4.379 & 1.10 & 0.55 & 2.420 \\
\hline $\mathrm{HNB}$ & 1.965 & 9.34 & 13.2 & 43.0 & 1047.883 & 7.982396 & 1.396122 & 4.472 & 0.85 & 0.28 & 2.986 \\
\hline HNS & 1.681 & 7.08 & 7.4 & 23.0 & 369.0609 & 2.028814 & 1.455287 & 4.041 & 0.75 & 0.40 & 2.664 \\
\hline HNS & 1.655 & 7.03 & 7.5 & 21.5 & 423.7580 & 3.131467 & 1.704155 & 4.332 & 1.00 & 0.40 & 2.804 \\
\hline HNS & 1.610 & 6.96 & 6.9 & 21.0 & 371.4426 & 3.482474 & 1.041547 & 4.172 & 0.90 & 0.33 & 2.714 \\
\hline HNS & 1.597 & 6.96 & 7.1 & 21.5 & 328.5734 & 4.244564 & 1.529860 & 4.077 & 1.20 & 0.40 & 2.598 \\
\hline HNS & 1.504 & 6.70 & 6.8 & 18.5 & 310.0104 & 3.426403 & 1.670635 & 4.235 & 1.10 & 0.42 & 2.649 \\
\hline HNS & 1.402 & 6.34 & 5.8 & 16.0 & 226.5460 & 2.106304 & 0.783032 & 3.935 & 0.72 & 0.30 & 2.522 \\
\hline HNS & 1.200 & 5.74 & 4.6 & 11.5 & 136.8456 & 9.270925 & 1.991536 & 4.300 & 2.50 & 0.59 & 2.438 \\
\hline HNS & 1.001 & 5.10 & 3.6 & 7.3 & 138.8149 & 2.779832 & 0.694139 & 4.657 & 1.00 & 0.35 & 2.567 \\
\hline NM & 1.13 & 6.28 & 5.0 & 12.0 & 297.7799 & 5.954922 & 1.108004 & 5.026 & 1.10 & 0.49 & 2.714 \\
\hline $\mathrm{NNE}$ & 1.034 & 5.31 & 3.8 & 8.9 & 94.87257 & 1.140533 & 0.619964 & 3.706 & 0.75 & 0.30 & 2.276 \\
\hline PETN & 1.503 & 7.48 & 8.5 & 24.0 & 351.0723 & 5.705547 & 1.216240 & 4.075 & 0.90 & 0.35 & 2.504 \\
\hline PETN & 1.263 & 6.59 & 7.2 & 16.0 & 228.1744 & 5.104579 & 1.412013 & 4.240 & 1.05 & 0.35 & 2.428 \\
\hline PF & 1.833 & 7.29 & 7.5 & 27.0 & 418.3832 & 5.083194 & 1.753291 & 4.110 & 0.95 & 0.65 & 2.608 \\
\hline
\end{tabular}


Table 5-3, part 2

\begin{tabular}{|c|c|c|c|c|c|c|c|c|c|c|c|}
\hline Explosive & $\begin{array}{c}\text { Initial } \\
\text { density } \\
\rho_{0} \\
(\mathrm{~g} / \mathrm{cc})\end{array}$ & $\begin{array}{l}\text { Detona- } \\
\text { tion } \\
\text { velocity } \\
\mathrm{D} \\
(\mathrm{mm} / \mu \mathrm{s})\end{array}$ & $\begin{array}{c}\text { Energy } \\
\text { of det- } \\
\text { onation } \\
\mathrm{E}_{0} \\
(\mathrm{~kJ} / \mathrm{cc})\end{array}$ & $\begin{array}{c}\text { Det } \\
\text { pres- } \\
\text { sure } \\
P_{j} \\
(\mathrm{GPa})\end{array}$ & $\begin{array}{c}\mathrm{A} \\
(\mathrm{GPa})\end{array}$ & $\begin{array}{c}\text { B } \\
(\mathrm{GPa})\end{array}$ & $\underset{(\mathrm{GPa})}{\mathrm{C}}$ & $\mathbf{R}_{1}$ & $\mathrm{R}_{2}$ & $\omega$ & $\gamma_{i}$ \\
\hline $\mathrm{RX}-23-\mathrm{AA}$ & 1.424 & 8.64 & 6.5 & 25.8 & 737.8071 & 5.34171 & 0.167361 & 4.610 & 0.73 & 0.35 & 3.120 \\
\hline $\mathrm{RX}-23-\mathrm{AB}$ & 1.356 & 7.48 & 4.1 & 17.0 & 809.7106 & 6.543083 & 0.097540 & 5.243 & 1.00 & 0.30 & 3.463 \\
\hline $\mathrm{RX}-23-\mathrm{AC}$ & 1.136 & 7.88 & 4.5 & 18.0 & 379.9134 & 1.772972 & 0.938430 & 4.296 & 0.76 & 0.60 & 2.919 \\
\hline TATB & 1.83 & 7.58 & 7.3 & 26.0 & 686.8140 & 7.811448 & 0.877917 & 4.598 & 1.20 & 0.30 & 3.044 \\
\hline TNGU & 1.885 & 8.71 & 10.5 & 37.0 & 792.6978 & 7.784202 & 2.005135 & 4.410 & 1.00 & 0.49 & 2.865 \\
\hline TNM & 1.65 & 6.45 & 3.6 & 15.5 & 642.2267 & 3.898275 & 0.258200 & 5.020 & 0.90 & 0.52 & 3.429 \\
\hline TNT & 1.632 & 7.07 & 7.1 & 20.5 & 524.4089 & 4.900052 & 0.626131 & 4.579 & 0.85 & 0.23 & 2.979 \\
\hline
\end{tabular}

Note: PF and TNGU have detonation velocities calculated from TIGER. 


\section{Chapter 6. One-Dimensional Plate Data}

\section{The Jump-Off Velocity of Metal Plates}

The cylinder came first; oddly, the conceptually simpler, 1-D plate shots came later with the development of the "electric gun." The "gun" comes in 25-mm (1-in.) and 51-mm (2-in.) diameter sizes, and we shall describe the former. Electric current from a capacitor runs through copper leads to a $0.05-\mathrm{mm}$ (2-mil) thick aluminum foil, which is vaporized. This drives a $0.13-\mathrm{mm}$ (5-mil) thick mylar (density $=1.4 \mathrm{~g} / \mathrm{cc}$ ) flyer with a $25-\mathrm{mm}$ diameter. The flyer passes through a Lucite "barrel," which is really a 5.6-mm-thick disc, with a 75-mm outer diameter and a 25-mm inner diameter. The sample of explosive sits inside a second Lucite barrel of the same dimensions. Glued to the explosive surface is the metal plate, whose unconfined face will be measured. The mylar flyer initiates the explosive. All samples reported here were made by Don Breithaupt.

The metal plate is glued onto the explosive using Eastman 910 epoxy, Shell 815 , or a high-viscosity, high-grade silicone vacuum grease. These substances are put on and then wiped off to form a thin film. Chet Lee reports that the grease sticks better to $\mathrm{LiF}$ crystals than to metal foils. Because the glue interface is important in the modeling of thin plates, we reviewed the shot folders for glue thickness data. In some cases, the explosive and foil were measured by micrometer before and after gluing. The average of 45 samples was found to be:

$$
\begin{aligned}
\text { glue thickness } & =0.022 \pm 0.019 \mathrm{~mm} \\
& =0.86 \pm 0.74 \mathrm{mil} .
\end{aligned}
$$

There were six cases in which the procedure had been repeated five times for each sample. The average standard deviation, considering each set separately, was $\pm 0.025 \mathrm{~mm}$, showing that the standard deviation in Eq. (1) is the error of measurement. Epoxy was mentioned as the major glue. Only one case of the grease was documented, in which the layer was measured at $1.8 \mathrm{mil}$.

The flyer has been calibrated by silvering its front surface and then driving it into a plate of glass. The velocity is calibrated as a function of the capacitor bank voltage. For a 25 -mm-diameter, 10 -mil mylar flyer (at 20,30 , and $40 \mathrm{kV}$ ), the calibrated velocities are $4.0,4.7$, and $5.3 \mathrm{~mm} / \mu \mathrm{s}$, respectively. The $51-\mathrm{mm}, 10-\mathrm{mil}$ flyer at the same voltages produces $2.1,3.6$, and $4.3 \mathrm{~mm} / \mu \mathrm{s}$.

The velocity is measured with a Fabry-Perot interferometer. The beam is about 5 to $10 \mathrm{~mm}$ wide but is focused to a small point on the surface of the plate. A 12.5-mm focal lens is used to watch the motion over a definite region. Use of the narrow Fabry beam has led to concern as to whether the measure-ment is 
sampling too small a region on the surface, especially for explosives with large grain sizes like LX-14. Chet Lee says that the small point of focused laser light is always larger than several hundred microns and that a width of $1 \mathrm{~mm}$ is a better number.

For straight-on metal plate shots, the jump-off velocity at the instant of impact is a critical parameter. The measured particle velocity on the free surface (outer face) of the metal, $u_{f s}$, often has this simple relation with the unmeasured jump-off velocity on the confined, inner face, $u_{m}:{ }^{1}$

$$
\mathrm{u}_{\mathrm{m}} \simeq \mathrm{u}_{\mathrm{fs}} / 2 .
$$

This relation occurs because the shock wave crossing the plate creates a rarefaction wave that moves backwards at the same velocity when it hits the unconfined wall. Thus, the forward wall velocity is the sum of the two equal velocities. Walsh and Christian calculated that the ratio of the backward to forward wave velocities should be 1 at the limit of zero shock and could rise slightly above 1 at high pressures. ${ }^{1}$ Eq. (2) requires that the shock wave move through the metal without decay. Thus, a long initial pressure pulse is needed. Then, the rarefaction wave in the product gas decouples the explosive from the wall and allows the shock wave to continue.

A consideration of the pressures generated in a metal plate hit straight on by an explosive led to the "impedance matching" equation 2,3

$$
P_{m}=P_{p}+\rho_{r} U_{r}\left(u_{p}-u_{m}\right),
$$

where $\mathrm{P}_{\mathrm{m}}$ is the pressure at the confined, inner metal face at the instant of impact; $P_{p}$ is the detonation pressure of the explosive; $\rho_{r}$ is the density of the gaseous detonation products at the detonation point; $\rho_{0}$ is the initial density of the explosive, $U_{r}$ is the shock velocity in the detonation products; and $u_{p}$ and $u_{m}$ are the jump-off particle velocities of the explosive and the metal. Eq. (3) holds only at the instant of initial impact, and it is an inspired assumption-not one that can be derived by first principles. In Eq. (3), we may consider the second term on the right as putting extra pressure into the metal as the result of the back-reflected rarefaction wave. Deal next made the Acoustic Approximation

$$
\rho_{\mathrm{r}} \mathrm{U}_{\mathrm{r}}=\left(4 / 3 \rho_{\mathrm{o}}\right)(3 / 4 \mathrm{D})=\rho_{0} \mathrm{D}
$$

where $\rho_{o}$ is the initial explosive density and $D$ is the explosive's detonation velocity. By using the mass/momentum conservation relations,

$$
P_{p}=\rho_{0} D u_{p},
$$


and

$$
P_{m}=\rho_{m} U_{m} u_{m},
$$

where $\rho_{m}$ is the initial density of the metal and $U_{\mathrm{s}}$ is the shock wave velocity on the inner face of the metal plate. This is related to the particle velocity by

$$
\mathrm{U}_{\mathrm{m}}=\mathrm{C}_{\mathrm{o}}+\mathrm{S}_{1} \mathrm{u}_{\mathrm{m}}
$$

For $\mathrm{Al}, \mathrm{OHFC} \mathrm{Cu}$, and $\mathrm{Ta}$, the densities are $2.703,8.93$, and $16.69 \mathrm{~g} / \mathrm{cc}$. The constants $C_{0}$ and $S_{1}$ are 5.24 and $1.40 ; 3.94$ and 1.489 ; and 3.41 and $1.2 \mathrm{~mm} / \mu \mathrm{s}$, respectively, and are in dimensionless units. 4

The jump-off velocities are those first measured as the initial step at time zero. This velocity declines rapidly with increasing metal-plate thickness until the plate becomes thicker than the reaction zone width of the explosive. At this point, the velocities decrease slowly as the metal thickness increases. 2 The velocities usually considered are those in the nearly constant range where the plate thickness has just exceeded the reaction zone width. If the plate thickness equals the reaction zone width for a near-ideal explosive, $P_{a} \sim P_{p}$, where $P_{a}$ is the adiabat pressure of the explosive defined in Chapter 1 . (We recall that the adiabat point is the point where the explosive, in large-size and at steady state, leaves the Rayleigh Line and starts down the Principal Adiabat.) Using the equations above, we obtain

$$
P_{a} \sim P_{p}=\left(\rho_{m} U_{m}+\rho_{0} D\right) u_{f s} / 4 .
$$

This equation is the usual means of experimentally obtaining the detonation pressure. Shvedov's detailed review of two solid explosive suggests that the adiabat pressures are good to perhaps \pm 10 to $15 \% .5$

\section{Experimental Plate Jump-Off Results}

Table 6-1 lists the jump-off velocities for plate shots of aluminum, copper, and tantalum. The data were all taken with Fabry-Perot interferometry, and the precision in a given shot between fringes was about \pm 0.01 to $0.02 \mathrm{~mm} / \mu \mathrm{s}$, far better than the spread of results for a given explosive. The detonation velocities were adjusted from cylinder data using the $2 / 3$ power-density relation listed in the previous chapter. This adjustment holds for both PETN and HNS samples.

The PETN has been divided into two parts. The samples of 1.71 to $1.73 \mathrm{~g} / \mathrm{cc}$ are considered to be normal PETN, and their detonation pressures averaged to $32 \pm 4 \mathrm{GPa}$. The PETN of 1.76 to $1.78 \mathrm{~g} / \mathrm{cc}$ is marked with a double asterisk and is not used in calculating the official PETN detonation pressure. 
These samples, according to C. Tarver and J. Kury, were so compressed that they became partly transparent. They believe that a shock wave then passed through this material with the detonation wave catching up later. Because the PETN was precompressed, the apparent detonation pressure would be too high. The pressure for these four samples was $38 \pm 2 \mathrm{GPa}$. This phenomenon would appear only in thin slabs of explosive and would not be a factor in the Cylinder Test.

Some of the LX-17 plate shots had 3-mm LX-10 booster pads to bring 20-mm-thick LX-17 to steady state.

If we ignore the highly scattered TNT data in Table 6-1 and average all data where the plate thickness is greater than the reaction zone, we find that the plate detonation pressures for LX-14, PBX-9404, and PETN are in agreement with the cylinder JWL and jump-off pressures. The exception is LX-17, where the $34 \mathrm{GPa}$ found from plates is considerably higher than the $26 \mathrm{GPa}$ value found previously from the cylinder JWL. It does agree, however, with the less certain cylinder jump-off pressure.

Fig. 6-1 shows the LX-14 data as a function of plate thickness. The 44-GPa LX-14 point is deep inside the 0.1-mm-thick reaction zone and surely represents the spike. The pressures near the $0.1-\mathrm{mm}$ zone edge are spread around $36 \mathrm{GPa}$, in agreement with pressures measured by other means. The plate thickness data for LX-17 is not in agreement and will be considered in the next chapter.

Finally, both J. Kury and D. Steinberg have mentioned that the large grain size of LX-14 has made its results harder to interpret than that of the fine-grained LX-17 (see the Appendix for grain sizes). We would expect the biggest problem with the hundred-micron particles of LX-14. The standard deviations for the jumpoff velocity, starting with the largest deviation, is given in the following table.

\begin{tabular}{ccccc} 
Explosive & $\begin{array}{c}\text { Plate } \\
\text { material }\end{array}$ & $\begin{array}{c}\text { Plate } \\
\text { thick- } \\
\text { ness } \\
\text { (mm) }\end{array}$ & $\begin{array}{c}\text { Average } \\
\text { jump-off } \\
\text { velocity } \\
\text { (mm/ } / \mathrm{s})\end{array}$ & $\begin{array}{c}\% \\
\text { Std. } \\
\text { dev. }\end{array}$ \\
\hline TNT & Cu & 0.025 to 0.05 & 1.91 & 13 \\
PETN & Ta & 0.10 & 1.59 & 11 \\
LX-14 & Cu & 2.5 & 2.07 & 6 \\
LX-14 & Cu & 0.26 to 0.53 & 2.18 & 5 \\
LX-14 & Ta & 0.25 to 0.77 & 1.61 & 5 \\
PETN & Ta & 0.25 & 1.41 & 4 \\
LX-17 & Ta & 0.10 to 2.5 & 1.61 & 4 \\
LX-17 & Ta & 0.25 & 1.63 & 3 \\
PBX-9404 & Ta & 0.25 to 0.51 & 1.73 & 2
\end{tabular}


The detonation pressures taken from the plates are summarized in Eq. (5) of Chapter 7.

\section{Establishing a Plate Test}

With cylinder tests at $\$ 30,000$ each, a plate shot at $1 / 10$ th the cost is an acceptable way to get a quick JWL. It is not a true "test" because we do not obtain a geometric relative volume. The JWL must be obtained by trial and error in the 1-D hydrocode, with the likelihood of a wide variation in the possible results.

We would like to have a plate geometry with as high a kinetic energy transfer efficiency as possible. For the cylinder, the greater the degree of confinement the more detonation energy is transferred to wall kinetic energy. Hence, a full-wall cylinder is more efficient than a half-wall, and tantalum is more efficient than copper. The opposite is true for the plate, because any forward resistance simply causes the gas to blow backward. We expect higher efficiency in thin plates of light metals.

Let $\mathrm{hf}, \mathrm{h}_{\mathrm{o}}$, and $\mathrm{hm}$ be the thicknesses of the flyer, explosive, and metal plate. The densities and velocities of the flyer and metal are $\rho_{f}, u_{f}, \rho_{m}$, and $u_{m}$. At a long enough time, the unconfined face metal velocity may be taken as an average velocity for the entire plate. The total detonation energy of the explosive in $\mathrm{kJ} / \mathrm{cc}$ is $E_{0}$. The percent of total energy appearing as kinetic energy of the plate, $k$, is

$$
k=100 *\left(\rho_{m} h_{m} u_{m}^{2}-\rho_{f} h_{f} u_{f}^{2}\right) / 2 h_{0} E_{0} .
$$

We need to pick a special time for comparing measurements. Kinetic energies for all three plate materials are listed in Table 6-2. The points being compared are the velocities at the scaled times of 0.5 and $1.0 \mu \mathrm{s}$ for a 10-mm-thick explosive. The scaled time for a sample of thickness $h_{0}$ (in $\mathrm{mm}$ ) is

$$
t_{0}(\mu s)=\left(h_{0} / 10\right) t_{10}
$$

where $t_{10}$ is the time for the $10-\mathrm{mm}$ explosive. Also shown is the thickness ratio of explosive to plate, $h_{0} / h_{m}$, in dimensionless units. For a family of metals with a constant thickness ratio, we may look for the same fraction, $f$, at the scaled time, $t_{0}$. We see that, for a given metal, $k$ increases as the ratio increases, peaks somewhere between 20 and 50 , and then decreases. Too much or too little explosive is inefficient as gas shoots out the back and sides.

The kinetic energy fraction data in Table 6-2 have a lot of scatter. Also complicating the results are the 3-mm LX-10 drivers used in the 51-mm-diameter phm86000-series LX-17 shots. We compare six families with the same metal at the two scaled times with thickness ratios of 20 to 50 . In general, we see that for efficiency LX-14 $\geq \mathrm{LX}-17 \gg$ PETN. For LX-14, the metal efficiencies are $\mathrm{Cu} \geq \mathrm{Ta}$ > Al. On the basis of this limited data, mainly LX-14 data, the highest efficiency 
is obtained with copper using a thickness ratio of 20 to 40 . Tantalum showed the same efficiency at a ratio of 40 and would be close in performance. Selecting 40 leads us to the often-used combina-tion of 10-mm explosive and 10-mil metal (or 20-mm explosive and 20-mil metal).

We consider a "standard" plate shot to be fired before the blitz of dimensionchanging begins. Chet Lee mentions that the laser light reflects better off shocked tantalum than off copper. Such a standard shot should be 20-mil tantalum with 20-mm explosive (or 10 and 10 ). The $20-\mathrm{mm}$ is selected to allow for expected steady state in nonideal explosives such as LX-17. The Fabry would be run at least for 1.5 scaled $\mu \mathrm{s}$, i.e., $3 \mu \mathrm{s}$ for $20 \mathrm{~mm}$. To avoid edge effects, we would run the 10-mm explosive with a 1-in. diameter and the $20 \mathrm{~mm}$ with a 2-in. diameter. Such a collection would allow easy comparison between plate shots of different explosives, much as we do now with cylinders.

John Kury has noted that we should be able to define geometric volumes for the plates. We integrate the Fabry velocity over the time of the shot to obtain the $R-R_{0}$ distance, $\Delta h$. The relative volume of the cylinder swept out by the explosive is then

$$
\mathrm{v} \sim\left(\mathrm{h}_{\mathrm{o}}+\Delta \mathrm{h}\right) / \mathrm{h}_{0}
$$

This would be true for the center of the plate, which is where we measure, until the side effects work their way in. Assuming shock velocities of $5.5 \mathrm{~mm} / \mu \mathrm{s}$ in $\mathrm{Cu}$ or Ta, we calculate a 2.3- $\mu \mathrm{s}$, 1-D time for a $25-\mathrm{mm}$-diameter gun shot and $4.6 \mu \mathrm{m}$ for $51-\mathrm{mm}$ shot. We now examine the longest running plate shots to see the results. The data are listed below:

\begin{tabular}{lccccccc} 
& No. & $\begin{array}{c}\text { Exp. } \\
\text { length } \\
(\mathrm{mm})\end{array}$ & $\begin{array}{c}\text { Last } \\
\text { time } \\
(\mu \mathrm{s})\end{array}$ & $\begin{array}{c}\text { Inte- } \\
\text { gral } \\
(\mathrm{mm})\end{array}$ & $\begin{array}{c}\text { Max. } \\
\text { vol. } \\
\text { v }\end{array}$ & $\begin{array}{c}\text { Rel. } \\
\text { slope }\end{array}$ & $\begin{array}{c}\text { Plate } \\
\text { thick } \\
(\mathrm{mm})\end{array}$ \\
\cline { 2 - 8 } PETN & ppe87003 & 5 & 0.9 & 3.3 & 1.7 & 0.09 & 0.10 \\
LX-17 & pta90005 & 5 & 1.5 & 3.5 & 1.7 & 0.11 & 0.25 \\
PETN & ppe87005 & 5 & 1.5 & 3.6 & 1.7 & 0.07 & 0.25 \\
LX-14 & phm85013* & 10 & 2.4 & 8.0 & 1.8 & 0.03 & 0.51 \\
LX-14 & phm90003 & 5 & 1.7 & 4.5 & 1.9 & 0.13 & 0.25
\end{tabular}

None of the plates was measured for long, and none reached the time for the side effects, even at $25 \mathrm{~mm}$. The first problem we see is that the integral to $R-R_{0}$ is not large. We did not reach even $v=2$, and this is partly due to the inefficiency of the linear geometry, changing as the first power in distance. The second problem is that the velocity saturates quickly-which occurs because most of the explosive blows away from the back and edges and the efficiency of putting energy into the forward direction is not high. The slope listed above is the increase 
(compared to the total height) seen at the end per $\mu \mathrm{s}$. All plates were made of Ta except for $\mathrm{Cu}$ in the asterisk case.

It appears then, that we could work to obtain a geometric volume if we used thin explosives of 4 or $5 \mathrm{~mm}$ combined with metal plates of 0.1 to $0.25 \mathrm{~mm}$. A goal of about $\mathrm{v}=3$ seems to be the maximum, and the velocity curve would have leveled off at that point. We also recall that the early $\mathrm{v} \sim 1$ results cannot be used without a hydrocode correction because we know that the explosive is coming from $\mathrm{v}<1$.

\section{The Lucite PETN Experiment}

PETN at densities of about $1.763 \mathrm{~g} / \mathrm{cc}$ was studied in a careful detonation pressure experiment. ${ }^{6} \mathrm{~A} 102-\mathrm{mm}$-diameter baratol plane wave lens was used to drive a PETN sample of either 25 or $50 \mathrm{~mm}$ in diameter. The explosive was placed against a stack of five carefully measured Lucite (polymethylmethacrylate) plastic discs. An electrical sensor on the far end picked up signals generated by the Lucite due to the shock electric effect. 7 The signals were placed on a high-speed oscilloscope, and the arrival time of the shock wave at each interface was measured.

The as-measured data for PETN samples of 25-mm (1-in.) and 13-mm (1/2in.) lengths are listed in Table 6-3. The time for the explosive/disc 1 signal is timezero by definition. The next times for the measured signals at discs $1 / 2,2 / 3,3 / 4$, $4 / 5$, and $5 /$ standoff. These times are used to calculate an average shock velocity, $\mathrm{U}_{\mathrm{m}}$, applicable at the mid-point of each disc. Note how the velocities are higher in the center of disc 1 . This led the researchers to initially use a quadratic fit of average velocity vs mid-point total distance in order to extrapolate back to time zero. The shock velocity was then converted into a particle velocity within the Lucite. Eq. (8) in the form

$$
P_{p}=\left(\rho_{m} U_{m}+\rho_{o} D\right) u_{m} / 2
$$

was next used. A detonation pressure of $33.7 \pm 0.4 \mathrm{GPa}$ was obtained, where the plus/minus is precision.

Lee et al. considered a time-zero timing error in the Lucite experiment. 8 The photographic record of the time shows the electrical signal rising to its highest potential at the explosive/disc 1 interface, then decaying exponentially downward, reaching the baseline at the disc $2 / 3$ interface. The time-zero signal has a measurable risetime and turnover, whereas the disc-to-disc signals are sharp blips on a nearly flat line. Lee et al. concluded that $8.8 \mathrm{~ns}$ should be added to all the times in Table 6-3. This decreased the resulting velocities, and they obtained a detonation pressure of $31.6 \pm 0.2 \mathrm{GPa}$.

J. Kury then ran various JWLs using the old 1-D code KOVEC for sample no. 40966 (13-mm thickness). ${ }^{9} \mathrm{He}$ found that 1-D runs of the $25-\mathrm{mm}$ samples produced shorter times for the last interfaces. The disc $5 /$ standoff interface occurs 
at 996 to $1002 \mu \mathrm{s}$ for 1-D runs of the $13 \mathrm{~mm}$ samples, but 961 - to $974-\mu \mathrm{s}$ values were obtained for the $25-\mathrm{mm}$ samples. These values are caused by the added push given the same target, which is reflected in the code but not in Eq. (14). Only a limited set of values from $31.5<\mathrm{P}_{\mathrm{p}}<32.5 \mathrm{GPa}$ and $8.5<\mathrm{E}_{\mathrm{o}}<10.5 \mathrm{~kJ} / \mathrm{cc}$ were run, and all interface times agreed to within $1 \%$. The best fit was to a JWL at $31.7 \mathrm{GPa}$ and $8.5 \mathrm{~kJ} / \mathrm{cc}$. Nevertheless, the standard values of $31.5 \mathrm{GPa}$ and $10.8 \mathrm{~kJ} / \mathrm{cc}$ were first selected from this work.

Kury has recently recalculated the experimental results. The actual data are not available because the experiment was done by J. E. Kurrle at Mason \& Hangar-Silas Mason Co. in Burlington, Iowa. Kury, therefore, returned to the results of Table 6-3, where he notes that the velocity of the disc $1 / 2$ interface is uniformly high. A linear fit works best across the final four points, and this curve should be extrapolated back to time zero. The new shock wave velocities are $6.74 \pm$ $0.07 \mathrm{~mm} / \mu \mathrm{s}$ for the $13-\mathrm{mm}$ samples and 6.90

$\pm 0.05 \mathrm{~mm} / \mu \mathrm{s}$ for the $25-\mathrm{mm}$ samples.

We next need D. Steinberg's EOS for Lucite. ${ }^{4}$ This is

$$
U_{m}=C_{o}+S_{1} u_{m}+S_{2}\left(u_{m} / U_{m}\right) u_{m}
$$

where the constants are $2.18 \mathrm{~mm} / \mu \mathrm{s}, 2.088$, and -1.124 , respectively. The resulting particle velocities are 2.82 and $2.93 \mathrm{~mm} / \mu \mathrm{s}$ for the 13 - and $25-\mathrm{mm}$ samples.

We must next decide on the detonation velocity for PETN. Nine cylinder shots and pin-switch measurements give a result of $8.26 \pm 0.05 \mathrm{~mm} / \mu \mathrm{s}$ with an average density of $1.765 \pm 0.004 \mathrm{~g} / \mathrm{cc} .{ }^{6}$ This is in agreement with the J. Kury / L. Green suggested value of $8.274 \mathrm{~mm} / \mu \mathrm{s}$ at $1.763 \mathrm{~g} / \mathrm{cc}^{9}$

Using Eq. (14), we obtain $31.4 \pm 0.7$ and $32.9 \pm 0.6 \mathrm{GPa}$ for the detonation pressures from the 13- and 25-mm samples, where the pluses and minuses are precision.

\section{Supracompression as a Search for C-J}

The most exciting approach in the quest for the C-J or at least the adiabat detonation point, is the supracompression experiment. A high-speed flyer is used to detonate an explosive above the adiabat pressure. In this case, the explosive is being driven by a piston that holds the reaction products at constant pressure for several microseconds before they decay. The flyer velocity is slowly reduced in succeeding shots, and the pressure plateau drops as well. At the adiabat point, the piston stops holding up the plateau, and the pressure declines immediately. The 1$D$ behavior holds until the side effects affect the experiment.

Unfortunately, our data were not taken with time-dependent gauges but with individual measurements of the explosive particle velocity, $u_{p}$, and shock 
velocity, $U_{\mathrm{s}}$. From the Rankine-Hugoniot momentum relation, we calculate the explosive pressure,

$$
P_{p}=\rho_{o} U_{s} u_{p}
$$

This pressure may be plotted as a function of $U_{s}$ until the known detonation velocity, $D$, is reached. If $\mathrm{D}$ is obtained from a steady-state cylinder shot and represents the infinite size of the explosive, then $P_{p} \rightarrow P_{c j}$ (or $P_{a}$ ).

A different formalism was used to express this problem at the time, and it was based on C-J Theory. From the corresponding mass conservation requirement, we have

$$
\mathrm{v}=1-\mathrm{u}_{\mathrm{p}} / \mathrm{U}_{\mathrm{s}},
$$

from which we get

$$
\partial u_{\mathrm{p}} / \partial \mathrm{v}=-\mathrm{U}_{\mathrm{s}} .
$$

We rearrange and multiply each side by $\partial \mathrm{U}_{\mathrm{s}}$ to obtain

$$
\partial U_{s} / \partial v=-U_{s}\left(\partial U_{s} / \partial u_{p}\right) \text {. }
$$

We now consider a single product Hugoniot, $\mathrm{H} 1$, as shown in Fig. 6-2, with a set of decreasing Rayleigh Lines $U_{0}, U_{1}$, and $U_{2}$. The intersection points drop from $A$ to $B$ to $C$, which is the C-J point. The detonation velocity cannot decrease any further if this is the only Hugoniot, so that at C-J

$$
\partial U_{S} / \partial v=0
$$

From Eq. (19), with $U_{\mathrm{s}}$ nonzero,

$$
\partial \mathrm{U}_{\mathrm{s}} / \partial \mathrm{u}_{\mathrm{p}}=0
$$

at the C-J point. The researchers looked for the condition of Eq. (21). It is crucial to note that Eq. (21) is true only if the explosive has reacted to equilibrium and can be represented by a single product Hugoniot. Eq. (21) was first derived by $\mathrm{E}$. Lee ${ }^{10}$, but the short derivation above comes from Al Nichols.

Let us consider an explosive not at equilibrium also shown schematically in Fig. 6-2. Suppose the first shot on the Rayleigh Line U1 produces the Hugoniot H1 and the intersection point $B$. The next shot is at lower flyer velocity and pressure so that the explosive has not reacted as far. Here, the Rayleigh Line U2 produces Hugoniot H2. Instead of intersecting at $\mathrm{C}$, we now intersect at $\mathrm{D}$, which is not the 
C-J point. The C-J point is never reached because each succeeding Hugoniot is less-reacted than the preceding one. The result is that, if we look at point $\mathrm{D}$ at which $U_{\mathrm{s}}=\mathrm{D}_{\mathrm{cj}}, \partial \mathrm{U}_{\mathrm{s}} / \partial \mathrm{u}_{\mathrm{p}}$ is not equal to zero because we came down a path from $\mathrm{B}$ to $\mathrm{D}$. We could even continue to $\mathrm{U}_{\mathrm{s}}<\mathrm{D}_{\mathrm{cj}}$ and possibly obtain detonation, until finally, the initiation pressure becomes too low for detonation to occur. None of the measured points would ever reach the adiabat point but would be sonic detonation points. These points are not characteristic of the bulk explosive but-are determined by the size and time of each particular experiment.

\section{The Supracompressed PETN Experiment}

Of special interest for the standard PETN JWL were the measurements on $1.76 \mathrm{~g} / \mathrm{cc}$ PETN hit with flyer plates from the H-Division two-stage gas gun, which is capable of driving explosives above the adiabat point. 8,11 More accurately, a flyer plate was used to strike a buffer plate of either aluminum or $1.763 \mathrm{~g} / \mathrm{cc}$ PETN, which then sent a shock wave into the PETN to detonate it. The optically measured time for the shock wave to pass through the explosive from the buffer plate to the edge gave the shock velocity, $\mathrm{U}_{\mathrm{s}}$. Pins were used to measure the flyerplate velocity, which was converted into the explosive particle velocity, $u_{p}$.

The data are listed in Table 6-4 with the calculated results and are summarized in Fig. 6-3, where it is seen that it is approaching $\partial U_{s} / \partial u_{p} \rightarrow 0$ at the vertical line, which is the cylinder detonation velocity. The listed error is given as belonging to the shock velocity, and it varies from 0.3 to $3.3 \%$. Mitchell and Nellis list $0.5-1.0 \%$ accuracy for 200-ns transit times on this same gun.11 It was these pressure-volume values that were tried out with the standard JWL in Chapter 3 and found to fit within $5 \%$ up to $80 \mathrm{GPa}$, even though one is an adiabat and the other a Hugoniot.

This leads us to attempt to find the adiabat point as an asymptote at slightly lower volumes, where we are searching for $U_{s}=D$, the detonation velocity for the infinite-size, steady-state cylinder. We have adjusted D slightly by the $2 / 3$ power of the density, to move from the standard $1.763 \mathrm{~g} / \mathrm{cc}$ PETN to the $1.760 \mathrm{~g} / \mathrm{cc}$ average for this experiment. We expect $D$ to be about $8.265 \mathrm{~mm} / \mu \mathrm{s}$.

Although $\partial \mathrm{U}_{\mathrm{s}} / \partial \mathrm{u}_{\mathrm{p}}$ seems to approach zero, it is difficult to pick the intersection point with the vertical detonation velocity line. Along the Rayleigh line, we require that

$$
\partial \mathrm{P}_{\mathrm{S}} \partial \mathrm{v}=-\rho_{0} \mathrm{D}^{2} .
$$

The value of this derivative is expected to be about $-120 \mathrm{~g} \cdot \mathrm{mm}^{2} / \mathrm{cc} \cdot \mu \mathrm{s}^{2}$. Unfortunately, the jitter in the few points in Table 6-4 makes this derivative useless. The range of the following points all are reasonable solutions for the detonation point: 


\begin{tabular}{ccc}
$\begin{array}{c}\mathrm{u}_{\mathrm{p}} \\
(\mathrm{mm} / \mu \mathrm{s})\end{array}$ & $\begin{array}{c}\mathrm{P}_{\mathrm{p}} \\
(\mathrm{GPa})\end{array}$ & $\mathrm{v}_{\mathrm{p}}$ \\
\hline 2.00 & 29.1 & 0.758 \\
2.11 & 30.7 & 0.745 \\
2.16 & $\mathbf{3 1 . 4}$ & $\mathbf{0 . 7 3 9}$ \\
2.27 & 33.0 & 0.725
\end{tabular}

Eq. (16) plus the $U_{s}-u_{p}$ relations for aluminum are used to get these results. The value of $31.5 \mathrm{GPa}$ was chosen at the time for the detonation pressure, $\mathrm{P}_{\mathrm{j}}$, in the standard PETN JWL. The error of trying to pick the intersection point, with $0.72<\mathrm{v}<0.76$, is considerably larger than the 1 to $2 \%$ error estimated by $\mathrm{C}$. Tarver and $M$. van Thiel to be in the impedance matching of each point.

In summary, the Lucite experiment gave detonation pressures for $1.763 \mathrm{~g} / \mathrm{cc}$ PETN of 31.5 to $33 \mathrm{GPa}$. The plate velocity-jump-off pressures are $34 \pm$ $4 \mathrm{GPa}$, and the cylinder velocity-jump-off pressures (see Chapter 5) are $32 \pm 8 \mathrm{GPa}$. The thermochemical codes (Chapter 8) add to the confusion by all coming in low at $30.6 \mathrm{GPa}$ in $\mathrm{BKWR}, 28.7 \mathrm{GPa}$ in $\mathrm{BKWS}, 27.5 \mathrm{GPa}$ in $\mathrm{JCZ}$, and 29.3 $\mathrm{GPa}$ in CHEQ.

The best measured detonation point comes from supracompression and is the only one we can call a possible adiabat pressure. The $1.763 \mathrm{~g} / \mathrm{cc}$ PETN adiabat pressure is

$$
\mathrm{P}_{\mathrm{a}}-31 \pm 2 \mathrm{GPa},
$$

which is $2 \mathrm{GPa}$ higher than the thermochemical code results.

PETN brings up the philosophical difficulties of the adiabat point vs the C-J point. According to $\mathrm{C}$. Tarver and L. Green, PETN has a reaction zone so small that they were never able to measure it. However, Hayes found some electrical conductivity in PETN that he attributed to carbon. ${ }^{12} \mathrm{~A}$. Nichols calculates 0.6 $\mathrm{mol} / \mathrm{mol}$ of diamonds in PETN at the C-J point (Table 8-4) in CHEQ, so that carbon precipitation is already under way. A C-J point, therefore, may never exist in any carbon-containing explosive because the time-dependent phenomenon of carbon coagulation is always present.

The practical question is whether the Principal Adiabat takes off at 32 or at $29 \mathrm{GPa}$. The larger question is that if true equilibrium never exists in any carboncontaining explosive, then all explosives must possess a size effect that would become apparent if we were careful enough. Thus, the adiabat point is defined as referring to "large-size" samples (for which we have data) rather than infinite-size, which exists only in the equilibrium code.

It finally suggests that the quest for C-J should perhaps move to compounds with no carbon. For us, such samples are the three RX-23-A explosives. These show the same 2-GPa difference between the JWL detonation pressure and the 
calculated C-J pressure. Overall, the homogeneous explosives in Table 5-4 show a difference of $2 \pm 1 \mathrm{GPa}$ between the JWL detonation pressure and the CHEQ C-J point. Therefore, no trend is evident.

\section{Supracompression of HMX and TATB}

Three samples were measured in supracompression: PBX-9404, RX-26-AF, and LX-17. The first is HMX-based and the last TATB-based; the second is a mixture of the two. This experiment was reported with more confidence than the PETN work just described. The data from Green, et al. are listed in Table 6-5 and are plotted in Fig. 6-4. ${ }^{13}$ The horizontal lines are the steady-state detonation velocities found from cylinder shots. Also included is the PBX-9404 data of Kinecke and West. ${ }^{14}$

It is clear in Fig. 6-4 that none of the three explosives show any tendency to turn toward the horizontal. Neither did any of the explosives in Kinecke and West's work. ${ }^{14}$ The PBX-9404 and LX-17 data have no room left to turn without running into the steady-state cylinder detonation lines-unless one assumes that the lowest measured points are incorrect. While more accurate data would be helpful, we must consider that nonequilibrium behavior may be present.

In the Green et al. paper, the belief that $\partial U_{s} / \partial u_{p}$ must go to zero caused them to assume that the true C-J pressures were lower than previously believed. JWLs were used to fit the supracompression data. The best example was PBX9404 , which L. Green has recently privately replotted. The data run from particle velocities of 5.5 to $2.3 \mathrm{~mm} / \mu \mathrm{s}$. On such a broad scale, the C-J region looks small indeed. Green mentions that the one point near C-J may have sufficient error to allow a bend in the curve. It has been moved up enough so that the cylinder detonation velocity fits underneath. The JWL curve is then fit over the entire extent of the data with a 34-GPa JWL passing through the data and a 37-GPa JWL not passing through. It is not mentioned how many other JWLs with 37-GPa detonation points were tried. The other published fits for LX-17 and RX-26-AF do not even look close. ${ }^{13}$

As a result of this supracompression experiment, we cannot decide whether we obtained an adiabat point with even the degree of equilibrium possessed by the PETN results. It appears that we did not. Further work will be needed, preferably with pressure gauges, to unravel this problem.

We shall extrapolate the data of Table 6-5 down to the steady-state detonation velocities as best we can. These are 8.76, 8.22 (extrapolated from 8.24 for $1.844 \mathrm{~g} / \mathrm{cc}$ ), and $7.63 \mathrm{~mm} / \mathrm{\mu s}$ for PBX-9404, RX-26-AF, and LX-17. The PBX9404 is close to the detonation point, as is the LX-17, except that its relative volume is too low. The RX-26-AF has a low volume as well, and the extrapolation is a long one. The detonation pressure results are shown below in $\mathrm{GPa}$, with the standard deviations being precision. 


\begin{tabular}{cccc} 
& \multicolumn{3}{c}{ One-dimensional plate } \\
\cline { 2 - 4 } & $\begin{array}{c}\text { Jump- } \\
\text { off } \\
\text { velocity }\end{array}$ & $\begin{array}{c}\text { Green } \\
\text { supra- } \\
\text { compress }\end{array}$ & $\begin{array}{c}\text { Our } \\
\text { supra- } \\
\text { compress }\end{array}$ \\
\cline { 2 - 4 } PBX-9404 & $39 \pm 1$ & 34 & $38 \pm 2$ \\
PETN & $34 \pm 4$ & 32 & $32 \pm 1.5$ \\
RX-26-AF & & 32 & $34 \pm 2$ \\
LX-17 & $34 \pm 0$ & 28 & $32 \pm 2$
\end{tabular}

(25)

We recall from Chapter 4 that the jump-off velocities for LX-17 included plate thicknesses from 0.10 to $2.5 \mathrm{~mm}$. With the Green pressures now being considered too low because of the mode of extrapolation, we see that the plate jump-off velocity and supracompression results are in agreement.

\section{References}

1. J. M. Walsh and R. H. Christian, Phys. Rev. 97, 1544 (1955).

2. R. E. Duff and E. Houston, J. Chem. Phys. 23, 1268 (1955).

3. W. E. Deal, J. Chem. Phys. 27, 796 (1957).

4. D. J. Steinberg, Equation of State and Strength Properties of Selected Materials, Lawrence Livermore National Laboratory, Livermore, CA, UCRL-MA-106439 (1991).

5. K. K. Shvedov, Combustion, Explosives, Shock Waves 23, 464 (1987).

6. H. C. Hornig, E. L. Lee, M. Finger and J. E. Kurrle, "Equation of State of Detonation Products," Proceedings Fifth Symposium (International) on Detonation, Pasadena, CA, August 18-21, 1970, p. 503.

7. B. Hayes, J. Appl. Phys. 38, 507 (1967).

8. E. L. Lee, M. van Thiel, L. G. Green, and A. Mitchell, "Detonation Product EOS: The Region above Chapman Jouget Pressure," presented at the Lawrence Livermore American Physical Society 1983 Topical Conference on Shock Waves in Condensed Matter, Santa Fe, NM, July 18-21, 1983.

9. L. Green, N. Holmes, and J. Kury, "Shock Measurements on Explosives in the Supra-Compressive Region," presented at the Int'1 Symposium on Pyrotechnics and Explosives, Beijing, China, October 12-15, 1987; (UCRL-95461, 1987). 
10. Memo from E. L. Lee to R. Weingart, December 20, 1984.

11. A. C. Mitchell and W. J. Nellis, Rev. Sci. Instr. 52, 347 (1981).

12. B. Hayes, "On Electrical Conductivity in Detonation Products," Proceedings Fourth Symposium (international) on Detonation, White Oak, MD, October 12-15, 1965, p. 595.

13. L. Green, E. Lee, A. Mitchell, and C. Tarver, "The Supra-Compression of LX-07, LX-17, PBX-9404, and RX-26-AF and the Equations of State of the Detonation Products," Proceedings Eighth Symposium (International) on Detonation, Albuquerque, NM, July 15-19, 1985, pp. 587-595.

14. J. H. Kinecke, Jr. and C. E. West, Jr., "Shocked States of Four Overdriven Explosives," Proceedings Fifth Symposium (International) on Detonation, Pasadena, CA, August 18-21, 1970, pp. 533-542. 


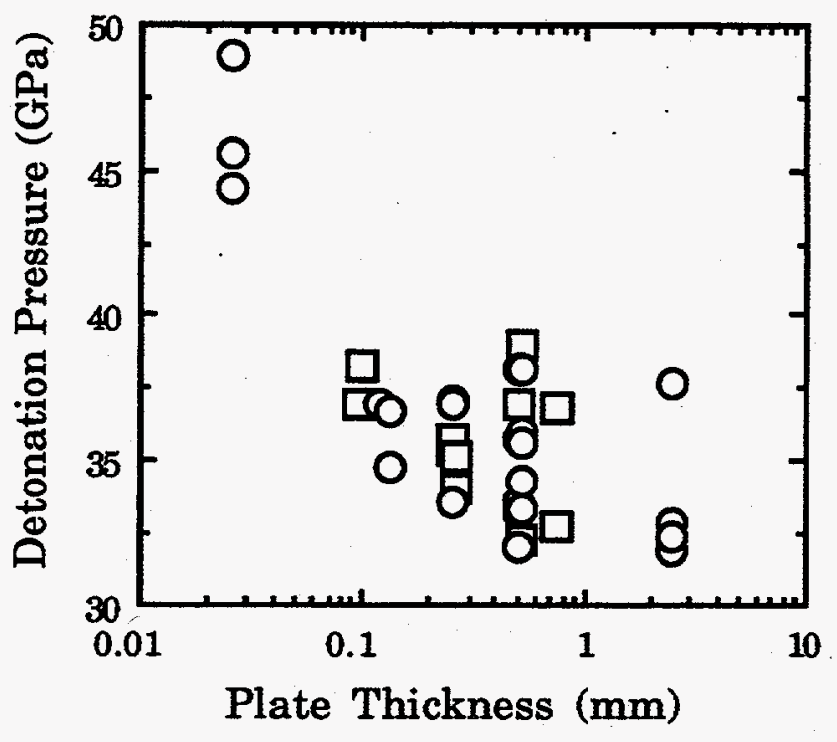

Fig. 6-1. Detonation pressure, as calculated from impedance matching, for metal plates pushed by $\mathrm{LX}-14$, which has a reaction zone of about $0.1 \mathrm{~mm}$. Hence, the $44-\mathrm{GPa} \mathrm{LX}-14$ point is the expected spike, and the $36 \mathrm{GPa}$ cluster of lower points is close to the expected C-J point. The data show LX-14 on Ta (open squares) and LX-14 on $\mathrm{Cu}$ (open circles).

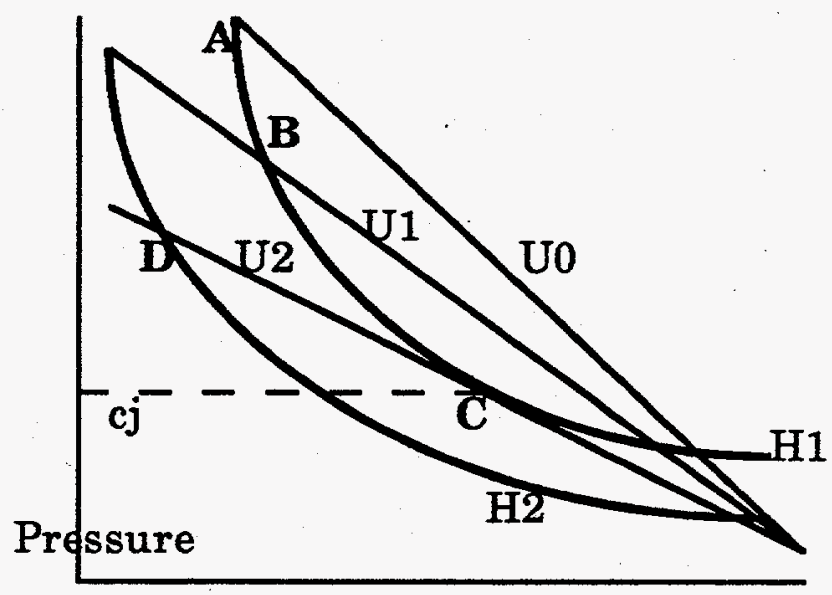

Relative Volume

Fig. 6-2. Schematic of detonation in the pressure-volume plane according to C-J Theory. If H1 is the only product Hugoniot, then supracompression Rayleigh Lines U0, U1, and U2 create intersection points A, B, and C. C is the C-J point, and the two curves are tangent. However, suppose $\mathrm{U} 1$ creates the nonequilibrium Hugoniot $\mathrm{H} 1$ with the intersection point $\mathrm{B}$. Then the next, lower pressure Rayleigh Line U2 creates the less-reacted Hugoniot H2 with the intersection point $D$. We never reach a C-J point with the tangency condition. 


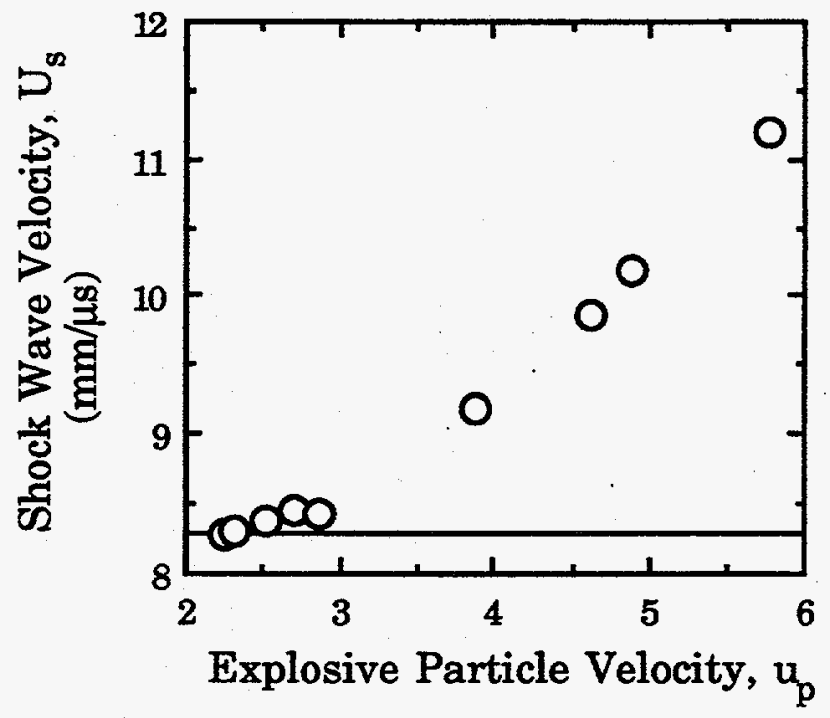

Fig. 6-3. Supracompression shock velocity vs. particle velocity data for $1.760 \mathrm{~g} / \mathrm{cc}$ PETN. The horizontal line is the steady state cylinder detonation velocity toward which the data are headed. The shape suggests that $\partial U_{\mathrm{S}} / \partial u_{p}$ is indeed heading toward zero as expected for an ideal explosive.

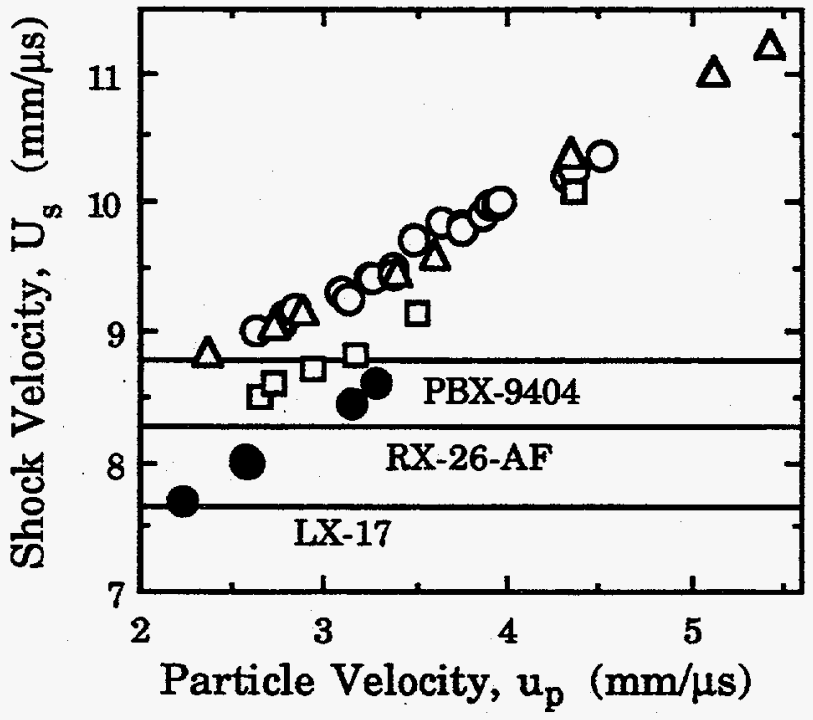

Fig. 6-4. Supracompression plot for three explosives. The horizontal lines are the steady state cylinder detonation velocities to which the points are extrapolated. None of the three shows any bending toward the horizontal, a sign of nonideal behavior. The explosives, from top to bottom, are: PBX-9404 (open circles) and (open triangles; RX-26-AF (open squares), and LX-17 (filled circles). 


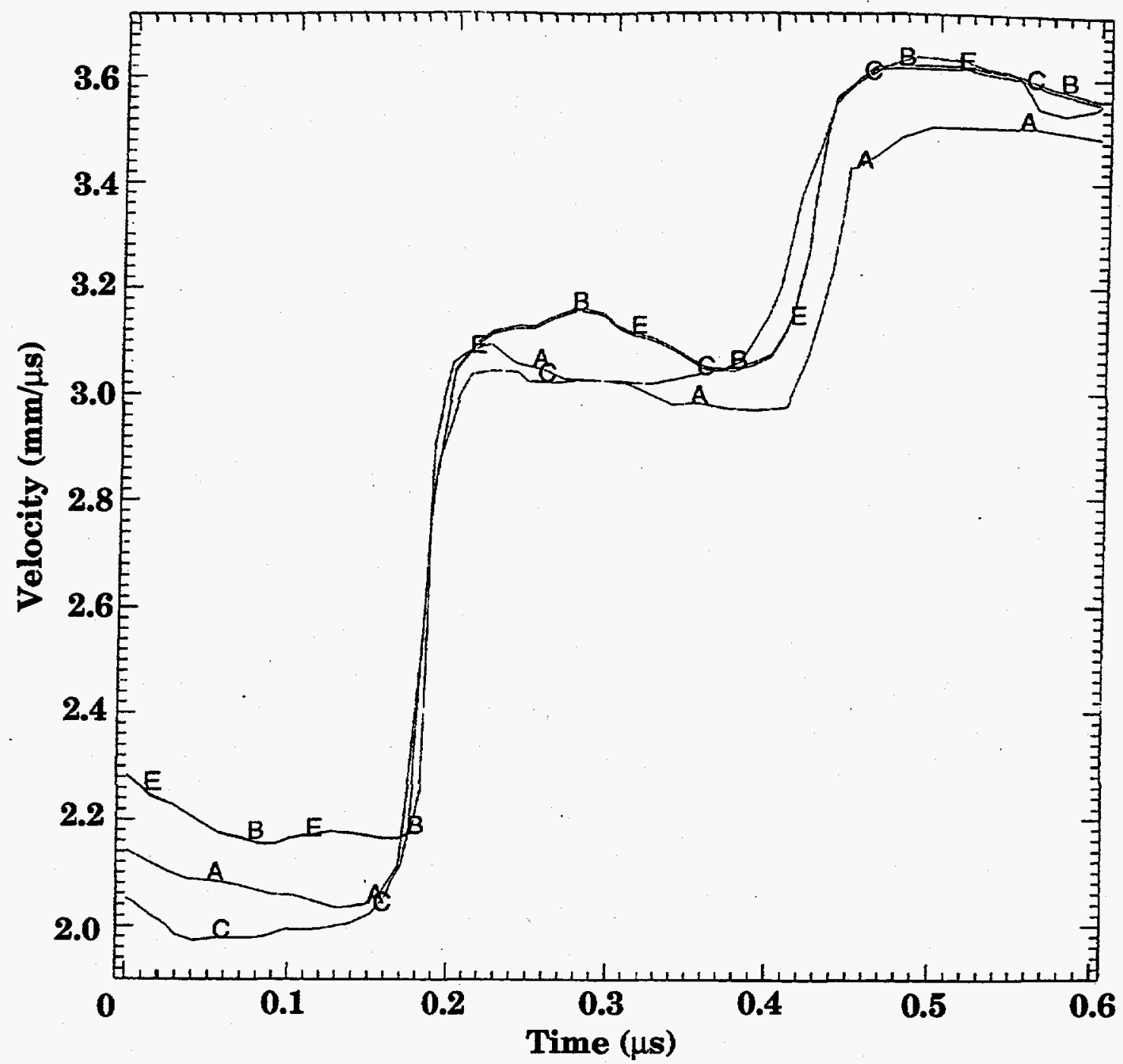

\begin{tabular}{|c|c|c|c|c|c|c|}
\hline $\begin{array}{l}\text { Curve } \\
\text { A }\end{array}$ & $\begin{array}{l}\text { Label } \\
\text { *1x14 in phm85039 f. old } \\
\text { dv9634b, } 9634\end{array}$ & $\underset{-0.0404}{\mathbf{X}-\min }$ & $\begin{array}{c}X-\max \\
0.972\end{array}$ & $\underset{2.03}{\text { Y-min }}$ & $\begin{array}{c}Y-\max \\
3.77\end{array}$ & $\begin{array}{c}\text { File } \\
\text { uphm850 }\end{array}$ \\
\hline & $\mathrm{m} / \mathrm{ms}$ ys $\mathrm{ms}$ & & & & & \\
\hline & & & 1.1 & & 4. & \\
\hline & *9577a1x-14 & -0.0186 & 1.43 & 2.15 & 4.28 & uphm85041 \\
\hline
\end{tabular}

Fig. 6-5. Overlay of four, identical 1-D electric gun shots with 20-mm LX-14 on 0.51-mm copper plates. The flyer velocity was $4.3 \mathrm{~mm} / \mu \mathrm{s}$, and Fabry interferometry was used. The variability in jump-off suggests that the detonation point is actually an undefined band. The samples are phm85017, 18, 39, and 41. 
Table 6-1. Jump-off velocities and calculated detonation pressures from 1-D plate shots. All flyers were $0.25 \mathrm{~mm}$ Mylar. The * indicates a fine-grained explosive; ** means the sample was probably overdriven. The samples are arranged in the order of increasing plate thickness.

\begin{tabular}{|c|c|c|c|c|c|c|c|c|c|}
\hline $\begin{array}{l}\text { Explo- } \\
\text { sive }\end{array}$ & $\begin{array}{c}\text { Shot } \\
\text { no. }\end{array}$ & Plate & $\begin{array}{c}\text { Jump-off } \\
\text { velocity } \\
(\mathrm{mm} / \mu \mathrm{s})\end{array}$ & $\begin{array}{c}\text { Calc } \\
\text { det } \\
\text { pressure } \\
\text { (GPa) }\end{array}$ & $\begin{array}{l}\text { Thick- } \\
\text { ness } \\
\text { explosive } \\
(\mathbf{m m})\end{array}$ & $\begin{array}{c}\text { Plate } \\
\text { thick- } \\
\text { ness } \\
(\mathrm{mm})\end{array}$ & $\begin{array}{c}\text { Explosive } \\
\text { density } \\
(\mathrm{g} / \mathrm{cc})\end{array}$ & $\begin{array}{c}\text { Flyer } \\
\text { velocity } \\
\text { (mm/us) }\end{array}$ & $\begin{array}{c}\text { Det } \\
\text { velocity } \\
\mathrm{D} \\
(\mathrm{mm} / \mu \mathrm{s})\end{array}$ \\
\hline \multirow[t]{23}{*}{$\overline{L X-14}$} & 9632 & $\mathrm{Cu}$ & 2.80 & 48.9 & 25.58 & 0.0254 & 1.83 & 4.3 & 8.79 \\
\hline & 9643 & $\mathrm{Cu}$ & 2.65 & 45.6 & 25.58 & 0.0254 & 1.83 & 4.3 & 8.79 \\
\hline & phm85047 & $\mathrm{Cu}$ & 2.59 & 44.4 & 25.58 & 0.0254 & 1.83 & 4.3 & 8.79 \\
\hline & phm85001 & $\mathrm{Ta}$ & 1.66 & 36.9 & 5.47 & 0.096 & 1.79 & 4.3 & 8.66 \\
\hline & phm90004 & $\mathrm{Ta}$ & 1.70 & 38.3 & 5.00 & 0.10 & 1.84 & 4.1 & 8.83 \\
\hline & phm85011 & $\mathrm{Cu}$ & 2.24 & 37.0 & 20.18 & 0.12 & 1.83 & 4.3 & 8.79 \\
\hline & phm85014 & $\mathrm{Cu}$ & 2.22 & 36.7 & 19.97 & 0.13 & 1.84 & 4.1 & 8.82 \\
\hline & phm85011 & $\mathrm{Cu}$ & 2.13 & 34.8 & 20.30 & 0.13 & 1.82 & 4.3 & 8.77 \\
\hline & phm90003 & $\mathbf{T a}$ & 1.59 & 35.4 & 5.00 & 0.25 & 1.84 & 4.1 & 8.83 \\
\hline & phm90001 & $\mathrm{Ta}$ & 1.61 & 35.8 & 10.92 & 0.25 & 1.82 & 4.1 & 8.77 \\
\hline & phm85040 & $\mathrm{Cu}$ & 2.24 & 37.1 & 40.00 & 0.25 & 1.84 & 4.3 & 8.82 \\
\hline & phm85035 & $\mathrm{Cu}^{*}$ & 2.24 & 36.9 & 40.15 & 0.257 & 1.83 & 4.3 & 8.79 \\
\hline & phm85036 & $\mathrm{Cu}^{*}$ & 2.07 & 33.6 & 40.15 & 0.257 & 1.83 & 4.3 & 8.79 \\
\hline & phm85003 & $\mathrm{Ta}$ & 1.61 & 35.1 & 13.22 & 0.264 & 1.69 & 4.3 & 8.35 \\
\hline & phm85004 & $\mathrm{Ta}$ & 1.57 & 34.1 & 13.22 & 0.264 & 1.69 & 4.3 & 8.35 \\
\hline & phm85017 & $\mathrm{Cu}$ & 2.29 & 38.1 & 20.15 & 0.505 & 1.83 & 4.3 & 8.80 \\
\hline & phm85018 & $\mathrm{Cu}$ & 2.07 & 33.6 & 20.15 & 0.505 & 1.83 & 4.3 & 8.79 \\
\hline & phm90002 & $\mathbf{T a}$ & 1.64 & 36.9 & 10.00 & 0.51 & 1.86 & 4.1 & 8.89 \\
\hline & phm85039 & $\mathrm{Cu}$ & 2.18 & 35.8 & 20.00 & 0.51 & 1.84 & 4.3 & 8.82 \\
\hline & phm85041 & $\mathrm{Cu}$ & 2.30 & 38.2 & 20.00 & 0.51 & 1.84 & 4.3 & 8.82 \\
\hline & phm85020 & $\mathrm{Al}$ & 3.58 & 33.2 & 20.23 & 0.515 & 1.83 & 4.3 & 8.79 \\
\hline & phm85021 & $\mathrm{Al}$ & 3.47 & 32.0 & 20.23 & 0.515 & 1.83 & 4.3 & 8.79 \\
\hline & phm85013 & $\mathrm{Cu}$ & 2.30 & 38.2 & 10.00 & 0.523 & 1.83 & 4.3 & 8.79 \\
\hline
\end{tabular}




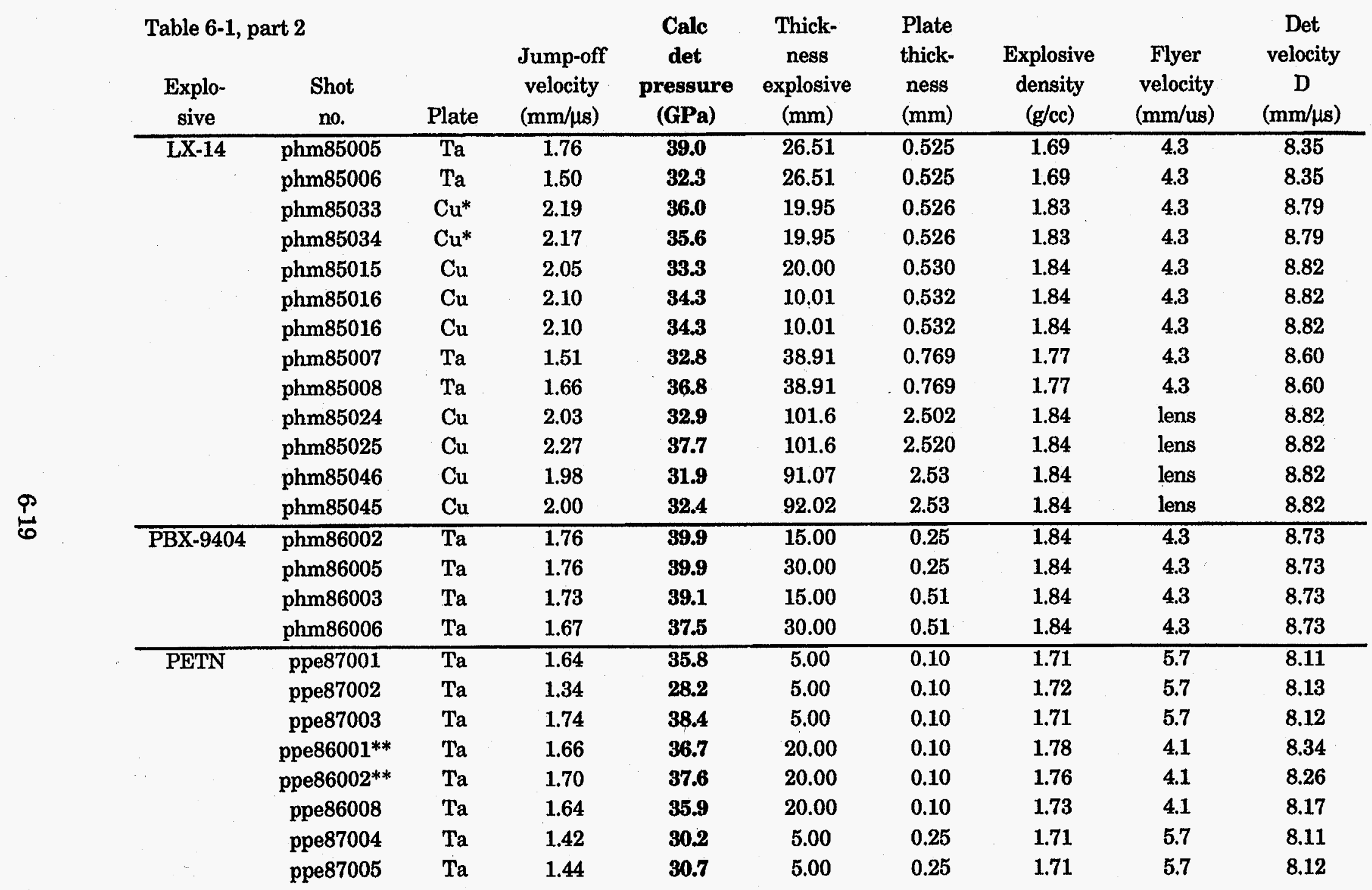




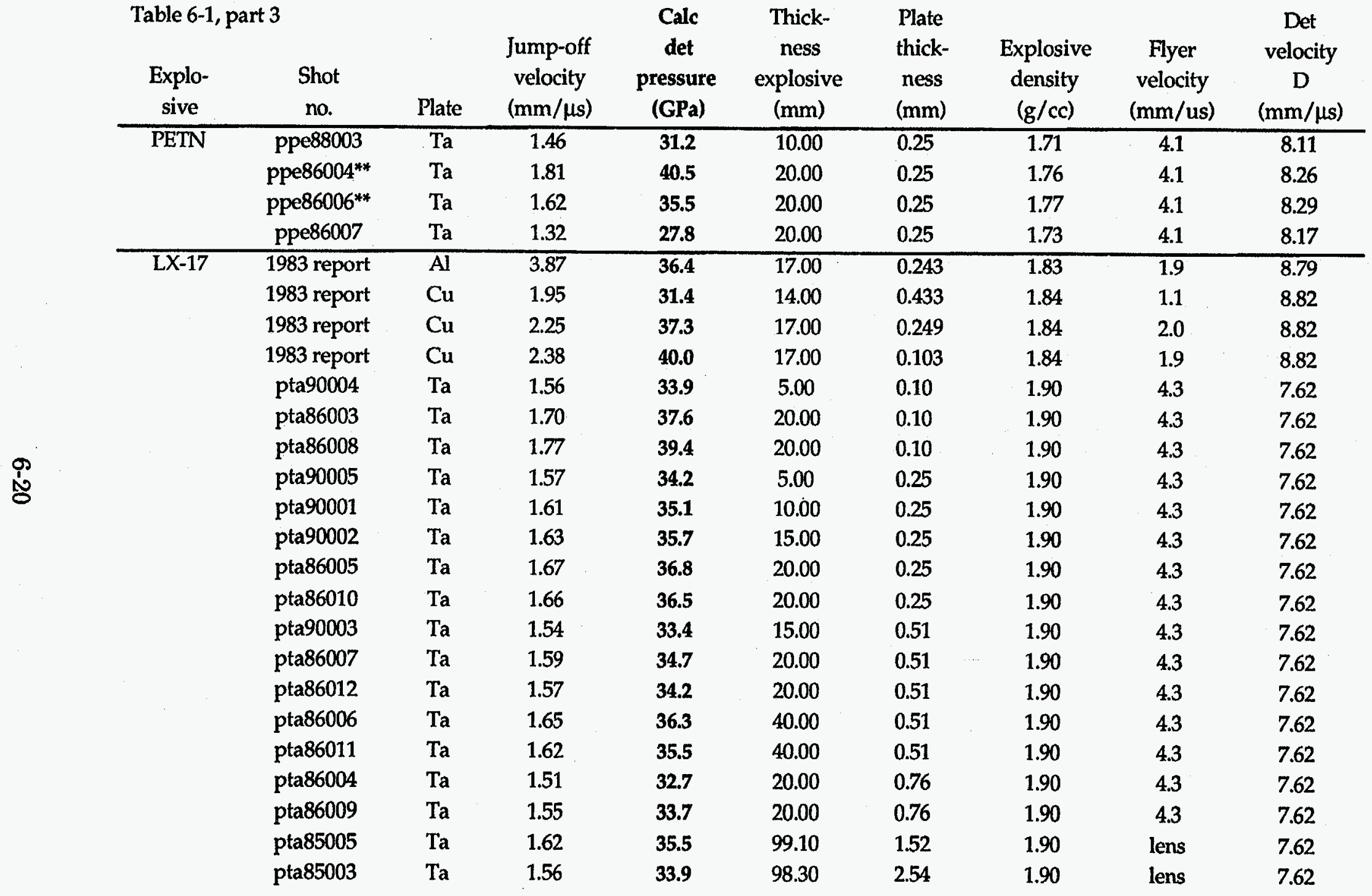




\begin{tabular}{|c|c|c|c|c|c|c|c|c|c|}
\hline \multirow[t]{4}{*}{$\begin{array}{c}\text { Table 6-1, } \\
\text { Explo- } \\
\text { sive }\end{array}$} & $\begin{array}{c}\text { Shot } \\
\text { no. }\end{array}$ & Plate & $\begin{array}{l}\text { Jump-off } \\
\text { velocity } \\
(\mathrm{mm} / \mu \mathrm{s})\end{array}$ & $\begin{array}{c}\text { Calc } \\
\text { det } \\
\text { pressure } \\
\text { (GPa) }\end{array}$ & $\begin{array}{l}\text { Thick- } \\
\text { ness } \\
\text { explosive } \\
\text { (mm) }\end{array}$ & $\begin{array}{l}\text { Plate } \\
\text { thick- } \\
\text { ness } \\
(\mathrm{mm})\end{array}$ & $\begin{array}{c}\text { Explosive } \\
\text { density } \\
(\mathrm{g} / \mathrm{cc})\end{array}$ & $\begin{array}{c}\text { Flyer } \\
\text { velocity } \\
\text { (mm/us) }\end{array}$ & $\begin{array}{c}\text { Det } \\
\text { velocity } \\
D \\
(\mathrm{~mm} / \mu \mathrm{s})\end{array}$ \\
\hline & pta85004 & $\overline{\mathrm{Ta}}$ & 1.55 & 33.7 & 99.10 & 2.54 & 1.90 & lens & 7.62 \\
\hline & pta85001 & $\mathrm{Cu}$ & 2.09 & 33.2 & 100.00 & 2.54 & 1.90 & lens & $7.62^{\circ}$ \\
\hline & pta85002 & $\mathrm{Cu}$ & 2.11 & 33.6 & 100.00 & 2.54 & 1.90 & lens & 7.62 \\
\hline \multirow[t]{9}{*}{ TNT } & ptn86011 & $\mathrm{Cu}$ & 2.04 & 30.7 & 17.80 & 0.03 & 1.62 & 4.3 & 7.05 \\
\hline & ptn86012 & $\mathrm{Cu}$ & 2.05 & 30.9 & 17.80 & 0.03 & 1.62 & 4.3 & 7.05 \\
\hline & ptn86004 & $\mathrm{Cu}$ & 1.42 & 19.9 & 38.60 & 0.03 & 1.62 & 4.3 & 7.05 \\
\hline & ptn86013 & $\mathrm{Cu}$ & 2.06 & 31.0 & 38.60 & 0.03 & 1.62 & 4.3 & 7.05 \\
\hline & ptn 86007 & $\mathrm{Cu}$ & 1.94 & 28.9 & 38.60 & 0.05 & 1.62 & 4.3 & 7.05 \\
\hline & ptn86008 & $\mathrm{Cu}$ & 1.97 & 29.4 & 38.60 & 0.05 & 1.62 & 4.3 & 7.05 \\
\hline & ptn86006 & $\mathrm{Cu}$ & 1.85 & 27.3 & 38.60 & 0.13 & 1.62 & 4.3 & 7.05 \\
\hline & ptn87001 & $\mathrm{Ta}$ & 1.01 & 12.0 & 101.60 & 1.52 & 1.63 & lens & 7.06 \\
\hline & ptn87002 & Ta & 1.04 & 20.5 & 101.60 & 1.52 & 1.63 & lens & 7.06 \\
\hline
\end{tabular}


Table 6-2. Fraction of kinetic energy put into various plates at the scaled times of 0.5 and $1.0 \mu \mathrm{s}$ for a $10 \mathrm{~mm}$-thick explosive. Sorting is by metal, then the ratio of explosive-to-plate thickness.

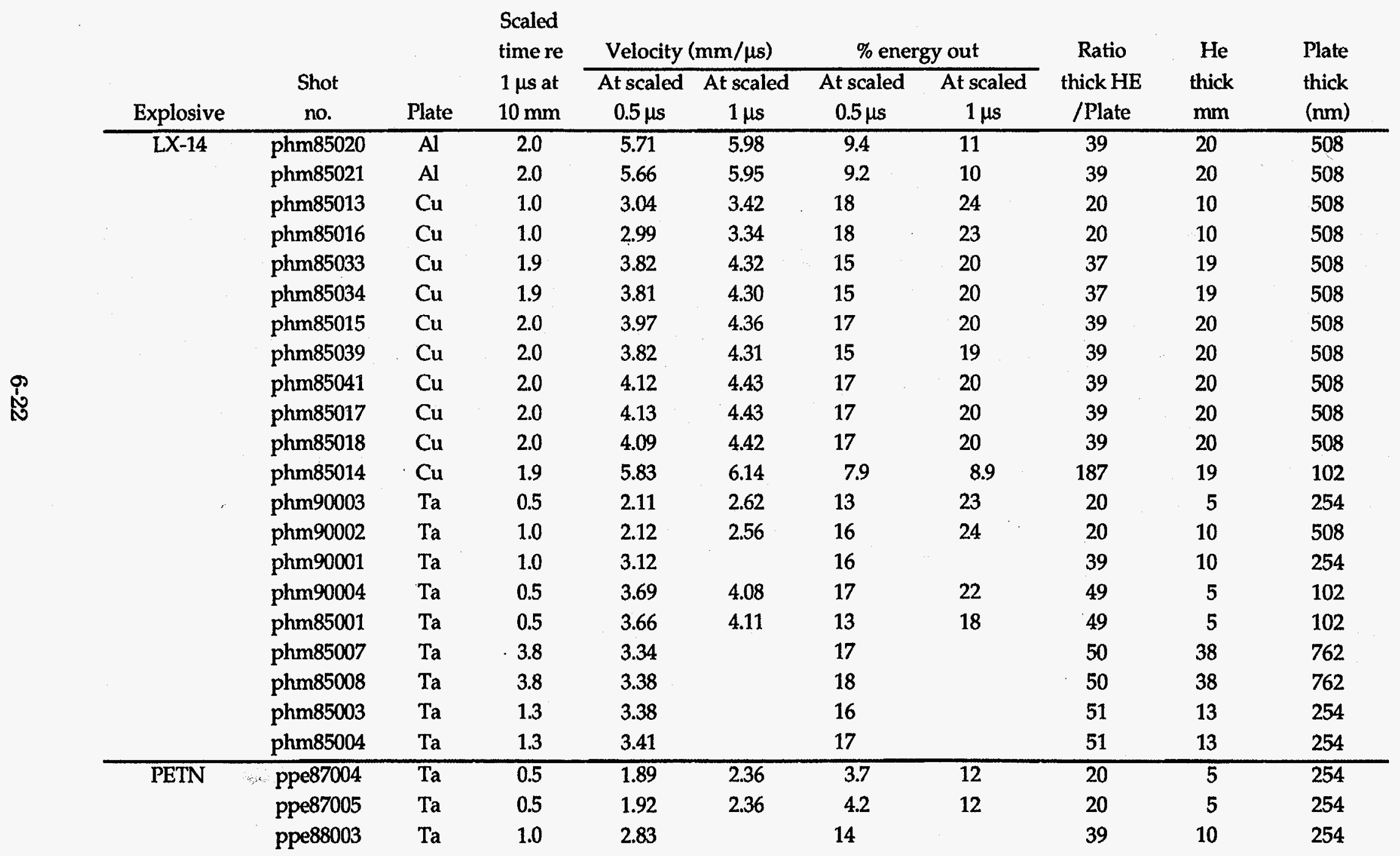




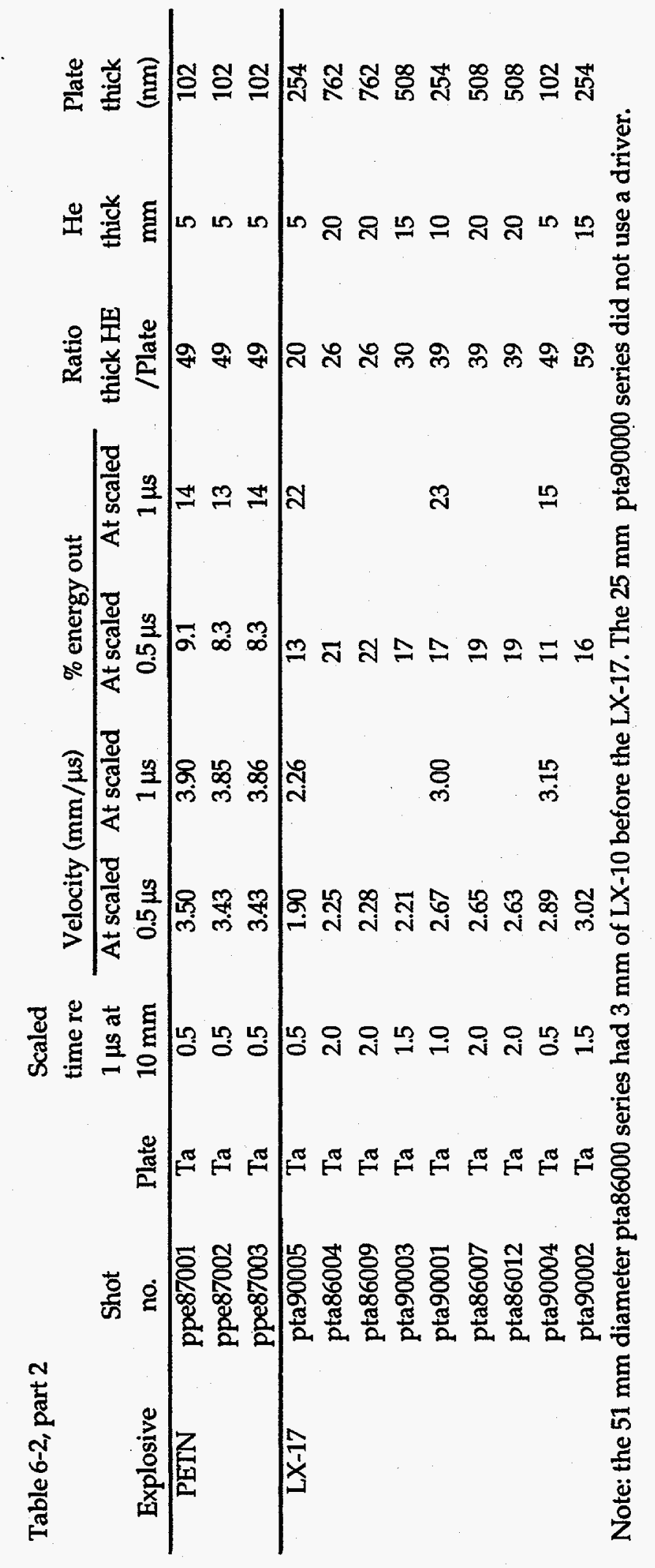


Table 6-3. Summary of as-measured Lucite PETN data for densities of about $1.763 \mathrm{~g} / \mathrm{cc}$. The times from top to bottom are for the interfaces between dises $1 / 2,2 / 3,3 / 4,4 / 5$, and $5 /$ standoff. The explosive/disc 1 interface is time zero by definition.

\begin{tabular}{|c|c|c|c|c|c|c|c|c|c|}
\hline \multicolumn{5}{|c|}{$25 \mathrm{~mm}$ ( 1 in.) length- Original data } & \multicolumn{5}{|c|}{$13 \mathrm{~mm}$ (1/2 in.) length- Original data } \\
\hline & $\begin{array}{c}\text { Dis- } \\
\text { tance } \\
(\mu \mathrm{m})\end{array}$ & $\begin{array}{c}\text { Mid } \\
\text { point } \\
(\mu \mathrm{m})\end{array}$ & $\begin{array}{r}\text { Time } \\
\text { (ns) }\end{array}$ & $\begin{array}{c}\text { Vel. } \\
\text { (mm/ } \\
\text { ms) }\end{array}$ & & $\begin{array}{c}\text { Dis- } \\
\text { tance } \\
(\mu \mathrm{m})\end{array}$ & $\begin{array}{c}\text { Mid } \\
\text { point } \\
(\mu \mathrm{m})\end{array}$ & $\begin{array}{c}\text { Time } \\
\text { (ns) }\end{array}$ & $\begin{array}{c}\text { Vel. } \\
(\mathrm{mm} / \\
\mathrm{ms})\end{array}$ \\
\hline Exp 40934 & 1265 & 633 & 181 & 6.99 & Exp 40936 & 1303 & 652 & 183 & 7.12 \\
\hline (D1A) & 2563 & 1914 & 371 & 6.83 & (D1HA) & 2548 & 1926 & 376 & 6.45 \\
\hline $25 \mathrm{~mm}$ dia. & 3830 & 3197 & 562 & 6.63 & $25 \mathrm{~mm}$ dia. & 3843 & 3196 & 577 & 6.44 \\
\hline$\times 25.40 \mathrm{~mm}$ & 5095 & 4463 & 755 & 6.55 & $\mathrm{x} 12.85 \mathrm{~mm}$ & 5108 & 4476 & 779 & 6.26 \\
\hline $1.763 \mathrm{~g} / \mathrm{cc}$ & 6360 & 5728 & 951 & 6.45 & $1.763 \mathrm{~g} / \mathrm{cc}$ & 6373 & $\mathbf{5 7 4 1}$ & 984 & 6.17 \\
\hline Exp 40933 & 1285 & 643 & 184 & 6.98 & Exp 40932 & 1295 & 648 & 184 & 7.04 \\
\hline (D1B) & 2570 & 1928 & 375 & 6.73 & (D1HB) & 2558 & 1927 & 378 & 6.51 \\
\hline $25 \mathrm{~mm}$ dia. & 3846 & 3208 & 570 & 6.54 & $25 \mathrm{~mm}$ dia. & 3830 & 3194 & 575 & 6.46 \\
\hline $\mathrm{x} 25.75 \mathrm{~mm}$ & 5131 & 4489 & 767 & 6.52 & $\mathrm{x} 12.73 \mathrm{~mm}$ & 5103 & 4467 & 777 & 6.30 \\
\hline $1.758 \mathrm{~g} / \mathrm{cc}$ & 6393 & 5762 & 965 & 6.37 & $1.763 \mathrm{~g} / \mathrm{cc}$ & 6373 & 5738 & 985 & 6.11 \\
\hline Exp 40931 & 1285 & 643 & 187 & 6.87 & Exp 40966 & 1285 & 643 & 182 & 7.06 \\
\hline (D2A) & 2548 & 1917 & 375 & 6.72 & (D2HA) & 2560 & 1923 & 377 & 6.54 \\
\hline $51 \mathrm{~mm}$ dia. & 3823 & 3186 & 567 & 6.64 & $51 \mathrm{~mm}$ dia. & 3838 & 3199 & 574 & 6.49 \\
\hline $\mathrm{x} 25.32 \mathrm{~mm}$ & 5105 & 4464 & 762 & 6.57 & $\mathrm{x} 12.62 \mathrm{~mm}$ & 5108 & 4473 & 778 & 6.23 \\
\hline $1.762 \mathrm{~g} / \mathrm{cc}$ & 6373 & 5739 & 959 & 6.44 & $1.763 \mathrm{~g} / \mathrm{cc}$ & 6388 & 5748 & 986 & 6.15 \\
\hline Exp 40912 & 1293 & 647 & 183 & 7.07 & Exp 40949 & 1280 & 640 & 181 & 7.07 \\
\hline (D2B) & 2578 & 1936 & 373 & 6.76 & (D2HB) & 2553 & 1917 & 373 & 6.63 \\
\hline $51 \mathrm{~mm}$ dia. & 3843 & 3211 & 564 & 6.62 & $51 \mathrm{~mm}$ dia. & 3840 & 3197 & 572 & 6.47 \\
\hline $\mathrm{x} 25.37 \mathrm{~mm}$ & 5121 & 4482 & 759 & 6.55 & $\mathrm{x} 12.51 \mathrm{~mm}$ & 5123 & 4482 & 774 & 6.35 \\
\hline $1.763 \mathrm{~g} / \mathrm{cc}$ & 6388 & 5755 & 955 & 6.46 & $1.764 \mathrm{~g} / \mathrm{cc}$ & 6411 & 5767 & 980 & 6.25 \\
\hline
\end{tabular}


Table 6-4. Supracompressed PETN experimental data. The line in italics is the expected C-J point with a detonation velocity, $D$, of $8.265 \mathrm{~mm} / \mu \mathrm{s}$. Although $\Delta \mathrm{U}_{\mathrm{S}} / \Delta \mathrm{u}_{\mathrm{p}}$ is approaching zero, how to extrapolate to the C-J point is not easy.

\begin{tabular}{|c|c|c|c|c|c|c|c|c|c|}
\hline \multirow{4}{*}{$\begin{array}{c}\text { Density } \\
\text { (g/cc) }\end{array}$} & \multicolumn{6}{|c|}{ PETN target } & & & \multirow{4}{*}{$\begin{array}{l}\text { Buffer } \\
\text { plate }\end{array}$} \\
\hline & \multirow{2}{*}{\multicolumn{2}{|c|}{ Meas. Velocity }} & $\mu s)$ & \multirow{3}{*}{$\begin{array}{c}\text { Calc. } \\
\text { pressure } \\
(\mathrm{GPa})\end{array}$} & \multirow{3}{*}{$\begin{array}{c}\text { Calc. } \\
\text { volume } \\
\mathbf{v}\end{array}$} & & & & \\
\hline & & & \multirow{2}{*}{$\frac{\text { Error }}{\mathrm{U}_{\mathfrak{S}}}$} & & & & \multicolumn{2}{|c|}{ Flyer plate } & \\
\hline & $\overline{\mathrm{U}_{\mathrm{s}}}$ & $\overline{u_{p}}$ & & & & $\Delta \mathrm{P} / \Delta \mathrm{v}$ & & $(\mathrm{mm} / \mu \mathrm{s})$ & \\
\hline 1.760 & 8.265 & & & & & & & & \\
\hline 1.761 & 8.298 & 2.320 & 0.074 & 33.9 & 0.720 & & $\mathrm{Al}$ & 3.960 & Al \\
\hline 1.761 & 8.384 & 2.518 & 0.032 & 37.2 & 0.700 & -158 & Al & 4.280 & $\mathrm{Al}$ \\
\hline 1.758 & 8.452 & 2.692 & 0.060 & 40.0 & 0.681 & -155 & $\mathbf{A l}$ & 4.555 & $\mathrm{Al}$ \\
\hline 1.763 & 8.429 & 2.856 & 0.048 & 42.4 & 0.661 & -120 & $\mathrm{Al}$ & 4.810 & PETN \\
\hline 1.757 & 9.194 & 3.886 & 0.300 & 62.8 & 0.577 & -243 & $\mathrm{Al}$ & 6.492 & PETN \\
\hline 1.757 & 9.859 & 4.629 & 0.049 & 80.2 & 0.530 & -372 & $\mathrm{Al}$ & 7.729 & PETN \\
\hline 1.766 & 10.200 & 4.883 & 0.120 & 88.0 & 0.521 & -844 & $\mathrm{Ta}$ & 5.998 & PETN \\
\hline 1.759 & 11.206 & 5.768 & 0.034 & 114 & 0.485 & -715 & $\mathrm{Ta}$ & 7.116 & PETN \\
\hline
\end{tabular}


Table 6-5. Summary of supracompressed data for three less-ideal explosives. "L" is the LLNL data; " $\mathrm{K}$ " is Kinecke and West. The Kinecke and West velocity in the next to last column is the buffer's unconfined face velocity. The LLNL velocity in the same column is the flyer velocity.

\begin{tabular}{|c|c|c|c|c|c|c|c|c|c|c|c|}
\hline \multirow{3}{*}{$\begin{array}{l}\text { Explo- } \\
\text { sive }\end{array}$} & \multirow{3}{*}{$\begin{array}{l}\text { Den- } \\
\text { sity } \\
\text { g/cc }\end{array}$} & \multicolumn{4}{|c|}{ all $\mathrm{mm} / \mu \mathrm{s}$} & \multirow{3}{*}{$\begin{array}{l}\text { Pres- } \\
\text { sure } \\
\text { (GPa) }\end{array}$} & \multirow{3}{*}{$\begin{array}{c}\text { Vol- } \\
\text { ume } \\
\mathbf{v}\end{array}$} & & \multirow{3}{*}{$\begin{array}{l}\text { Flyer } \\
\text { plate }\end{array}$} & \multirow{3}{*}{$\begin{array}{c}\text { Vel. } \\
\text { mm/ } \\
\mu \mathrm{s}\end{array}$} & \multirow{3}{*}{$\begin{array}{c}\text { Buffer } \\
\text { plate }\end{array}$} \\
\hline & & \multicolumn{2}{|c|}{ Velocity } & \multicolumn{2}{|c|}{ Listed error } & & & & & & \\
\hline & & $\overline{\mathrm{U}_{\mathrm{s}}}$ & $u_{p}$ & $\overline{U_{s}}$ & $u_{p}$ & & & & & & \\
\hline PBX- & 1.844 & 8.85 & 2.353 & 0.04 & 0.01 & 38.4 & 0.734 & $\bar{L}$ & Al & 4.164 & 9404 \\
\hline \multirow[t]{28}{*}{9404} & 1.839 & 9.01 & 2.63 & 0.11 & & 43.6 & 0.708 & $\mathbf{K}$ & Mo & 3.34 & Mo \\
\hline & 1.841 & 9.07 & 2.723 & 0.06 & 0.02 & 45.5 & 0.700 & $\mathbf{L}$ & Al & 4.779 & $\mathrm{Al}$ \\
\hline & 1.839 & 9.07 & 2.77 & 0.12 & & 46.2 & 0.695 & $\mathbf{K}$ & Mo & 3.50 & Mo \\
\hline & 1.839 & 9.12 & 2.79 & 0.10 & & 46.8 & 0.694 & $\mathbf{K}$ & Mo & 3.55 & Mo \\
\hline & 1.839 & 9.17 & 2.84 & 0.08 & & 47.9 & 0.690 & $\mathbf{K}$ & Mo & 3.61 & Mo \\
\hline & 1.841 & 9.17 & 2.874 & 0.08 & 0.02 & 48.5 & 0.687 & L & $\mathrm{Al}$ & 5.032 & Al \\
\hline & 1.839 & 9.31 & 3.08 & 0.14 & & 52.7 & 0.669 & $\mathbf{K}$ & Mo & 3.91 & Mo \\
\hline & 1.839 & 9.24 & 3.12 & 0.18 & & 53.0 & 0.662 & $\mathbf{K}$ & Mo & 3.97 & Mo \\
\hline & 1.839 & 9.41 & 3.24 & 0.08 & & 56.1 & 0.656 & $\mathbf{K}$ & Mo & 4.12 & Mo \\
\hline & 1.839 & 9.42 & 3.25 & 0.14 & & 56.3 & 0.655 & $\mathbf{K}$ & Mo & 4.13 & Mo \\
\hline & 1.839 & 9.43 & 3.37 & 0.21 & & 58.4 & 0.643 & $\mathbf{K}$ & Mo & 4.29 & Mo \\
\hline & 1.839 & 9.49 & 3.37 & 0.13 & & 58.8 & 0.645 & $\mathbf{K}$ & Mo & 4.29 & Mo \\
\hline & 1.844 & 9.47 & 3.399 & 0.05 & 0.02 & 59.4 & 0.641 & L & $\mathrm{Al}$ & 5.901 & 9404 \\
\hline & 1.839 & 9.70 & 3.49 & 0.13 & & 62.3 & 0.640 & $\mathbf{K}$ & Mo & 4.45 & Mo \\
\hline & 1.844 & 9.59 & 3.591 & 0.10 & 0.04 & 63.5 & 0.626 & L & $\mathrm{Al}$ & 6.218 & 9404 \\
\hline & 1.839 & 9.83 & 3.63 & 0.15 & & 65.6 & 0.631 & $\mathrm{~K}$ & Mo & 4.64 & Mo \\
\hline & 1.839 & $9: 78$ & 3.76 & 0.11 & & 67.6 & 0.616 & $\mathbf{K}$ & Mo & 4.80 & Mo \\
\hline & 1.839 & 9.81 & 3.75 & 0.12 & & 67.7 & 0.618 & $\mathbf{K}$ & Mo & 4.79 & Mo \\
\hline & 1.839 & 9.89 & 3.86 & 0.07 & & 70.2 & 0.610 & $\mathbf{K}$ & Mo & 4.92 & Mo \\
\hline & 1.839 & 9.96 & 3.91 & 0.09 & & 71.6 & 0.607 & $\mathrm{~K}$ & Mo & 4.99 & Mo \\
\hline & 1.839 & 9.98 & 3.94 & 0.11 & & 72.3 & 0.605 & $\mathbf{K}$ & Mo & 5.03 & Mo \\
\hline & 1.839 & 10.01 & 3.97 & 0.13 & & 73.1 & 0.603 & $\mathbf{K}$ & Mo & 5.07 & Mo \\
\hline & 1.839 & 10.19 & 4.32 & 0.12 & & 81.0 & 0.576 & $\mathbf{K}$ & Mo & 5.53 & Mo \\
\hline & 1.839 & 10.23 & 4.36 & 0.24 & & 82.0 & 0.574 & $\mathbf{K}$ & Mo & 5.59 & Mo \\
\hline & 1.841 & 10.37 & 4.343 & 0.07 & 0.02 & 82.9 & 0.581 & L & $\mathrm{Al}$ & 7.533 & $\mathrm{Al}$ \\
\hline & 1.839 & 10.36 & 4.52 & 0.11 & & 86.1 & 0.564 & $\mathbf{K}$ & Mo & 5.78 & Mo \\
\hline & 1.841 & 11.03 & 5.130 & 0.06 & 0.03 & 104.2 & 0.535 & L & $\mathrm{Ta}$ & 6.402 & 9404 \\
\hline & 1.843 & 11.23 & 5.424 & 0.07 & 0.04 & 112.3 & 0.517 & L & $\mathrm{Ta}$ & 6.760 & 9404 \\
\hline $\mathrm{RX}-26$ & 1.835 & 8.50 & 2.64 & 0.04 & 0.01 & 41.2 & 0.689 & $\overline{\mathrm{L}}$ & $\overline{\mathrm{Al}}$ & 4.547 & $\overline{\mathrm{Al}}$ \\
\hline \multirow[t]{5}{*}{$\mathbf{A F}$} & 1.837 & 8.62 & 2.73 & 0.08 & 0.03 & 43.2 & 0.683 & L & Al & 4.710 & $\mathrm{Al}$ \\
\hline & 1.832 & 8.72 & 2.93 & 0.02 & 0.01 & 46.8 & 0.664 & L & $\mathrm{Al}$ & 5.028 & $\mathrm{Al}$ \\
\hline & 1.836 & 8.82 & 3.17 & 0.04 & 0.15 & 51.3 & 0.641 & L & $\mathrm{Al}$ & 5.416 & RX26 \\
\hline & 1.837 & 9.14 & 3.50 & 0.08 & 0.04 & 58.8 & 0.617 & L & Al & 5.988 & Al \\
\hline & 1.837 & 10.09 & 4.36 & 0.07 & 0.03 & 80.8 & 0.568 & L & Al & 7.493 & $\mathrm{Al}$ \\
\hline
\end{tabular}


Table 6-5, part 2

\begin{tabular}{|c|c|c|c|c|c|c|c|c|c|c|c|}
\hline \multirow{3}{*}{$\begin{array}{c}\text { Explo- } \\
\text { sive }\end{array}$} & \multirow{3}{*}{$\begin{array}{c}\text { Den- } \\
\text { sity } \\
\text { g/cc }\end{array}$} & \multicolumn{4}{|c|}{ all $\mathrm{mm} / \mu \mathrm{s}$} & \multirow{3}{*}{$\begin{array}{c}\text { Pres- } \\
\text { sure } \\
\text { (GPa) }\end{array}$} & \multirow{3}{*}{$\begin{array}{l}\text { Vol- } \\
\text { ume } \\
\mathbf{v}\end{array}$} & & \multirow{3}{*}{$\begin{array}{l}\text { Flyer } \\
\text { plate }\end{array}$} & \multirow{3}{*}{$\begin{array}{c}\text { Flyer } \\
\mathrm{mm} / \\
\mu \mathrm{s}\end{array}$} & \multirow{3}{*}{$\begin{array}{c}\text { Buffer } \\
\text { plate }\end{array}$} \\
\hline & & \multicolumn{2}{|c|}{ Velocity } & \multicolumn{2}{|c|}{ Listed error } & & & & & & \\
\hline & & $\overline{\mathrm{U}_{\mathrm{s}}}$ & $\overline{u_{p}}$ & $\mathrm{U}_{\mathrm{s}}$ & $\overline{u_{p}}$ & & & & & & \\
\hline \multirow[t]{7}{*}{ LX-17 } & 1.906 & 7.70 & 2.222 & 0.04 & 0.02 & 32.6 & 0.711 & $\mathbf{L}$ & $\mathrm{Al}$ & 3.813 & Al \\
\hline & 1.903 & 7.70 & 2.223 & 0.04 & 0.02 & 32.6 & 0.711 & $\mathbf{L}$ & $\mathrm{Al}$ & 3.813 & LX17 \\
\hline & 1.901 & 8.02 & 2.563 & 0.04 & 0.01 & 39.1 & 0.680 & $\mathbf{L}$ & $\mathrm{Al}$ & 4.400 & LX17 \\
\hline & 1.898 & 7.98 & 2.569 & 0.04 & 0.01 & 38.9 & 0.678 & $\mathbf{L}$ & $\mathrm{Al}$ & 4.400 & LX17 \\
\hline & 1.905 & 8.00 & 2.587 & 0.02 & 0.01 & 39.4 & 0.677 & $\mathbf{L}$ & Al & 4.436 & LX17 \\
\hline & 1.903 & 8.44 & 3.134 & 0.04 & 0.02 & 50.3 & 0.629 & $\mathbf{L}$ & Al & 5.355 & LX17 \\
\hline & 1.902 & 8.60 & 3.284 & 0.03 & 0.01 & 53.7 & 0.618 & $\mathbf{L}$ & $\mathrm{Al}$ & 5.612 & $\mathrm{Al}$ \\
\hline
\end{tabular}




\section{Chapter 7. TATB Nonideality}

\section{Detonation Front Curvature}

LX-17, which is based on TATB, is the LLNL version of a nonideal explosive. It is not very nonideal, nothing like a composite explosive. However, it was the first LLNL production explosive to substantially deviate from classical behavior. We noted in the preceding chapter how the cylinder JWL detonation pressure, $P_{j}$, is significantly lower than the impedance-match plate push pressure, $P_{d}$, which is caused by nonideality. This result caused confusion when the first LX-17 JWLs were made. Moreover, LX-17 has a size effect. The critical or failure diameter of $L X-17$ is listed as less than $9.4 \mathrm{~mm}$ for $20-\mu \mathrm{m}$ powder and between 6.4 and $9.5 \mathrm{~mm}$ for $60-\mu \mathrm{m}$ material. ${ }^{1}$ Campbell and Engelke found no detonation at diameters below $8 \mathrm{~mm}$ in bare rate sticks of PBX-9502 (95\% TATB, 5\% Kel-F).2

LLNL velocities for LX-17 increased slightly from 7.59 to $7.63 \mathrm{~mm} / \mu \mathrm{s}$ from the 25- to the 51-mm cylinder. The PBX-9502 sticks of 50-mm diameter showed a detonation velocity of $7.665 \mathrm{~mm} / \mu \mathrm{s}$, while a $108-\mathrm{mm}$ stick gave 7.729 $\mathrm{mm} / \mu \mathrm{s} .{ }^{3}$ There is no reason to suppose that $108 \mathrm{~mm}$ is infinite-diameter, but our largest 51-mm-diameter LX-17 shots certainly are not. We would estimate an infinite-size detonation velocity of about $7.69 \mathrm{~mm} / \mu \mathrm{s}$ for our LX-17 at $1.905 \mathrm{~g} / \mathrm{cc}$.

However, the curvature of its detonation front graphically gives the explosive a nonideal character not possessed by the other explosives so far considered in this report. The curvature of the detonation front is measured end-on in a cylinder test. A metal fixture over the end has a slit running across a diameter. Streak camera film is pulled past the slits as the detonation front arrives. The fastest part of the front along the axis of the cylinder arrives first at the film, and the explosive-metal interfaces arrive later. The lag of the detonation front may then be calculated from the streak-camera speed and the detonation velocity, which is the same over the entire front at steady state.

Five cylinder experiments have been run at LLNL, and the results are shown in Fig. 7-1 and Table 7-1. The first three-LX-04, LX-10, and LX-17did not have the end-slit on the diameter. Instead, the longest slit was displaced 1.0 to $2.5 \mathrm{~mm}$ from the diameter. The explosive-wall interface was difficult to see and the total picture of the cylinder top was distorted-which is why the radii listed in Table 7-1 are less than $50.8 \mathrm{~mm}$. For LX-04 and LX-10, other, more-off-center, slits were selected to obtain the best interface data, and an unknown amount of distortion affected these results. Recently, the slit was moved onto the diameter. The two subsequent RX-52 runs are excellent, with good interfaces and a complete diameter is observed. Both are TATB-based explosives. RX-52-AD contains 65 wt\% TATB, 31.9\% FEFO and 3.1 oil, and has 
a $1.81 \mathrm{~g} / \mathrm{cc}$ density. RX-52-AE contains $65.0 \%$ TATB and 35\% RX-44 lacquer. From Fig. 7-1, we note that the TATB/FEFO explosives show the same amount of curvature as the LX-17.

Also plotted in Fig. 7-1 is LANL data on PBX-9502 (95 wt\% TATB, 5\% Kel-F, $1.89 \mathrm{~g} / \mathrm{cc}$ ) kindly given us by John Bdzil. 4 Three different diameters of rate sticks are included, and we see the increased curvature of the detonation front as the diameter decreases. The data were taken on rate sticks, not cylinders, so there is no lateral confinement with copper. We see that there is more curvature with less confinement.

Of importance is the limiting angle of the detonation front with the cylinder wall. Lambourn and Swift define the angle $\Theta_{\mathfrak{c}}$ as the angle of incidence, that is, the angle between the detonation front and the normal to the wall. 5 This angle is hard to measure, and the LX-17 data in Fig. 7-1 are not good enough. The RX-52 data are better, and we analyze five points near the edge to obtain:

$$
\begin{array}{ll}
\text { RX-52-AD } & 12^{\circ}, 13^{\circ} \\
\text { RX-52-AE } & 12^{\circ}, 14^{\circ} .
\end{array}
$$

These data are in agreement with the British observation that an angle of about $12^{\circ}$ is seen for all explosives against any material. 6 The LANL data in Fig. 7-1 at 50-, 18-, and 12-mm diameters produce limiting angles of 27, 22, and $23^{\circ}$. The reason for the discrepancy, a factor of 2 , is not known at this time.

An outgrowth of the experimentally measured curved detonation front is the "corner-turning" mapping model of Lambourn and Swift (the WBL-for Whitham, Bdzil, Lambourn) ${ }^{5}$ and J. B. Bdzil (the DSD-for Detonation Shock Dynamics). ${ }^{7-9}$ In the code, a perpendicular basis vector is assigned to each element of the detonation surface. Let the angle between the basis vector and the direction of detonation along the cylinder axis be $\phi$. The detonation velocity, $D$, lies along the axis. The detonation velocity normal to the detonation front is $D \cos \phi$. The code is written so that the normal of the detonation velocity determines the position of the next element. Because the maximum curvature is next to the walls, corner-turning is allowed. The hydrocode can now run around corners using input from experiment, but without making any adjustments to the inherent EOS of the explosive. Fine zoning is needed if extreme curvature is to be shown accurately.

This approach requires that the detonation front curvature be measured and available as input. Some means must be found to modify the detonation velocity for different sizes of cylinders. The measured steady-state detonation velocity, $D_{s}$, in a cylinder is usually related to the infinite volume velocity, $D_{\infty}$, by 


$$
D_{s}=D_{\infty}(1-A / R),
$$

where $A$ is a constant and $R$ is the radius. The corner-turning models assign a velocity to each part of the curved front, $D_{\mathcal{K}}$, according to

$$
D_{\kappa}=D_{s}(1-\alpha \kappa),
$$

where $\kappa$ is the curvature at each point of the detonation front and $\alpha$ is a constant. The velocity, $D_{k}$, is perpendicular to the front at each point, and this provides a vector that causes motion away from the cylinder axis and around corners.

The corner-turning models all require actual data in order to derive Eqs. (2) and (3), which are input to the code. Detonation velocity is the only hard data that comes out of most detonation measurements so that explicitly including it as input seems reasonable and desirable. The program burn, which also uses explicit velocities, is the only initiation sequence used in a production code at LLNL. Neither the beta burn nor Ignition \& Growth require a detonation velocity - nor can it be seen in their outputs, short of measuring the difference between two graphs at different times. The presence of an explicit detonation velocity appears to be a necessary component in selling a production code.

Harold Zimmerman has compared the curvature phenomenon with the 1-D supracompression data in the previous chapter. For the size effect in cylinders, $\mathrm{D}_{\mathrm{s}}<\mathrm{D}_{\infty}$. He notes that Hull looked at colliding shock waves. ${ }^{10}$ Instead of finding a straight Mach stem between them, he found a concave shock front that agrees with Eq. (3), but here $\kappa$ is negative and $D_{S}>D_{\infty}$. Thus, for the same explosive, Eq. (3) holds with $U_{\mathrm{s}}$ passing continuously through the C-J (actually, the adiabat point). In order to have $\partial U_{s} / \partial u_{p}$ equal zero, $u_{p}$ would have to go through an infinite jump. Thus, $\partial \mathrm{U}_{\mathrm{s}} / \partial \mathrm{u}_{\mathrm{p}}$ is unequal to zero along this path. However, A. Nichols believes that the size effect in the cylinder is a different effect than initiation and that the colliding shock waves create states on a different Hugoniot.

\section{Summary of Measured Pressures and Theory}

The detonation pressures measured in this report often represent different things. To go further requires consideration of the basic theories. The old C-J Theory starts with detonation at the C-J point and an adiabat expanding to larger volumes. The JWL is made to fit this theory, although there is no reason why the JWL detonation point has to be the C-J point. In any case, the use of the JWL with program burn in hydrocodes predisposes its users to the C-J model. 
The newer ZND Theory (for Zeldovich, von Neumann, and Doring) starts with the solid explosive being compressed to the von Neumann spike. As the explosive burns, it drops down the Rayleigh Line to the C-J point and then moves down the adiabat. Time is introduced directly to slow the burning and spread out the reaction zone. The only $\mathrm{ZND}$ input to hydrocodes is Ignition \& Growth (I\&G or "Reactive Flow"). It has been used mainly on LX-17, usually to model initiation experiments. Craig Tarver has been the keeper of the model and the theory behind it for the last decade.

We first consider the C-J Theory. Fig. 7-2 schematically shows the P-v plane. The Rayleigh Line is A'I, with the initial explosive at $v=1$ at point I. In the conventional C-J detonation theory for an ideal explosive, the explosive is compressed up the Rayleigh Line to the C-J point at B. The gaseous products then expand down the adiabat BDF. At point $D$, where vB $\sim 0.91$ for $L X-17$, the energy of compression has been used to compress the next section of explosive, and the energy of detonation, $E_{\mathrm{d}}$, changes sign. The energy of detonation used to compress the next section of explosive is the area in the triangle, BDH. At larger volumes, the energy of detonation available externally (which totals $\mathrm{E}_{0}$ ) is the area inside FDHI, where F and I extend on to the right.

Next, we turn to the ZND Theory. In Fig. 7-2, the LX-17 is driven up the Rayleigh Line to the von Neumann spike at point A'. Here, the energy of compression from the preceding slice of explosive compresses the slightlyburned but mostly solid LX-17 to about $43 \mathrm{GPa}$ and $1800 \mathrm{~K}$. The explosive continues to burn and falls down the Rayleigh Line to the I\&G C-J point, A, at 26 to $27 \mathrm{GPa}$ and perhaps $2500 \mathrm{~K}$. At this point, the burn fraction, $\mathrm{F}$, is 1 . The products then expand down the adiabat ACE. The energy of compression in triangle ACG has been passed to the next zone of explosive by point $C$, which is at about $v_{A} \sim 0.93$ for LX-17. The energy of detonation available externally, $E_{0}$, lies in ECGI.

In ZND Theory, no energy of detonation is obtained as the explosive moves down the Rayleigh Line from the spike to the C-J point. The energy of compression is simply released to be passed to the next section of explosive. The C-J point in ZND Theory and I\&G lies at a lower pressure than it does in pure C-J theory. The volume at which $\mathrm{E}_{\mathrm{d}}=0$ is larger in I\&G, i.e., $\mathrm{v}_{\mathrm{A}}>\mathrm{v}_{\mathrm{B}}$. The external energy of detonation, $E_{0}$, is the same in both. Thus, the adiabats must cross one another.

We now try to summarize the two approaches using the data of the preceding two chapters. For a near-ideal explosive hitting a metal of thickness equal to the explosive's reaction zone, we may list these pressures:

$$
\left(\mathbf{P}_{\mathrm{k}}>\right) \mathrm{P}_{\mathrm{a}} \sim \mathrm{P}_{\mathrm{p}} \sim \mathrm{P}_{\mathrm{j}}>\mathrm{P}_{\mathrm{cj}}
$$


The spike pressure, $P_{k}$, is the highest, but the spike will not be seen in the jump-off of the metal plate. The pressure found from impedance-matching the plate shot, $P_{p}$, and the cylinder JWL, $P_{j}$, are essentially equal. In C-J Theory, one would equate these with the C-J pressure, $P_{c j}$. However, thermochemical codes give" lower pressures so that the nonequilibrium adiabat pressure, $P_{a}$, is the inherent explosive property. We recall that the adiabat pressure is the point at which an infinite-size, steady-state (but not equilibrated) explosive leaves the Rayleigh Line and moves onto the Principal Adiabat. In I\&G, the C-J point, a true thermodynamic equilibrium point, is probably never reached.

We next summarize the various detonation pressures obtained for five explosives in this report. We have these results, where the plus/minus values are precision:

\begin{tabular}{ccccccc} 
& $\begin{array}{c}\text { 1-D Plate, } P_{p} \\
\text { Jump- } \\
\text { off } \\
\text { velocity }\end{array}$ & $\begin{array}{c}\text { Supra- } \\
\text { com- } \\
\text { press }\end{array}$ & $\begin{array}{c}\text { Cylinder } \\
\text { Jump- } \\
\text { off } \\
\text { vel., } P_{p}\end{array}$ & $\begin{array}{c}\text { 3-point } \\
\text { JWL } \\
\text { Fit, } P_{j}\end{array}$ & $\begin{array}{c}\text { Haselman } \\
\text { compres-. } \\
\text { sion, } P_{p}\end{array}$ & $\begin{array}{c}\text { TIGER } \\
\text { BKWR } \\
P_{c j}\end{array}$ \\
\hline LX-14 & $\mathbf{3 5} \pm 2$ & & $37 \pm 3$ & $38 \pm 2$ & 36 & 35 \\
PBX-9404 & $39 \pm 2$ & $38 \pm 2$ & $34 \pm 5$ & $38 \pm 2$ & 37 to 39 & 36 \\
PETN & $32 \pm 4$ & $31 \pm 2$ & $31^{*} \pm 3$ & $32 \pm 2$ & & 31 \\
RX-26-AF & & $34 \pm 2$ & $36 \pm 2$ & $34 \pm 2$ & 32.5 & 32 \\
LX-17 & 34 & $32 \pm 2$ & $32 \pm 4$ & $26 \pm 1$ & 30 & 27
\end{tabular}

The detonation pressures for the plate are those taken at the end of the reaction zone and represent the closest approach to C-J. The asterisk reminds us that PETN is set to $31 \mathrm{GPa}$ for the cylinder jump-off, and the others are calculated from it.

For the first three explosives in Eq. (5), based on nearly ideal HMX and PETN, we see that the detonation and JWL pressures are in agreement. These would be called C-J pressures in C-J Theory, but the thermochemical codes always say that true equilibrium is 1 to $3 \mathrm{GPa}$ lower. Our agreement breaks down for LX-17, where the jump-off and supracompression pressures are much higher than the JWL and calculated C-J pressures. We also recall that $26 \mathrm{GPa}$ was consistent with a detonation pressure in the cylinder as obtained by comparing the percent of kinetic energy put into wall motion. We also note that the 34 and $26 \mathrm{GPa}$ values found for LX-17 fit Tarver's values assigned to the spike and adiabat pressures, respectively, in the I\&G model.

We now consider the data on the spike obtained from plates. The classic effect of plate thickness for LX-14 was seen in the previous chapter. The detonation pressures are determined by the impedance-match equation. There, thin plates showed a 44-GPa spike pressure, whereas at the 0.1-mm zone boundary, the pressure was about $36 \mathrm{GPa}$, in agreement with the other data. 
The corresponding data for LX-17 are shown in Fig. 7-3 for copper and tantalum plates. The spike pressure is about 38 to $39 \mathrm{GPa}$ and the near-C-J pressure at the zone boundary of $2 \mathrm{~mm}$ is $34 \mathrm{GPa}$. These numbers are higher than those obtained by I\&G and by the efficiency and JWL fit in the cylinder. It appears that the impedance-matching pressure equation does not work for LX-17.

Hugoniot measurements on unreacted $\mathrm{LX}-17$ have been made to $16 \mathrm{GPa}$, over halfway to the detonation point. ${ }^{11}$ Tarver estimates from I\&G that only a few percent have reacted at the spike. Hence, the initial shock delivered to a metal plate is by mostly solid LX-17 moving at $7.63 \mathrm{~mm}$. The shock wave delivered to a metal wall is a thin-pulse spike.

We return to the impedance-match equation derived in the previous chapter. It is

$$
P_{m}=P_{p}+\rho_{o} U_{0}\left(u_{p}-u_{m}\right),
$$

where $P_{m}$ is the pressure in the metal, $P_{p}$ the pressure in the explosive, $u_{p}$ the instantaneous particle velocity in the explosive, and $u_{m}$ the particle velocity on the confined face of the metal. The LX-17 has not turned into gaseous products, so the Acoustic Approximation is literally true. All of Eq. (6) seems fine; the problem apparently arises with the relation

$$
\mathrm{u}_{\mathrm{m}}=\mathrm{Gu}_{\mathrm{fs}},
$$

where $u_{f s}$ is the free surface particle velocity and $G=1 / 2$ for a wide pressure pulse. We suggest that, for a projectile of solid LX-17, the pressure pulse is so thin the rarefaction wave degrades the velocity of the shock wave in the metal. Then, a smaller number is doubled at the unconfined face, and $G>1 / 2$. The result would be to lower the detonation pressure calculated by the impedancematch equation.

\section{The Ignition and Growth Model}

We shall now briefly describe the I\&G model created by Cochran and Chan. 12 It uses three sets of equations: a solid explosive EOS, a reaction products EOS, and a set of burn rate commands. A. Nichols notes that the JWLs are the EOSs, and the rate equations are hydrocode pulse-shaping commands-no different from program or beta-burn. However, the kinetic behavior is so deeply imbedded in the model that the entire package soon becomes considered an EOS.

We recall that the EOS usually used is the JWL, in which the pressure adiabat is 


$$
P_{s}(v)=A \exp \left(-R_{1} v\right)+B \exp \left(-R_{2} v\right)+C v-(1+\omega) .
$$

In the I\&G model, the EOS is called the Gruneison form of the JWL, and it is

$$
P_{S}(v)=R_{1} \exp \left(-R_{5} v\right)+R_{2} \exp \left(-R_{6} v\right)+R_{3} T / v,
$$

where the terminology used in the new DYNA2D manual will be used throughout. ${ }^{13}$ Eq. (8) is not the same as Eq. (9). The third term in this EOS is simply replaced by a different kind of function. Because of this, any fitting routine will likely produce a different set of $R_{i}$ in place of $A$ and $B$.

All other codes have only the product EOS, but I\&G has two: the explosive (reactant) EOS,

$$
P_{s e}(v)=R_{1 e} \exp \left(-R_{5 e} v\right)+R_{2 e} \exp \left(-R_{6 e} v\right)+R_{3 e} T / v
$$

and the product EOS,

$$
P_{s p}(v)=R_{1 p} \exp \left(-R_{5 p} v\right)+R_{2 p} \exp \left(-R_{6 p} v\right)+R_{3 p} T / v \text {. }
$$

The EOSs are identical in structure. However, the explosive EOS is a Hugoniot, and the product EOS is an adiabat used as a Hugoniot above the adiabat point. The intent is to blend them while the explosive burns between the spike and adiabat points.

The constant $R_{3}$ may be written

$$
R_{3}=\omega c_{v}
$$

where $c_{v}$ is a constant with the appearance of a heat capacity at constant volume.

The fraction of explosive reacted in each element is $F$, which starts at perhaps 0.03 to 0.06 and ends fully burned at 1 . The burning rate is

$$
\partial \mathrm{F} / \partial \mathrm{t}=\partial \mathrm{F} /\left.\partial \mathrm{t}\right|_{1}+\partial \mathrm{F} /\left.\partial \mathrm{t}\right|_{2}+\partial \mathrm{F} /\left.\partial \mathrm{t}\right|_{3} .
$$

where the burning process moves through terms 1,2 , and 3 in order.

The initiation term is

$$
\partial F / \partial t I_{1}=F_{q}(1-F)^{F_{F}}\left[\frac{1}{v_{e}}-1-C_{c r i t}\right]^{\eta}
$$


where $v_{e}$ is the relative volume of the solid explosive and $F_{q}, F_{r}, C_{c r i t}$, and $\eta$ are constants. This term is needed to start an explosive burn with a low-level trigger such that initiation may fail or take some time to get started. It probably is not needed in detonation caused by a detonator, but it can be used to turn on the detonation faster than can be done with a program burn.

The $\mathrm{G}_{1}$ growth term in DYNA2D is the only such term when two terms (the other being initiation) are used. When three terms are used, it is the fastgrowth kinetics term. This term is

$$
\partial F / \partial \mathrm{l}_{2}=G_{1}(1-F)^{s_{1}} F^{a_{1}} P_{s}^{m},
$$

where $G_{1}, s_{1}$, and $a_{1}$ are constants. One might expect the rate to go only as a function of $(1-F)$. C. Tarver says that the $(1-F) F$ form is included to bring the rate in the code gently to zero as $\mathrm{F} \rightarrow 1$.

It is the $G_{1}$ growth term, with its pressure dependence, that creates the curved detonation front in a cylinder. The rarefaction wave at the cylinder wall lowers the pressure in the adjacent explosive. This turns down the reaction rate during initiation so that the explosive at the walls burns more slowly. For a slow initiation, the calculated curvature is very large and obvious. As it approaches steady state, the detonation front tries to straighten out. At steady state, the curvature is much more gentle.

The $\mathrm{G}_{2}$ growth term represents slow kinetics when three terms are used. It is not included for the two-term model. It is

$$
\partial F / \partial \mathrm{t}_{3}=G_{2}(1-F)^{s_{2}} F^{a_{2}} P_{s}^{n},
$$

where $G_{2}, s_{2}$, and $a_{2}$ are constants. Because this term is always dropped in the two-term model, confusion with the $\mathrm{G}_{1}$ coefficients can easily result.

Originally, the second growth term was added as a fast-growth term to describe thin-pulse initiation. Therefore, the $\mathrm{G}_{1}$ term is slow for the two-term description of LX-17, but the $\mathrm{G}_{2}$ term is slow for the three-term model. This is locked in by the limits set on $F$ for the various terms. Looking across a table of I\&G constants does not allow easy comparison.

By the time the second growth term is done, $F=1$ and the adiabat point is reached for an infinite diameter explosive. For a smaller charge, the adiabat point is never reached, and the adiabat starts from a sonic point. The adiabat point is not equated with the C-J point because we cannot be sure that this point really is at thermodynamic equilibrium.

Table 7-2 lists the I\&G constants found for all explosives run with I\&G at LLNL.14-26 For convenience, we list some of the compositions in wt \% and with names. Comp B is RDX 63, TNT 36, and wax 1 . H-6 is RDX 45, TNT 30, 
$\mathrm{Al} \mathrm{20,} \mathrm{wax} \mathrm{5,} \mathrm{and} \mathrm{CaCl}_{2}$ 0.5. LX-10 is $\mathrm{HMX} 90$ and Viton A 5. Propellant $\mathrm{B}$ is AP 88 and HMX 12. RX-03-BB is the experimental ancestor of LX-17. RX-25$\mathrm{BF}$ is $\mathrm{HMX} 38.4, \mathrm{AP} 35.5, \mathrm{ZrH}_{2} 22.1$, and estane 4.0. $\mathrm{RX}-35-\mathrm{BH}$ has the same components, but with values of $19.3,47.1,29.8$, and 3.8. RX-26-AF is TATB 46.6, HMX 49.3, and estane 4.1. RX-HD, an ANFO explosive, is 78.65, water 9.45 , calcium nitrate 5.52 , fuel 6.38 , and plastic microballoons 0.08 .

For the PETN/Al and TNT/Al explosives, we list wt\%, names with 5- $\mu \mathrm{m}$ aluminum, and names with $18-\mu \mathrm{m}$ aluminum. For PETN/Al, they are 95/5 RX-40-AI, RX-40-AF; 90/10 RX-40-AJ, RX-40-AG; 80/20 RX-40-AK, and RX-40-AH. For TNT/AL, we have 95/5 RX-40-CI, RX-40-CF and 90/10 RX-40-CJ and RX-40-CG.

Most I\&G runs are for initiation, but a few are for the overdriven or supracompressed explosive; LX-17 has a set for both. In the ignition model, where the detonation pressure starts below $26 \mathrm{GPa}$, the three terms, in order, describe (1) hot-spot creation, (2) hot-spot spreading, and (3) hot-spot coalescing. The supracompression model, for detonation pressures greater than $26 \mathrm{GPa}$, has the three terms refer to (1) ignition, (2) the main explosive reaction to product gases, and (3) precipitation of carbon. For the third term, Tarver has set the exponent equal to 1 , so we have

$$
\partial \mathrm{F} / \partial \mathrm{tI}_{3}=\mathrm{G}_{2}(1-\mathrm{F}) \mathrm{FP}_{\mathrm{s}},
$$

which looks more like traditional kinetics with a pressure to the first power.

One possibility is that carbon condensation occurs after the sonic point. If it does, I\&G cannot properly describe it. Tarver, however, notes the work of Kolomiichuk and Mal'kov on ultradispersed diamond as seen by $x$-ray diffraction in the final debris of PETN, TNT, and other explosives. ${ }^{27}$ These authors varied the diameter of their charges by a factor of 10 and the mass by a factor of 40 but saw no appreciable change in the size of the diamond distributions. Because only the reaction zone width is invariant to sample size, the authors concluded that all diamond condensation occurs in the reaction zone, i.e., before the adiabat point.

We return to the listing of the I\&G constants. These constants are used according to these rules:

$$
\begin{aligned}
& \partial \mathrm{F} /\left.\partial \mathrm{Fl}\right|_{1} \rightarrow 0 \text { when } \mathrm{F} \geq \mathrm{F}_{\max , \mathrm{ig}}, \\
& \partial \mathrm{F} /\left.\partial \mathrm{F}\right|_{2} \rightarrow 0 \text { when } \mathrm{F} \geq \mathrm{F}_{\max , \mathrm{gr}}, \\
& \partial \mathrm{F} /\left.\partial \mathrm{F}\right|_{3} \rightarrow 0 \text { when } \mathrm{F} \leq \mathrm{F}_{\min , \mathrm{gr}} .
\end{aligned}
$$

$F_{\max , \text { ig }}$ and $F_{\min , g r}$ set the upper limits of the terms. In the 1985 version, both terms 1 and 2 can run to $F=0.5$, but Tarver says that the first term rarely 
turns on more than about 0.03 . In the 1989 version, the first term is limited to 0.0232 while the second term runs on to 0.85 . The third term takes over from the second and may or may not run all the way to 1.00 .

The I\&G model can also model slow-reacting aluminized explosives. The fast-growth term now becomes the total descriptor for the base explosive, and the slow-growth term describes the reaction of its products with the aluminum. In DYNA2D, two EOSs are now used, although C. Tarver has used up to five in the past. A. Nichols has recently introduced a three-EOS model into CALE. It has two temperature-dependent product JWLs-one for the main explosive and the other for the aluminized products. The first EOS is used with the fastgrowth term and the second EOS with the slow-growth term. The fastexplosive EOS was created from CHEQ and represents the $\mathrm{C}, \mathrm{H}, \mathrm{N}$, and $\mathrm{O}$ gaseous products of the explosive itself. The slow aluminized EOS was created from TIGER BKWR, which is, at present, the only code that includes gaseous aluminum compounds. This EOS has the solid product $\mathrm{Al}_{2} \mathrm{O}_{3}$, plus what is left from the reaction with the second EOS gases. A three-term EOS can also be considered for the carbon coagulation problem. The second EOS would be identical to the $\mathrm{C}, \mathrm{H}, \mathrm{N}, \mathrm{O}$ gas EOS above, and the third EOS contains solid carbon plus gas.

The idea of simplifying I\&G to freshen it up has recently become popular. M. Murphy et al. have taken out the fast-growth term and returned to the original two-term formulation, which is useful for certain problems. ${ }^{19}$ They also realized that a major drawback was the lack of physical reality in the constants, which they tried to relate to measurable quantities. They related the exponent $\mathrm{n}$ in the slow growth term to the slope of the run distance-todetonation (Pop) plots. This slope, $\Delta \ln x / \Delta \ln P$, is about $3.5 \mathrm{~mm} / \mathrm{GPa}$ for $\mathrm{LX}-17$ and about $1.5 \mathrm{~mm} / \mathrm{GPa}$ for PBX-9404 and Comp B. They suggested that these numbers be related to the exponents 3 and 2, respectively, in the I\&G model.

Murphy et al. estimated the amplitude of the slow-growth term, $\mathrm{G}_{2}$ (in $\mu s^{-1}$ ) for Weapons Grade Comp B as

$$
\mathrm{G}_{2} \sim 1800 / \mathrm{D}_{\mathrm{f}} \text { for } 4.4<\mathrm{D}_{\mathrm{f}}<7.2 \mathrm{~mm},
$$

where $D_{f}$ is the failure diameter. For Comp B, one expects the slow growth term to represent carbon coagulation, so this effect presumably is the key to nonideality in this case.

Harold Zimmerman has suggested some additions for the next-stage I\&G model. The current model assumes that the reactant and the products are at the same temperature. This, in turn, requires small zoning in order to imagine a real volume where this might be so. In fact, it is doubtful that temperature equilibrium exists even in a small volume. Zimmerman wants to go to larger zones, in which reactant and products will be tracked separately in each element for volume, pressure, and artificial viscosity, $Q$. This approach 
leads to separate temperatures. His hope is that all the parameters can be kept track of "subzonally," thereby allowing the use of larger zones. Again, the reactant and products will be described by the temperature-dependent JWLs, and the C-term will be temperature-dependent.

\section{Inner Workings of I\&G}

The only detailed discussion of the I\&G model has been given by Cochran and Chan. ${ }^{12}$ They describe two versions of the model with significant differences when only part of the explosive is burned. The first and more physical model is used in DYNA2D. Here, there is pressure equilibration between the reactant and products. The equations are

$$
\begin{aligned}
& P(v, T, F)=P_{e}\left(v_{e}, T\right)=P_{r}\left(v_{r}, T\right), \\
& E=(1-F) E_{s e}\left(v_{e}, T\right)+F E_{s r}\left(v_{r}, T\right)-\text { constant, } \\
& v=(1-F) v_{e}+F v_{p} .
\end{aligned}
$$

Many of the code iterations involve a variable $\beta$, which is called a real volume fraction occupied by the specific material. 12 The volume relations are:

$$
\begin{aligned}
& v_{e}=\beta v /(1-F) \\
& v_{p}=(1-\beta) v / F \\
& v=v_{e} v_{p} /\left[v_{p} \beta+v_{e}(1-\beta)\right] .
\end{aligned}
$$

This method required considerable reiteration to get the pressures and was considered too slow. A second and less physical method was devised and used in KOVEC and HEMP. The pressures and energies were split into mechanical (function of volume only) and thermal parts (volume and temperature). This is the form of the temperature-dependent JWLs listed above, where the $R_{1}$ and $R_{2}$ terms are mechanical and the $R_{3}$ term is thermal. The mechanical pressure, $P_{m}$, and the energy, $E_{m}$, are related by

$$
\partial \mathrm{E}_{\mathrm{m}} / \partial \mathrm{v}=-\mathrm{P}_{\mathrm{m}}
$$

The pressure then becomes

$$
P(v, T, F)=(1-F) P_{e}(v, T)+F P_{r}(v, T) .
$$


We are now using the concept of partial pressures with no need to keep track of separate volumes; also,

$$
E=(1-F) E_{S}(v, T)+F E_{S}(v, T)-\text { constant. }
$$

In both models, there is no apparent requirement of temperature equilibrium between the two parts. A total thermal energy, $E_{t}$, is calculated and an overall temperature computed using

$$
\mathrm{T}=\left(\mathrm{E}_{\mathrm{t}}+\mathrm{Q}\right) / \mathrm{c}_{\mathrm{v}}
$$

where $Q$ is the artificial viscosity. $D$. Sharp has noted that one of the functions of $Q$ is to add entropy to a model that doesn't otherwise have it. Eq. (31) shows how the entropy of the shock translates into additional temperature.

\section{Results from the I\&G Model}

Fig. 7-4 shows the curvature of the steady-state detonation front in LX-17 using the two-term I\&G model in DYNA2D. The cylinder was $12 \mathrm{~cm}$ long and $50 \mathrm{~mm}$ in diameter with 13,920 zones-12,000 of them in the explosive. The explosive was 50 elements wide $(0.16 \mathrm{~mm} / \mathrm{zone})$ compared to 12 in the standard cylinder model. A merged explosive-wall configuration was used. A programmed burn was used to start the burn before it switched to I\&G. This is a coarse-zoned run, but it took about 5 times as long as a programmed burn of the same zoning. Cycle times were 25 to $30 \mu$ s as compared with 5 to 6 with a programmed burn, and zone-tangling was pronounced.

The curvature in Fig. 7-4 agrees with the data in Fig. 7-1, although it does not appear to do so because Fig. 7-1 magnifies the lag in the detonation front, whereas Fig. 7-4 has the same magnification throughout. We see that the curvature is really not very great for LX-17. The calculated maximum pressure in the center of the cylinder is $30 \mathrm{GPa}$, which drops to $24 \mathrm{GPa}$ at the wall.

We may compare the $0.16-\times 0.16-\mathrm{mm} / \operatorname{explosive~zone~sizing~in~the~I\& G~}$ model with the $0.05-\times 1-\mathrm{mm} /$ zone size used by John Walton in HEMP to describe the standard PETN JWL in Chapter 3. The I\&G zoning is a factor of four greater in number of zones. Moreover, the HEMP zoning used to get the oscillations right in the metal far exceeds anything used in the I\&G model.

LX-17 was modeled in HEMP using the 1985 three-term model by Aldis, Quirk, and Breithaupt. 28 They report good agreement for LX-17 in copper cylinders but some deviation in the single tantalum shot. L. Haselman's view of the HEMP runs was that the energy was low even with I\&G. Tarver states that the constant $R_{3 p}$ term is the reason for this. An average heat capacity of the detonation products is used to cover $2000 \mathrm{~K}$, and any changes in the 
experimental details can affect this term by $5 \%$. The constant $R_{3 p}$ was developed from copper cylinders and should be changed for tantalum. We note that the $1985 \mathrm{JWL}$ was based on the cylinder JWL, which was also low in energy. Finally, we have noted above that the I\&G models are different in HEMP and DYNA, so that Tarver and Aldis could have gotten different results with the same EOS.

\section{Estimating the Reactant and Product JWLs}

We next consider the estimating of temperature-dependent JWLs. For the unreacted explosive, Tarver often uses the rule of thumb

$$
\mathrm{R}_{5 \mathrm{e}} \sim \mathrm{10R}_{6 \mathrm{e}} .
$$

At $\mathrm{v}=1$ and zero pressure, another constraint appears as

$$
R_{1 e} \exp \left(-R_{5 e}\right)+R_{2 e} \exp \left(-R_{6}\right) e+R_{3 e} T_{0} \simeq 0,
$$

where $T_{0}$ is $298 \mathrm{~K}$. The constant $c_{v}=R_{3 e} / \omega$ is not a real heat capacity taken from the thermodynamic literature but is a constant of the fit.

The derivation of the product EOS is more critical. The simplest way to connect this with the temperature-dependent JWL is to define the temperature function

$$
\mathrm{T}(\mathrm{v})=\mathrm{M} / \mathrm{v}^{\mathrm{n}},
$$

which we substitute into the temperature-dependent JWL. At the detonation point of the JWL, we have

$$
\begin{aligned}
\mathrm{dP}_{\mathrm{j}} / \mathrm{dv}_{\mathrm{j}}=-\rho_{0} \mathrm{D}^{2}= & -R_{1 \mathrm{p}} R_{5 p} \exp \left(-R_{5 p} v_{j}\right)-R_{2 p} R_{6 p} \exp \left(-R_{6 p} v_{j}\right) \\
& -(n+1) R_{3 p} M / v_{j}{ }^{n+2} \\
P_{j}= & R_{1 p} \exp \left(-R_{5 p} v_{j}\right)+R_{2 p} \exp \left(-R_{6 p} v_{j}\right)+R_{3 p} M / v_{j}{ }^{n+1} \\
E_{s}(j)= & \left(R_{1 p} / R_{5 p}\right) \exp \left(-R_{5 p} v_{j}\right)+\left(R_{2 p} / R_{6 p}\right) \exp \left(-R_{6 p} v_{j}\right) \\
& +R_{3 p} M / n v_{j}{ }^{n}
\end{aligned}
$$

These are the same equations as those of the regular JWL, where

$$
\mathrm{C} \longleftrightarrow \mathrm{R}_{3 \mathrm{p}} \mathrm{M}
$$

and 
This equality is the result of the temperature fit and not the result of mathematical equality. As an example, for $1.763 \mathrm{~g} / \mathrm{cc}$ PETN we obtain for the detonation point and volumes of $1.87,2.2,4.1$, and 6.5 the calculated temperatures of $3338,1798,1630,1181$, and $968 \mathrm{~K}$, respectively. This can be fit to

$$
\mathrm{T}=2684 / \mathrm{v}^{0.573},
$$

so that $M=2684$ and $n=0.573$. The latter is accidentally close to the 0.57 for $\omega$ in the regular JWL. Leaving $n$ as 0.57 , we have

$$
R_{3 p}=C / M=0.0372735 / 2684=1.389 e-5 \text {. }
$$

This allows the quick creation of the temperature-dependent JWL, here with identical $A$ and $B$ terms. If $\mathbf{n}$ had been different, $A$ and $B$ would have changed somewhat. It is important to remember that the temperature calibration is unknown and uncertain both in TIGER and in the hydrocode where the JWL will be used. Hence, the use of the new JWL will be empirically judged by the hydrocode results for that problem.

\section{Changes for a Future Production Model}

The present I\&G model depends on the symmetry of its JWLs and cannot easily be changed. Also, there will always be a need for a full-scale scientific version of I\&G. However, there is a real and immediate need for a faster, less complicated production version of I\&G. The following ideas might be considered.

- Use of the partial pressure mixing rule for computational speed.

- Explicit use of the detonation velocity, with linking to the corner-turning models. The detonation velocity, as a function of distance from the initiator, would be used as an advanced kind of programmed burn.

- Use of a nontemperature-dependent product EOS, with the regular JWL being the most obvious.

- Use of a $U_{\mathrm{s}}-u_{\mathrm{p}} \mathrm{EOS}$ for the unreacted explosive. 
We may further consider the unreacted EOS. One drawback of the JWL form, as M. Murphy et al. have noted, ${ }^{23}$ is that real data don't come in this format. They come as the constants $C_{0}$ and $S_{1}$ in the equation

$$
\mathrm{U}_{\mathrm{s}}=\mathrm{C}_{\mathrm{o}}+\mathrm{S}_{1} \mathrm{u}_{\mathrm{p}}
$$

From mass conservation comes,

$$
u_{p}=U_{s}(1-v)
$$

and from mass and momentum conservation

$$
\mathrm{P}=\rho_{\mathrm{o}} \mathrm{U}_{\mathrm{s}} \mathrm{u}_{\mathrm{p}}
$$

We substitute Eq. (42) into Eq. (43), eliminate $u_{p}$, and solve for $U_{s}$ to get

$$
\mathrm{U}_{\mathrm{s}}=\frac{\mathrm{C}_{\mathrm{o}}}{\mathrm{S}_{1}(\mathrm{v}-1)+1}
$$

We substitute Eqs. (42), (43), and (45) into Eq. (44) to obtain the $\mathrm{U}_{\mathrm{s}}-\mathrm{u}_{\mathrm{p}}$ EOS

$$
P_{e}=\rho_{o} C_{0}^{2} \frac{1-v}{\left[S_{1}(v-1)+1\right]^{2}}
$$

This is the Hugoniot of the unreacted explosive.

Eq. (46) runs upward in pressure until it intersects the Rayleigh Line, defined by

$$
P=\rho_{0} D^{2}(1-v) .
$$

We eliminate pressure between Eqs. (45) and (47) to obtain the spike volume

$$
\mathrm{v}_{\mathrm{k}}=\frac{1}{\mathrm{~S}_{1}}\left(\frac{\mathrm{C}_{\mathrm{o}}}{\mathrm{D}}-1\right)+1
$$

The spike pressure is then calculated from Eq. (47).

$$
P_{k}=\rho_{0} D^{2}\left(1-v_{k}\right)
$$


The two EOSs may be compared for LX-17. We calculate below the Spike pressure and the $\mathrm{v}=1$ pressure using both the temperature-dependent JWL but also the older regular JWL. A temperature of $1800 \mathrm{~K}$ at the Spike point was obtained from C. Tarver and used in the calculation. For LX-17, $\mathrm{C}_{0}=$ $2.74 \mathrm{~mm} / \mu \mathrm{s}$ and $S_{1}=2.6 \mathrm{~mm} / \mu \mathrm{s} .{ }^{29}$ We get these results:

\begin{tabular}{cll} 
& Volume & $\begin{array}{c}\text { Pressure } \\
\text { (GPa) }\end{array}$ \\
\hline Regular JWL & 0.676 & 35.5 \\
& 1.00 & 2.3 \\
T-dependent JWL & 0.695 & 33.5 \\
& 1.00 & 0.7 \\
$\mathrm{U}_{\mathrm{s}}-\mathrm{u}_{\mathrm{p}}$ & 0.701 & 33.2 \\
& 1.00 & 0.0
\end{tabular}

We see that neither JWL is near zero pressure for $v=1$. However, the form of the $U_{\mathrm{s}}-u_{\mathrm{p}}$ EOS forces it to be zero for the initial state of the explosive. It is, in effect, a specialized EOS that runs from $v=1$ to compressed states.

Mike Murphy has suggested that the $U_{\mathrm{s}}-u_{\mathrm{p}}$ EOS be used in the codes so that more convenient input can be used. ${ }^{23}$ This EOS usually appears with the substitution

$$
\mu=\frac{1}{\mathrm{v}}-1=\frac{\rho}{\rho_{\mathrm{o}}}-1
$$

Then, Eq. (51) becomes

$$
P_{e}=\frac{\rho_{o} \mu(1+\mu) C_{o}^{2}}{\left[1-\left(S_{1}-1\right) \mu\right]^{2}}
$$

Another form is derived from the Gruneison EOS form of

$$
P_{e}=\gamma_{0} E_{e} / v+f(v)
$$

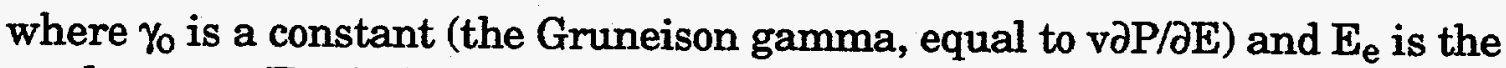
total energy. Eq. (52) is substituted into Eq. (53), which is solved for f(v). This is put back into Eq. (53) to obtain 


$$
P_{e}=\frac{\rho_{o} \mu(1+\mu) C_{o}^{2}}{\left[1-\left(S_{1}-1\right) \mu\right]^{2}}\left(1-\frac{\gamma_{o}}{v} \mu\right)+\frac{\gamma_{o}}{v} E_{e}
$$

This is the energy form, and it is comparable to the pressure-energy form of the JWL in Chapter 2, Eq. (15). It is not comparable to the temperaturedependent JWL, in which $c_{\mathrm{v}} \mathrm{T}$ is a thermal energy, not a total energy. A disadvantage of Eq. (54) is that another constant needs to be known.

Eqs. (51) and (52) constitute the simplest unreacted explosive EOS given that only $C_{0}$ and $S_{1}$ are available. A major problem is that the $U_{s}-u_{p}$ data may not be very good. Sometimes the fit is so bad that $C_{0}$ is just a constant and does not equal the speed of sound. At the moment, finding decent two-constant data appears more difficult than adding a third constant, $\mathbf{S}_{2}$. Also, measured unreacted data and even a measured detonation velocity may not be available. In this case, one can calculate the C-J pressure and volume and the detonation velocity from TIGER. Then, add 2 GPa to the C-J pressure to approximate the adiabat pressure and calculate the detonation volume on the Rayleigh Line. Then, as a rough summary suggested by $\mathrm{C}$. Tarver, use the relation

$$
P_{k} / P_{j} \sim 1.25
$$

The volume ratio, $v_{k} / v_{j}$ will be about 0.94 .

\section{References}

1. B. M. Dobratz and P. C. Crawford, LLNL Explosives Handbook, Lawrence Livermore National Laboratory, Livermore, CA, UCRL-52997 (1985), pp. 8-32.

2. A. W. Campbell and R. Engelke, "The Diameter Effect in HighDensity Heterogeneous Explosives," Proceedings Sixth Symposium (international) on Detonation, Coronado, CA, August 24-27, 1976, p. 642.

3. A. W. Campbell, Propellants, Explosives, Pyrotechnics 9, 183 (1984).

4. J. B. Bdzil, Los Alamos National Laboratory, Los Alamos, NM, 87545, private communication, 1993.

5. B. D. Lambourn and D. C. Swift, "Application of Whitham's Shock Dynamics Theory to the Propagation of Divergent Detonation Waves," Proceedings Ninth Symposium (International) on Detonation, Portland, OR, August 28-September 1, 1989, pp. 784-797. 
6. D. C. Swift, AWE, Aldermaston, England, private communication, 1993.

7. J. B. Bdzil, J. Fluid Mech. 108, 195 (1981).

8. D. S. Stewart and J. B. Bdzil, "Examples of Detonation Shock Dynamics for Detonation Wave Spread Applications," Proceedings Ninth Symposium (International) on Detonation, Portland, OR, August 28September 1, 1989, pp. 773-783.

9. J. Bdzil and W. Fickett, DSD Technology: A Detonation Reactive Huygens Code, Los Alamos National Laboratory, Los Alamos, NM, LA-12235MS (1992).

10. L. M. Hull, "Mach Reflection of Spherical Detonation Waves," Tenth International Detonation Symposium, Boston, MA, July 12-16, 1993, Paper Summaries, p. 87.

11. R. K. Jackson, L. G. Green, R. H. Bartlett, W. W. Hofer, P. E. Kramer, R. S. Lee, E. J. Nidick, Jr., L. L. Shaw, and R. C. Weingart, "Initiation and Detonation Characteristics of TATB," Proceedings Sixth Symposium (International) on Detonation, Coronado, CA, August 24-27, 1976, p. 755.

12. S. G. Cochran and J. Chan, Shock Initiation and Detonation Models in One and Two Dimensions, Lawrence Livermore National Laboratory, Livermore, CA, UCID-18024 (1979).

13. R. G. Whirley and B. E. Engelmann, DYNA2D A Nonlinear Explicit, Two-Dimensional Finite Element Code for Solid Mechanics-User Manual, J. O. Hallquist, originator (April, 1992), pp. 121-125.

14. E. L. Lee and C. M. Tarver, Phys. Fluids 23, 2362 (1980).

15. C. M. Tarver and J. O. Hallquist, "Modeling Two-Dimensional Shock Initiation and Detonation Wave Phenomena in PBX 9404 and LX-17," Proceedings Seventh Symposium (International) on Detonation, Annapolis, MD, June 16-19, 1981, pp. 488-497.

16. C. M. Tarver, L. M. Erickson, and N. L. Parker, "Shock Initiation, Detonation Wave Propagation and Metal Acceleration Measurements and Calculations for RX-26-AF," Shock Waves in Condensed Matter, American Physical Society, Santa Fe, NM, July 18-21, 1983, pp. 609-612. 
17. C. M. Tarver, J. O. Hallquist, and L. M. Erickson, "Modeling Short Pulse Duration of Solid Explosives," Proceedings Eighth Symposium (International) on Detonation, Albuquerque, NM, July 15-19, 1985, pp. 951961.

18. P. A. Urtiew, L. M. Erickson, D. F. Aldis, and C. M. Tarver, "Shock Initiation of LX-17 as a Function of its Initial Temperature," Proceedings Ninth Symposium (International) on Detonation, Portland, OR, August 28-September 1, 1989, pp. 112-122.

19. M. J. Murphy, R. L. Simpson, R. D. Breithaupt, and C. M. Tarver, "Reactive Flow Measurements and Calculations for $\mathrm{ZrH}_{2}$-Based Composite Explosives," Proceedings Ninth Symposium (International) on Detonation, Portland, OR, August 28-September 1, 1989, pp. 525-534.

20. L. G. Green, C. M. Tarver, and D. J. Erskine, "Reaction Zone Structure in Supracompressed Detonating Explosives," Proceedings Ninth Symposium (International) on Detonation, Portland, OR, August 28September 1, 1989, pp. 670-682.

21. C. M. Tarver and L. G. Green, "Using Small Scale Tests to Estimate the Failure Diameter of a Propellant," Proceedings Ninth Symposium (International) on Detonation, Portland, OR, August 28-September 1, 1989, pp. 701-710.

22. W. C. Tao, C. M. Tarver, D. L. Ornellas, C. Lee, T. Cook, and J. Kury, "Understanding Composite Explosive Energetics: IV. Reactive Flow Modeling of Aluminum Reaction Kinetics in PETN and TNT using Normalized Product Equation of State," Tenth International Detonation Symposium, Boston, MA, July 12-16, 1993, Paper Summaries, pp. 52-54.

23. M. J. Murphy, E. L. Lee, A. M. Weston, and A. E. Williams, "Modeling Shock Initiation in Composition B," Tenth International Detonation Symposium, Boston, MA, July 12-16, 1993, Paper Summaries, p. 181.

24. P. A. Urtiew, T. M. Cook, J. L. Maienschein, and C. M. Tarver, "Shock Sensitivity of IHE at Elevated Temperatures," Tenth International Detonation Symposium, Boston, MA, July 12-16, 1993, Paper Summaries, Ppp. 528-530.

25. C. M. Tarver, P. A. Urtiew, S. K. Chidester, and L. G. Green, Propellants, Explosives \& Pyrotechnics 18, 117 (1993). 
26. Craig Tarver, LLNL, unpublished data kindly provided for this report, 1994.

27. V. N. Kolomiichuk and I. Yu. Mal'kov, Combustion, Explosions \& Shock Waves 29, 113 (1993).

28. D. F. Aldis, W. Quirk and R. D. Breithaupt, The Effect of Detonation Curvature on Cylindrical Wall Motion, Lawrence Livermore National Laboratory, Livermore, CA, UCRL-ID-107480 (1991).

29. B. M. Dobratz and P. C. Crawford, LLNL Explosives Handbook, Lawrence Livermore National Laboratory, Livermore, CA, UCRL-52997, Change 2, January 31, 1985, p. 7-33. 


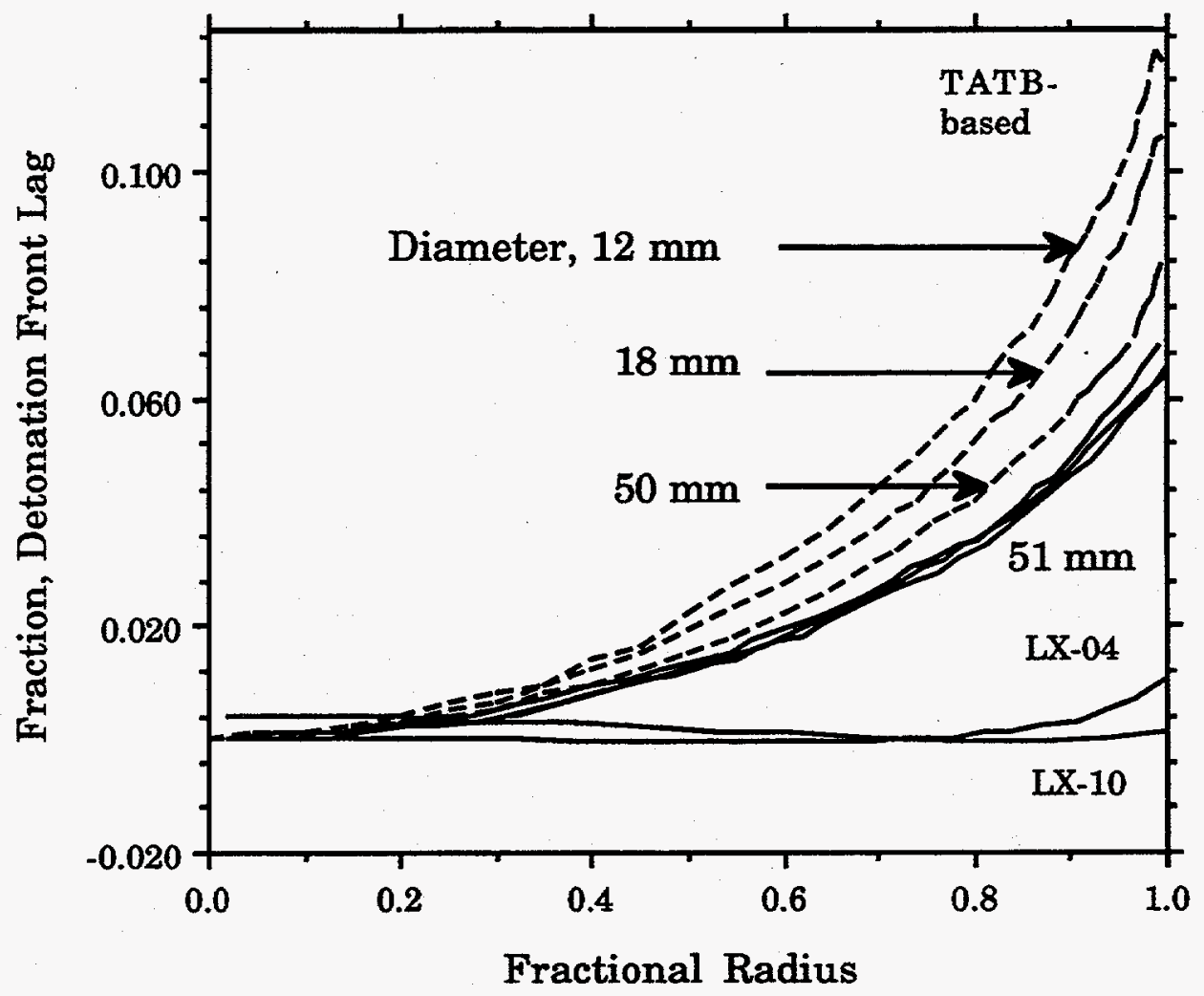

Fig. 7-1. Detonation front curvature as measured end-on in cylinder shots. The $\mathrm{X}$-axis is the fractional radius-equal to 0 at the cylinder center and 1 at the edge. The Y-axis is the lag of the detonation front relative to the radius. The $Y$-axis is expanded and greatly magnifies the curvature effect. The HMX explosives show no curvature except near the wall, but the TATB explosives are all curved across their radii. A set of three unconfined LANL TATB shots shows increasing curvature with decreasing actual cylinder diameter. 


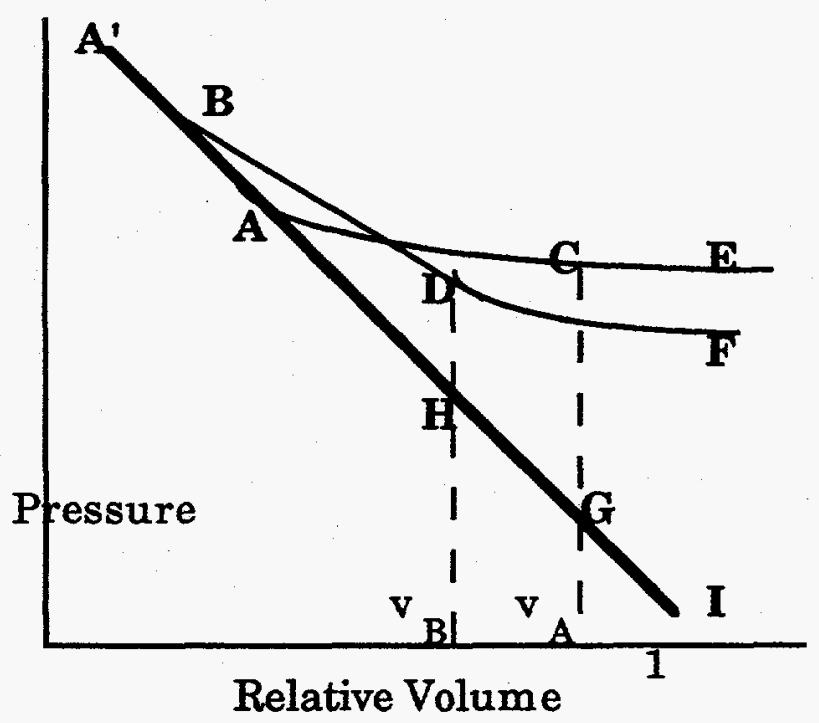

Fig. 7-2. Schematic of the pressure-relative plane for the EOS models. The Rayleigh Line is $A^{\prime} I$, with the initial $v=1$ solid explosive point at $\mathrm{I}$. For an ideal explosive in $\mathrm{C}-J$ theory, the C-J point is $\mathrm{B}$, the energy of compression is the area of the triangle $\mathrm{BDH}$, and the energy of detonation, $E_{0}$, is the area FDHI. For the nonideal explosive in the I\&G model and ZND theory, the spike point is $A^{\prime}$ and the $C-J$ point $A$. The energy of compression is ACG, and the energy of detonation, $E_{0}$, is ECGI. The pure-CJ adiabat, BDF, crosses the I\&G adiabat, ACE. The two energies, $E_{0}$, are the same. Points $E$ and $F$ are supposed to be far out at 1 atmosphere.

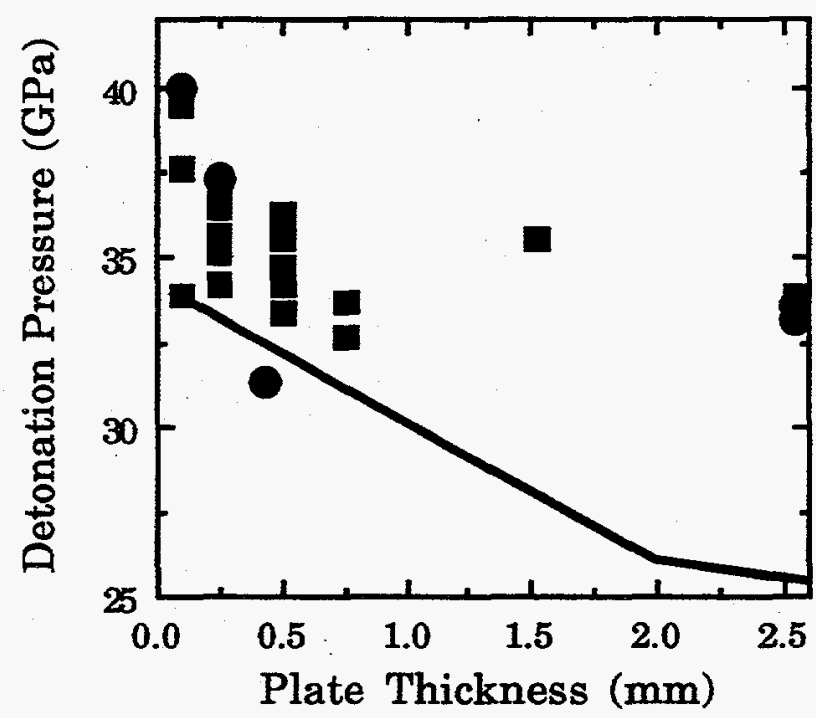

Fig. 7-3. Detonation pressure, as calculated from impedance matching, for metal plates pushed by LX-17, which has a reaction zone of about $2 \mathrm{~mm}$. The line is Tarver's I\&G view of LX-17, which is generally supported by the Cylinder Test. The discrepancy in the data is considered from the point of view of the failure of the impedance-matching equation. The data are LX-17 on $\mathrm{Ta}$ (solid squares) and $\mathrm{Cu}$ (solid circles). 


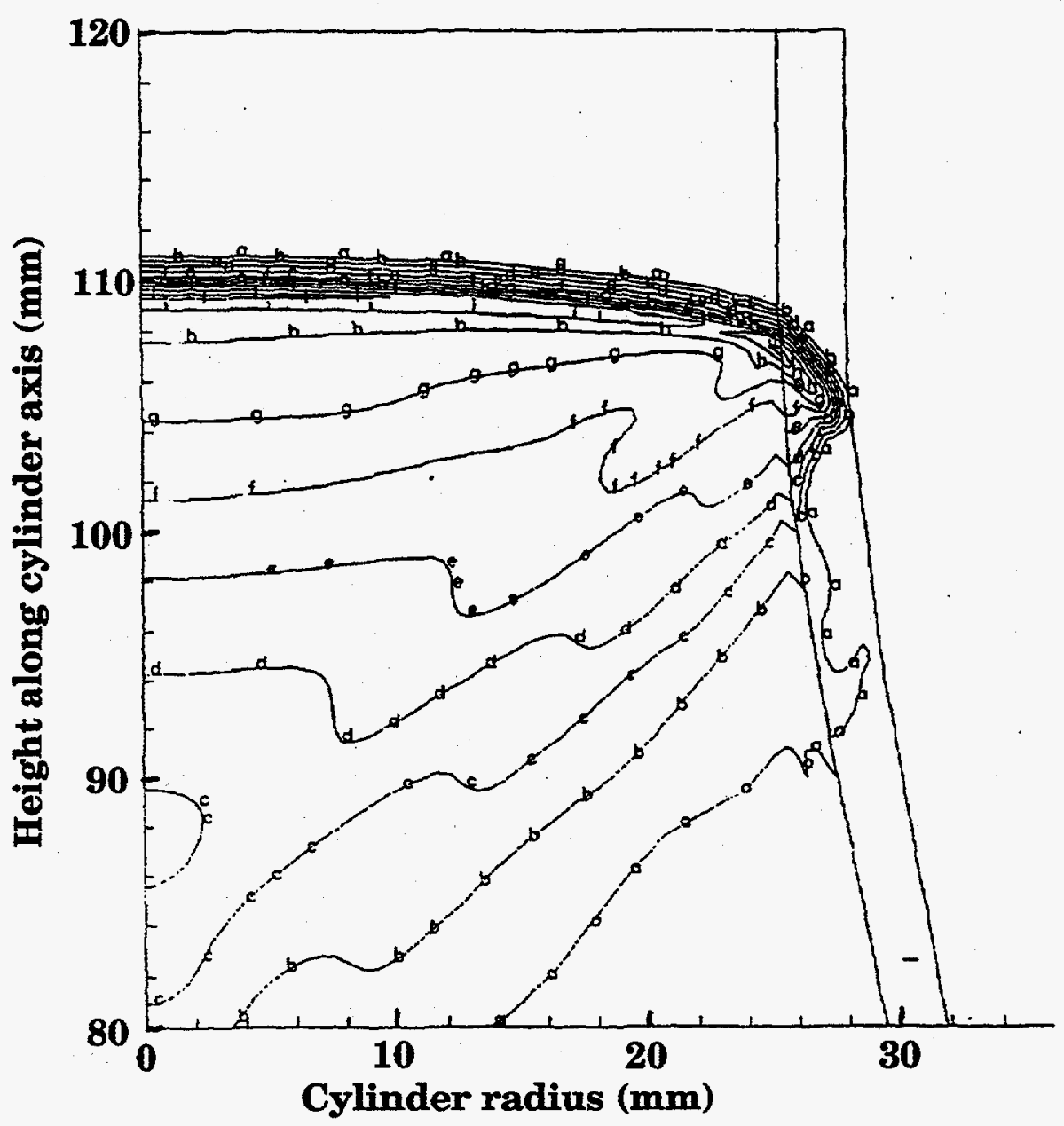

Pressure

(GPa)

\begin{tabular}{llll}
\hline$a=0.0500$ & $d=0.132$ & $g=0.214$ & $j=0.295$ \\
$b=0.0773$ & $e=0.159$ & $h=0.241$ & $k=0.323$ \\
$c=0.105$ & $f=0.186$ & $i=0.268$ & $\mathrm{l}=0.350$ \\
\hline
\end{tabular}

Fig. 7-4. Detonation front for LX-17 as calculated in DYNA2D using the two-term parameters of Table 3. The curvature corresponds to that shown in Fig. 7-1, although the unmagnified scale shown here shows that the curvature is not great. The maximum pressure is $30 \mathrm{GPa}$ in the center of the cylinder and $24 \mathrm{GPa}$ at the wall. 
Table 7-1. Detonation front data for three TATB-based explosives and two HMX-based explosives. The RX-52 data are by far the best. All cylinders are $51 \mathrm{~mm}$ in diameter. The length listed below is that of the measurement slit, unfortunately off-center from the diameter in three cases. The headings are: A ratio of radius (edge = 1); B detonation front lag (mm); and $C$ ratio detonation lag to radius.

\begin{tabular}{|c|c|c|c|c|c|c|c|c|c|c|c|}
\hline \multicolumn{3}{|c|}{$\begin{array}{r}\text { Cyl \#584, RX-52-AD } \\
50.8 \mathrm{~mm} \text { diameter }\end{array}$} & \multicolumn{3}{|c|}{$\begin{array}{l}\text { Cyl\#585, RX-52-AE } \\
50.8 \mathrm{~mm} \text { diameter }\end{array}$} & \multicolumn{3}{|c|}{$\begin{array}{c}\text { Cyl \#556, LX-17 } \\
46.7 \mathrm{~mm} \text { diameter }\end{array}$} & \multicolumn{3}{|c|}{$\begin{array}{c}\text { Cyl \#557, LX-04 } \\
46.2 \text { mm diameter }\end{array}$} \\
\hline $\bar{A}$ & $\overline{\mathbf{B}}$ & $\bar{C}$ & $\bar{A}$ & $\bar{B}$ & $\bar{C}$ & $\overline{\mathbf{A}}$ & $\bar{B}$ & $\bar{C}$ & $\overline{\mathbf{A}}$ & $\bar{B}$ & $\bar{C}$ \\
\hline-1.00 & 1.72 & 0.068 & -0.99 & 1.71 & 0.067 & -1.00 & 1.78 & 0.070 & -1.00 & 0.30 & 0.012 \\
\hline-0.97 & 1.57 & 0.062 & -0.97 & 1.55 & 0.061 & -0.98 & 1.69 & 0.067 & -0.98 & 0.24 & 0.010 \\
\hline-0.95 & 1.43 & 0.056 & -0.94 & 1.37 & 0.054 & -0.96 & 1.60 & 0.063 & -0.95 & 0.19 & 0.007 \\
\hline-0.91 & 1.28 & 0.051 & -0.91 & 1.23 & 0.048 & -0.93 & 1.46 & 0.057 & -0.89 & 0.13 & 0.005 \\
\hline-0.87 & 1.14 & 0.045 & -0.89 & 1.13 & 0.044 & -0.90 & 1.33 & 0.052 & -0.82 & 0.06 & 0.003 \\
\hline-0.82 & 0.99 & 0.039 & -0.85 & 0.98 & 0.038 & -0.86 & 1.17 & 0.046 & -0.76 & 0.04 & 0.001 \\
\hline-0.77 & 0.85 & 0.034 & -0.80 & 0.86 & 0.034 & -0.81 & 1.03 & 0.040 & -0.24 & -0.01 & 0.000 \\
\hline-0.70 & 0.70 & 0.028 & -0.76 & 0.74 & 0.029 & -0.76 & 0.88 & 0.035 & -0.02 & -0.01 & 0.000 \\
\hline-0.64 & 0.58 & 0.023 & -0.68 & 0.59 & 0.023 & -0.70 & 0.74 & 0.029 & 0.25 & -0.01 & 0.000 \\
\hline-0.56 & 0.46 & 0.018 & -0.59 & 0.43 & 0.017 & -0.62 & 0.57 & 0.022 & 0.78 & 0.01 & 0.000 \\
\hline-0.44 & 0.32 & 0.012 & -0.51 & 0.29 & 0.012 & -0.55 & 0.43 & 0.017 & 0.84 & 0.03 & 0.001 \\
\hline-0.31 & 0.18 & 0.007 & -0.37 & 0.16 & 0.006 & -0.45 & 0.30 & 0.012 & 0.87 & 0.05 & 0.002 \\
\hline-0.18 & 0.09 & 0.004 & -0.24 & 0.06 & 0.002 & -0.34 & 0.17 & 0.007 & 0.91 & 0.09 & 0.003 \\
\hline-0.05 & 0.04 & 0.002 & -0.08 & 0.00 & 0.000 & -0.22 & 0.07 & 0.003 & 0.94 & 0.12 & 0.005 \\
\hline 0.09 & 0.01 & 0.000 & 0.11 & 0.02 & 0.001 & -0.02 & 0.00 & 0.000 & 0.97 & 0.18 & 0.007 \\
\hline 0.20 & 0.06 & 0.002 & 0.22 & 0.07 & 0.003 & 0.13 & 0.01 & 0.000 & 0.99 & 0.23 & 0.009 \\
\hline 0.34 & 0.14 & 0.005 & 0.33 & 0.16 & 0.006 & 0.31 & 0.10 & 0.004 & 1.00 & 0.26 & 0.010 \\
\hline 0.46 & 0.25 & 0.010 & 0.47 & 0.29 & 0.012 & 0.46 & 0.25 & 0.010 & \multirow{2}{*}{\multicolumn{3}{|c|}{$\begin{array}{c}\text { Cylinder \#558, LX-10 } \\
76.8 \mathrm{~mm} \text { diameter }\end{array}$}} \\
\hline 0.58 & 0.39 & 0.016 & 0.57 & 0.43 & 0.017 & 0.58 & 0.41 & 0.016 & & & \\
\hline 0.67 & 0.56 & 0.022 & 0.65 & 0.56 & 0.022 & 0.64 & 0.53 & 0.021 & $\bar{A}$ & $\overline{\mathrm{B}}$ & $\bar{C}$ \\
\hline 0.74 & 0.70 & 0.028 & 0.72 & 0.71 & 0.028 & 0.71 & 0.66 & 0.026 & -1.00 & 0.03 & 0.001 \\
\hline 0.81 & 0.88 & 0.034 & 0.79 & 0.85 & 0.034 & 0.77 & 0.79 & 0.031 & -0.77 & 0.01 & 0.000 \\
\hline 0.86 & 1.02 & 0.040 & 0.83 & 0.96 & 0.038 & 0.82 & 0.95 & 0.037 & -0.51 & 0.08 & 0.002 \\
\hline 0.88 & 1.08 & 0.043 & 0.86 & 1.11 & 0.044 & 0.86 & 1.07 & 0.042 & -0.22 & 0.13 & 0.005 \\
\hline 0.92 & 1.24 & 0.049 & 0.91 & 1.28 & 0.050 & 0.90 & 1.19 & 0.047 & 0.09 & 0.14 & 0.005 \\
\hline 0.96 & 1.41 & 0.056 & 0.93 & 1.42 & 0.056 & 0.93 & 1.34 & 0.053 & 0.33 & 0.10 & 0.005 \\
\hline 0.98 & 1.52 & 0.060 & 0.96 & 1.58 & 0.062 & 0.97 & 1.50 & 0.059 & 0.55 & 0.04 & 0.003 \\
\hline \multirow[t]{2}{*}{1.00} & 1.66 & 0.065 & 0.98 & 1.66 & 0.065 & 0.99 & 1.58 & 0.062 & 0.74 & -0.01 & 0.002 \\
\hline & & & 0.99 & 1.74 & 0.069 & 1.00 & 1.65 & 0.065 & 1.00 & 0.06 & 0.000 \\
\hline
\end{tabular}


Table 7-2. List of all LLNL-derived I\&G parameters used in DYN2D. A blank space means zero. A list of compositions is given in the text. For the PETN- and TNT-aluminized explosives, two values of $\mathrm{G}_{2}$ are given. The first is for $5-\mu \mathrm{m}$ aluminum and the second for $18-\mu \mathrm{m}$ aluminum. All units are in Mbars except for detonation velocity, which is in $\mathrm{mm} / \mathrm{\mu s}$.

\begin{tabular}{|c|c|c|c|c|c|c|c|}
\hline & \multirow[b]{2}{*}{$\begin{array}{l}\text { DYNA2D } \\
\text { manual }\end{array}$} & \multirow[b]{2}{*}{$\begin{array}{c}\text { Tarver's } \\
\text { terms }\end{array}$} & \multicolumn{3}{|r|}{ COMP B } & H-6 & \multirow{2}{*}{$\begin{array}{c}\text { LX-10 } \\
\text { Three- } \\
\text { term } \\
\text { initiation }\end{array}$} \\
\hline & & & $\begin{array}{l}\text { COMP B } \\
\text { (LANL) } \\
\text { initiation }\end{array}$ & $\begin{array}{c}\text { COMP B } \\
\text { (Military) } \\
\text { initiation }\end{array}$ & $\begin{array}{c}\text { Three- } \\
\text { term } \\
\text { initiation }\end{array}$ & $\begin{array}{c}\text { Three- } \\
\text { term } \\
\text { initiation }\end{array}$ & \\
\hline \multirow{10}{*}{$\begin{array}{l}\text { Unreacted } \\
\text { explosive } \\
\text { JWL }\end{array}$} & density (g/cc) & $\overline{\rho_{0}}$ & 1.712 & 1.630 & 1.712 & 1.76 & 1.865 \\
\hline & $\mathrm{R}_{1 \mathrm{e}}$ (Mbars) & $\mathbf{A}$ & 778.1 & 1479 & 778.1 & 152.7 & 9522 \\
\hline & $\mathrm{R}_{2 \mathrm{e}}(\mathrm{Mbars})$ & B & -0.05031 & -0.05261 & -0.05031 & -0.05175 & -0.05944 \\
\hline & $\mathrm{R}_{3 \mathrm{e}}(\mathrm{Mbar} / \mathrm{K})$ & & 2.22E-05 & 2.27E-05 & 2.22E-05 & $2.88 \mathrm{E}-05$ & $2.47 \mathrm{E}-05$ \\
\hline & $\mathbf{R}_{\mathbf{5 e}}$ & $\mathbf{R}_{\mathbf{1}}$ & 11.3 & 12 & 11.3 & 9.5 & 14.1 \\
\hline & $\mathrm{R}_{6 \mathrm{e}}$ & $\mathbf{R}_{\mathbf{2}}$ & 1.13 & 1.2 & 1.13 & 0.95 & 1.41 \\
\hline & $\omega_{e}$ & $\omega$ & 0.8938 & 0.912 & 0.8938 & 0.976 & 0.8867 \\
\hline & $c_{\text {ve }}$ & $\mathbf{C}_{\mathbf{v}}$ & 2.487E-05 & 2.487E-05 & 2.487E-05 & 2.951E-05 & 2.781E-05 \\
\hline & $T_{0}(K)$ & $\mathbf{T}_{\mathbf{0}}$ & 298 & 298 & 298 & 298 & 298 \\
\hline & $\mathbf{P}_{\mathbf{k}}$ (Mbars) & & 0.334 & 0.268 & 0.334 & & \\
\hline \multirow{10}{*}{$\begin{array}{l}\text { Reacted } \\
\text { products } \\
\text { JWL }\end{array}$} & $\mathrm{D}(\mathrm{mm} / \mu \mathrm{s})$ & $\overline{\mathrm{D}}$ & 7.98 & 7.70 & 7.98 & 7.47 & \\
\hline & $\mathrm{R}_{1 \mathrm{p}}$ (Mbars) & $\mathbf{A}$ & 5.242 & 5.5748 & 5.242 & 7.5807 & 8.807 \\
\hline & $\mathrm{R}_{2 \mathrm{p}}(\mathrm{Mbars})$ & B & 0.07678 & 0.0783 & 0.07678 & 0.08513 & 0.1836 \\
\hline & $\mathrm{R}_{3 \mathrm{p}}(\mathrm{Mbar} / \mathrm{K})$ & & 3.4E-06 & 3.4E-06 & 3.4E-06 & 2.0E-06 & 3.8E-06 \\
\hline & $R_{5 p}$ & $\mathbf{R}_{1}$ & 4.2 & 4.5 & 4.2 & 4.9 & 4.62 \\
\hline & $\mathrm{R}_{6 \mathrm{p}}$ & $\mathbf{R}_{\mathbf{2}}$ & 1.1 & 1.2 & 1.1 & 1.0 & 1.32 \\
\hline & $\omega_{p}$ & $\omega$ & 0.34 & 0.34 & 0.34 & 0.20 & 0.38 \\
\hline & $c_{v p}$ & $\mathbf{C}_{\mathbf{v}}$ & $1.0 \mathrm{E}-05$ & $1.0 \mathrm{E}-05$ & $1.0 \mathrm{E}-05$ & $1.0 \mathrm{E}-05$ & $1.0 \mathrm{E}-05$ \\
\hline & $Q_{r}(M b \cdot c c / c c)$ & $\mathbf{E}_{o}$ & 0.085 & 0.081 & 0.085 & 0.103 & 0.104 \\
\hline & $\mathbf{P}_{\mathbf{a}}$ (Mbars) & & 0.295 & 0.250 & 0.295 & 0.240 & \\
\hline \multirow{4}{*}{$\begin{array}{l}\text { Initiation } \\
\text { term }\end{array}$} & $\mathbf{F}_{\mathrm{q}}\left(\mu \mathrm{s}^{-1}\right)$ & $\bar{I}$ & 44 & $\overline{44}$ & $4.0 \mathrm{E}+06$ & $4.0 \mathrm{E}+08$ & $7.43 \mathrm{E}+11$ \\
\hline & $F_{r}$ & b & 0.222 & 0.222 & 0.667 & 0.667 & 0.667 \\
\hline & $\mathrm{C}_{\text {crit }}$ & $\mathbf{a}$ & 0.01 & 0.01 & & & \\
\hline & $\eta$ & $\mathbf{x}$ & 4 & 4 & 7 & 7 & 20 \\
\hline \multirow{4}{*}{$\begin{array}{c}\text { Fast } \\
\text { growth } \\
\text { term }\end{array}$} & $\mathrm{G}_{1}\left(\mu \mathrm{s}^{-1} \mathrm{Mb}^{-\mathrm{z}}\right)$ & $\overline{\mathbf{G}_{1}}$ & 414 & $\overline{514}$ & 85 & $\overline{6}$ & 120 \\
\hline & $\mathrm{s}_{1}$ & c & 0.222 & 0.222 & 0.222 & 0.667 & 0.667 \\
\hline & $a_{1}$ & d & 0.667 & 0.667 & 0.667 & 0.667 & 0.333 \\
\hline & $\mathbf{m}$ & $\mathbf{y}$ & 2 & 2 & 2 & 1 & 2 \\
\hline \multirow{4}{*}{$\begin{array}{l}\text { Slow } \\
\text { growth } \\
\text { term }\end{array}$} & $\mathrm{G}_{2}\left(\mu \mathrm{s}^{-1} \mathrm{Mb}^{-\mathrm{z}}\right)$ & $\overline{\mathrm{G}_{2}}$ & & & 660 & 5500 & 400 \\
\hline & $\mathbf{s}_{2}$ & e & & & 0.333 & 0.333 & 0.333 \\
\hline & $a_{2}$ & $\mathbf{g}$ & & & 1 & 1 & 1 \\
\hline & $\mathbf{n}$ & $\mathbf{z}$ & & & 3 & 3 & 2 \\
\hline \multirow[t]{3}{*}{ Limits } & $\overline{F_{\max , \text { ig }}}$ & $F_{\text {igmax }}$ & 0.3 & 0.3 & 0.022 & 0.02 & 0.3 \\
\hline & $F_{\max , g r}$ & $F_{G 1 \max }$ & 1 & 1 & 0.6 & 0.5 & 0.5 \\
\hline & $F_{\min , g r}$ & $F_{\mathrm{G} 2 \min }$ & 1 & 1 & & & 0.5 \\
\hline Ref. & & & 23 & 23 & 26 & 26 & 25 \\
\hline
\end{tabular}


Table 7-2, part 2

\begin{tabular}{|c|c|c|c|c|c|c|c|}
\hline & LX-17 & LX-17 & $\mathbf{L X} \cdot 17$ & LX-17 & LX-17 & LX-17 & PBX-9404 \\
\hline & $\begin{array}{l}\text { Two-term } \\
\text { initiation }\end{array}$ & $\begin{array}{l}\text { Three-term } \\
\text { initiation }\end{array}$ & $\begin{array}{l}\text { Three-term } \\
\text { supracomp }\end{array}$ & $\begin{array}{l}\text { cold } 219 \mathrm{~K} \\
\text { initiation }\end{array}$ & $\begin{array}{l}\text { heat } 361 \mathrm{~K} \\
\text { initiation }\end{array}$ & $\begin{array}{l}\text { heat 523 K } \\
\text { initiation }\end{array}$ & $\begin{array}{l}\text { Two-term } \\
\text { initiation }\end{array}$ \\
\hline$\rho_{0}$ & 1.905 & 1.905 & 1.905 & 1.905 & 1.905 & $\overline{1.7}$ & 1.842 \\
\hline $\mathbf{R}_{1 \mathbf{e}}$ & 778.1 & 778.1 & 778.1 & 778.1 & 778.1 & 244.8 & 9522 \\
\hline $\mathrm{R}_{2 \mathrm{e}}$ & -0.05031 & -0.05031 & -0.05031 & -0.05031 & -0.05031 & -0.0454 & -0.05944 \\
\hline $\mathbf{R}_{3 \mathbf{e}}$ & $2.22 \mathrm{E}-05$ & 2.22E-05 & 2.22E-05 & 2.22E-05 & $2.22 \mathrm{E}-05$ & 2.22E-05 & 2.47E-05 \\
\hline $\mathbf{R}_{5 \mathbf{e}}$ & 11.3 & 11.3 & 11.3 & 11.3 & 11.3 & 11.3 & 14.1 \\
\hline$R_{6 e}$ & 1.13 & 1.13 & 1.13 & 1.3 & 1.3 & 1.13 & 1.41 \\
\hline$\omega_{e}$ & 0.8939 & 0.8938 & 0.8938 & 0.8938 & 0.8938 & 0.894 & 0.8867 \\
\hline$c_{\mathrm{ve}}$ & $2.487 \mathrm{E}-05$ & 2.487E-05 & $2.487 \mathrm{E}-05$ & $2.487 \mathrm{E}-05$ & $2.487 \mathrm{E}-05$ & $2.487 E-05$ & 2.781E-05 \\
\hline $\mathbf{T}_{\mathbf{0}}$ & 298 & 298 & 298 & 298 & 298 & 523 & 298 \\
\hline $\mathbf{P}_{\mathbf{k}}$ & 0.337 & 0.337 & 0.337 & & & & 0.398 \\
\hline$\overline{\mathrm{D}}$ & 7.596 & 7.596 & 7.596 & 7.596 & 7.596 & & 8.8 \\
\hline $\mathbf{R}_{1 p}$ & 6.5467 & 5.31396 & 43.42773 & 5.31396 & 5.31396 & 6.5467 & 8.524 \\
\hline $\mathbf{R}_{2 p}$ & 0.071236 & 0.0270309 & 1.94564 & 0.0270309 & 0.0270309 & 0.0712 & 0.1802 \\
\hline $\mathbf{R}_{\mathbf{3 p}}$ & $3.5 \mathrm{E}-06$ & 3.5E-06 & $6.0 \mathrm{E}-06$ & $4.6 E-06$ & $4.6 \mathrm{E}-06$ & $3.5 \mathrm{E}-06$ & 3.8E-06 \\
\hline $\mathrm{R}_{5 p}$ & 4.45 & 4.1 & 8.5 & 4.1 & 4.1 & 4.45 & 4.6 \\
\hline$R_{6 p}$ & 1.2 & 1.1 & 3.28 & 1.1 & 1.1 & 1.2 & 1.3 \\
\hline$\omega_{p}$ & 0.35 & 0.46 & 0.6 & 0.46 & 0.46 & 0.35 & 0.38 \\
\hline$c_{\mathrm{vp}}$ & $1.0 \mathrm{E}-05$ & $1.0 \mathrm{E}-05$ & $1.0 \mathrm{E}-05$ & $1.0 \mathrm{E}-05$ & $1.0 \mathrm{E}-05$ & $1.0 \mathrm{E}-05$ & $1.0 \mathrm{E}-05$ \\
\hline $\mathbf{Q}_{\mathbf{r}}$ & 0.069 & 0.069 & 0.07 & 0.069 & 0.069 & 0.062 & 0.102 \\
\hline $\mathbf{P}_{\mathbf{a}}$ & 0.275 & 0.290 & 0.250 & 0.290 & 0.290 & & 0.370 \\
\hline$\overline{F_{q}}$ & 50 & $4.0 \mathrm{E}+06$ & $4.0 \mathrm{E}+06$ & $2.8 \mathrm{E}+06$ & $6.0 \mathrm{E}+06$ & $1.0 \mathrm{E}+04$ & $\overline{44}$ \\
\hline $\mathbf{F}_{\mathbf{r}}$ & 0.222 & 0.667 & 0.667 & 0.667 & 0.667 & 0.667 & 0.222 \\
\hline $\mathrm{C}_{\mathrm{crt}}$ & & 0.22 & 0.22 & 0.22 & 0.22 & 0.22 & \\
\hline$\eta$ & 4 & 7 & 7 & 7 & 7 & 7 & 4 \\
\hline$\overline{G_{1}}$ & 500 & 0.6 & $\overline{48}$ & 0.42 & 1.2 & 75 & 850 \\
\hline $\mathrm{s}_{1}$ & 0.222 & 0.667 & 0.111 & 0.667 & 0.667 & 0.667 & 0.222 \\
\hline$a_{1}$ & 0.667 & 0.111 & 0.111 & 0.111 & 0.111 & 0.111 & 0.667 \\
\hline $\mathbf{m}$ & 3 & 1 & 1 & 1 & 1 & 2 & 2 \\
\hline $\mathrm{G}_{2}$ & & 400 & 500 & 160 & 400 & 400 & \\
\hline $\mathbf{s}_{2}$ & & 0.333 & 1 & 0.333 & 0.333 & 0.333 & \\
\hline a2 & & 1 & 1 & 1 & 1 & 1 & \\
\hline $\mathbf{n}$ & & 3 & 3 & 3 & 3 & 3 & \\
\hline$\overline{F_{x i g}}$ & $\overline{1}$ & 0.5 & 0.0232 & 0.5 & 0.5 & 0.4 & $\overline{1}$ \\
\hline$F_{x g r}$ & & 0.5 & 0.85 & 0.5 & 0.5 & 0.5 & \\
\hline$F_{n g r}$ & & & & & & 0.5 & \\
\hline Ref. & $\overline{15}$ & 17 & 20 & $\overline{18}$ & 18 & 24 & 15 \\
\hline
\end{tabular}


Table 7-2, part 3

\begin{tabular}{|c|c|c|c|c|c|c|c|}
\hline & | PBX-9404 & PBX-9404 & PETN & PETN & PETN & PETN & \multirow{2}{*}{$\begin{array}{c}\text { PETN/A15 } \\
\begin{array}{c}\text { Three-term } \\
\text { initiation }\end{array}\end{array}$} \\
\hline & $\begin{array}{l}\text { Two-term } \\
\text { initiation }\end{array}$ & $\begin{array}{c}\text { Three-term } \\
\text { initiation }\end{array}$ & $\begin{array}{l}\text { Two-term } \\
\text { initiation }\end{array}$ & $\begin{array}{l}\text { Two-term } \\
\text { initiation }\end{array}$ & $\begin{array}{l}\text { Two-term } \\
\text { initiation }\end{array}$ & $\begin{array}{l}\text { Two-term } \\
\text { initiation }\end{array}$ & \\
\hline$\rho_{0}$ & 1.842 & 1.843 & 1.00 & 1.60 & 1.72 & 1.75 & 1.775 \\
\hline $\mathbf{R}_{1 \mathbf{e}}$ & 9522 & 9522 & 13.12 & 21.88 & 346.6 & 37.46 & 12510 \\
\hline $\mathbf{R}_{\mathbf{2 e}}$ & -0.05944 & -0.05944 & -0.0784 & -0.58 & -3.3 & -1.313 & -0.06053 \\
\hline $\mathbf{R}_{\mathbf{3 e}}$ & 2.47E-05 & 2.47E-05 & 3.40E-07 & 9.31E-06 & 2.18E-05 & 2.65E-05 & 2.47E-05 \\
\hline $\mathbf{R}_{\mathbf{5 e}}$ & 14.1 & 14.1 & 11.0 & 7.8 & 10.0 & 7.2 & 14.4 \\
\hline $\mathrm{R}_{6 \mathrm{e}}$ & 1.41 & 1.41 & 5.5 & 3.9 & 5.0 & 3.6 & 1.44 \\
\hline$\omega_{e}$ & 0.8867 & 0.8867 & 0.02027 & 0.3468 & 0.7556 & 1.173 & 0.9875 \\
\hline$c_{\text {ve }}$ & $2.781 \mathrm{E}-05$ & $2.781 \mathrm{E}-05$ & $1.676 \mathrm{E}-05$ & $2.685 \mathrm{E}-05$ & 2.887E-05 & 2.263E-05 & 2.504E-05 \\
\hline $\mathbf{T}_{\mathrm{o}}$ & 298 & 298 & 298 & 298 & 298 & 298 & 298 \\
\hline $\mathbf{P}_{\mathbf{k}}$ & 0.398 & 0.398 & & & & 0.452 & \\
\hline$\overline{\mathrm{D}}$ & 8.8 & 8.80 & & & & 8.21 & 8.10 \\
\hline $\mathbf{R}_{1 \mathbf{p}}$ & 8.524 & 8.524 & 2.372 & 6.253 & 6.17 & 6.17 & 5.942 \\
\hline$R_{2 p}$ & 0.1802 & 0.1802 & 0.1061 & 0.2329 & 0.16926 & 0.16926 & 0.441 \\
\hline $\mathbf{R}_{\mathbf{3 p}}$ & $3.8 \mathrm{E}-06$ & 3.8E-06 & 2.4E-06 & 2.8E-06 & $2.5 \mathrm{E}-06$ & 2.5E-06 & 5.2E-06 \\
\hline $\mathbf{R}_{5 p}$ & 4.6 & 4.6 & 5.6 & 5.25 & 4.4 & 4.4 & 4.9 \\
\hline$R_{6 p}$ & 1.3 & 1.3 & 1.8 & 1.6 & 1.2 & 1.2 & 2.3 \\
\hline$\omega_{p}$ & 0.38 & 0.38 & 0.24 & 0.28 & 0.25 & 0.25 & 0.52 \\
\hline$c_{\mathrm{vp}}$ & $1.0 \mathrm{E}-05$ & $1.0 E-05$ & $1.0 \mathrm{E}-05$ & $1.0 \mathrm{E}-05$ & $1.0 \mathrm{E}-05$ & $1.0 \mathrm{E}-05$ & $1.0 \mathrm{E}-05$ \\
\hline$Q_{r}$ & 0.102 & 0.102 & 0.05706 & 0.0913 & 0.09815 & 0.101 & 0.120 \\
\hline $\mathbf{P}_{\mathbf{a}}$ & 0.370 & 0.370 & & & & 0.335 & 0.320 \\
\hline$\overline{F_{q}}$ & 44 & $7.43 \mathrm{E}+11$ & 20 & 20 & 20 & 20 & 20 \\
\hline$F_{r}$ & 0.222 & 0.667 & 0.222 & 0.222 & 0.222 & 0.222 & 0.222 \\
\hline $\mathrm{C}_{\text {crt }}$ & 0.01 & & & & & & \\
\hline$\eta$ & 4 & 20 & 4 & 4 & 4 & 4 & 4 \\
\hline$\overline{\mathrm{G}_{1}}$ & 850 & 3.1 & 400 & 400 & 400 & 400 & 1000 \\
\hline$s_{1}$ & 0.222 & 0.667 & 0.222 & 0.222 & 0.222 & 0.222 & 1 \\
\hline $\mathbf{a}_{1}$ & 0.667 & 0.111 & 0.667 & 0.667 & 0.667 & 0.667 & 0.667 \\
\hline $\mathbf{m}$ & 2 & 1 & 1.4 & 1.4 & 1.4 & 1.4 & 1 \\
\hline$\overline{\mathrm{G}_{2}}$ & & 400 & & & & & $66,18.4$ \\
\hline s2 & & 0.333 & & & & & 1 \\
\hline$a_{2}$ & & 1 & & & & & 1 \\
\hline $\mathbf{n}$ & & 2 & & & & & 1 \\
\hline $\mathrm{F}_{\text {xig }}$ & 0.3 & 0.3 & 1 & $\overline{1}$ & 1 & $\overline{1}$ & 0.03 \\
\hline$F_{x g r}$ & 1 & 0.5 & & & & & 0.86 \\
\hline$F_{\text {ngr }}$ & 1 & & & & & & 0.86 \\
\hline Ref. & 23 & 17 & $\overline{14}$ & $\overline{14}$ & 14 & 14 & 22 \\
\hline
\end{tabular}


Table 7-2, part 4

\begin{tabular}{|c|c|c|c|c|c|c|c|}
\hline & PETN/Al10 & PETN/A120 & Prop B & RX-03-BB & RX-25-BF & RX-25-BH & RX-26-AF \\
\hline & $\begin{array}{c}\text { Three-term } \\
\text { initiation }\end{array}$ & $\begin{array}{l}\text { Three-term } \\
\text { initiation }\end{array}$ & $\begin{array}{c}\text { Three-term } \\
\text { initiation }\end{array}$ & $\begin{array}{l}\text { Two-term } \\
\text { initiation }\end{array}$ & $\begin{array}{c}\text { Three-term } \\
\text { initiation }\end{array}$ & $\begin{array}{l}\text { Three-term } \\
\text { initiation }\end{array}$ & $\begin{array}{c}\text { Three-term } \\
\text { initiation }\end{array}$ \\
\hline$p_{0}$ & 1.800 & 1.893 & 1.848 & 1.90 & 2.149 & 2.30 & 1.836 \\
\hline $\mathbf{R}_{1 \mathrm{e}}$ & 12510 & 12510 & 40.66 & 108.2 & 286.9 & 286.9 & 2011 \\
\hline $\mathrm{R}_{2 \mathrm{e}}$ & -0.06053 & -0.06053 & -1.339 & -2.406 & -0.1453 & -0.1453 & -0.05204 \\
\hline $\mathbf{R}_{3 e}$ & 2.47E-05 & 2.47E-05 & 2.09E-05 & 3.41E-05 & $2.23 \mathrm{E}-05$ & 2.23E-05 & 2.27E-05 \\
\hline $\mathbf{R}_{5 \mathbf{e}}$ & 14.4 & 14.4 & 7.2 & 8.2 & 10.0 & 10.0 & 12.4 \\
\hline $\mathbf{R}_{6 e}$ & 1.44 & 1.44 & 3.6 & 4.1 & 2.0 & 2.0 & 1.24 \\
\hline$\omega_{\mathrm{e}}$ & 0.9875 & 0.9875 & 0.8351 & 1.251 & 0.8161 & 0.8161 & 0.9451 \\
\hline$c_{v e}$ & 2.504E-05 & $2.504 \mathrm{E}-05$ & $2.504 \mathrm{E}-05$ & 2.724E-05 & $2.730 \mathrm{E}-05$ & $2.730 \mathrm{E}-05$ & 2.406E-05 \\
\hline $\begin{array}{l}\mathrm{T}_{\mathbf{o}} \\
\mathrm{P}_{\mathrm{k}}\end{array}$ & 298 & 298 & 298 & $\begin{array}{c}298 \\
0.355\end{array}$ & 298 & 298 & 298 \\
\hline $\mathrm{D}$ & 8.00 & $\overline{7.88}$ & & 7.596 & 7.506 & 6.01 & 8.239 \\
\hline $\mathbf{R}_{1 p}$ & 5.022 & 8.126 & 7.737 & 6.5467 & 53.24 & 20.62243 & 8.018 \\
\hline$R_{2 p}$ & 0.269 & 0.654 & 0.1155 & 0.071236 & 0.514 & 0.286777 & 0.5264 \\
\hline $\mathbf{R}_{3 p}$ & 5.0E-06 & $4.2 \mathrm{E}-06$ & 2.4E-06 & 3.5E-06 & $6.0 \mathrm{E}-06$ & $6.0 \mathrm{E}-06$ & 3.4E-06 \\
\hline $\mathbf{R}_{5 p}$ & 4.5 & 5.55 & 4.8 & 4.45 & 8.0 & 7.0 & 5.0 \\
\hline$R_{6 p}$ & 2 & 2.23 & 1.2 & 1.2 & 1.75 & 1.0 & 2.1 \\
\hline$\omega_{p}$ & 0.50 & 0.42 & 0.24 & 0.35 & 0.60 & 0.60 & 0.34 \\
\hline cvp & $1.0 \mathrm{E}-05$ & $1.0 \mathrm{E}-05$ & $1.0 \mathrm{E}-05$ & $1.0 \mathrm{E}-05$ & $1.0 \mathrm{E}-05$ & $1.0 \mathrm{E}-05$ & $1.0 \mathrm{E}-05$ \\
\hline $\mathbf{Q}_{\mathbf{r}}$ & 0.120 & 0.123 & 0.12 & 0.069 & 0.10 & 0.08 & 0.085 \\
\hline $\mathrm{P}_{\mathrm{a}}$ & 0.325 & 0.320 & & 0.275 & 0.280 & 0.210 & 0.325 \\
\hline$\overline{F_{q}}$ & 20 & 20 & 4 & 50 & $7.43 \bar{E}+11$ & $7.43 \mathrm{E}+11$ & $\overline{14}$ \\
\hline$F_{r}$ & 0.222 & 0.222 & 0.667 & 0.222 & 0.667 & 0.667 & 0.667 \\
\hline $\mathrm{C}_{\mathrm{crt}}$ & & & & & 0.03 & & \\
\hline$\eta$ & 4 & 4 & 4 & 4 & 20 & 20 & 4 \\
\hline$\overline{\mathrm{G}_{1}}$ & 1000 & 1000 & 3.1 & 125 & 3.1 & 3.1 & 488 \\
\hline s1 & 1 & 1 & 0.667 & 0.222 & 0.667 & 0.667 & 0.667 \\
\hline $\mathbf{a}_{1}$ & 0.667 & 0.667 & 0.111 & 0.667 & 0.111 & 0.111 & 0.333 \\
\hline $\mathbf{m}$ & 1 & 1 & 1 & 2 & 1 & 1 & 2 \\
\hline $\mathrm{G}_{2}$ & $66,18.4$ & $66,18.4$ & 18 & & 25 & 85 & 500 \\
\hline s2 & 1 & 1 & 0.111 & & 0.667 & 0.667 & 0.222 \\
\hline$a_{2}$ & 1 & 1 & 1 & & 0.111 & 0.111 & 0.667 \\
\hline $\mathbf{n}$ & 1 & 1 & 2 & & 1.2 & 2 & 3 \\
\hline$\overline{F_{\text {xig }}}$ & 0.03 & 0.03 & 0.015 & 1 & 0.03 & 0.03 & 0.05 \\
\hline$F_{\mathrm{Xgr}}$ & 0.74 & 0.58 & 0.12 & & 0.38 & 0.19 & 0.5 \\
\hline $\mathrm{F}_{\mathrm{ngr}}$ & 0.74 & 0.58 & & & & & \\
\hline Ref. & 22 & 22 & 21 & $\overline{14}$ & 19 & 19 & 16 \\
\hline
\end{tabular}


Table 7-2, part 5

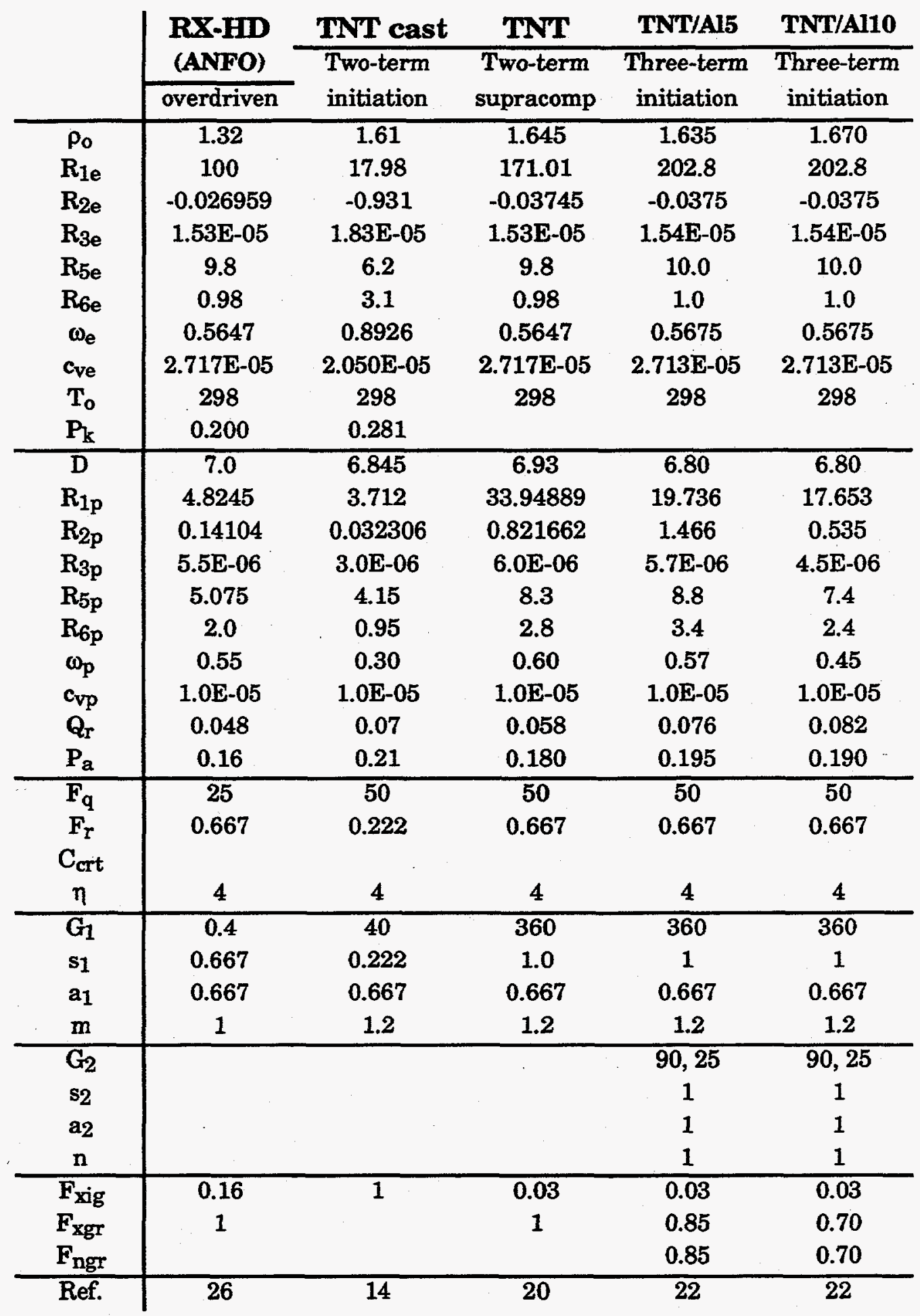




\section{Chapter 8. Thermochemical Codes}

\section{Descriptions of the Codes}

Besides the hydrocode, the other major class of explosive code is the thermochemical code. These codes start with an explosive of given composition, density, and heat of formation and calculate the products at various relative volumes along with their pressures and energies. The models assume thermodynamic equilibrium and are based on thermodynamic data tables. The codes know nothing about chemical kinetics.

The most generally used code is TIGER. It has two different submodels: the BKW (for Becker, Kistiakowsky, and Wilson) and the JCZ3 (for Jacobs, Cowperthwaite, and Zwisler). The BKW dates to World War II and calculates a Gas Law compressibility, ${ }^{1-4}$

$$
\mathrm{PV} / \mathrm{RT}=1+\operatorname{xexp}(\beta \mathrm{x})
$$

where

$$
x=\kappa \sum_{i} x_{i} k_{i} / V(T+\vartheta)^{\alpha}
$$

Here, $\mathrm{P}$ is the pressure, $\mathrm{V}$ the molar volume of the detonation products, $\mathrm{T}$ the temperature, $R$ the gas constant, $x_{i}$ the mol fraction of component $i$, and the rest are constants-with the $k_{i}$ known as covolumes because they mock up the molar volumes occupied by the compounds.

The Tiger JCZ3 code sought to be more physical by including intermolecular Lennard-Jones potentials between the various gaseous species. ${ }^{5} \mathrm{~A}$ single gaseous phase was created, and each product species has the two Lennard-Jones constants, which should be directly derivable from data. Both models are able to handle liquid and solid phases created at high temperature separately from the gas phases. A liquid like water that condenses at low temperature is not handled accurately and is better left as vapor. Both models are quick and can be run on a PC386 in a few minutes. Only gaseous $\mathrm{C}, \mathrm{H}, \mathrm{N}, \mathrm{O}$, and $\mathrm{F}$ compounds are available in $\mathrm{JCZ3}$, although the list could be extended. It is common in JCZ3 to ignore gaseous species that we don't have and run with a condensed one (e.g., $\mathrm{Al}_{2} \mathrm{O}_{3}$ ) that does not require Lennard-Jones constants.

The new CHEQ (for chemical equilibrium) code, created by Francis Ree, was a considerable extension of JCZ3, and was again based on intermolecular potentials.6,7 The code is unusual in being able to calculate the equilibrium properties of nonsoluble phases of gaseous and solid detonation products. The 
goal of CHEQ is to be a truly scientific code for explosives. However, the CHEQ code takes overnight to two days on a MIPPS2000 to obtain the CJ point and the adiabat. It has been rewritten for general use in windows format by A. Nichols. 8 Because it is slow, CHEQ will not be used for the rough performance calculations on new compounds. Its greatest power lies in its ability to predict the detailed shape of the adiabat with some hope of being correct. CHEQ2.5 is used here. Also included for comparison are recent results by G. Kerley using PANDA, the Sandia National Laboratories' (SNL) analog of CHEQ.9,10

For quick calculations, TIGER is still the best code. However, it comes in many versions, in addition to the basic choice of BKW or JCZ3. BKW can be used as BKWR (for revised) and BKWS (for SNL). The difference lies mainly in the basic constants, which are listed in Table 8-1. The thermodynamic libraries are also slightly different, even though they are fits of the literature JANNAF data. Also, the LLNL PC program is slightly different from the SNL Sun/Cray program-so the platform should be mentioned. This lack of standardization has followed TIGER throughout its life as a public domain code.

The BKWR version is old and was created to produce accurate detonation velocities and pressures. ${ }^{11}$ Both the constants ( $\alpha$ is $0.5, \beta 0$. is 176 , $\kappa$ is 11.80 , and $\Theta$ is $1850 \mathrm{~K}$ ) and the covolumes were arrived at by fiddling over time. However, the C-J detonation temperatures are about a thousand degrees too low, and the energies of detonation, $E_{\mathrm{d}}$, at $\mathrm{v} \sim 2$ to 7 are uniformly about $10 \%$ too high. J. Kury fixed these discrepancies by using $1.763 \mathrm{~g} / \mathrm{cc}$ PETN as a standard. At $\mathrm{v}=2.2$, the standard cylinder $\mathrm{JWL}$ for PETN gives $\mathrm{E}_{\mathrm{d}}(\mathrm{PETN}$, cylinder $)=6.51 \mathrm{~kJ} / \mathrm{cc}$, while $\mathrm{E}_{\mathrm{d}}(\mathrm{PETN}, \mathrm{BKWR})=7.30 \mathrm{~kJ} / \mathrm{cc}$. This ratio of 0.89 is applied to the BKWR value for an unknown explosive, also at $\mathrm{v}=2.2$ to obtain

$$
E_{d}(B K W R \text { corrected })=\frac{E_{d}(\text { PETN, cylinder })}{E_{d}(\text { PETN, BKWR })} E_{d}(B K W R)
$$

This effectively lowers all detonation from $2<\mathrm{v}<7$ energies by $10 \%$. For the total energy of detonation, $E_{0}$, the cylinder and $B K W R$ values are 10.80 and $10.68 \mathrm{~kJ} / \mathrm{cc}$, so that the correction is negligible.

To summarize, the calculated BKWR energies for PETN are corrected at each of the three cylinder volumes as listed below.

\begin{tabular}{cccc} 
& \multicolumn{2}{c}{ Det. energies (kJ/cc) } & \\
\cline { 2 - 3 } $\begin{array}{c}\text { Relative } \\
\text { Volume }\end{array}$ & $\begin{array}{c}\text { BKWR } \\
\text { calculated }\end{array}$ & $\begin{array}{c}\text { BKWR } \\
\text { corrected }\end{array}$ & Ratio \\
\hline 2.2 & 7.30 & 6.51 & 0.892 \\
4.1 & 8.81 & 7.87 & 0.893 \\
6.5 & 9.39 & 8.55 & 0.910
\end{tabular}


This method is an awkward but effective correction to BKWR, which was originally designed for detonation velocities and pressures, so that it will now handle energies. This arrangement has persisted because the energy of detonation has not been considered a prime variable for matching until now.

The low detonation temperatures were noticed by Hobbs and Baer at SNL, and they recently created the new version of BKWS. $12-15$ The covolumes are listed in Table 8-1 and differ from the LLNL set. The thermodynamic library is different as well. The constants $\alpha, \beta$, $\kappa$, and $\Theta$ were first set in BKWS at $0.5,0.174,11.85$, and $5160 \mathrm{~K}$ and have since been reset to $0.5,0.298,10.5$, and $6620 \mathrm{~K}$. The temperatures were raised by increasing $\Theta$, and the energies of detonation decreased as a result. This allows the calculated energies of detonation to be used without correction.

Hobbs and Baer also used a generating algorithm to turn out a large number of covolumes for compounds and free radicals from all over the periodic table, although the constants have been derived solely for CHNO explosives. Thus, TIGER can be run on all kinds of reactions, whether detonating or not.

\section{Comparison of Code Results}

We shall now compare the thermochemical code results for a set of homogeneous explosives listed in Tables 8-2 and 8-3. The code results are compared with detonation velocities measured in the cylinders and total energies of detonation measured by calorimetric detonation. ${ }^{16}$ The energy of detonation, $\mathbf{E}_{\mathrm{d}}$, at some given volume is determined from the equation

$$
E_{d}=\left(\frac{u}{u(P E T N)}\right)^{2} E_{d}(\text { PETN })
$$

The cylinder velocities are given by $u$. The codes are run with all species frozen into final equilibrium at $1800 \mathrm{~K}$. All the codes in Tables 8-2 and 8-3 were run on the PC with the LLNL TIGER program. SNL constants and library were used for BKWS. The minimum library listed in Table 8-1 was used. Although Hobbs and Baer list library data for many radicals, these are passed through quickly by TIGER and add nothing to the result except running time, while increasing the probability of a crash. If a solid final species was likely, no gaseous intermediates were used. All water was allowed to go only to gas because partial condensation often occurs in the code. The presence of formic acid, $\mathrm{HCOOH}$, is essential in the library or the detonation velocity jumps to large and unrealistic values.

The results of Tables 8-2 and 8-3 show that the TIGER codes produce results as good as the larger CHEQ and PANDA codes do. Earlier in this 
report we calculated total energies of detonation to within $\pm 10 \%$ assuming incomplete burning of $\mathrm{CO}$. With the TIGER codes, we can improve this to about $\pm 5 \%$, at least for these explosives. Within the three versions of TIGER, JCZ3 is slightly off on detonation velocity, which could be fixed by renormalizing. BKWS is certainly more realistic with hotter temperatures, and there is no need to fudge the energies, but the spread of energy results in BKWS is larger than for BKWR. Worse yet, some favorite explosives do not fare well. JCZ3 has another problem, seen when we compare the energies at $\mathrm{v}$ $=2.2$ and 6.5. The average energy in JCZ3 moves $7 \%$ (from -1 to +6 ), whereas the $4 \%$ seen in the other codes is more reasonable. Hence, JCZ3 dumps its energy too fast.

The thermochemical code calculates the C-J pressure-the true equilibrium value. A benefit of the fudged energies in BKWR is that the calculated $\mathrm{C}-\mathrm{J}$ pressure is generally close to the measured detonation or JWL pressures. However, the C-J pressures calculated by JCZ3 and CHEQ are low, as seen in this table.

\begin{tabular}{l|ccc} 
& BKWR & JCZ3 & CHEQ \\
\cline { 2 - 4 } Average & 1 & -10 & -13 \\
Std. dev. & 9 & 11 & 20 \\
& & & \\
No. larger & 8 & 3 & 2 \\
No. smaller & 12 & 17 & 18
\end{tabular}

This pressure is important because it defines the starting point of the adiabat. For $1.763 \mathrm{~g} / \mathrm{cc}$ PETN, the standard JWL C-J point is $31.5 \mathrm{GPa}$ at a volume, $\mathrm{v}_{\mathrm{cj}}$, of 0.739. In CHEQ, it is $29.3 \mathrm{GPa}$ at 0.763 . The thermochemical code cannot see nonequlibrium processes that could cause the actual measured detonation pressure to be higher.

Finally, we consider the C-J temperatures for which the measurements will really be adiabat temperatures. Measured temperatures are obtained from a multifrequency optical measurement in the visible region. Little data exists, and it is not clear how to interpret it. At the very least, the entire time track needs to be shown, and this is a rare occurrence. For example, Kato et al. show detonated TNT of $1.51 \mathrm{~g} / \mathrm{cc}$ rising to a peak at about 3600 to $4000 \mathrm{~K}$ over $0.5 \mu \mathrm{s} .17$ The TNT then decays to 2500 to $2700 \mathrm{~K}$ at about $2.5 \mu \mathrm{s}$. The experiment stops there, with the temperature still declining. They appear to show a $2800-\mathrm{K}$ calculated adiabat temperature, but there is no way to tell how they got it. The predicted tempera-tures for $1.6 \mathrm{~g} / \mathrm{cc}$ TNT are BKWR $2670 \mathrm{~K}$, JCZ3 $3070 \mathrm{~K}$, and CHEQ $3820 \mathrm{~K}$. This is the origin of the statement that BKWR is too low and the other two are at least reasonable. However, we cannot tell 
where the adiabat point is in the data. The $3800-\mathrm{K}$ high point might be the adiabat point, but some think this is a hot-spot effect.

\section{Detonation Temperature for Nitromethane}

Eventually, measured temperatures may be good enough to use to calibrate thermochemical codes. Nitromethane (NM) is a popular substance for measuring detonation temperatures because it is transparent and the light is easily collected. Kato et al. reviewed eleven literature measurements and found a value of $3500 \pm 200 \mathrm{~K}^{18}$ They measured NM at five wavelengths from 0.55 to $0.95 \mu \mathrm{m}$ and obtained values of $3400 \pm 50 \mathrm{~K}$. All standard deviations are probably precision rather than accuracy. Their value was the maximum measured at time zero, and they followed the decay of the Taylor wave for $2 \mu \mathrm{s}$.

A good detonation temperature has recently been optically measured for (unactivated) nitromethane by Choong-Shik Yoo of H Division. ${ }^{19}$ The intent was to create the pressure plateau of supracompression, discussed as the best detonation-point searching tool in Chapter 6. Four shots were run on the H-Division two-stage gas gun. A 4-mm-thick aluminum flyer hit a sample cell made of a 2-mm aluminum buffer plate, $6 \mathrm{~mm}$ of nitromethane, and a 2-mm sapphire window. The diameter of the NM was $19 \mathrm{~mm}$ so that it took $1.5 \mu \mathrm{s}$ for the edge effects to reach the sample center. Four flyer velocities of $3.11,2.88$, 2.55 , and $2.24 \mathrm{~mm} / \mu \mathrm{s}$ were used.

The experiment was modeled in the LLNL 1-D code using the NM JWL presented in Chapter 5. The JWL carried the assumptions that the NM detonates at time zero and that the detonation pressure is $12.0 \mathrm{GPa}$. Above this pressure, a totally flat pressure plateau is obtained using the JWL. Just below the detonation pressure, the code again shows a flat plateau but with a small spike at the start. Thus, finding the detonation point in the code would be difficult, going by just the pressure traces.

Fig. 8-1 shows the optical results of the nitromethane experiment in terms of temperature. All three runs were above the 12.0-GPa cylinder detonation pressure, as calculated by the 1-D code. The supracompression plateau is very obvious, and it shortens as one drops toward the detonation point. The lowest flyer velocity failed to detonate the nitromethane and so. confirmed the presence of the detonation point at a slightly higher pressure. The preliminary plateau results from this work are as follows: 


\begin{tabular}{cccccc}
$\begin{array}{c}\text { Shot } \\
\text { no. }\end{array}$ & $\begin{array}{c}\text { Flyer } \\
\text { velocity } \\
(\mathrm{mm} / \mu \mathrm{s})\end{array}$ & $\begin{array}{c}1-\mathrm{D} \\
\text { pressure } \\
(\mathrm{GPa})\end{array}$ & $\begin{array}{c}1-\mathrm{D} \\
\text { relative } \\
\text { volume }\end{array}$ & $\begin{array}{c}\text { Average } \\
\text { meas. } \\
\text { temp. }(\mathrm{K})\end{array}$ & $\begin{array}{c}\text { Time } \\
\text { meas. } \\
(\mu \mathrm{s})\end{array}$ \\
\hline 1 & 3.11 & 16.0 & 0.657 & $3967 \pm 18$ & 0.69 \\
2 & 2.88 & 14.7 & 0.679 & $3904 \pm 19$ & 0.59 \\
3 & 2.55 & 12.8 & 0.713 & $3886 \pm 40$ & 0.34 \\
\multicolumn{2}{l}{ Cylinder C-J } & 12.0 & $\mathbf{0 . 7 3 1}$ & $\mathbf{3 8 4 0}$ & \\
4 & 2.24 & 11.2 & 0.749 & &
\end{tabular}

The standard deviations represent precision.

We extrapolate linearly to the expected JWL pressure at $12.0 \mathrm{GPa}$ and obtain

$$
\mathrm{T}_{\mathrm{p}}=3840 \mathrm{~K}
$$

for NM. Although this is really a detonation or, at best, an adiabat temperature, it is tempting to use it as a code calibration of the C-J temperature. CHEQ at $3770 \mathrm{~K}$ is closest in predicting this result and BKWR, as expected, is worst.

It is interesting to speculate whether the $400-\mathrm{K}$ difference between the Taylor wave and the supracompression experiments is real. C. Tarver notes that the initial hottest temperatures may be missed in the Taylor wave measurement because it decays so quickly. However, the supracompression plateau could last long enough for carbon to precipitate, thereby releasing energy that pushes the temperature up.

\section{Freezing the Compositions}

A command in TIGER freezes the compositions at the arbitrary temperature of $1800 \mathrm{~K}$. This prevents the carbon monoxide from reacting all the way to $\mathrm{CO}_{2}$. We recall that BKWR is always cold and CHEQ is hot, so that the 1800-K freeze in effect freezes over a wide range of "real" temperatures. Below, we compare CHEQ runs with Ornellas' calorimetry in mols gas per mol explosive. 


\begin{tabular}{ccccc} 
& \multirow{2}{*}{$\begin{array}{c}\text { Approx. } \\
\text { density }\end{array}$} & \multicolumn{3}{c}{ Carbon monoxide } \\
\cline { 4 - 6 } Explosive & (g/cc) & & Meas'd & \multicolumn{2}{c}{ CHEQ } \\
\cline { 4 - 5 } BTF & 1.85 & 4.6 & 3.9 & Eqm \\
\hline FEFO & 1.61 & 1.9 & 1.8 & 0.6 \\
HMX & 1.89 & 1.1 & 1.6 & 0 \\
HMX & 1.19 & 2.7 & 2.6 & 0.1 \\
HNB & 1.96 & 0.3 & 0 & 0 \\
HNS & 1.68 & 4.7 & 5.9 & 1 \\
NM & 1.13 & 0.6 & 0.6 & 0 \\
PETN & 1.76 & 1.7 & 1.6 & 0 \\
TNT & 1.63 & 2.0 & 2.4 & 0.2
\end{tabular}

The measured and 1800-K frozen CHEQ runs agree, but the CHEQ runs allowed to react to equilibrium down to low temperature have almost no carbon monoxide left. All the samples listed above were heavily confined within the calorimeter so that the reshocking at the calorimeter wall is thought not to raise the temperature above 1500 to $1800 \mathrm{~K} .16$ The reshock model could profitably be run again in more detail.

Table 8-4 shows the detailed compositions for TIGER BKWR and CHEQ for three explosives at the C-J point, the $1800-\mathrm{K}$ freeze point, and at equilibrium at $1 \mathrm{~atm}$. The latter two points are on the adiabat. Our intent is to guess the kinetics. We see that the results of TIGER and CHEQ are in agreement for each explosive but the kinetics differ. The kinetics may be summarized as follows:

\begin{tabular}{|c|c|c|}
\hline PETN: & $\begin{array}{l}\text { at } \mathrm{C}-\mathrm{J} \\
\text { to } 1800 \mathrm{~K} \\
\text { to equilibrium }\end{array}$ & $\begin{array}{l}\text { have } \mathrm{CO}_{2}+\mathrm{HCOOH} \\
\mathrm{HCOOH} \rightarrow \mathrm{CO}+\mathrm{H}_{2} \mathrm{O} \\
2 \mathrm{CO}+\mathrm{H}_{2} \mathrm{O} \rightarrow \mathrm{CO}_{2}+\mathrm{CH}_{4}\end{array}$ \\
\hline BTF: & $\begin{array}{l}\text { at C-J } \\
\text { to } 1800 \mathrm{~K} \\
\text { to equilibrium }\end{array}$ & $\begin{array}{l}\text { have } \mathrm{C}+\mathrm{CO}_{2} \\
\mathrm{C}+\mathrm{CO}_{2} \rightarrow 2 \mathrm{CO} \\
2 \mathrm{CO} \rightarrow \mathrm{C}+\mathrm{CO}_{2}\end{array}$ \\
\hline TATI & $\begin{array}{l}\text { at C-J } \\
\text { to } 1800 \mathrm{~K} \\
\text { to equilibrium }\end{array}$ & $\begin{array}{l}\text { have } \mathrm{C}+\mathrm{CO}_{2} \\
\text { no change } \\
2 \mathrm{C}+\mathrm{H}_{2} \mathrm{O} \rightarrow\end{array}$ \\
\hline
\end{tabular}

The reactions between $1800 \mathrm{~K}$ and the one-atmosphere equilibrium represent the kinetics that we freeze without the physical understanding of why. 


\section{Phase Transitions and Look-Up Tables From CHEQ}

CHEQ's specialty is calculating multiple phases. CHEQ has aroused interest in the solid graphite-to-diamond transition and the splitting of nitrogen-water into two gas phases.

The precipitation of carbon is well-known and necessary if no oxygen is there to burn it; the presence of diamonds in detonation soot has also been seen in TNT and TATB-based explosives. ${ }^{20}$ Steinberg and Ree suggested that the presence of the diamond-graphite transition can be seen in the initial density-detonation velocity curve. 21,22 PETN, for example, shows an absolutely straight line for detonation velocity vs sample density, but no one expects carbon precipitation in this oxygen-rich explosive. A different result appears for HMX and RDX, for which a small change-of-slope appears between 1.0 and $1.5 \mathrm{~g} / \mathrm{cc}^{22,23}$

Can the phase transition actually be seen in an explosive? The effect of this phase transition in TATB has been calculated by A. Nichols using CHEQ2.5 and the results are in Table 8-5. The three combinations tried are (1) all carbon phases in equilibrium, (2) diamond only, and (3) graphite only. The mixed-phase and diamond-only phase begin at the same C-J point because diamond is the high-pressure equilibrium phase. In these runs, the $\mathrm{N}_{2}-\mathrm{H}_{2} \mathrm{O}$ was allowed to separate into two phases. The diamond-only model has a C-J point $3 \mathrm{GPa}$ lower than the graphite-only, but this would be hard to check, given the problems we have in determining where the LX-17 detonation pressure is. The detonation energies offer a better chance. The percent comparison with the mixed-phase carbon model gives these results:

\begin{tabular}{cccc} 
& $\% \mathrm{E}_{\mathrm{d}}$ & $(\mathrm{kJ} / \mathrm{cc})$ & \\
\cline { 2 - 4 } Carbon phases & $\mathrm{v}=1.2$ & $\mathrm{v}=2.2$ & $\mathrm{v}=6.5$ \\
\hline Diamond: mixed & -2 & -3 & -2 \\
Graphite: mixed & 8 & 3 & 2
\end{tabular}

An all-graphite version of TATB at $8 \%$ should be obvious near the C-J point, and the study of plates should answer the question. All other points with a 2 to $3 \%$ difference are more difficult but should also be possible.

The phase splitting of nitrogen-water into a nitrogen-rich gas phase and a water-rich gas phase is more controversial because doubts exists as to whether or not there is time for phase separation in a detonation. The phase splitting has been measured isothermally and reversibly to $830 \mathrm{~K}$ and $2.1 \mathrm{GPa} .{ }^{24-26}$ These pressures are far too low to be easily extrapolated to the explosive regime. Fig. 8-2 shows the phase diagram as calculated by CHEQ. The two-phase line is that for a 50-50 mol\% overall gaseous combination. The isothermal data are 
hardly to be found. The dashed lines are the adiabats for dense HMX and TATB, where two phases are calculated by CHEQ. As their pressures drop, the two phases merge and one is created. Steinberg sought to find the nitrogen-water transition for $\mathrm{HMX}$ at about $1.5 \mathrm{~g} / \mathrm{cc}$ with a C-J pressure vs density plot, but he concluded that the evidence was ambiguous. ${ }^{23}$ Recently, Koshi et al. added evidence to support the presence of the phase transition. They performed a Monte Carlo calculation on up to 256 particles and found that phase separation occurred in tens of picoseconds-certainly a fast time and one that would cause phase separation in a real explosive. 27

We now run TATB again in CHEQ with both $\mathrm{N}_{2}-\mathrm{H}_{2} \mathrm{O}$ phases and with only phase allowed. In these runs, the carbon has the mixed phase capability. The detailed results are listed in Table 8-5, and the percent energy comparisons are:

\begin{tabular}{cccc} 
& $\% \mathrm{E}_{\mathrm{d}}$ & $(\mathrm{kJ} / \mathrm{cc})$ & \\
\cline { 2 - 4 } $\mathrm{N}_{2}-\mathrm{H}_{2} \mathrm{O}$ phases & $\mathrm{v}=1.2$ & $\mathrm{v}=2.2$ & $\mathrm{v}=6.5$ \\
\hline One-phase: & 0.8 & 0.0 & -0.2 \\
Two-phase & & &
\end{tabular}

The code says that phase separation of nitrogen and water will not be measurable in TATB.

Haselman, van Thiel, and Ree first incorporated the phase transitions into the EOS for LX-14 and LX-17. Their presence may be seen in the function $\gamma=-\partial \ln P / \partial \operatorname{lnv}$ as shown in Fig. 8-3 using CHEQ2 in 1991. For LX-17, the higher temperature dip is assigned to the graphite-diamond phase transition and the lower temperature one to the nitrogen-water transition. 28 The situation is reversed for LX-14, which burns hotter, although Fig. 8-3 shows the two transitions merged into one large dip. Also shown is the JWL no. LH for LX-17, which is smooth and peaks near $\mathrm{v} \sim 1$.

The dips in $\gamma$ correspond to blips in the adiabat pressure, which appear small but might affect the detonation energy. Clearly, a JWL cannot reproduce blips, and this has led to the Look-Up Table. Fig. 8-4 shows the difference between the adiabat pressure calculated by the JWLs and those calculated from the Look-Up Tables for LX-14 and LX-17. The pressure differences are up to $0.9 \mathrm{GPa}$, and two separate features may seen in LX-17. The Look-Up Tables that generated these pressures were built from the output of CHEQ2.

Table 8-6 shows the Look-up Tables derived from CHEQ by L. Haselman for LX-14 and LX-17. These may be used, with an interpolation routine, to generate the Principal Adiabat described in Chapter 1. From Table 8-6, we note that the function $\mathrm{f}$ falls, as expected, from a higher value at small volumes. It passes through a minimum and rises again at large volumes. We recall from Chapter 2 that $f$ should approach $\omega$ and be constant at large volumes. It does not 
in this table because of the definition of the adiabat energy, $\mathrm{E}_{\mathrm{s}}$. CHEQ calculates an internal energy per unit mass, $E_{\mathbf{i}}$, which is converted into the energy of detonation per $\mathrm{cc}, \mathrm{E}_{\mathrm{d}}$, by

$$
E_{d}=E_{i} \rho_{o}+H_{f},
$$

where $\mathrm{H}_{\mathrm{f}}$ is the heat of formation. In Eq. (15), $\mathrm{E}_{d}$ and $\mathrm{E}_{\mathrm{i}}$ are positive, according to the convention of this report. Of necessity, however, $\mathrm{H}_{\mathrm{f}}$ retains the negative chemist's convention-which is the reason for the plus sign in Eq. (15). (CHEQ actually uses negative values of $E_{d}$ and $E_{i}$,).

The total energy of detonation, $E_{0}$, is found from Eq. (15) using the value of $E_{i}$ at $1 \mathrm{~atm}$. If we define the adiabat energy by

$$
E_{s}=E_{o}-E_{d}(v),
$$

we will obtain a function for $f$, the quantity in the Look-Up Table, that has a minimum at large volumes.

In the JWL, however, we recall that $\mathrm{E}_{0}$ is obtained at $\mathrm{v} \rightarrow \infty$ where $P \rightarrow 0$, and this sets $E_{s}=0$. We therefore define $E_{0}(\infty)$, which would be the energy of detonation, at $\mathrm{v} \rightarrow \infty$. Then,

$$
E_{\mathrm{s}}=E_{o(\infty)}-E_{d},
$$

and $f$ will now be constant at large volumes as expected. For $1.763 \mathrm{~g} / \mathrm{cc}$ PETN in CHEQ, $E_{0}$ is $10.36 \mathrm{~kJ} / \mathrm{cc}$, and $\mathrm{E}_{0}\left(\infty_{\infty}\right)$ is $11.00 \mathrm{~kJ} / \mathrm{cc}$. This adds a large $0.64 \mathrm{~kJ} / \mathrm{cc}$ to the adiabat energy everywhere, and it creates a near-constant value of $f$ of

$$
f(\text { PETN })=0.289 \pm 0.004,19<v<1780 .
$$

The added energy in adjusting the adiabat energy back to 1 atm is larger in CHEQ, where it is supposed to be accurate, than it is in the JWL, where a convergent integral at $\mathrm{v} \longrightarrow \infty$ is required. In other words, the JWL pressure is deliberately made to decrease faster at large volumes to make simple integration possible.

\section{References}

1. M. Cowperthwaite and W. H. Zwisler, Tiger Computer Program Documentation, Stanford Research Institute Publication Z106, 1973.

2. R. D. Cowan and W. Fickett, J. Chem. Phys. 24, 932 (1955). 
3. M. Finger, E. Lee, F. H. Helm, B. Hayes, H. Hornig, R. McGuire, M. Kahara, and M. Guidry, "The Effect of Elemental Composition on the Detonation Behavior of Explosives," Proceedings of the Sixth Symposium (International) on Detonation, Coronado, CA, August 24-27, 1976 (Office of Naval Research, Arlington, VA, ACR-221), pp. 710-722.

4. C. L. Mader, "Numerical Modeling of Detonations," University of California, Berkeley, 1979, pp. 412-448.

5. M. Cowperthwaite and W. H. Zwisler, "The JCZ Equations of State for Detonation Products and their incorporation into the Tiger Code," Proceedings of the Sixth Symposium (International) on Detonation, Coronado, CA, 24-27 August 1976 (Office of Naval Research, Arlington, VA ACR-221), pp. 162-172.

6. F. H. Ree, J. Chem. Phys. 81, 1251 (1984).

7. F. H. Ree, J. Chem. Phys. 84, 5845 (1986).

8. A. L. Nichols III and F. H. Ree, CHEQ 2.0 User's Manual, Lawrence Livermore National Laboratory, Livermore, CA, UCRL-MA-106754 (1990).

9. G. I. Kerley, "Theoretical Equations of State for the Detonation Products of Explosives," Proceedings Eighth Symposium (International) on Detonation, Albuquerque, NM, July 15-19, 1985, p. 540.

10. G. I. Kerley and T. L. Christian-Frear, "Prediction of Explosive Cylinder Tests using Equations of State from the PANDA Code," preprint, private communication, 1993.

11. M. Finger, E. Lee, F. H. Helm, B. Hayes, H. Hornig, R. McGuire, M. Kahara, and M. Guidry, "The Effect of Elemental Composition on the Detonation Behavior of Explosives," Proceedings Sixth Symposium (International) on Detonation, Coronado, CA, August 24-27, 1976, p. 710.

12. M. L. Hobbs and M. R. Baer, Nonideal Thermoequilibrium Calculations using a Large Product Species Data Base, Sandia National Laboratories, Albuquerque, NM, SAND92-0482 (1992).

13. M. L. Hobbs and M. R. Baer, "Calibration of the BKW-EOS and Application to Aluminized Composite Explosives," 5th International Conference of the Groupe de Travail de Pyrotechnie Euro Pyro 93, (1993) p. 1. 
14. M. L. Hobbs and M. R. Baer, "Calibrating the BKW-EOS with a Large Product Species Data Base and Estimated C-J Properties," Tenth International Detonation Symposium, Boston, MA, (1993), preprint.

15. M. L. Hobbs and M. R. Baer, Sandia National Laboratories, Albuquerque, NM, private communications, 1992-1993.

16. D. L. Ornellas, Calorimetric Determinations of the Heat and Products of Detonation for Explosives: October 1961 to April 1982, Lawrence Livermore National Laboratory, Livermore, CA, UCRL-52821 (1982).

17. Y. Kato, N. Mori, H. Sakai, T. Sakurai, and T. Hikita, "Detonation Temperature of Some Liquid and Solid Explosives," Proceedings Ninth Symposium (International) on Detonation, Portland, OR, August 28September 1, 1989, II, pp. 939-946.

18. Y. Kato, N. Mori, H. Sakai, K. Tanaka, T. Sakurai, and T. Hikita, "Detonation Temperature of Nitromethane and some Solid High Explosives," Proceedings Eighth (International) Symposium of Detonation, Albuquerque, NM, July 15-19, 1985, pp. 558-566.

19. C.-S. Yoo, Lawrence Livermore National Laboratory, Livermore, CA, to be published.

20. N. R. Greiner, D. S. Phillips, J. D. Johnson, and F. Volk, Nature 333, 440 (1988).

21. F. Ree, J. Thermo. Phys. 36, 3373 (1987).

22. D. J. Steinberg, "Comparison of Experimental Data on Detonation Velocity and Chapman-Jouget Pressure vs Initial HE Density with Predictions from Ree's Model Equation of State," Proceedings Eighth (International) Symposium of Detonation, Albuquerque, NM, July 15-19, 1985, pp. 513-520.

23. M. van Thiel and F. H. Ree, J. Appl. Phys. 62, 1761 (1987).

24. M. L. Japas and E. U. Franck, Ber. Bunsenges. Phys. Chem. 89, 793 (1985).

25. M. G. E. van Hinsburg, R. Verbrugge, and J. A. Schouten, Eleventh Symposium on Thermophysical Properties, Boulder, CO, June 23-27, 1991.

26. M. Costantino and S. F. Rice, J. Phys. Chem. 95, 9034 (1991). 
27. M. Koshi, H. Matsui, T. Saito, and K. Takayama, "A Theoretical Study for Gas-Gas Separation in High Temperature and High Pressure Fluid," Tenth International Detonation Symposium, Boston, MA, July 12-16, 1993, Paper Summaries, pp. 118-121.

28. M. van Thiel, memo to L. Haselman, April 22, 1991. 


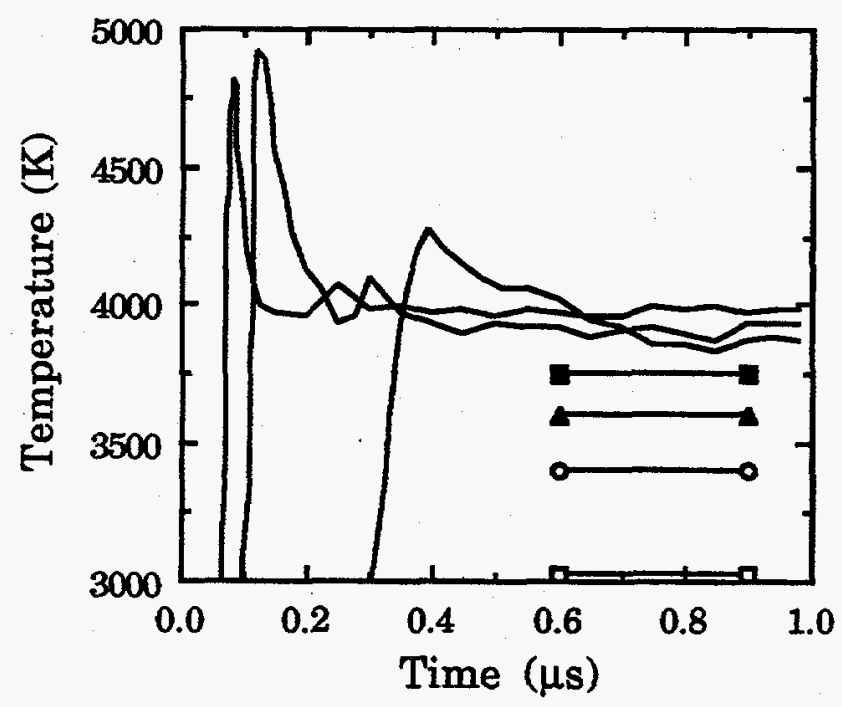

Fig. 8-1. Measured spectral emission data for temperature for the three supracompression runs above the detonation pressure of nitromethane. From left to right, the pressures are 16.0, 14.7 , and $12.8 \mathrm{GPa}$. The averaged data are extrapolated to $12.0 \mathrm{GPa}$ to obtain a detonation temperature of $3840 \mathrm{~K}$. From top to bottom, the code results are from CHEQ, JCZ3, BKWS and BKWR.

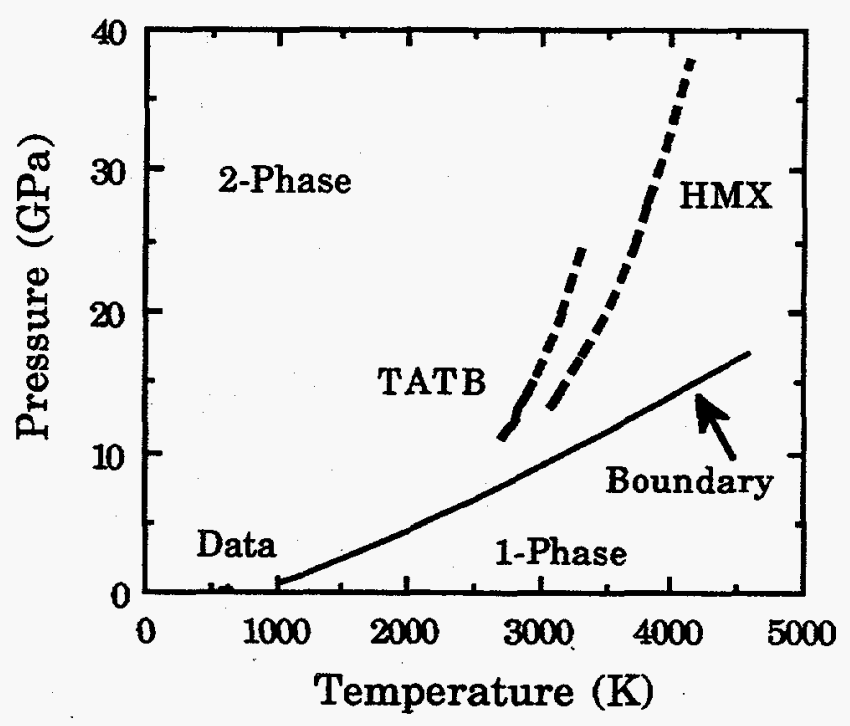

Fig. 8-2. CHEQ's predictions of $\mathrm{N}_{2}-\mathrm{H}_{2} \mathrm{O}$ phase separation. The line represents the separation in a $50-50 \mathrm{~mol} \%$ mix of nitrogen and water, with the two-phase region at the top. The measured data are shown in the blip at the far left. The calculated two-phase lines in detonating HMX and TATB are shown by the two dashed lines. At lower pressures, one-phase behavior results. 


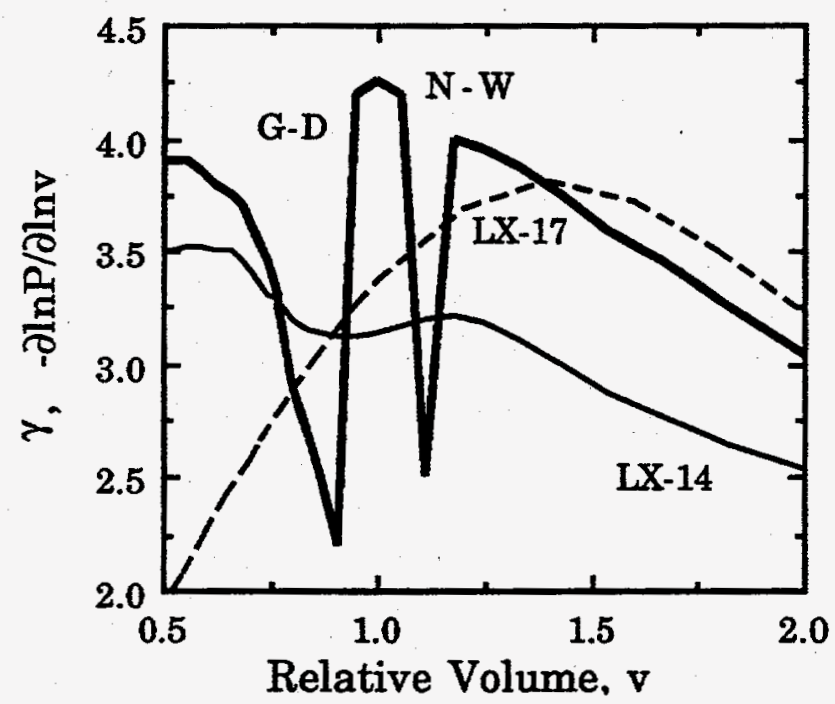

Fig. 8-3. Adiabatic $\gamma$, equal to - $\partial \ln P / \partial \ln v$, as a function of the relative volume for $\mathrm{LX}-14$ and LX-17. The solid lines are the predictions from CHEQ. For LX-17 (heavy line), the graphitediamond (G-D) and nitrogen-water (N-W) phase transitions are indicated. The dotted line is the LH JWL for LX-17.

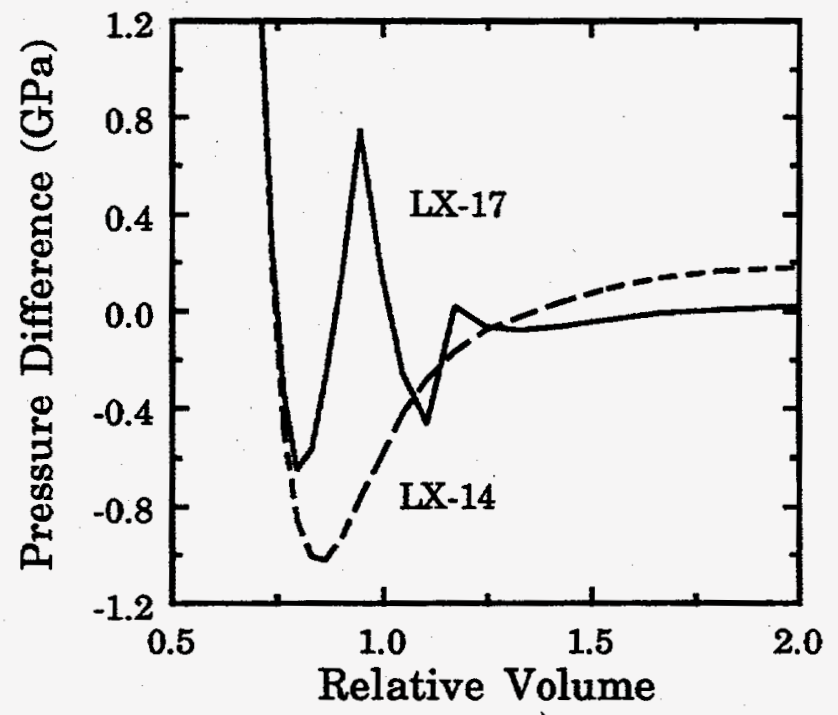

Fig. 8-4. Pressure difference between the Look-Up Table and the JWL for LX-14 and LX-17 as a function of relative volume. The pressure blips are the result of the suspected phase transitions. Confirming the existence of these blips is a challenge for the future. 
Table 8-1. Constants used in the two versions of BKW and JCZ3. The constants $\alpha, \beta, x$, and $\Theta$ define the version of BKW. The other constants go into the respective libraries. The elements are $\mathrm{C}, \mathrm{H}, \mathrm{N}, \mathrm{O}, \mathrm{F}, \mathrm{Cl}, \mathrm{Al}, \mathrm{Li}, \mathrm{Na}, \mathrm{K}$, and $\mathrm{Zr}$. The abbreviation $\mathrm{A}$ is Angstroms.

\begin{tabular}{|c|c|c|c|c|c|}
\hline${ }^{\circ}$ & & $\begin{array}{l}\text { LLNL } \\
\text { BKWR }\end{array}$ & $\begin{array}{c}\text { SNL } \\
\text { BKWS }\end{array}$ & \multicolumn{2}{|c|}{ JCZ3-both libraries } \\
\hline BKW & $\alpha$ & 0.5 & 0.5 & & \\
\hline defining & $\beta$ & 0.176 & 0.298 & & \\
\hline constants & $\kappa$ & 11.8 & 10.5 & & \\
\hline & $\theta(\mathrm{K})$ & 1850 & 6620 & & \\
\hline & & \multicolumn{2}{|c|}{ Covolumes $\left(A^{3}\right)$} & $r_{0}(\mathrm{~A})$ & $e_{0}(K)$ \\
\hline Libraries- & $\mathrm{CH}_{3} \mathrm{OH}$ & & 800 & & \\
\hline Common & $\mathrm{CH}_{4}$ & 550 & 493 & 4.29 & 154 \\
\hline \multirow[t]{10}{*}{ gases } & $\mathrm{CO}$ & 440 & 614 & 4.05 & 120 \\
\hline & $\mathrm{CO}_{2}$ & 610 & 663 & 4.20 & 200 \\
\hline & $\mathrm{H}_{2}$ & 98 & 153 & 3.34 & 37 \\
\hline & $\mathrm{H}_{2} \mathrm{O}$ & 270 & 376 & 3.35 & 138 \\
\hline & $\mathrm{HCN}$ & 986 & 892 & & \\
\hline & HCOOH & 722 & 865 & 4.15 & 462.5 \\
\hline & $\mathrm{N}_{2}$ & 404 & 376 & 4.05 & 120 \\
\hline & $\mathrm{NH}_{3}$ & 384 & 418 & 3.35 & 138 \\
\hline & NO & 386 & 394 & 3.97 & 105 \\
\hline & $\mathrm{O}_{2}$ & 325 & 316 & 3.73 & 132 \\
\hline Other & $\mathrm{CCl}_{4}$ & 1840 & 1840 & & \\
\hline \multirow[t]{5}{*}{ gases } & $\mathrm{CF}_{4}$ & 1100 & 1260 & 5.00 & 220 \\
\hline & $\mathrm{Cl}_{2}$ & 532 & 872 & 4.61 & 336.9 \\
\hline & $F_{2}$ & 387 & 343 & 3.50 & 200 \\
\hline & $\mathrm{HCl}$ & 643 & 570 & & \\
\hline & HF & 389 & 351 & 3.30 & 100 \\
\hline Condensed & $\mathrm{Al}_{2} \mathrm{O}_{3}$ & $\mathrm{Li}_{2} \mathrm{O}$ & $\mathrm{Na}_{2} \mathrm{O}$ & $\mathrm{AlF}_{3}$ & \\
\hline \multirow[t]{3}{*}{ species } & C & $\mathrm{Li}_{2} \mathrm{CO}_{3}$ & $\mathrm{ZrO}_{2}$ & $\mathbf{K F}$ & \\
\hline & $\mathrm{K}_{2} \mathrm{CO}_{3}$ & LiOH & & $\mathrm{LiF}$ & \\
\hline & $\mathrm{K}_{2} \mathrm{O}$ & $\mathrm{Na}_{2} \mathrm{CO}_{3}$ & & $\mathrm{NaF}$ & \\
\hline
\end{tabular}


Table 8-2. Comparison of experimental cylinder detonation velocities and the calorimetric total detonation energies with the values calculated by five thermochemical codes. The \%-calculated compares the measured value with the calculated value (calculated value in the denominator).

\begin{tabular}{|c|c|c|c|c|c|c|c|c|c|c|}
\hline \multirow[b]{2}{*}{ Explosive } & \multirow[b]{2}{*}{$\begin{array}{c}\text { Density } \\
(g / c c)\end{array}$} & \multicolumn{5}{|c|}{ Detonation velocity } & \multicolumn{4}{|c|}{ Total energy of detonation } \\
\hline & & $\begin{array}{c}\% \text { cf. } \\
\text { BKWR }\end{array}$ & $\begin{array}{c}\text { \% cf. } \\
\text { BKWS }\end{array}$ & $\begin{array}{l}\% \text { cf. } \\
\text { JCZ3 }\end{array}$ & $\begin{array}{l}\% \text { cf. } \\
\text { CHEQ }\end{array}$ & $\begin{array}{c}\% \mathrm{cf} . \\
\text { PANDA }\end{array}$ & $\begin{array}{c}\% \mathrm{cf} . \\
\text { BKWR }\end{array}$ & $\begin{array}{c}\% \mathrm{cf} . \\
\text { BKWS }\end{array}$ & $\begin{array}{l}\% \text { cf. } \\
\text { JCZ3 }\end{array}$ & $\begin{array}{l}\text { \% cf. } \\
\text { CHEQ }\end{array}$ \\
\hline BTF & 1.852 & $\overline{2}$ & $\overline{4}$ & -4 & $\overline{2}$ & $\overline{-1}$ & $\overline{3}$ & -2 & 9 & 1 \\
\hline 1,2-DP & 1.26 & -3 & 4 & -3 & -4 & & 12 & 7 & 5 & $-\mathbf{3}$ \\
\hline FEFO & 1.607 & 2 & 1 & -1 & -2 & & -7 & -3 & -4 & -5 \\
\hline HMX & 1.893 & 0 & -3 & 0 & -3 & 0 & -4 & -2 & 1 & -2 \\
\hline HMX & 1.188 & -4 & -1 & 0 & -3 & -1 & -6 & -4 & -3 & -3 \\
\hline HNB & 1.965 & 6 & 6 & 4 & 7 & 1 & -2 & -1 & 2 & 5 \\
\hline HNS & 1.655 & 1 & -1 & 3 & 2 & & 2 & -9 & 12 & 7 \\
\hline HNS & 1.001 & -5 & -4 & -5 & -9 & -2 & -1 & -13 & 5 & -4 \\
\hline NM & 1.13 & -6 & -5 & 3 & 0 & 1 & -10 & -8 & -2 & -4 \\
\hline PETN & 1.763 & -1 & -5 & 2 & -1 & 0 & -5 & -3 & -1 & -2 \\
\hline PETN & 1.503 & -1 & -3 & 3 & 0 & 1 & -2 & -1 & -1 & 2 \\
\hline RX-23-AA & 1.424 & 2 & 0 & 8 & 2 & 1 & 1 & 2 & 4 & -4 \\
\hline $\mathrm{RX}-23-\mathrm{AB}$ & 1.356 & 1 & -3 & 5 & 2 & 1 & 5 & 7 & 7 & 10 \\
\hline RX-23-AC & 1.136 & -1 & 6 & 23 & -1 & 1 & -8 & -5 & -9 & -12 \\
\hline TATB & 1.86 & -4 & -6 & -3 & -4 & -6 & 9 & -7 & 6 & -3 \\
\hline TNT & 1.632 & 2 & -1 & 8 & 5 & 1 & -9 & -8 & 17 & -1 \\
\hline Average & & -1 & -1 & $\overline{3}$ & 0 & $\overline{0}$ & -1 & -3 & 3 & -1 \\
\hline Stdev & & 3 & 4 & 7. & 4 & 2 & 6 & 5 & 7 & 5 \\
\hline
\end{tabular}


Table 8-3. Comparison of experimental cylinder detonation velocities at relative volumes of 2.2 and 6.5 with the values calculated by five thermochemical codes. The \%-calculated compares the measured value with the calculated value (calculated value in the denominator). The cylinder velocities-squared have been set with PETN energies to calculate all other detonation energies.

\begin{tabular}{lccccc|ccccc|} 
& \multicolumn{3}{c}{ Energy of detonation at $\mathrm{v}=2.2$} & \multicolumn{3}{c|}{ Energy of detonation at $\mathrm{v}=6.5$} \\
\cline { 2 - 11 } Explosive & \% cf. & \% cf. & \% cf. & \% cf. & \% cf. & \% cf. & \% cf. & \% cf. & \% cf. & \% cf. \\
\hline BTF & 0 & BKWS & JCZ3 & CHEQ & PANDA & BKWR & BKWS & JCZ3 & CHEQ & PANDA \\
1,2-DP & -17 & 15 & -12 & -2 & -4 & 4 & -3 & 0 & 1 & 3 \\
FEFO & -13 & -7 & -7 & -2 & & -7 & 18 & 7 & 11 & \\
HMX & -7 & -6 & -6 & -3 & 0 & -7 & -2 & 0 & 1 & \\
HMX & 3 & -1 & 5 & 18 & 4 & 7 & -2 & 2 & 2 & 6 \\
HNB & -1 & -1 & 0 & 12 & 13 & 1 & 1 & 6 & 11 & 11 \\
HNS & -6 & -14 & -10 & -1 & & 0 & -9 & 2 & 0 & \\
HNS & -10 & -17 & -8 & 5 & -10 & -4 & -12 & 1 & 2 & -3 \\
NM & -9 & -10 & -2 & 9 & 0 & -6 & -6 & 4 & 8 & 5 \\
PETN & 0 & -5 & 3 & 10 & 7 & 0 & -3 & 6 & 10 & 8 \\
PETN & -1 & -5 & 4 & 18 & 11 & 2 & -1 & 9 & 14 & 11 \\
RX-23-AA & 4 & 2 & 11 & 10 & 6 & 10 & 8 & 17 & 15 & 14 \\
RX-23-AB & 1 & -2 & 6 & 28 & 6 & 6 & 3 & 11 & 39 & 8 \\
RX-23-AC & -4 & 2 & 18 & 18 & 1 & 1 & 4 & 17 & 16 & 8 \\
TATB & -3 & -14 & -9 & -7 & -9 & 0 & -12 & -3 & -8 & -7 \\
TNT & -5 & -12 & -8 & 0 & -3 & 1 & -7 & 4 & -3 & 2 \\
\hline Average & -4 & -5 & -1 & 7 & 2 & 0 & -1 & 6 & 8 & 6 \\
Stdev & 6 & 8 & 8 & 10 & 7 & 5 & 8 & 6 & 11 & 6
\end{tabular}


Table 8-4. Product compositions from TIGER, CHEQ, and calorimeter measurement. The sequence in time is the C-J point, the 1800-K freeze, and the unfrozen 1-atmosphere equilibrium point. The latter two are on the Principal Adiabat. CHEQ gives the phase of carbon as diamond (d), graphite (g), and liquid (1). All units are in mol per mol of initial explosive.

\begin{tabular}{ccccccccc} 
& & & \multicolumn{7}{c}{ Product concentration (mol/mol) } \\
\cline { 4 - 9 } & Condition & & CO & $\mathrm{CO}_{2}$ & $\mathrm{C}$ & $\mathrm{CH}_{4}$ & $\mathrm{H}_{2} \mathrm{O}$ & $\mathrm{N}_{2}$ \\
\hline PETN & C-J & BKWR & 1.8 & 3.2 & 0.0 & 0.0 & 3.9 & 1.9 \\
1.74 & C-J & CHEQ & 0.4 & 4.0 & $0.6(\mathrm{~d})$ & 0.1 & 3.7 & 1.9 \\
g/cc & freeze 1800 K & BKWR & 1.2 & 3.7 & 0.0 & 0.1 & 3.4 & 2.0 \\
& freeze 1800 K & CHEQ & 1.6 & 3.4 & 0.0 & 0.0 & 3.6 & 2.0 \\
& calorimeter & measd & 1.6 & 3.3 & 0.0 & 0.0 & 3.5 & 2.0 \\
& eqm 1 atm & CHEQ & 0.0 & 4.4 & $0.2(\mathrm{~g})$ & 0.3 & 3.2 & 2.0 \\
& eqm 1 atm & BKWR & 0.0 & 4.5 & 0.0 & 0.5 & 3.0 & 2.0 \\
\hline BTF & C-J & BKWR & 0.4 & 2.8 & 2.8 & 0.0 & 0.0 & 3.0 \\
1.86 & C-J & CHEQ & 0.8 & 2.6 & $2.6(\mathrm{l})$ & 0.0 & 0.0 & 3.0 \\
g/cc & freeze 1800 K & BKWR & 3.1 & 1.4 & 1.4 & 0.0 & 0.0 & 3.0 \\
& freeze 1800 K & CHEQ & 3.9 & 1.1 & $1.1(\mathrm{~g})$ & 0.0 & 0.0 & 3.0 \\
& calorimeter & measd & 2.9 & 1.6 & 1.6 & 0.0 & 0.1 & 2.9 \\
& eqm 1 atm & CHEQ & 0.6 & 1.7 & $2.7(\mathrm{~g})$ & 0.0 & 0.0 & 3.0 \\
& eqm 1 atm & BKWR & 0.0 & 3.0 & 3.0 & 0.0 & 0.0 & 3.0 \\
\hline TATB & C-J & BKWR & 0.6 & 1.3 & 4.1 & 0.0 & 2.7 & 2.9 \\
1.83 & C-J & CHEQ & 0.0 & 1.6 & $4.4(\mathrm{~d})$ & 0.0 & 2.8 & 2.9 \\
g/cc & freeze 1800 K & BKWR & 0.3 & 1.6 & 4.1 & 0.0 & 2.7 & 2.9 \\
& freeze 1800 K & CHEQ & 0.8 & 1.5 & $3.6(\mathrm{~g})$ & 0.2 & 2.3 & 2.9 \\
& calorimeter & measd & $\mathbf{0 . 4}$ & $\mathbf{2 . 0}$ & $\mathbf{3 . 6}$ & $\mathbf{0 . 0}$ & $\mathbf{2 . 1}$ & $\mathbf{2 . 3}$ \\
& eqm 1 atm & CHEQ & 0.0 & 1.7 & $4.1(\mathrm{~g})$ & 0.2 & 2.6 & 3.0 \\
& eqm 1 atm & BKWR & 0.0 & 3.0 & 1.5 & 1.5 & 0.0 & 3.0
\end{tabular}

Table 8-5. CHEQ runs on TATB with different phase combinations. The carbon is either in mixed equilibrium or has been constrained to be pure diamond or pure graphite. The mixed carbon runs have been done with one or two phases of nitrogen and water. the differences between the carbon phases can be measured; the differences in $\mathrm{N}_{2}-\mathrm{H}_{2} \mathrm{O}$ cannot.

\begin{tabular}{|c|c|c|c|c|c|c|}
\hline \multirow{2}{*}{$\begin{array}{l}\text { Carbon } \\
\text { phases }\end{array}$} & $\mathrm{N}_{2}-\mathrm{H}_{2} \mathrm{O}$ & $\mathbf{P}_{\mathbf{c j}}$ & $\mathbf{T}_{\mathrm{cj}}$ & $\mathrm{E}_{\mathrm{d}}$ & $(\mathrm{kJ} / \mathrm{cc})$ & \\
\hline & phases & (GPa) & (K) & $v=1.2$ & $v=2.2$ & $v=6.5$ \\
\hline Mixed & Two-phase & 26.4 & $\overline{3280}$ & 2.58 & 5.00 & 6.16 \\
\hline Diamond & Two-phase & 26.4 & 3280 & 2.54 & 4.84 & 6.03 \\
\hline Graphite & Two-phase & 29.7 & 3170 & 2.78 & 5.14 & 6.26 \\
\hline $\mathrm{N}_{2}-\mathrm{H}_{2} \mathrm{O}$ & Carbon & $P_{c j}$ & Temp. & $E_{d}$ & $(\mathrm{~kJ} / \mathrm{cc})$ & \\
\hline phases & phases & $(\mathrm{GPa})$ & (K) & $\mathrm{v}=1.2$ & $v=2.2$ & $v=6.5$ \\
\hline Two-phase & Mixed & $\overline{26.4}$ & 3280 & 2.58 & 5.00 & 6.16 \\
\hline One-phase & Mixed & 28.4 & 3091 & 2.60 & 5.00 & 6.15 \\
\hline
\end{tabular}


Table 8-6. L. Haselman's CHEQ-based Look-Up Tables for the adiabats of LX-14 and LX-17. Pressure is in Mbars, energy in Mbar $\mathrm{cc} / \mathrm{cc}$, detonation velocity in $\mathrm{mm} / \mathrm{\mu s}$, and density in $\mathrm{g} / \mathrm{cc}$. The adiabat point is in boldface. $\eta$ is the inverse of $v$. Sub-a refers to the adiabat detonation point.

\begin{tabular}{|c|c|c|c|c|c|c|c|c|c|c|c|}
\hline & \multicolumn{4}{|c|}{ LX-14, Table no. TL } & \multirow[b]{2}{*}{0.8815} & \multicolumn{5}{|c|}{ LX-17, Table no. L15 } & \multirow[b]{2}{*}{0.7600} \\
\hline & & $\overline{\mathrm{P}_{\mathrm{a}}}$ & 0.3324 & $\overline{\mathrm{D}}$ & & & & $\overline{P_{a}}$ & 0.255 & $\overline{\mathbf{D}}$ & \\
\hline & & $\mathbf{v a}_{\mathbf{a}}$ & 0.7669 & $\rho_{0}$ & 1.835 & & & $v_{a}$ & 0.7676 & po & 1.900 \\
\hline & & $\gamma_{a}$ & 3.2896 & $\mathbf{E}_{\mathbf{o}}$ & 0.100 & & & $\gamma_{a}$ & $\mathbf{3 . 3 0 3 7}$ & $\mathrm{E}_{\mathrm{o}}$ & 0.069 \\
\hline & & $\mathbf{E}_{\mathfrak{a}}$ & 0.1387 & & & & & $\mathbf{E}_{\mathbf{a}}$ & 0.0986 & & \\
\hline & $\eta$ & $\gamma$ & $\begin{array}{c}\mathbf{P}_{\mathbf{S}} \\
(\mathbf{M b})\end{array}$ & $\begin{array}{c}\mathrm{E}_{\mathrm{S}} \\
(\mathrm{Mb} \cdot \mathrm{cc} \\
/ \mathrm{cc})\end{array}$ & f & $\mathbf{v}$ & $\eta$ & $\gamma$ & $\begin{array}{c}\mathbf{P}_{\mathbf{S}} \\
(\mathrm{Mb})\end{array}$ & $\begin{array}{c}\mathrm{E}_{\mathbf{s}} \\
(\mathrm{Mb} \cdot \mathrm{cc} \\
/ \mathrm{cc})\end{array}$ & f \\
\hline 0.5000 & 2.00 & 3.51 & 1.4681 & 0.3317 & 2.2128 & 5000 & 2.00 & 90 & 1.2813 & 0.2564 & 2.4991 \\
\hline 0.5263 & .90 & 3.51 & 1.2275 & 0.2964 & 2.1799 & 0.5263 & 1.90 & 3.90 & .0471 & 0.2259 & 2.4400 \\
\hline 0.5556 & 1.80 & 3.52 & 1.0162 & 0.2637 & 2.1408 & & 1.80 & 3.90 & 8461 & 0.1983 & 2.3702 \\
\hline 0.5882 & 1.70 & 3.52 & 0.8318 & 0.2336 & 2.0942 & 0.5882 & 1.70 & 3.85 & 0.6773 & 0.1736 & 2.2953 \\
\hline 0.6250 & 1.60 & 3.51 & 0.6723 & 0.2061 & 2.0385 & .6250 & 1.60 & 3.80 & 0.5363 & 0.1514 & 2.2143 \\
\hline 0.6667 & 1.50 & 51 & 0.5362 & 0.1811 & 1.9740 & .6667 & 1.50 & 3.75 & .4196 & 0.1316 & 2.1258 \\
\hline 0.6897 & 1.45 & 3.46 & 0.4762 & 0.1695 & 1.9376 & 0.6897 & 1.45 & 3.70 & 0.3698 & 0.1225 & 2.0814 \\
\hline 0.7143 & 1.40 & 3.39 & 0.4218 & 0.1584 & 1.9014 & 0.7143 & 1.40 & 3.60 & 0.3257 & .1140 & 2.0406 \\
\hline 0.7407 & 1.35 & 3.31 & 0.3728 & 0.1479 & 1.8666 & 0.7407 & 1.35 & 3.45 & 0.2871 & .1059 & 2.0077 \\
\hline 0.7669 & 1.3040 & 3.29 & 0.3324 & 0.1387 & 1.8373 & 0.7676 & 1.3027 & $\mathbf{3 . 3 0 3 7}$ & 0.2550 & 0.0986 & 1.9848 \\
\hline 0.7692 & 1.30 & 3.27 & 0.3291 & 0 & 1.8347 & & 1.30 & 3.25 & 0.2533 & 82 & 1.9835 \\
\hline 0.8000 & 1.25 & 3.20 & 0.2895 & 0.1285 & 1.8028 & 0.8000 & 1.25 & 2.90 & 0.2231 & 09 & 1.9631 \\
\hline 0.8333 & 1.20 & 3.15 & 0.2541 & 0.1194 & 1.7732 & .8333 & 1.20 & 2.70 & 0.1981 & & 1.9681 \\
\hline 0.8696 & 1.15 & 3.13 & 0.2222 & 0.1108 & 1.7438 & .8696 & 1.15 & 2.50 & 0.1765 & 0.0771 & 1.9901 \\
\hline 0.9091 & .10 & 12 & 0.1934 & 0.1026 & 1.7131 & 91 & 1.10 & 2.20 & 0.1577 & 0.0705 & 2.0325 \\
\hline 0.9524 & 1.05 & 12 & 0.1673 & 0948 & 1.6799 & 9524 & 1.05 & 4.20 & 1419 & 0.0640 & 2.1094 \\
\hline & 1.00 & 13 & 0.1437 & 874 & 1.6433 & & 1.00 & 4.25 & 159 & & 1.9998 \\
\hline & o & 17 & 0.1224 & & 13 & & 0.95 & 20 & 334 & 25 & 1.8748 \\
\hline & 90 & 20 & 0.1032 & 39 & 1.5511 & & 0.90 & 50 & .0747 & 0.0 & 1.7440 \\
\hline 1.1765 & 85 & 3.21 & 0.0860 & 0.0677 & 1.4934 & & 0.85 & 4.00 & 0.0646 & 0.0430 & 1.7677 \\
\hline 1.2500 & 0.80 & 18 & 0.0708 & 0620 & 1.4280 & 30 & 0.80 & 3.95 & .0509 & 0.0388 & 1.6396 \\
\hline 1.3333 & 75 & 10 & 0.0577 & 0.0567 & 1.3587 & 1.3333 & 0.75 & 3.87 & 0.0396 & 0.0351 & 1.5053 \\
\hline & 0.70 & 2.99 & 0.0467 & 0.0517 & 1.2896 & & 0.70 & 75 & 0.0304 & 0.0318 & 1.3683 \\
\hline 1.5385 & 0.65 & 2.87 & 0.0375 & 0.0471 & 1.2234 & 1.5385 & 0.65 & 3.60 & 0.0231 & 0.0288 & 1.2333 \\
\hline 1.6667 & 0.60 & 2.76 & 0.0298 & 0.0428 & 1.1607 & 1.6667 & 0.60 & 3.45 & 0.0174 & 0.0263 & 1.1036 \\
\hline 1.8182 & 0.55 & 2.64 & 0.0235 & 0.0388 & 1.1008 & 1.8182 & 0.55 & 3.25 & 0.0129 & 0.0240 & 0.9798 \\
\hline & 0.50 & 2.53 & 0.0183 & 0.0350 & 1.0451 & 000 & 0.50 & 3.05 & 0.0095 & 0.0220 & 0.8667 \\
\hline 2.2222 & 0.45 & 2.41 & 0.0141 & 0.0315 & 0.9931 & .2222 & 0.45 & 2.85 & 0.0069 & 0.0202 & 0.7641 \\
\hline 2.5000 & 0.40 & 2.29 & 0.0106 & 0.0281 & 0.9465 & 2.5000 & 0.40 & 2.60 & 0.0050 & 0.0185 & 0.6719 \\
\hline 2.8571 & 0.35 & 2.17 & 0.0079 & 0.0248 & 0.9056 & 2.8571 & 0.35 & 2.30 & 0.0035 & 0.0170 & 0.5940 \\
\hline 3.3333 & 0.30 & 2.05 & 0.0057 & 0.0216 & 0.8710 & 3.3333 & 0.30 & 2.00 & 0.0025 & 0.0156 & 0.5340 \\
\hline
\end{tabular}

$\mathrm{E}_{\mathrm{S}}$

\begin{tabular}{|c|c|c|c|c|c|c|c|c|c|c|c|}
\hline \multirow[b]{6}{*}{ 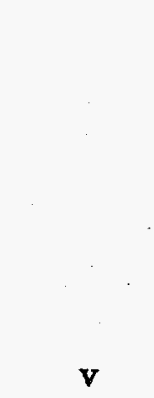 } & \multicolumn{4}{|c|}{ LX-14, Table no. TL } & \multirow[b]{2}{*}{0.8815} & & \multicolumn{4}{|c|}{ LX-17, Table no. L15 } & \multirow[b]{2}{*}{0.7600} \\
\hline & & $\overline{\mathbf{P}_{\mathbf{a}}}$ & 0.3324 & $\overline{\mathrm{D}}$ & & & & $\overline{\mathbf{P}_{\mathbf{a}}}$ & 0.255 & $\overline{\mathbf{D}}$ & \\
\hline & & $\mathbf{v}_{\mathbf{a}}$ & 0.7669 & $\rho_{0}$ & 1.835 & & & $v_{a}$ & 0.7676 & po & 1.900 \\
\hline & & $\gamma_{0}$ & 3.2896 & $\mathrm{E}_{\mathbf{o}}$ & 0.100 & & & $\gamma_{a}$ & 3.3037 & $\mathrm{E}_{\mathrm{o}}$ & 0.069 \\
\hline & & $\mathbf{E}_{\mathfrak{a}}$ & 0.1387 & & & & & $\mathbf{E}_{\mathbf{a}}$ & 0.0986 & & \\
\hline & $\eta$ & $\gamma$ & $\begin{array}{c}\mathbf{P}_{\mathbf{S}} \\
(\mathbf{M b})\end{array}$ & $\begin{array}{c}\mathrm{E}_{\mathrm{S}} \\
(\mathrm{Mb} \cdot \mathrm{cc} \\
/ \mathrm{cc})\end{array}$ & $f$ & $v$ & $\eta$ & $\gamma$ & $\begin{array}{c}\mathbf{P}_{\mathbf{S}} \\
(\mathrm{Mb})\end{array}$ & $\begin{array}{c}\mathbf{E}_{\mathbf{s}} \\
(\mathbf{M b} \cdot \mathbf{c c} \\
/ \mathrm{cc})\end{array}$ & $f$ \\
\hline 0.5000 & .00 & 3.51 & 1.4681 & 0.3317 & 2128 & .5000 & 2.00 & 90 & 1.2813 & 0.2564 & 2.4991 \\
\hline 0.5263 & 1.90 & 3.51 & 1.2275 & 0.2964 & 2.1799 & 5263 & 1.90 & 3.90 & .0471 & 0.2259 & 2.4400 \\
\hline 0.5556 & 1.80 & 3.52 & 1.0162 & 0.2637 & 2.1408 & 0.5556 & 1.80 & 3.90 & 0.8461 & 0.1983 & 2.3702 \\
\hline 0.5882 & 1.70 & 3.52 & 0.8318 & 0.2336 & 2.0942 & 882 & 1.70 & 85 & 6773 & .1736 & 2.2953 \\
\hline 0.6250 & 1.60 & 3.51 & 0.6723 & 0.2061 & 2.0385 & 0.6250 & 1.60 & 3.80 & 0.5363 & 0.1514 & 2.2143 \\
\hline 0.6667 & 1.50 & 3.51 & 0.5362 & 0.1811 & 1.9740 & .6667 & 1.50 & 3.75 & 4196 & .1316 & 2.1258 \\
\hline 0.6897 & 1.45 & 3.46 & 0.4762 & 0.1695 & 1.9376 & .6897 & 1.45 & 70 & 3698 & 1225 & 2.0814 \\
\hline 0.7143 & 1.40 & 3.39 & 0.4218 & 0.1584 & 1.9014 & 0.7143 & 1.40 & 3.60 & .3257 & 0.1140 & 2.0406 \\
\hline 0.7407 & 1.35 & 3.31 & 0.3728 & 0.1479 & 1.8666 & 0.7407 & 1.35 & 3.45 & 0.2871 & 0.1059 & 2.0077 \\
\hline 0.7669 & 1.3040 & 3.29 & 0.3324 & 0.1387 & 1.8373 & 0.7676 & 1.3027 & 3.3037 & 0.2550 & 0.0986 & 1.9848 \\
\hline 0.7692 & 1.30 & 3.27 & 0.3291 & 0.1380 & 1.8347 & 0.7692 & 1.30 & 3.25 & 0.2533 & 0.0982 & 1.9835 \\
\hline 0.8000 & 1.25 & 3.20 & 0.2895 & 0.1285 & 1.8028 & 0.8000 & 1.25 & 2.90 & 0.2231 & 0.0909 & 1.9631 \\
\hline 0.8333 & 1.20 & 3.15 & 0.2541 & 0.1194 & 1.7732 & 33 & 1.20 & 2.70 & 1981 & & 1.9681 \\
\hline 0.8 & 1.15 & 3.13 & 0.2 & & & & 1.15 & 50 & 1765 & & 901 \\
\hline 0.9091 & 1.10 & 3.12 & 0.1934 & 0.1026 & 1.7131 & 91 & 1.10 & 2.20 & 0.1577 & 0.0705 & 2.0325 \\
\hline 0.9524 & 1.05 & 3.12 & 0.1673 & 0.0948 & 1.6799 & 24 & 1.05 & 4.20 & 0.1419 & 40 & 2.1094 \\
\hline 1.0000 & 1.00 & 3.13 & 0.1437 & 0.0874 & 1.6433 & 200 & 1.00 & 4.25 & 1159 & 0.0579 & 1.9998 \\
\hline 1.0526 & 0.95 & 3.17 & 0.1224 & 0.0805 & 1.6013 & 526 & 0.95 & 4.20 & .0934 & 0.0525 & 1.8748 \\
\hline 1.1111 & 0.90 & 3.20 & 0.1032 & 0739 & 1.5511 & 1111 & 0.90 & 2.50 & .0747 & 0.0476 & 1.7440 \\
\hline 1.1765 & .85 & 3.21 & 0.0860 & 0.0677 & 1.4934 & 1.1765 & 0.85 & 4.00 & 0646 & 0.0430 & 1.7677 \\
\hline 1.2500 & 0.80 & 3.18 & 0.0708 & 20 & 1.4280 & 00 & 0.80 & 3.95 & 509 & 38 & 1.6396 \\
\hline 1.3333 & 0.75 & 3.10 & 0.0577 & 567 & 1.3587 & .3333 & 0.75 & 3.87 & 0396 & 0.0351 & 1.5053 \\
\hline 1.4286 & 0.70 & 2.99 & 0.0467 & 0.0517 & 1.2896 & .4286 & 0.70 & 3.75 & 0.0304 & 0.0318 & 1.3683 \\
\hline 1.5385 & 0.65 & 2.87 & 0.0375 & 0.0471 & 1.2234 & .5385 & 0.65 & 3.60 & 0.0231 & 0.0288 & 1.2333 \\
\hline 1.6667 & 0.60 & 2.76 & 0.0298 & 0.0428 & 1.1607 & 1.6667 & 0.60 & 3.45 & .0174 & 0.0263 & 1.1036 \\
\hline 1.8182 & 0.55 & 2.64 & 0.0235 & & 1.1008 & & 0.55 & 3.25 & 0.0129 & 0.0240 & 0.9798 \\
\hline 2.0000 & 0.50 & 2.53 & 0.0183 & 0.0350 & 1.0451 & .0000 & 0.50 & 3.05 & 0.0095 & 0.0220 & 0.8667 \\
\hline 2.2222 & 0.45 & 2.41 & 0.0141 & 0.0315 & 0.9931 & 2.2222 & 0.45 & 2.85 & 0.0069 & 0.0202 & 0.7641 \\
\hline 2.5000 & 0.40 & 2.29 & 0.0106 & 0.0281 & 0.9465 & 2.5000 & 0.40 & 2.60 & 0.0050 & 0.0185 & 0.6719 \\
\hline 2.8571 & 0.35 & 2.17 & 0.0079 & 0.0248 & 0.9056 & 8571 & 0.35 & 2.30 & 0.0035 & 0.0170 & 0.5940 \\
\hline 3.3333 & 0.30 & 2.05 & 0.0057 & 0.0216 & 0.8710 & 3.3333 & 0.30 & 2.00 & 0.0025 & 0.0156 & 0.5340 \\
\hline
\end{tabular}

\begin{tabular}{|c|c|c|c|c|c|c|c|c|c|c|c|}
\hline & \multicolumn{4}{|c|}{ LX-14, Table no. TL } & \multirow[b]{2}{*}{0.8815} & \multicolumn{5}{|c|}{ LX-17, Table no. L15 } & \multirow[b]{2}{*}{0.7600} \\
\hline & & $\overline{\mathrm{P}_{\mathrm{a}}}$ & 0.3324 & $\overline{\mathrm{D}}$ & & & & $\overline{P_{a}}$ & 0.255 & $\overline{\mathbf{D}}$ & \\
\hline & & $\mathbf{v a}_{\mathbf{a}}$ & 0.7669 & $\rho_{0}$ & 1.835 & & & $v_{a}$ & 0.7676 & po & 1.900 \\
\hline & & $\gamma_{a}$ & 3.2896 & $\mathbf{E}_{\mathbf{o}}$ & 0.100 & & & $\gamma_{a}$ & $\mathbf{3 . 3 0 3 7}$ & $\mathrm{E}_{\mathrm{o}}$ & 0.069 \\
\hline & & $\mathbf{E}_{\mathfrak{a}}$ & 0.1387 & & & & & $\mathbf{E}_{\mathbf{a}}$ & 0.0986 & & \\
\hline & $\eta$ & $\gamma$ & $\begin{array}{c}\mathbf{P}_{\mathbf{S}} \\
(\mathbf{M b})\end{array}$ & $\begin{array}{c}\mathrm{E}_{\mathrm{S}} \\
(\mathrm{Mb} \cdot \mathrm{cc} \\
/ \mathrm{cc})\end{array}$ & f & $\mathbf{v}$ & $\eta$ & $\gamma$ & $\begin{array}{c}\mathbf{P}_{\mathbf{S}} \\
(\mathrm{Mb})\end{array}$ & $\begin{array}{c}\mathrm{E}_{\mathbf{s}} \\
(\mathrm{Mb} \cdot \mathrm{cc} \\
/ \mathrm{cc})\end{array}$ & f \\
\hline 0.5000 & 2.00 & 3.51 & 1.4681 & 0.3317 & 2.2128 & 5000 & 2.00 & 90 & 1.2813 & 0.2564 & 2.4991 \\
\hline 0.5263 & .90 & 3.51 & 1.2275 & 0.2964 & 2.1799 & 0.5263 & 1.90 & 3.90 & .0471 & 0.2259 & 2.4400 \\
\hline 0.5556 & 1.80 & 3.52 & 1.0162 & 0.2637 & 2.1408 & & 1.80 & 3.90 & 8461 & 0.1983 & 2.3702 \\
\hline 0.5882 & 1.70 & 3.52 & 0.8318 & 0.2336 & 2.0942 & 0.5882 & 1.70 & 3.85 & 0.6773 & 0.1736 & 2.2953 \\
\hline 0.6250 & 1.60 & 3.51 & 0.6723 & 0.2061 & 2.0385 & .6250 & 1.60 & 3.80 & 0.5363 & 0.1514 & 2.2143 \\
\hline 0.6667 & 1.50 & 51 & 0.5362 & 0.1811 & 1.9740 & .6667 & 1.50 & 3.75 & .4196 & 0.1316 & 2.1258 \\
\hline 0.6897 & 1.45 & 3.46 & 0.4762 & 0.1695 & 1.9376 & 0.6897 & 1.45 & 3.70 & 0.3698 & 0.1225 & 2.0814 \\
\hline 0.7143 & 1.40 & 3.39 & 0.4218 & 0.1584 & 1.9014 & 0.7143 & 1.40 & 3.60 & 0.3257 & .1140 & 2.0406 \\
\hline 0.7407 & 1.35 & 3.31 & 0.3728 & 0.1479 & 1.8666 & 0.7407 & 1.35 & 3.45 & 0.2871 & .1059 & 2.0077 \\
\hline 0.7669 & 1.3040 & 3.29 & 0.3324 & 0.1387 & 1.8373 & 0.7676 & 1.3027 & $\mathbf{3 . 3 0 3 7}$ & 0.2550 & 0.0986 & 1.9848 \\
\hline 0.7692 & 1.30 & 3.27 & 0.3291 & 0 & 1.8347 & & 1.30 & 3.25 & 0.2533 & 82 & 1.9835 \\
\hline 0.8000 & 1.25 & 3.20 & 0.2895 & 0.1285 & 1.8028 & 0.8000 & 1.25 & 2.90 & 0.2231 & 09 & 1.9631 \\
\hline 0.8333 & 1.20 & 3.15 & 0.2541 & 0.1194 & 1.7732 & .8333 & 1.20 & 2.70 & 0.1981 & & 1.9681 \\
\hline 0.8696 & 1.15 & 3.13 & 0.2222 & 0.1108 & 1.7438 & .8696 & 1.15 & 2.50 & 0.1765 & 0.0771 & 1.9901 \\
\hline 0.9091 & .10 & 12 & 0.1934 & 0.1026 & 1.7131 & 91 & 1.10 & 2.20 & 0.1577 & 0.0705 & 2.0325 \\
\hline 0.9524 & 1.05 & 12 & 0.1673 & 0948 & 1.6799 & 9524 & 1.05 & 4.20 & 1419 & 0.0640 & 2.1094 \\
\hline & 1.00 & 13 & 0.1437 & 874 & 1.6433 & & 1.00 & 4.25 & 159 & & 1.9998 \\
\hline & o & 17 & 0.1224 & & 13 & & 0.95 & 20 & 334 & 25 & 1.8748 \\
\hline & 90 & 20 & 0.1032 & 39 & 1.5511 & & 0.90 & 50 & .0747 & 0.0 & 1.7440 \\
\hline 1.1765 & 85 & 3.21 & 0.0860 & 0.0677 & 1.4934 & & 0.85 & 4.00 & 0.0646 & 0.0430 & 1.7677 \\
\hline 1.2500 & 0.80 & 18 & 0.0708 & 0620 & 1.4280 & 30 & 0.80 & 3.95 & .0509 & 0.0388 & 1.6396 \\
\hline 1.3333 & 75 & 10 & 0.0577 & 0.0567 & 1.3587 & 1.3333 & 0.75 & 3.87 & 0.0396 & 0.0351 & 1.5053 \\
\hline & 0.70 & 2.99 & 0.0467 & 0.0517 & 1.2896 & & 0.70 & 75 & 0.0304 & 0.0318 & 1.3683 \\
\hline 1.5385 & 0.65 & 2.87 & 0.0375 & 0.0471 & 1.2234 & 1.5385 & 0.65 & 3.60 & 0.0231 & 0.0288 & 1.2333 \\
\hline 1.6667 & 0.60 & 2.76 & 0.0298 & 0.0428 & 1.1607 & 1.6667 & 0.60 & 3.45 & 0.0174 & 0.0263 & 1.1036 \\
\hline 1.8182 & 0.55 & 2.64 & 0.0235 & 0.0388 & 1.1008 & 1.8182 & 0.55 & 3.25 & 0.0129 & 0.0240 & 0.9798 \\
\hline & 0.50 & 2.53 & 0.0183 & 0.0350 & 1.0451 & 000 & 0.50 & 3.05 & 0.0095 & 0.0220 & 0.8667 \\
\hline 2.2222 & 0.45 & 2.41 & 0.0141 & 0.0315 & 0.9931 & .2222 & 0.45 & 2.85 & 0.0069 & 0.0202 & 0.7641 \\
\hline 2.5000 & 0.40 & 2.29 & 0.0106 & 0.0281 & 0.9465 & 2.5000 & 0.40 & 2.60 & 0.0050 & 0.0185 & 0.6719 \\
\hline 2.8571 & 0.35 & 2.17 & 0.0079 & 0.0248 & 0.9056 & 2.8571 & 0.35 & 2.30 & 0.0035 & 0.0170 & 0.5940 \\
\hline 3.3333 & 0.30 & 2.05 & 0.0057 & 0.0216 & 0.8710 & 3.3333 & 0.30 & 2.00 & 0.0025 & 0.0156 & 0.5340 \\
\hline
\end{tabular}

$\mathbf{E}_{\mathbf{s}}$ 
Table 8-6, part 2

\begin{tabular}{|c|c|c|c|c|c|c|c|c|c|c|c|}
\hline $\mathbf{v}$ & $\eta$ & $\gamma$ & $\begin{array}{c}\mathbf{P}_{\mathbf{s}} \\
(\mathbf{M b})\end{array}$ & $\begin{array}{c}\mathbf{E}_{\mathbf{S}} \\
(\mathbf{M b} \cdot \mathrm{cc} \\
/ \mathrm{cc})\end{array}$ & $f$ & $\mathbf{v}$ & $\eta$ & $\gamma$ & $\begin{array}{c}\mathbf{P}_{\mathbf{S}} \\
(\mathrm{Mb})\end{array}$ & $\begin{array}{c}\mathbf{E}_{\mathrm{s}} \\
(\mathbf{M b} \cdot \mathrm{cc} \\
/ \mathrm{cc})\end{array}$ & $\mathrm{f}$ \\
\hline 4.0000 & 0.25 & 1.91 & 0.0039 & 0.0185 & 0.8467 & 4.0000 & 0.25 & 1.75 & 0.0017 & 0.0142 & 0.4926 \\
\hline 5.0000 & 0.20 & 1.77 & 0.0026 & 0.0153 & 0.8402 & 5.0000 & 0.20 & 1.55 & 0.0012 & 0.0128 & 0.4672 \\
\hline 6.6667 & 0.15 & 1.66 & 0.0016 & 0.0120 & 0.8677 & 6.6667 & 0.15 & 1.4092 & 0.0008 & 0.0112 & 0.4575 \\
\hline 10 & 0.10 & 1.64 & 0.0008 & 0.0083 & 0.9749 & 10 & 0.10 & 1.30 & 0.0004 & 0.0093 & 0.4649 \\
\hline 20 & 0.05 & 1.97 & 0.0003 & 0.0037 & 1.3713 & 20 & 0.05 & 1.30 & 0.0002 & 0.0066 & 0.5033 \\
\hline 100 & 0.01 & 3.09 & 0 & 0 & 4.0682 & 100 & 0.01 & 1.30 & 0.0000 & 0.0028 & 0.5851 \\
\hline 1000 & 0.001 & & 0 & 0 & 2.6853 & 1000 & 0.001 & 1.30 & 0.0000 & 0.0006 & 0.7352 \\
\hline
\end{tabular}




\section{Chapter 9. Composite Explosives}

\section{The Problem of Nonreactivity}

Composite explosives are mixtures in which the combination is expected to produce a positive added result. It is common to start with a conventional CHNO explosive as the base. If this explosive is oxygen-poor, an oxidizer is added. If the explosive is oxygen-rich (which seldom happens), a reducing agent is added. A special reducing agent is a metal like aluminum that takes away oxygen from the original gaseous products and prolongs the reaction from microseconds to milliseconds. Some explosives are odd mixtures of all of these.

Special types of composites may be considered. Most notable is the industrial explosive, ANFO, which is made up of two components (ammonium nitrate and fuel oil) that do not detonate separately but do detonate when mixed. Another is a combination of two CHNO explosives with widely different properties. Finally, individual compounds like TATB act like composites in the drawn-out mode of their reaction.

For all homogeneous explosives (including TATB), we have assumed that virtually all of it detonates in the cylinder so that we may take the energy obtained in the calorimeter and use it for the initial guess in the JWL. For composites, this assumption does not work well because the explosives did not fully react. They may not have reacted because:

1. The sample was small enough, i.e., less than the "infinite diameter" sample, to have size effects.

2. The particles are so large that true mixing cannot occur at the available temperatures - even in the largest possible sample. Aluminum particles covered with an oxide layer fall into this category.

When all we have is TIGER and some cylinder data, we must somehow guess our way through these two. Looking for standards becomes the first task.

\section{Cylinder Data and Infinite-Size}

Various cylinder data are listed in Tables 9-1 and 9-2. Compounds have these abbreviations: Al, aluminum; AN, ammonium nitrate; AP, ammonium perchlorate; $\mathrm{CaN}$, calcium nitrate; $\mathrm{EDD}$, ethylene diamine dinitrate; est, estane; LiP, lithium perchlorate; $\mathrm{KP}$, potassium perchlorate; $\mathrm{PE}$, polyethylene; $\mathrm{RDX}$, cyclotrimethylene trinitramine; $\mathrm{V}$, Viton; and $\mathrm{ZrH}_{2}$, zirconium hydride. 
Calorimetry data are the cornerstone of establishing a system. Unfortunately, few composites have been run. In Table 9-1, we list the available measured total energies of detonation, $E_{0}$, with water present as vapor and the $P V$ adjustment from the measured heat. A percent comparison with TIGER BKWR is also shown. Not one of these values is anomalously high but those below $-10 \%$ are suspicious. One wonders whether or not all the explosive detonated in the calorimeter. AN/TNT mixes and EAR-1 are in this category.

Table 9-2 shows detonation velocity. The measured values are compared with those from TIGER BKWR. In bold face are the runs that may be infinitediameter results. The first type of explosive that fits this criterion is the $100-\mathrm{mm}$ copper cylinder shot in a series extending from $25 \mathrm{~mm}$ and where the detonation velocities appear to be converging over a narrow range. Probably a 200-mm cylinder would be a little larger, but we have no data to check. A good example is LX-17, which has never been measured above $51 \mathrm{~mm}$. The comparable LANL explosive, PBX-9502, shows a higher velocity at $108 \mathrm{~mm}^{1}$ and has been used to estimate the infinite-diameter value for LX-17.

We have taken a partial and quickly available collection of cylinder data, including measured detonation velocities-velocities at $\mathrm{v}=2.2,4.1$, and 6.5 and the JWL total detonation energy, $\mathrm{E}_{\mathbf{0}}$. The percent comparison with TIGER BKWR is listed. We are looking for standards in which all numbers are within $10 \%$ of the TIGER run. The very narrow set of explosives in this group include the binary organics RX-26-AF and RX-36-AH, QM-100 (ANFO at $1.25 \mathrm{~g} / \mathrm{cc}$ ), QM-100R (QM-100 laced with RDX), and RX-25-BF (odd mixture with $\mathrm{ZrH}_{2}$ ).

In bold face are the samples thought to be close to infinite-diameter size. There are two ways to make this determination. The first is to fire several cylinder shots of different diameter and take the result from the largest-as long as the results are similar. An example is RX-11-BD, which was run in 25-, $50-$, and $100-\mathrm{mm}$ sizes with all detonation velocities the same. However, both the total detonation velocity and energy are $20 \%$ below the TIGER values. Clearly, something is wrong.

The second method of obtaining the infinite size detonation velocity is to fire a huge pile of the explosive-an obviously rare occurrence. Four emulsion explosives are listed in Table 9-2 and shown in Fig. 9-1; all have extreme size effects. ${ }^{2-6}$ All are types of ANFO (ammonium nitrate (AN) plus fuel oil). These explosives are QM-100, QM-100R, $0.8 \mathrm{~g} / \mathrm{cc}$ ANFO, and RX-HD. The QM-100 pair have the AN in small particle size so that the mixture is creamy. The explosive is thought to burn easily. The ANFO and RX-HD both contain AN as prill-round pellets of 1 to $2.5 \mathrm{~mm}$ in diameter that look like BB pellets. The fuel oil soaks to some extent into the prill and otherwise sits outside between the grains. This kind of AN does not burn easily.

The ANFO and RX-HD have been fired in huge shots at NTS: 109 tons for the ANFO and 1400 tons for the RX-HD. The first was shot above ground; 
the second was fired in a cavity in the rock. These deliver detonation velocities that surely represent infinite diameter. However, the nominal explosive density is that of the average mixture in the tank truck. When it is poured into the hole trapped air can move to the top, and a density gradient in the pile is created.

We have also used the $1800-\mathrm{K}$ freeze to model our cylinder results. If a large pile of explosive is confined hotter for longer, it may well burn to equilibrium. However, the emulsion explosives burn almost totally by $1800 \mathrm{~K}$ in TIGER so there is little difference.

Finally, we note a common property of composites shown well by RX-04-DS. Here, the detonation velocity and total energy agree with those of TIGER. However, the energies at $v=2.2$ and 6.5 are quite low-caused by the long reaction time of the composite, here, aluminum with gaseous HMX reaction products. The long reaction time appears in the Cylinder Test as a small but increasing amount of reaction, so that the slope from $v=2.2$ to 6.5 is less steep for the composite than for HMX. The integral that computes energy thus covers a lot of extrapolated territory.

\section{Percent Detonated in a Cylinder}

A crisis arises in Table 9-2: we have no good composite standards and we cannot trust the calculations. Nevertheless, people still estimate the percent reacted. Two problems illustrate the degree of accuracy.

Consider the total detonation energy, $\mathbf{E}_{\mathbf{0}}$. Both the TIGER BKWR value and the cylinder value are good to no better than $\pm 10 \%$. For the QM-100, we have $3.6 \mathrm{~kJ} / \mathrm{cc}$ from the cylinder and $3.5 \mathrm{~kJ} / \mathrm{cc}$ from TIGER. In terms of energy, it all reacts, so we turn to the detonation velocities. The percent detonated in the cylinder for QM-100:

$$
\% \text { detonated } \sim \mathrm{D} / \mathrm{D}_{\infty} \sim 6.258 / 6.5 \sim 96 \% \text {, }
$$

where $D$ is the detonation velocity in the cylinder and $D_{\infty}$ is the velocity at infinite diameter. Eq. (1) is for emulsions in which the components do not detonate.

The second example is more common, because it is easier to tell if only a little reacts. We consider $67.7 \mathrm{wt} \% \mathrm{TNM} / 32 / 3 \% \mathrm{Al}$. TNM was not measured in the calorimeter, so we take the cylinder value of $3.6 \mathrm{~kJ} / \mathrm{cc}$ for the total detonation energy of the pure explosive. The volume fraction for TNM is 0.75 , so the TNM detonation energy in the mix is $2.7 \mathrm{~kJ} / \mathrm{cc}$. The mixture energies from the cylinder and TIGER are 10.5 and $21.4 \mathrm{~kJ} / \mathrm{cc}$. We calculate

$$
\% \text { detonated } \sim(10.5-2.7) /(21.4-2.7) \sim 42 \% \text {. }
$$


John Kury estimates that 30 to $60 \%$ is the likely spread of the result. The calculation assumes that the TNM would have detonated even if the aluminum were inert.

\section{Possible Standards}

If we are describe composites in thermochemical codes, we need standards that can be fired in a cylinder no larger than $102 \mathrm{~mm}$ in diameter, the maximum size allowed at LLNL's Site 300. From Table 9-2, these two warrant a better look.

1. Fine aluminum in HMX with an inert binder. The RX-04-DS 50-mm samples in Table 9-2 show good agreement with TIGER, and aluminum (unlike potassium) is an easy element to run. The 25-mm-diameter aluminized samples have detonation velocities of $-5 \%$ compared to TIGER, whereas at $51 \mathrm{~mm}$, the velocities are $-2 \%$. Many are of the opinion that $5-\mu \mathrm{m}$ (but not $18-\mu \mathrm{m}$ ) aluminum, if under $10 \mathrm{wt} \%$, should all react. ${ }^{7}$ However, Finger et. al. calculated the percent reacted using RUBY, an ancestor of TIGER. They found $50 \%$ reacted in 25 -mm-diameter cylinders and $75 \%$ reacted in $50-\mathrm{mm}$-diameter cylinders. ${ }^{8}$ The $50 \%$ value at $25 \mathrm{~mm}$ was found only after $12 \mu \mathrm{s}$. All this lets us hope that nearly complete reaction can be seen in a 100-mm cylinder, which seems to be the lower limit of "infinite-diameter" behavior for most composites.

2. HMX/ KP with an inert binder. The lack of a size effect in the cylinder, coupled with the lack of TIGER agreement, has already been noted. Finger et. al. found nearly complete reaction after $0.5 \mu$ s with $3-\mu \mathrm{m}$ particles, but only $60 \%$ reaction with $10-\mu \mathrm{m}$ particles. ${ }^{8}$ This affect seemed to extend as far as 50 vol\% KP. If we select a full burn to $\mathrm{CO}_{2}$, then one mol of $\mathrm{HMX}$ reacts with one mol of KP:

$$
\mathrm{C}_{4} \mathrm{H}_{8} \mathrm{~N}_{8} \mathrm{O}_{8}+\mathrm{KClO}_{4} \rightarrow 4 \mathrm{CO}_{2}+7 / 2 \mathrm{H}_{2} \mathrm{O}+\mathrm{HCl}+1 / 2 \mathrm{~K}_{2} \mathrm{O}+4 \mathrm{~N}_{2}
$$

This would amount to a $65 / 30 / 5 \mathrm{wt} \%$ mix of $\mathrm{HMX} / \mathrm{KP} /$ estane, which contains more HMX than many shots. Kury believes that complete burning to $\mathrm{CO}_{2}$ does not show as increased wall velocity because the $\mathrm{CO}_{2}$ has more internal degrees of freedom into which energy can be funneled.

John Kury notes that the energy of detonation of $\mathrm{HMX} / \mathrm{KP}$ is no more than that of pure HMX; therefore, the oxidizing power of KP is poorly used. However, the C-J temperature of HMX of $3800 \mathrm{~K}$ (JCZ3) can be increased, thereby possibly assisting the reaction efficiency. The explosive with the least oxygen and the highest temperature is $\mathrm{BTF}$ at $5000 \mathrm{~K}$. To achieve burning to $\mathrm{CO}_{2}$, we write 


$$
\mathrm{C}_{6} \mathrm{H}_{6} \mathrm{O}_{6}+2 \mathrm{KClO}_{4} \rightarrow 6 \mathrm{CO}_{2}+2 \mathrm{H}_{2} \mathrm{O}+2 \mathrm{HCl}+\mathrm{K}_{2} \mathrm{O} \text {. }
$$

The mix is $45 / 50 / 5 \mathrm{wt} \% \mathrm{BTF} / \mathrm{KP} /$ estane. Unfortunately, the theoretical energy of detonation is again calculated to be unchanged, with the oxidation just replacing the lost BTF.

\section{The Need for Predictive Capability}

The results of Fig. 9-1 show that not one of the four ANFO mixes can be fired in a 100-mm cylinder and get the infinite diameter result. Large, expensive, and inconvenient shots are required. This shows the need for a data compilation and code that allows the calculation of size effects and run-todetonation distances in these materials. In the meantime, all composite cylinder shots should have the end measurement for detonation front curvature taken automatically for future reference.

\section{References}

1. A. W. Campbell, Propellants, Explosives, Pyrotechnics 9, 183 (1984).

2. F. Helm, M. Finger, B. Hayes, E. Lee, H. Cheung, and J. Walton, High Explosive Characterization for the Dice Throw Event, Lawrence Livermore National Laboratory, Livermore, CA, UCRL-52042 (1976).

3. Don Larson, LLNL, private communication, 1993.

4. Reported from Alpha Explosives, LaRoche Industries, Inc., Geneva, UT.

5. Reported from Ireco, Inc., West Jordan, UT.

6. Bob Rencke, Defense Nuclear Agency, Kirtland Air Force Base, Albuquerque, NM, private communication, 1993.

7. General discussion at 10th Detonation Symposium, Boston, MA, July 12-18,1993.

8. M. Finger, H. C. Hornig, E. L. Lee, and J. W. Kury, "Metal Acceleration by Composite Explosives," Proceedings Fifth Symposium (International) on Detonation, Pasadena, CA, August 18-21, 1970, p. 137. 


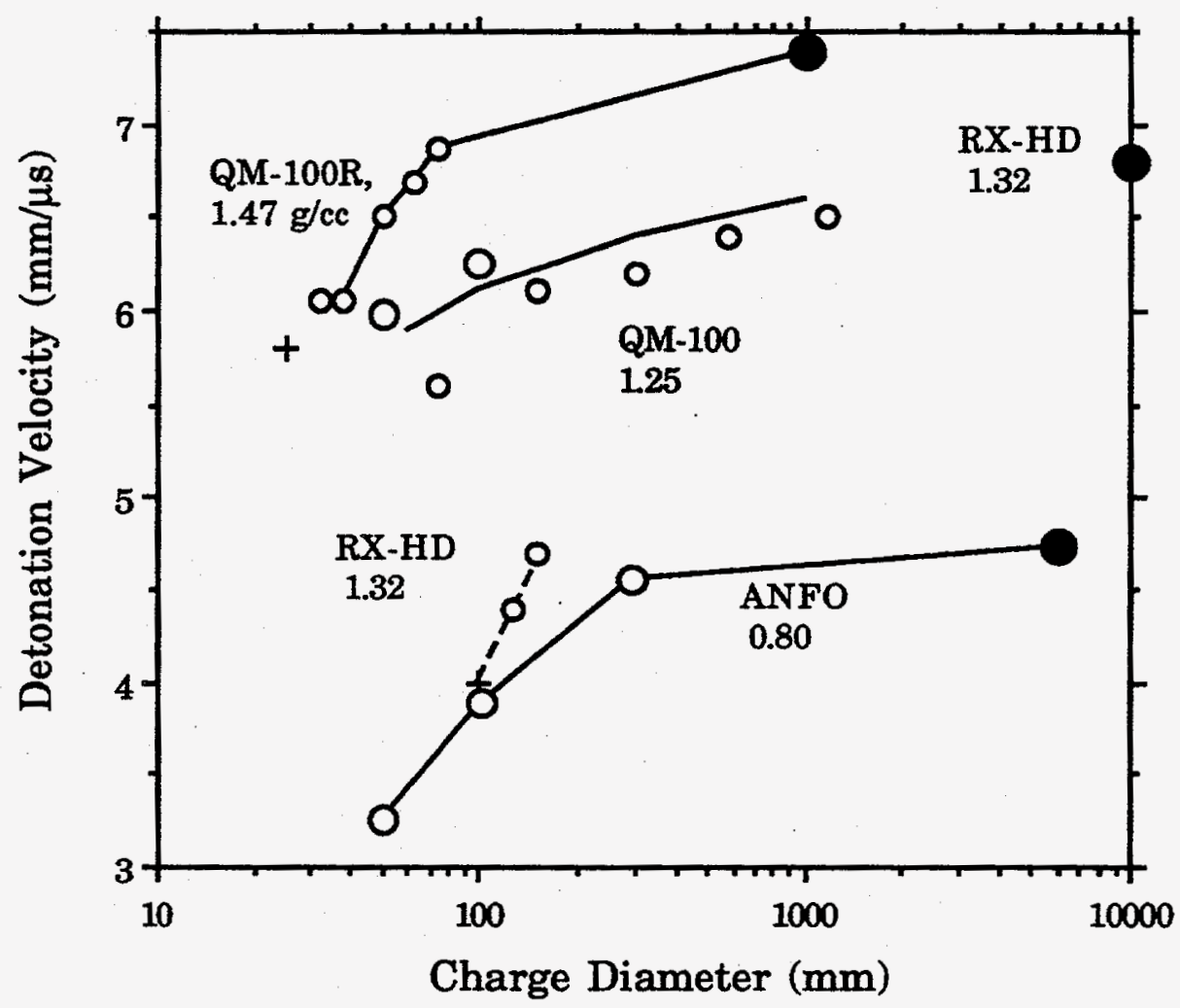

Fig. 9-1. Detonation velocity vs diameter for four emulsion explosives with extreme size effects. The curves drawn through various data points are not comparable, making prediction all but impossible. The data points indicate a bare cylinder shot without detonation ( + ) and with detonation (small open circles); a copper cylinder shot (large open circles); and a large-pile shot considered to represent infinite diameter (solid circles). The data points of each explosive are grouped and labeled. 
Table 9-1. Comparison of total detonation energies, $\mathbf{E}_{\mathbf{0}}$, measured by the calorimeter and calculated by TIGER BKWR. Energies include water as the gas. An 1800-K freeze was used in the code runs.

\begin{tabular}{|c|c|c|c|c|c|}
\hline & & \multirow[b]{2}{*}{$\begin{array}{c}\text { Composition } \\
\text { wt\% }\end{array}$} & \multirow[b]{2}{*}{$\begin{array}{c}\text { Density } \\
(\mathrm{g} / \mathrm{cc})\end{array}$} & \multicolumn{2}{|c|}{ Total det energy } \\
\hline & $\begin{array}{c}\text { Explosive } \\
\text { name }\end{array}$ & & & $\begin{array}{l}\text { Meas'd } \\
\text { f. heat } \\
(\mathrm{kJ} / \mathrm{cc})\end{array}$ & $\begin{array}{c}\% \\
\text { cf. } \\
\text { BKWR }\end{array}$ \\
\hline Organic & $\overline{\mathrm{RX}}-36-\mathrm{AA}$ & HMX 34.56; TATB 32.21; BTF 33.23 & 1.813 & 9.5 & -2 \\
\hline Bineries & RX-36-AF & HMX 53.51\%; TATB $46.49 \%$ & 1.812 & 9.1 & $\mathbf{0}$ \\
\hline Organicl & RX-22-AG & HMX 81.7; LP 18.3 & 1.91 & 12.4 & 6 \\
\hline \multirow[t]{8}{*}{ Oxidizer } & TNT/AN & TNT $80.3 ;$ AN 19.7 & 1.583 & 6.8 & -3 \\
\hline & EAR & $\operatorname{EDD} 43.04 ;$ AN $41.36 ;$ RDX 15.60 & 1.593 & 6.6 & -5 \\
\hline & EAR & EDD 43.04; AN 41.36; RDX 15.60 & 0.994 & 4.2 & -3 \\
\hline & AN/TNT & AN 58.7; TNT 41.3 & 1.614 & 6.4 & -11 \\
\hline & AN/TNT & AN $60.3 ;$ TNT 39.7 & 1.604 & 6.1 & -13 \\
\hline & AN/TNT & AN 61.4; TNT 38.6 & 1.616 & 6.3 & -11 \\
\hline & AN/TNT & AN 61.4; TNT 38.6 & 0.886 & 3.4 & -6 \\
\hline & AN/TNT & AN 81.1; TNT 18.9 & 1.621 & 5.5 & -16 \\
\hline Organicl & RX-04-DS & HMX 81.0: Al 9.9; Viton 9.1 & 1.933 & $\overline{12.7}$ & -3 \\
\hline \multirow[t]{2}{*}{ Reducer } & TNM/Al & TNM 67.7; Al 32.3 & 1.828 & 21.2 & $\mathbf{0}$ \\
\hline & TNM/C & TNM 83; C 15; Cabosil 2 & 1.67 & 11.3 & -1 \\
\hline Organicl & EAR-1 & EDD $41.1 ; \mathrm{AN} 40.9 ; \mathrm{RDX} 11.9 ; \mathrm{Al} 6.2$ & 1.624 & 7.2 & -15 \\
\hline Oxidizer/ & RX-25-BF & HMX 37.0; AP 36.9; $\mathrm{ZrH}_{2} 22.1$, est 4.0 & 2.15 & 11.2 & $\overline{-5}$ \\
\hline Reducer & RX-25-BF & HMX 37.0; AP $36.9 ; \mathrm{ZrH}_{2} 22.1$, est 4.0 & 2.15 & 11.2 & $\mathbf{- 5}$ \\
\hline
\end{tabular}


Table 9-2. Comparison of measured detonation velocities with the calculations of TIGER BKWR. Bold numbers are those thought to represent infinite diameter shots by (1) being the largest cylinder of a set or (2) an actual huge shot. Abbreviations are explained in the text. In each section, explosives are arranged in decreasing percent agreement with TIGER.

\begin{tabular}{|c|c|c|c|c|c|c|c|c|}
\hline & & Cyl- & & & Diam- & & $\begin{array}{r}\text { Det v } \\
\text { (m }\end{array}$ & $\begin{array}{l}\text { locity } \\
/ \mu s)\end{array}$ \\
\hline Categories & Name & $\begin{array}{c}\text { inder } \\
\text { no. }\end{array}$ & Composition; wt\% & $\begin{array}{l}\text { Density } \\
\text { (g/cc) }\end{array}$ & $\begin{array}{l}\text { eter } \\
(\mathrm{mm})\end{array}$ & $\begin{array}{l}\text { Wall } \\
(\mathrm{mm})\end{array}$ & Measd & $\begin{array}{c}\% \text { cf. } \\
\text { BKWR }\end{array}$ \\
\hline Standards & LX-14 & three & HMX 95.5; estane 4.5 & 1.830 & 51 & 2.7 & 8.80 & $\overline{0}$ \\
\hline & LX-17 & & TATB 92.5; Kel-F 7.5 & 1.905 & 100 & est & 7.69 & -2 \\
\hline & PBX-9502 & LANL & TATB 95; Kel-F 5 & 1.886 & 108 & & 7.73 & -2 \\
\hline & LX-17 & five & TATB 92.5; Kel-F 7.5 & 1.905 & 51 & 2.7 & 7.63 & -3 \\
\hline & $\mathrm{LX}-17$ & 453 & TATB 92.5; Kel-F 7.5 & 1.913 & 25 & 1.4 & 7.59 & -3 \\
\hline Organic & $\mathrm{RX-36-AH}$ & 501 & HMX 51.3; BTF 43.7; Viton 5.0 & 1.83 & 25 & 2.7 & 8.511 & 2 \\
\hline Bineries & $\mathrm{RX}-26-\mathrm{AF}$ & 455 & HMX 49.3; TATB 46.6; estane 4.1 & 1.85 & 25 & 1.36 & 8.241 & -2 \\
\hline & $\mathrm{RX}-26-\mathrm{AF}$ & five & HMX 49.3; TATB 46.6; estane 4.1 & 1.844 & 51 & 2.7 & 8.240 & -2 \\
\hline Organic/ & $\mathrm{RX}-11-\mathrm{BB}$ & 256 & HMX 50; AP 40; Viton 10/ AP $5 \mu \mathrm{m}$ & 1.889 & 51 & 5.2 & 8.119 & -2 \\
\hline Oxidizer & RX-34-AI & 525 & AP 52.8; BTF 47.2 & 1.824 & 25 & 2.6 & 7.435 & -7 \\
\hline & $\mathrm{RX}-22-\mathrm{AG}$ & 253 & HMX 73.6; LiP 25.4 & 1.988 & 25 & 2.6 & 8.426 & -12 \\
\hline & RX-11-AF & 239 & $\mathrm{HMX} 52.3 ; \mathrm{KP} 42.7 ; \mathrm{PE} ; 5.0 / \mathrm{KP} 2.7 \mu \mathrm{m}$ & 1.994 & 50 & 5.2 . & 7.757 & -13 \\
\hline & $\mathrm{RX}-11-\mathrm{BA}$ & 301 & HMX 53.9; NaP 41.1; est 5.0/ NaP $0.5 \mu \mathrm{m}$ & 2.009 & 51 & 5.2 & 7.859 & -13 \\
\hline & $\mathrm{RX}-11-\mathrm{AI}$ & 240 & $\mathrm{HMX} 52.3 ; \mathrm{KP} 42.7 ; \mathrm{PE} ; 5.0 / \mathrm{KP} 10 \mu \mathrm{m}$ & 1.985 & 51 & 5.2 & 7.630 & -14 \\
\hline & $\mathrm{RX}-11-\mathrm{AF}$ & 238 & HMX 52.3; KP 42.7; PE; 5.0/ KP $2.7 \mu \mathrm{m}$ & 1.994 & 25 & 2.6 & 7.629 & -14 \\
\hline & RX-11-AJ & 242,243 & $\mathrm{HMX} 52.3 ; \mathrm{KP} 42.7 ; \mathrm{PE} ; 5.0 / \mathrm{KP} 50 \mu \mathrm{m}$ & 1.992 & 51 & 5.2 & 7.499 & -16 \\
\hline & $\mathrm{RX}-11-\mathrm{BD}$ & 380 & $\mathrm{KP} 49.3 ; \mathrm{HMX} 42.0$; estane 8.7 / KP $3 \mu \mathrm{m}$ & 2.034 & 25 & 2.6 & 6.976 & -22 \\
\hline & $R X-11-B D$ & 395 & KP 49.3; HMX 42.0; estane $8.7 / \mathrm{KP} 3 \mu \mathrm{m}$ & 2.095 & 51 & 5.1 & 7.083 & -22 \\
\hline & $\mathrm{RX}-11-\mathrm{BD}$ & 384 & $\mathrm{KP} 49.3 ; \mathrm{HMX} 42.0$; estane $8.7 / \mathrm{KP} 3 \mu \mathrm{m}$ & 2.033 & 19 & 1.9 & 6.949 & -22 \\
\hline & $\mathrm{RX}-34-\mathrm{AA}$ & 327 & AN $60 ;$ TNT $40 /$ AN $5 \mu \mathrm{m}$ & 1.615 & 25 & 2.5 & 6.068 & -23 \\
\hline & $\mathrm{RX}-34-\mathrm{AB}$ & 424 & AN $60 ;$ TNT $40 /$ AN $25 \mu \mathrm{m}$ & 1.61 & 51 & 5.2 & 6.047 & -24 \\
\hline & $\mathrm{RX}-34-\mathrm{AC}$ & 425 & AN 60; TNT 40/ AN $200 \mu \mathrm{m}$ & 1.62 & 51 & 5.2 & 6.032 & -24 \\
\hline & $R X-11-B G$ & 387 & KP 60.0; HMX 31.6; estane 8.4/ KP $3 \mu \mathrm{m}$ & 2.103 & 19 & 1.9 & 6.394 & -30 \\
\hline
\end{tabular}




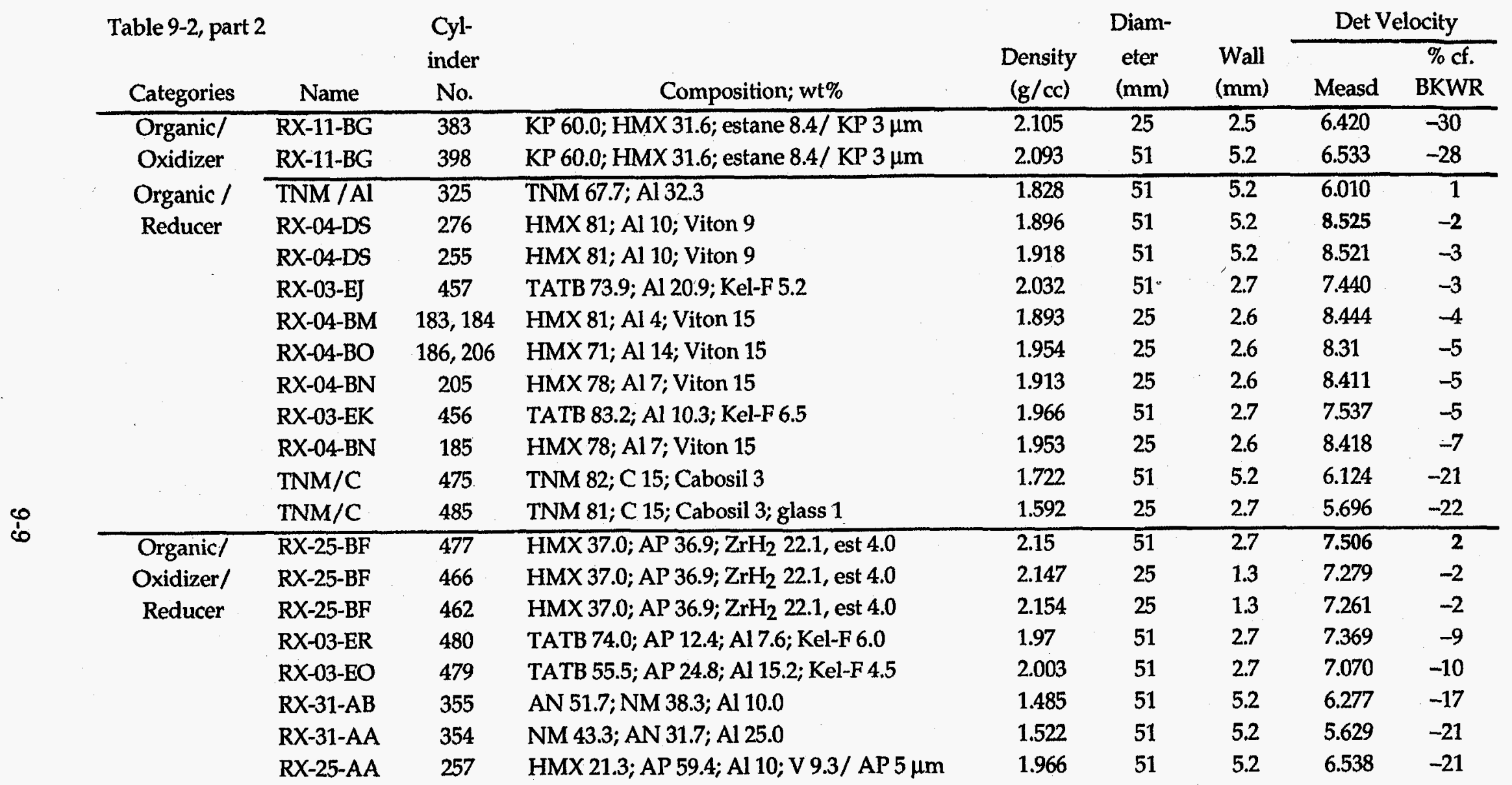




\begin{tabular}{|c|c|c|c|c|c|c|c|c|}
\hline \multicolumn{2}{|c|}{ Table 9-2, part 3} & \multirow{2}{*}{$\begin{array}{c}\text { Cyl- } \\
\text { inder } \\
\text { No. }\end{array}$} & \multirow[b]{2}{*}{ Composition; wt\% } & \multirow{2}{*}{\multicolumn{2}{|c|}{$\begin{array}{l}\text { Diam- } \\
\text { eter } \\
(\mathrm{mm})\end{array}$}} & \multirow[b]{2}{*}{$\begin{array}{c}\text { Wall } \\
(\mathrm{mm})\end{array}$} & \multicolumn{2}{|c|}{ Det Velocity } \\
\hline Categories & Name & & & & & & Measd & $\begin{array}{c}\% \text { cf. } \\
\text { BKWR }\end{array}$ \\
\hline \multirow{2}{*}{$\begin{array}{l}\text { Non-Det- } \\
\text { onable }\end{array}$} & QM-100 & Alpha & AN 75; $\mathrm{H}_{2} \mathrm{O} 18 ;$ fuel oil 5 : glass 2 & 1.25 & 1220 & bare & 6.5 & $\overline{-1}$ \\
\hline & QM-100R & DNA & AN $44.5 ; \mathrm{RDX} 40 ; \mathrm{H}_{2} \mathrm{O} 11$; fuel oil 4.4 & 1.47 & 1400 & & 7.4 & -4 \\
\hline \multirow[t]{10}{*}{ Reactants } & RX-HD & NTS & AN 78.6; CaN $5.5 ; \mathrm{H}_{2} \mathrm{O}, 9.4$; fuel oil 6.4 & 1.34 & 10000 & contd & 6.8 & -4 \\
\hline & QM-100 & 582 & AN 75; $\mathrm{H}_{2} \mathrm{O} 18 ;$ fuel oil 5 : glass 2 & 1.25 & 102 & 10.2 & 6.258 & -5 \\
\hline & QM-100R & 587,8 & AN 44.5; RDX $40 ; \mathrm{H}_{2} \mathrm{O} 11$; fuel oil 4.4 & 1.51 & 102 & 10.2 & 7.420 & -5 \\
\hline & QM-100 & 581 & AN 75; $\mathrm{H}_{2} \mathrm{O} 18$; fuel oil 5: glass 2 & 1.25 & 51 & 5.2 & 5.990 & -9 \\
\hline & QM-100R & Ireco & AN 44.5; $\mathrm{RDX} 40 ; \mathrm{H}_{2} \mathrm{O} 11 ;$ fuel oil 4.4 & 1.47 & 75 & bare & 6.87 & -11 \\
\hline & ANFO & NTS & AN $94.2 ;$ fuel oil 5.8 & 0.80 & 6000 & & 4.74 & -12 \\
\hline & ANFO & 356 & AN 94; fuel oil 6 & 0.84 & 292 & 29.9 & 4.564 & -15 \\
\hline & ANFO & 357 & AN 94.2; fuel oil 5.8 & 0.82 & 292 & 29.9 & 4.553 & -16 \\
\hline & ANFO & 298 & AN 94.8; fuel oil 5.2 & 0.78 & 102 & 10.2 & 3.890 & -24 \\
\hline & ANFO & 361 & AN 94.2; fuel oil 5.8 & 0.80 & 51 & 5.2 & 3.252 & -38 \\
\hline
\end{tabular}




\section{Appendix: \\ Composition and Grain Sizes of Explosives}

We here describe the explosives considered from Chapters 2 to 8 . Table A-1 lists the explosives and their components, along with their formulas, densities, molecular weights, and heats of formation.

Three particle sizes make up HMX going into $\mathrm{LX}-14-0: 65 \mathrm{wt} \%$ class $\mathrm{A}(1), 25 \%$ special class, and $10 \%$ class (2). Folding these together, we have roughly the following spectrum of grain size.1,2 Large and small grains have been blended together for optimum packing.

\begin{tabular}{cc}
$\begin{array}{c}\text { Approx. grain } \\
\text { size }(\mu \mathrm{m})\end{array}$ & $\begin{array}{c}\text { Approx. } \\
\text { wt \% }\end{array}$ \\
\hline 0 to 50 & 18 \\
50 to 70 & 6 \\
70 to 200 & 18 \\
200 to 400 & 23 \\
400 to 600 & 23 \\
600 to 1200 & 11
\end{tabular}

LX-14-0 is a mixture of HMX particles coated with a urethane polymer. HMX is present at $95.5 \mathrm{wt} \% \pm 0.5 \%$ for a lot and $\pm 0.6 \%$ for a batch. The size spread of the particles ranges from 300 to $4800 \mu \mathrm{m} .{ }^{3}$ It is generally assumed that the HMX particle size listed in the above table is reproduced in the formulation. All the LLNL copper-cylinder shots (nos. 353, 469, 510, 520, and 521) are LX-14-0.

LX-17 consists of TATB powder coated with Kel-F binder. The TATB shall be present in $92.5 \mathrm{wt} \% \pm 0.3 \%$ for the lot and $\pm 0.5 \%$ for the batch. The first three columns of the table below lists the \% particle size fractions of the virgin TATB used in the formulation. The last two columns list the \% particle sizes in the final $\mathrm{LX}-17.4$

\begin{tabular}{ccccc}
$\begin{array}{c}\text { Sieve } \\
\text { size }(\mu \mathrm{s})\end{array}$ & $\begin{array}{c}\text { TATB in } \\
\text { LX-17-0 }\end{array}$ & $\begin{array}{c}\text { TATB in } \\
\text { LX-17-1 }\end{array}$ & $\begin{array}{c}\text { Sieve } \\
\text { size }(\mu \mathrm{s})\end{array}$ & LX-17 \\
\hline$>45$ & 40 & 25 & $4800-8000$ & 1 \\
20 to 45 & 25 & 25 & $3400-4800$ & 9 \\
$<20$ & 35 & 50 & $180-3400$ & 87
\end{tabular}


We note that LX-17 has a much smaller and more uniform explosive particle size than LX-14.

Three LLNL cylinder shots used wet-aminated TATB in the form LX-17-1 (nos. 522, 523, and 554). The detonation front curvature shot (556) was also LX-17-1. The previous cylinder shots $(349,432,434,439$, and 453$)$ were $\mathrm{RX}-03-\mathrm{BB}$, the experimental form of $\mathrm{LX}-17$ used before production. The metal plate shots include the dry-aminated product, LX-17-0, for the pta90000 series and the wet-aminated LX-17-1 for the others.

\section{References}

1. Military Specification, MU-H-45444A, Amendment 3, Picatinny Arsenal, July 31, 1962.

2. Military Specification, MIL-H-48358, Amendment 2, Picatinny Arsenal, April 8, 1988.

3. LX-14-0 Molding Powder, Specification Sheet RM253683, Issue G, D. Duffek, LLNL FSCM No. 14067, January 20, 1984.

4. LX-17 High Explosive Molding Powder, Specification Sheet RM255117, Issue P, D. Duffek, LLNL FSCM No. 14067, August 13, 1985.

\section{Acknowledgments}

We would especially like to thank Al Nichols, Craig Tarver, and John Kury for their extensive help in compiling this work. Chapters 1 through 8 were written for the Nuclear Weapons Program; Chapter 9 was written for the Technical Maturation Fund. We would like to thank Mike Anastasio for his continued support of EOS. 
Table A-1. Inventory of explosives mentioned in Chapters 1 to 7 of this report. Components are listed in wt\%. Pure components used in mixtures are listed at the bottom. "S" indicates a solid, and " $L$ " indicates a liquid. The formulas are rounded off to the nearest tenth. The asterisk indicates a theoretical material density.

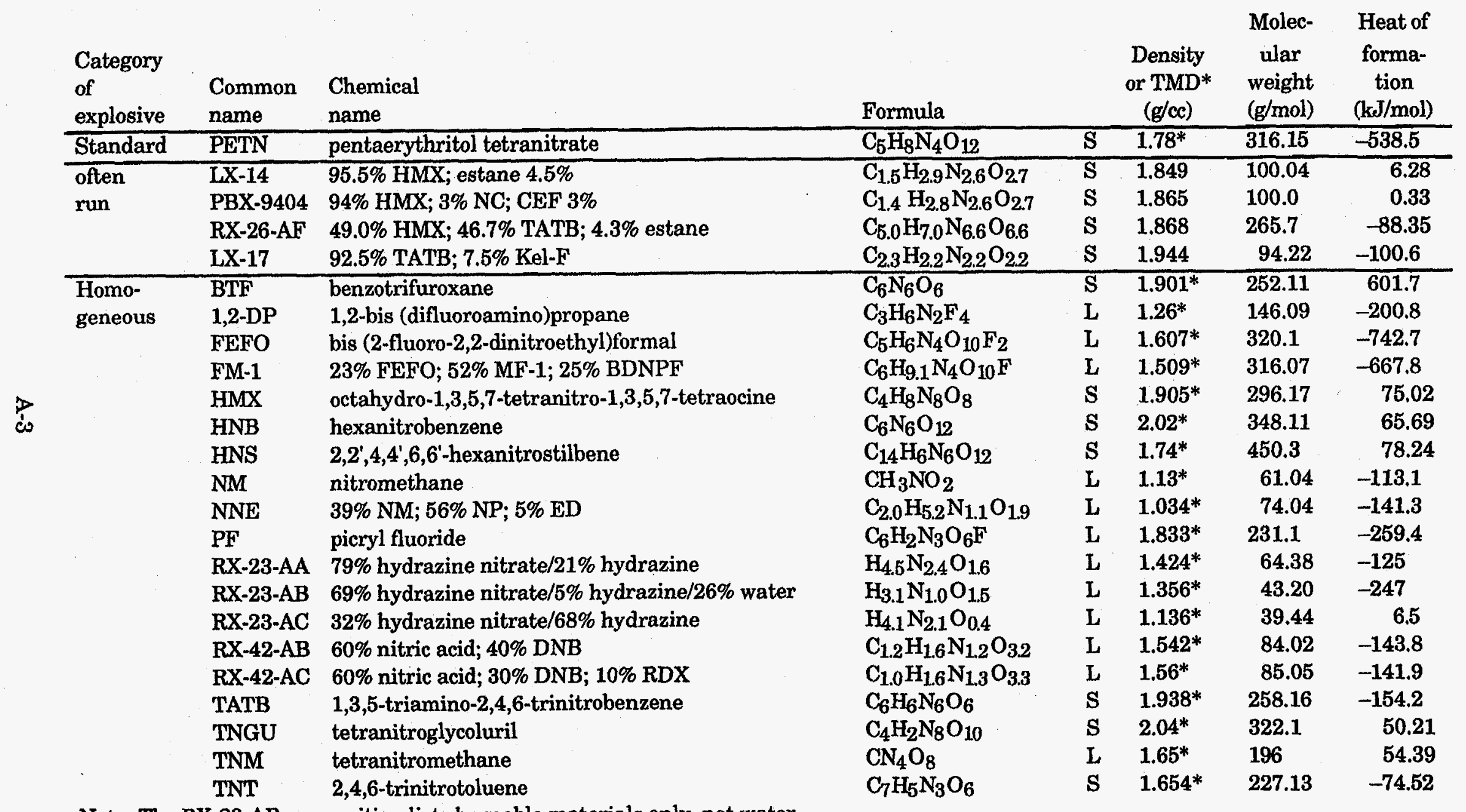

Note: The $\mathrm{RX}-23-\mathrm{AB}$ composition lists burnable materials only, not water. 
Table A-1, part 2

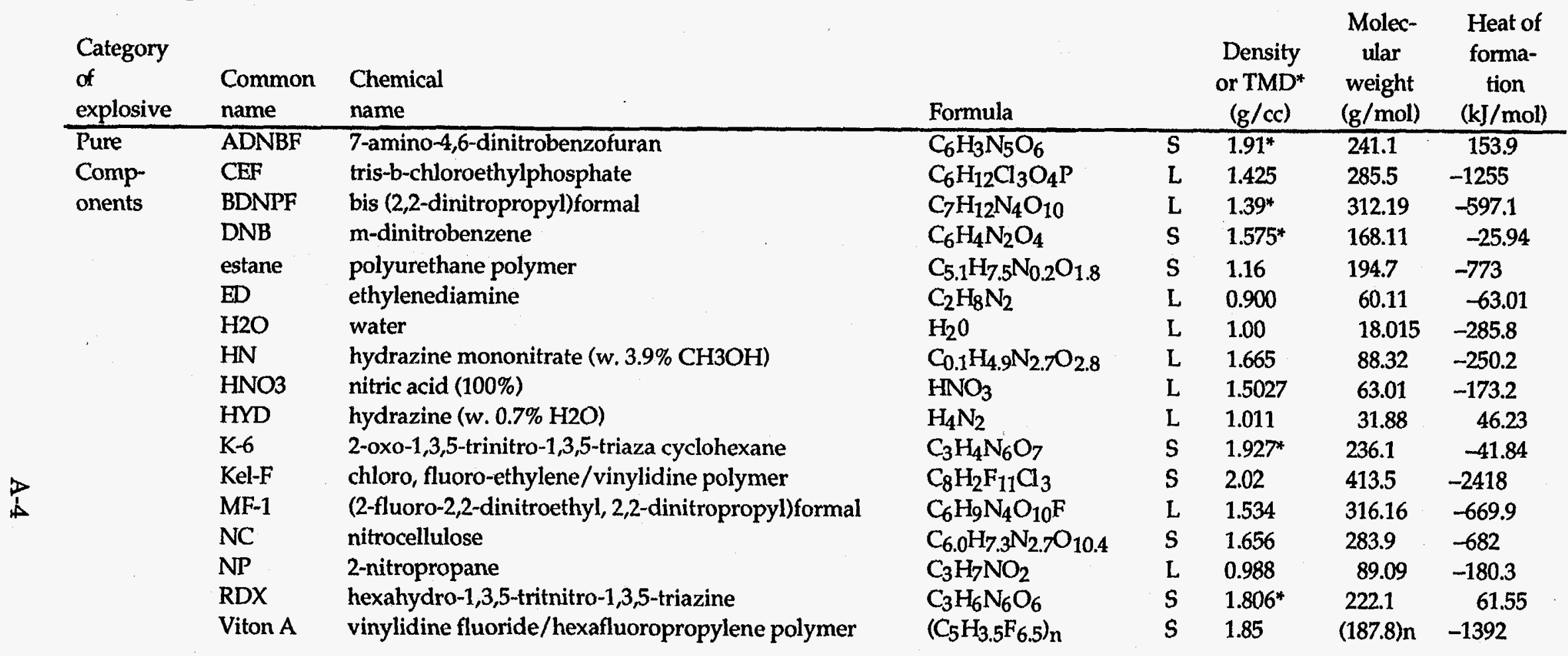

